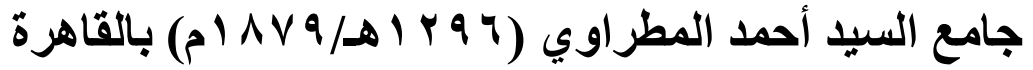 دراسة أثارية معمارية
}

\author{
منى السيد عثمان مرعي
}

يُنسب هذا الجامع إلي العارف بالله الثيخ السيد أحمد المطراوي الذي توفى في أواخر القرن السادس الهجري (ب (م)، حيث

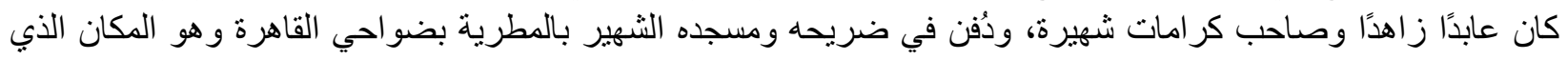
كان قد اتخذه خلوة له.

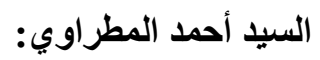
هو السيد أحمد بن السيد علي الثريف بن السيد نجم الدين الثريف بن السيد نجيم الدين الثريف بن السيد ناصر الدين

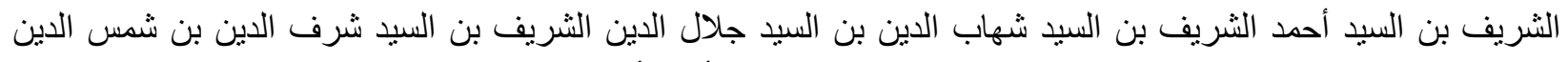

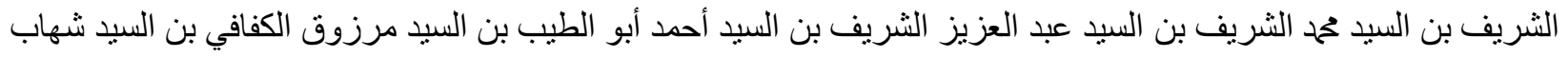

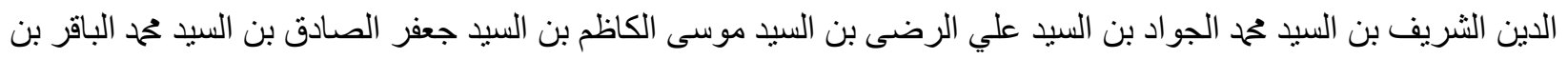

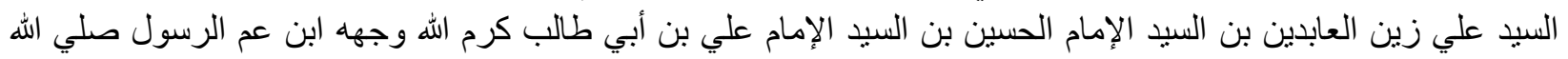

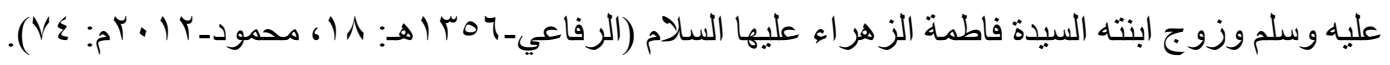

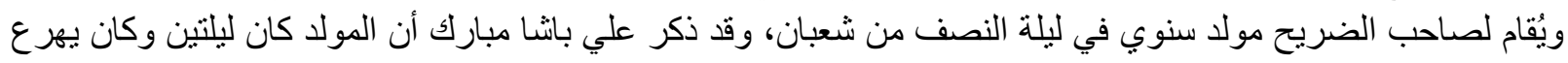

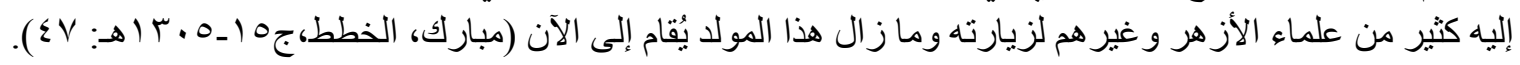
تاريخ البناء:

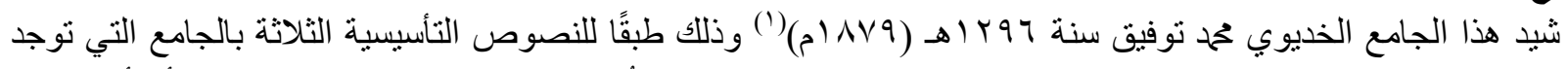

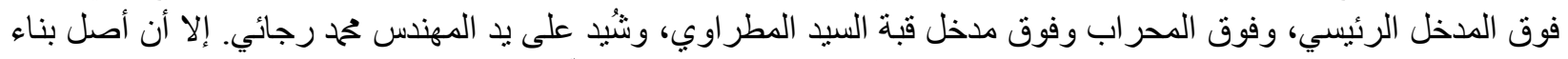

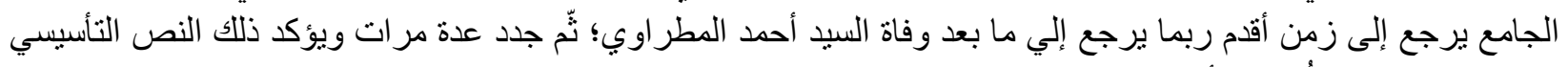

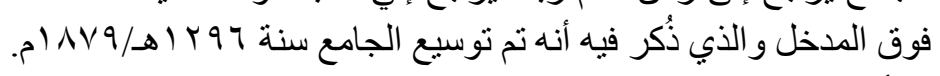

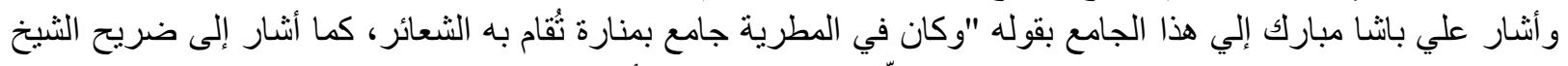

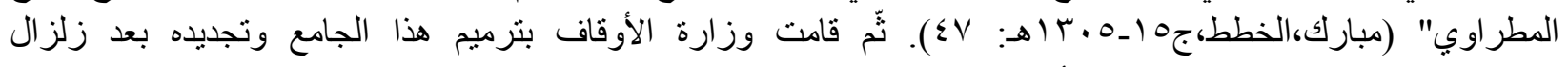

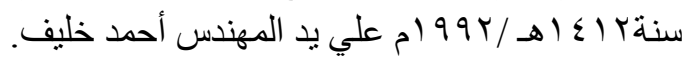
الموقع:

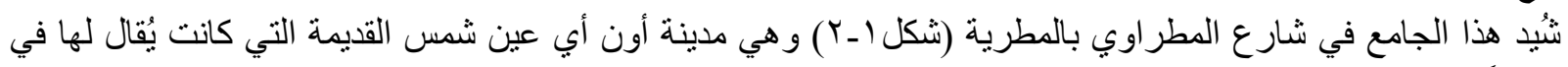

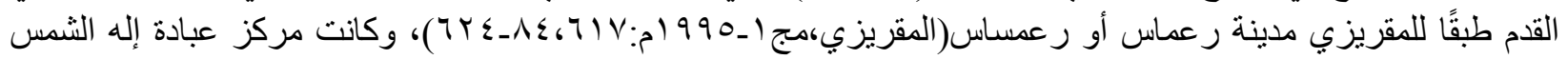

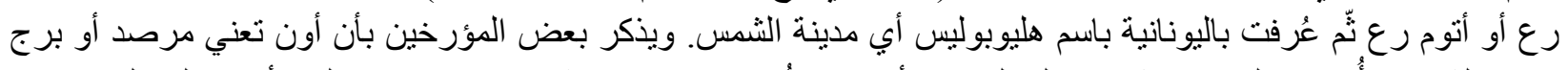

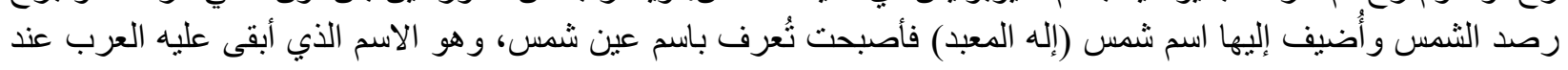

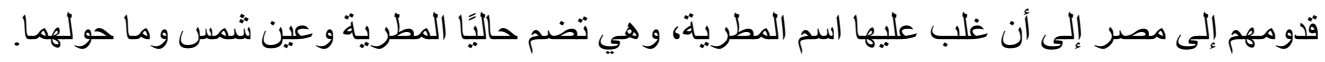

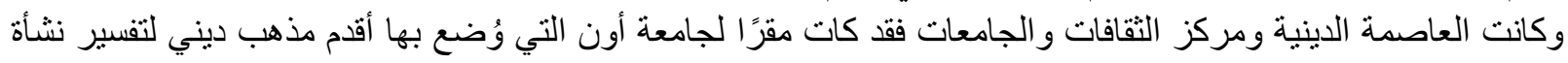

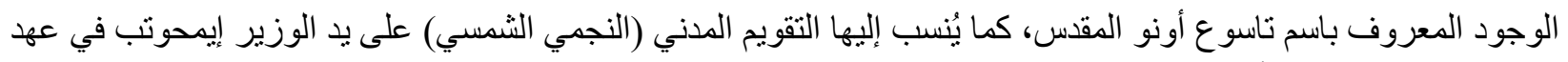

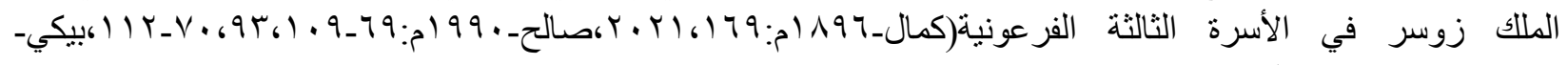

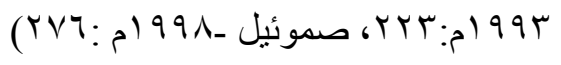

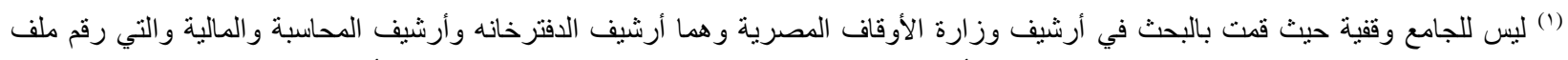

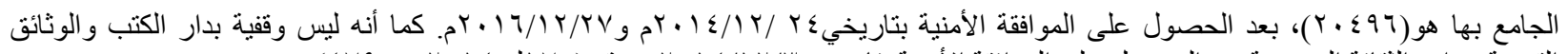

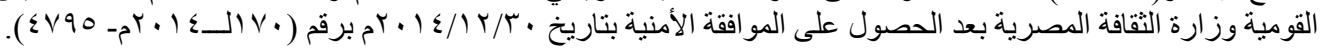


و أصبحت المطرية أحد أحياء القاهرة، وتقع في شرقها، بعد أن كانت قديمًا قرية من قري مصر عند الموضع الذي به شجر

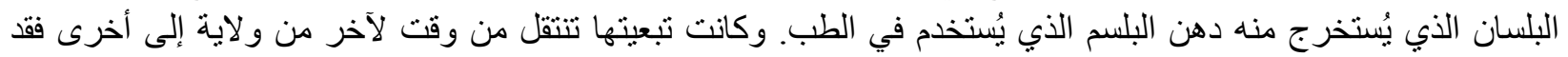

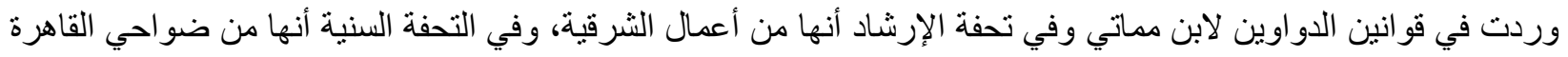

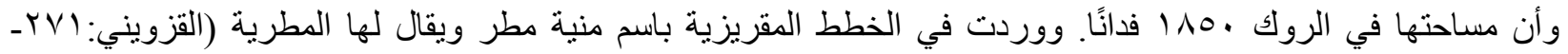

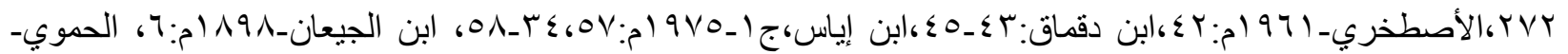

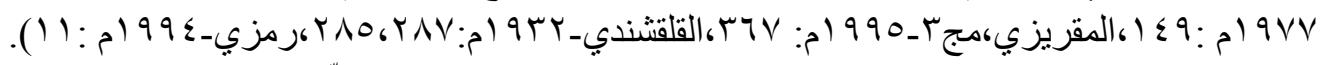

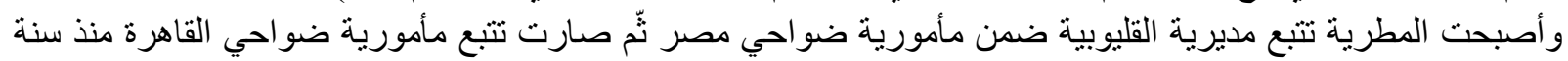

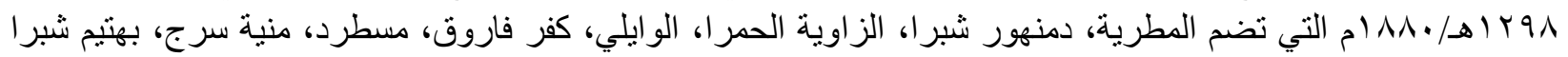

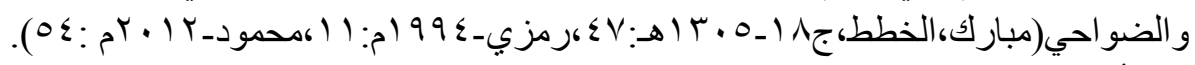

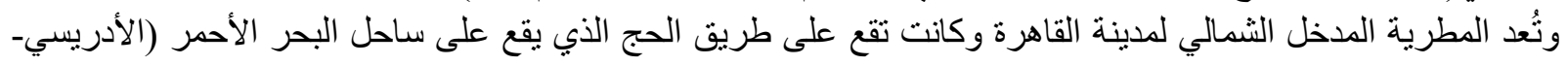

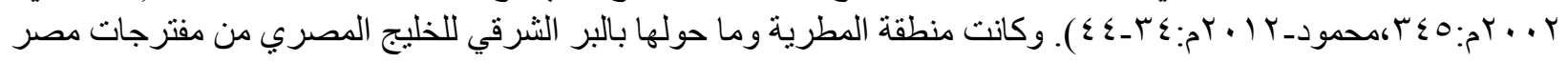

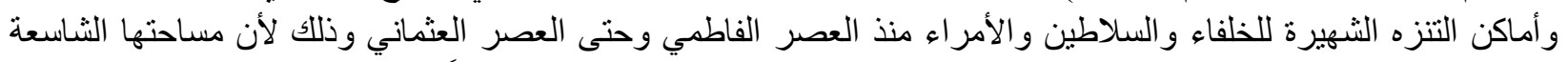

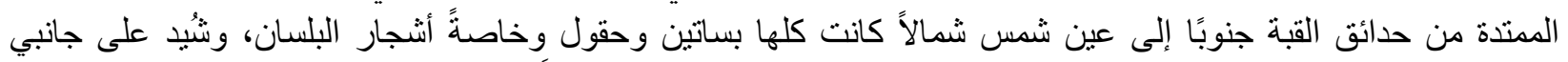

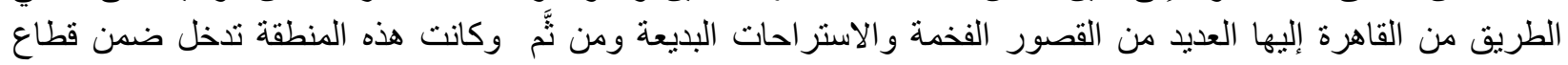

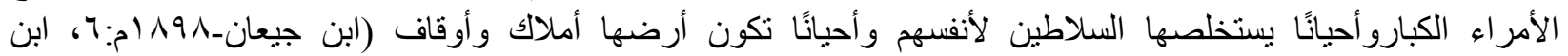

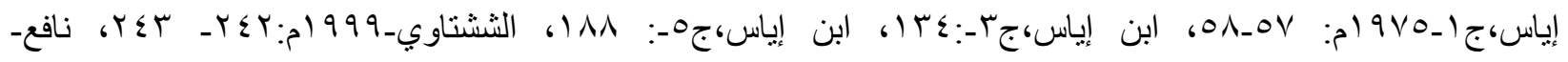
.

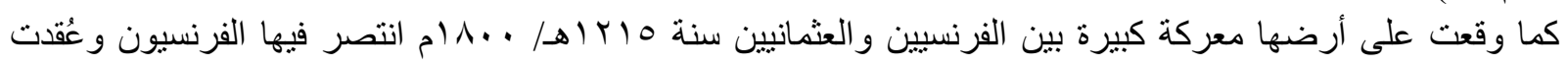

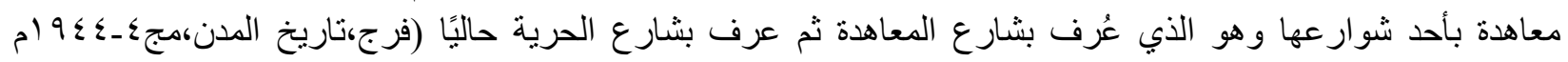

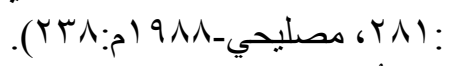

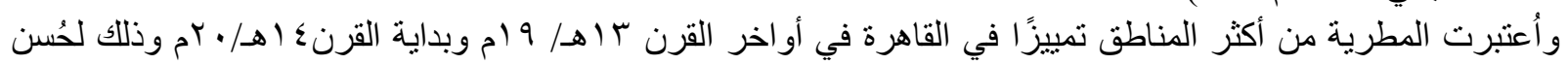

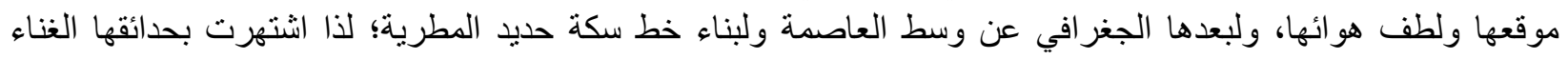

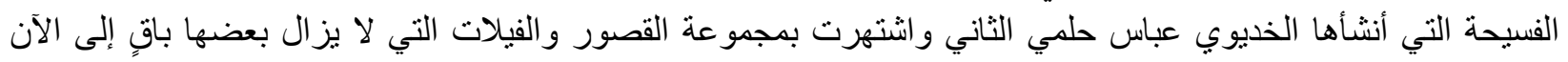

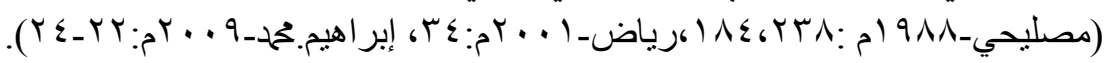

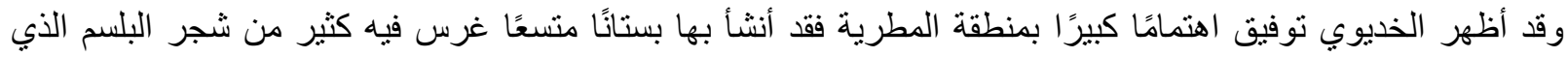

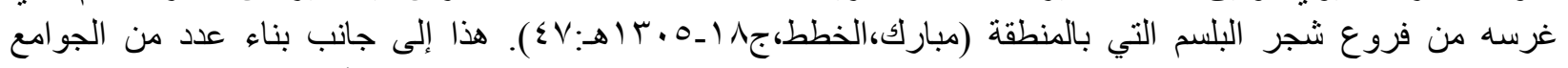

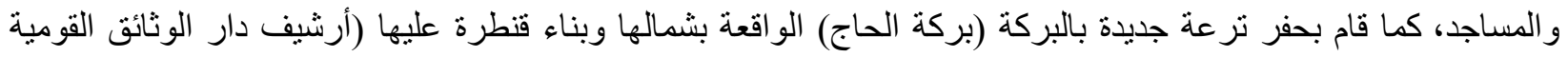

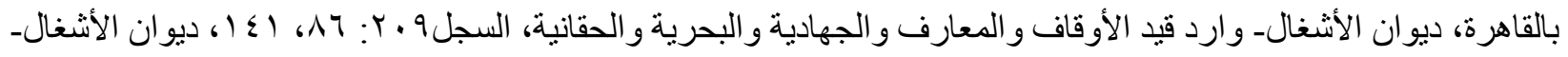

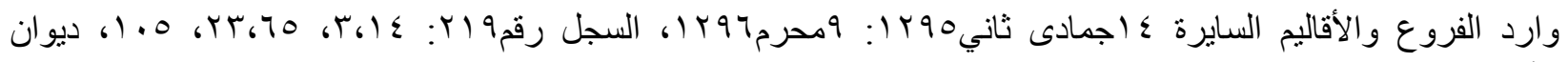

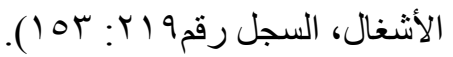

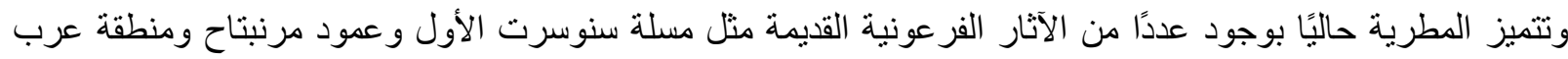

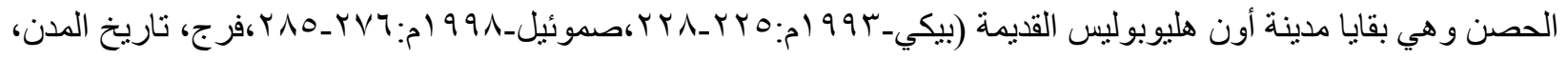

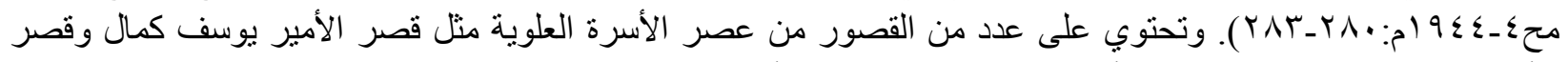

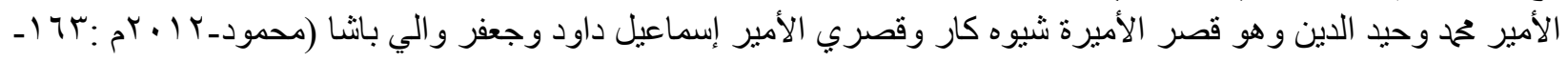

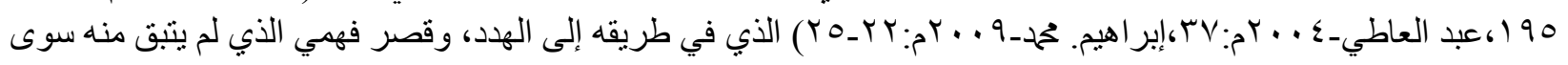
مبنى صغير بقبة ذات مضاوي.

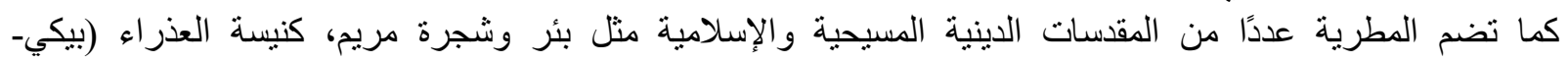

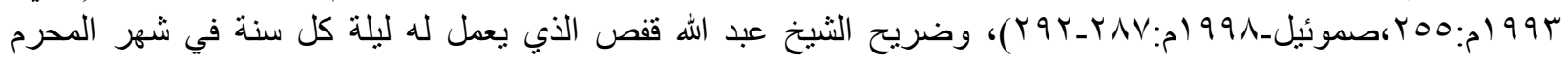

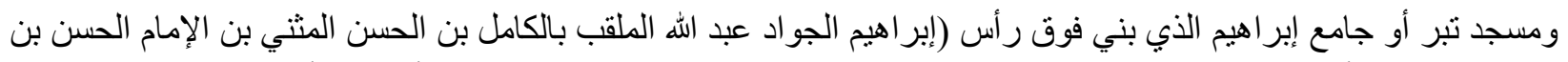

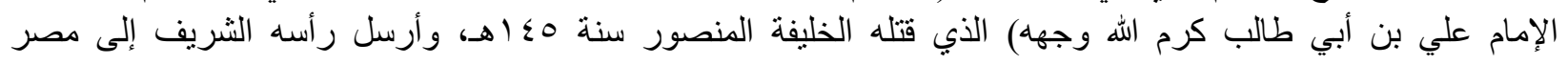




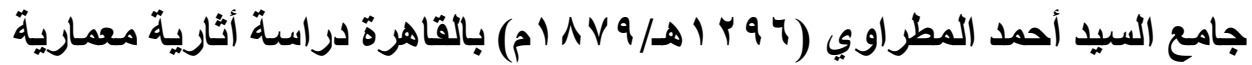

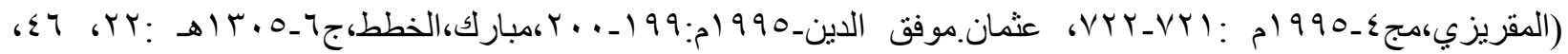

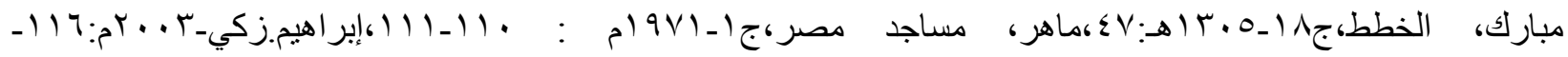

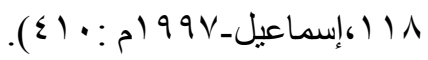

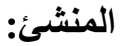

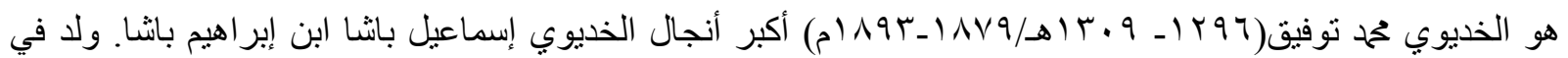

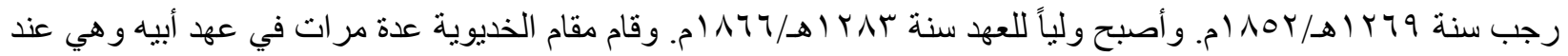

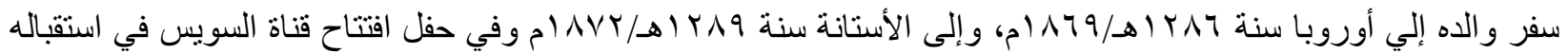
الملوك و الأمر اء.

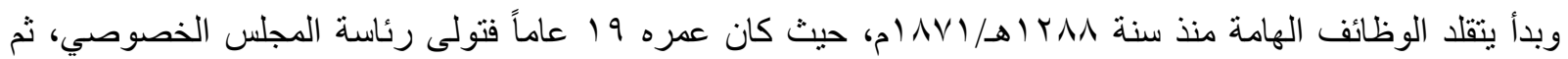

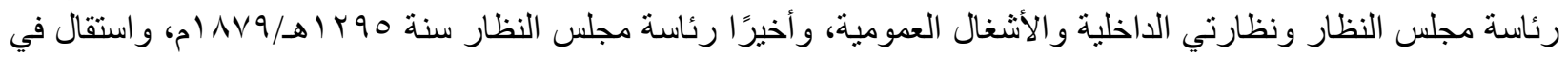

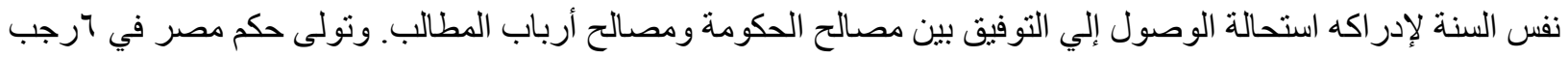

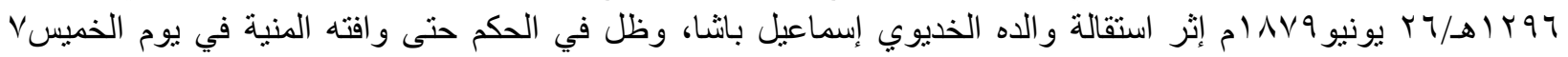

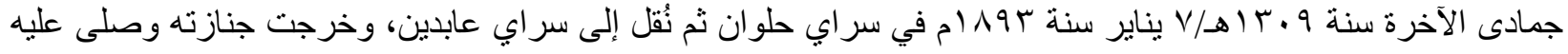

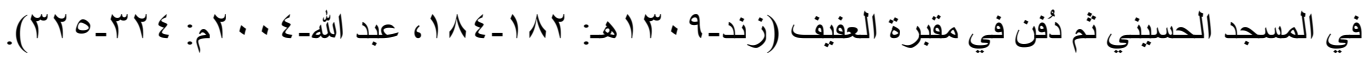

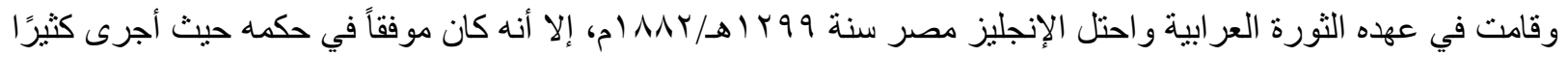

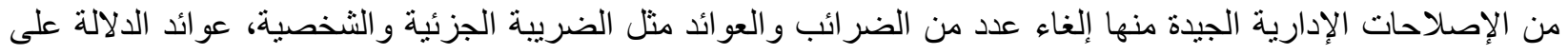

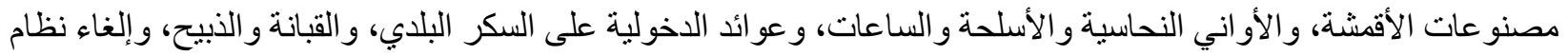

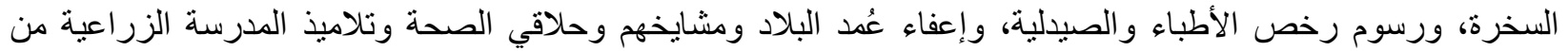

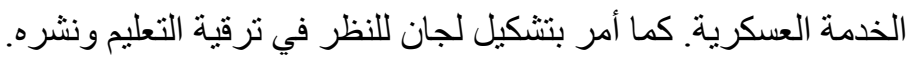

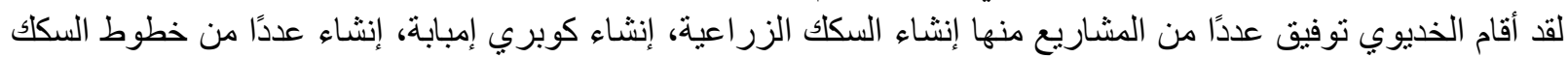

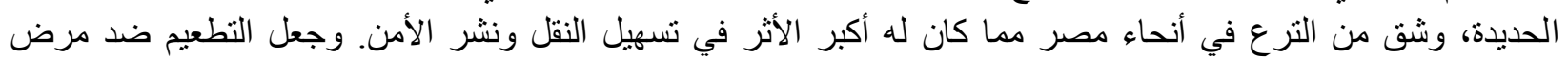

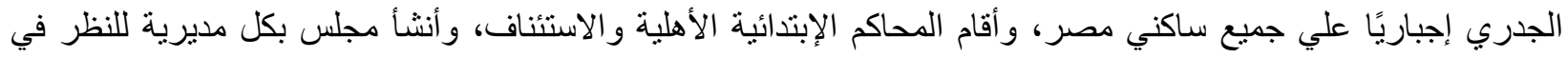

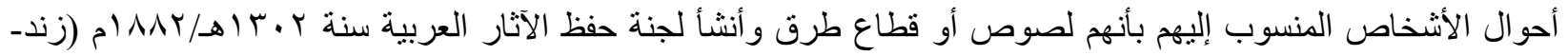
9

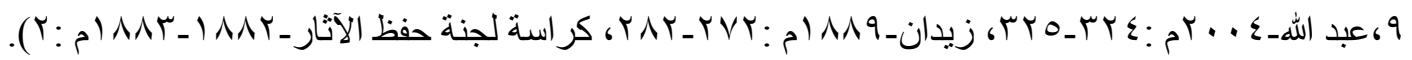

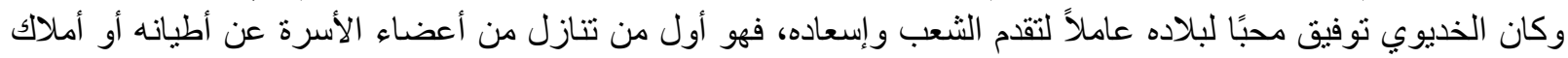

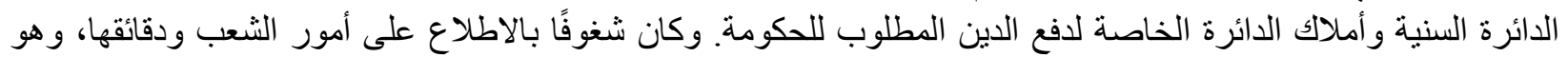

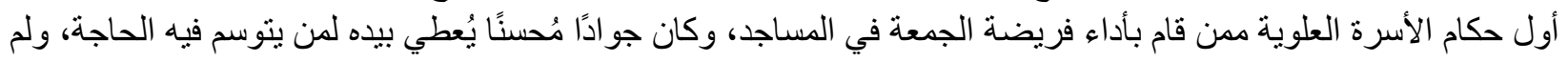

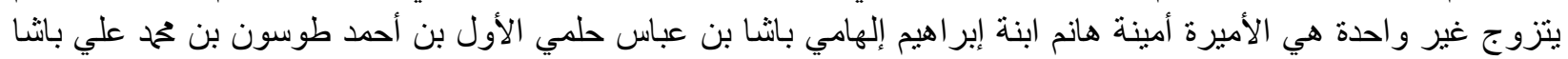

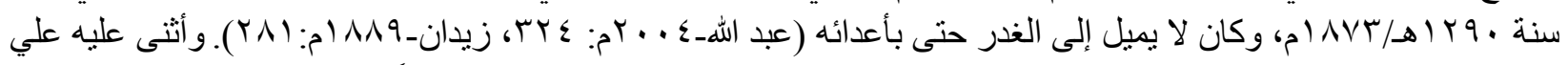

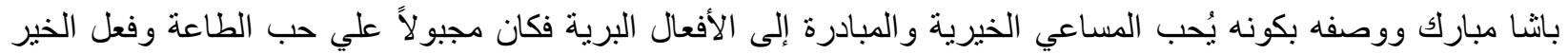

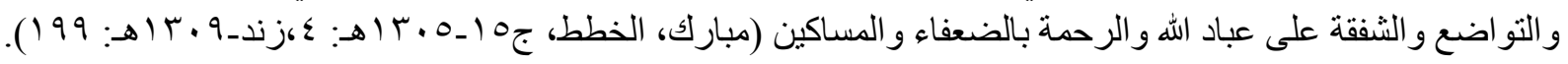

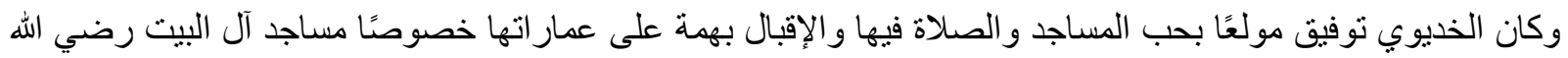

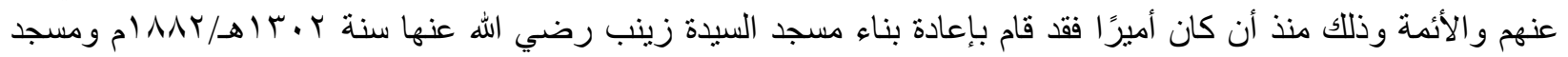

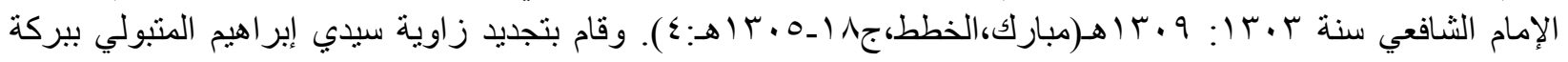

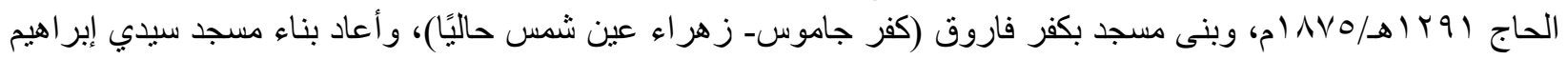

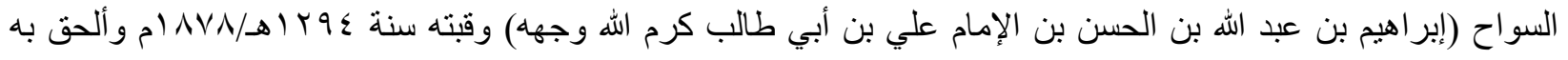

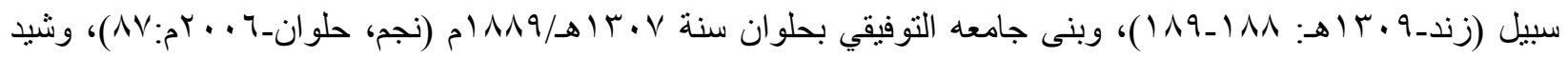

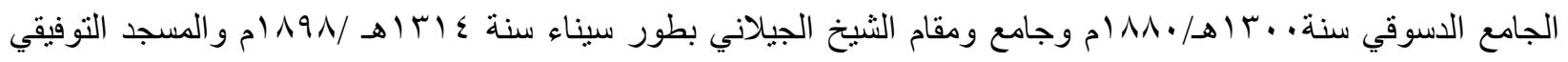

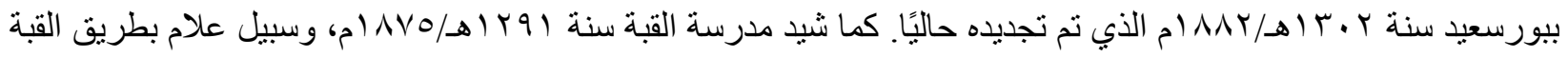




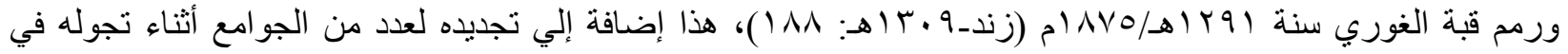

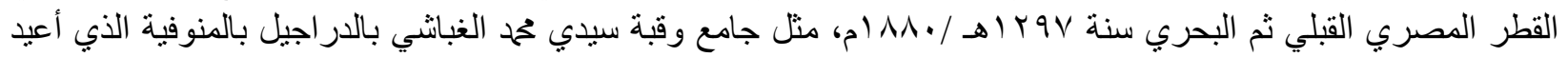
بنائه في عصر الرئيس محمد أنور السادات، مع بقاء القبة الضريحية على حانه حالتها الأصلية.

الوصف المعماري للجامع:

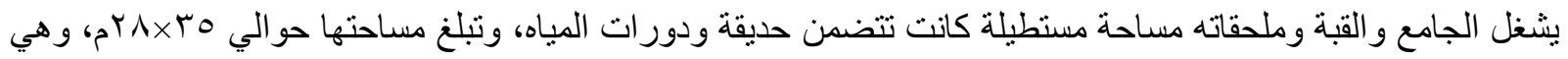

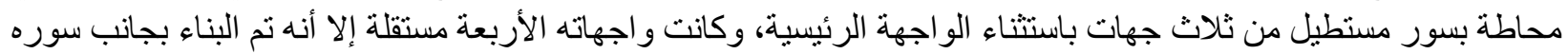

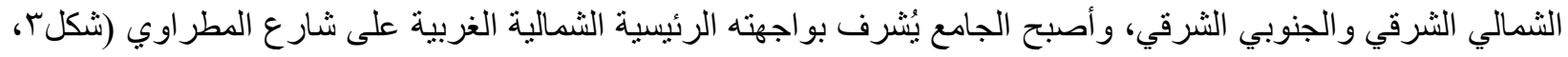

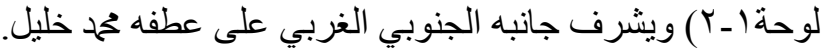

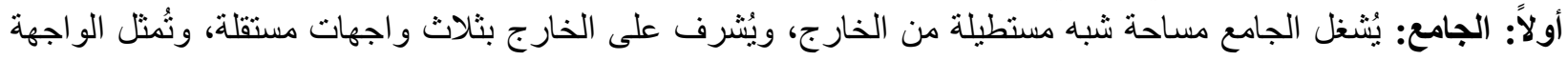

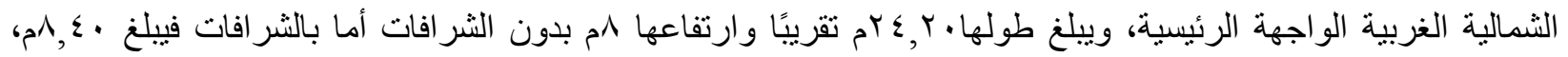
ويبلغ سمكها • Vسم.

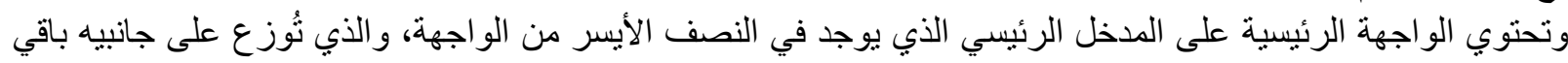

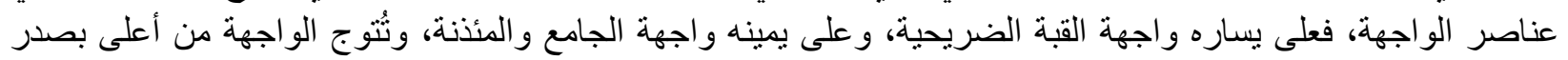

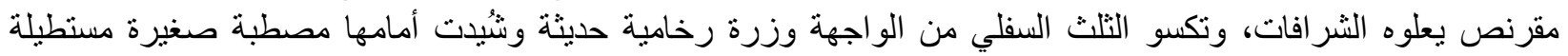

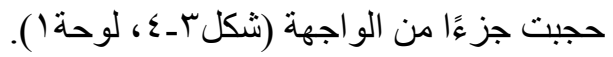
واجهة القبة:

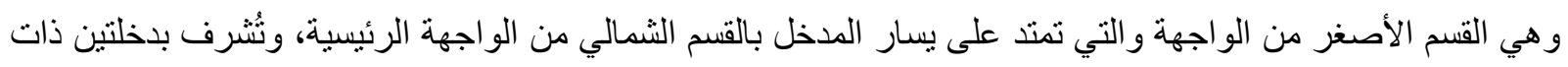

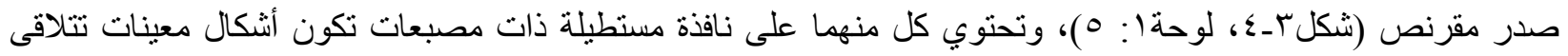

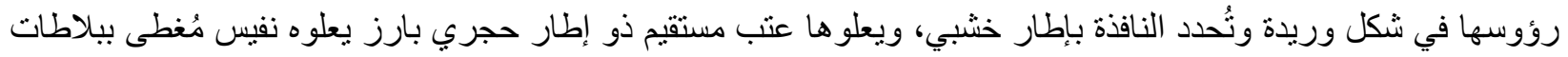

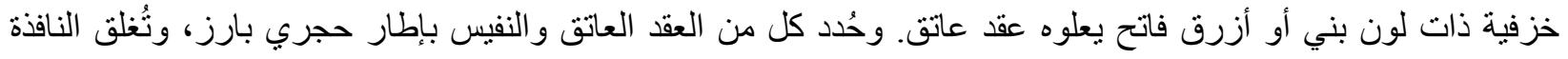

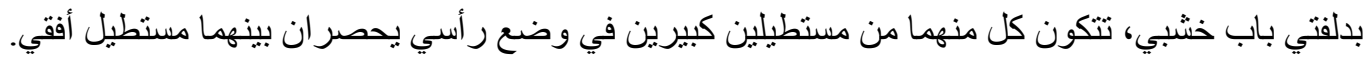

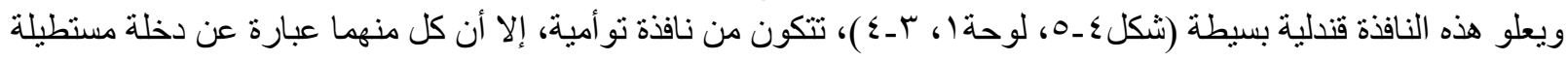

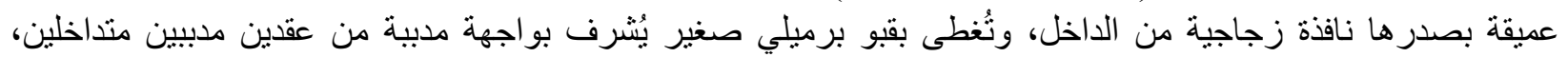

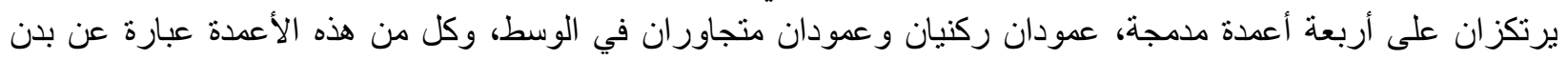

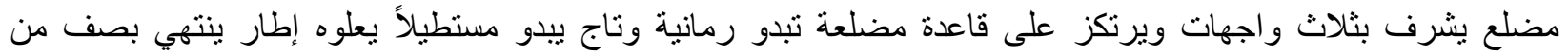

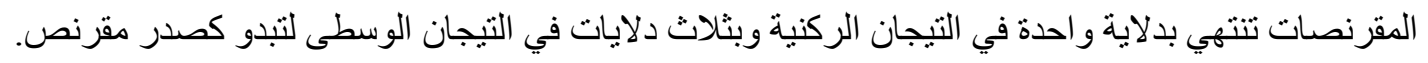

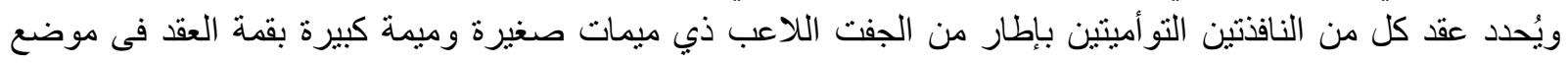

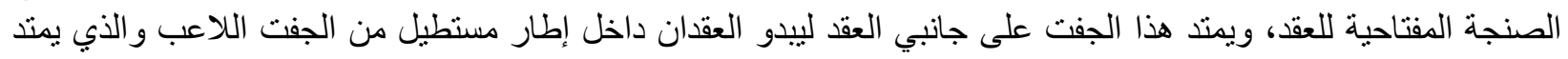

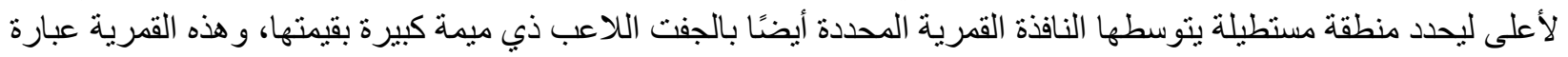

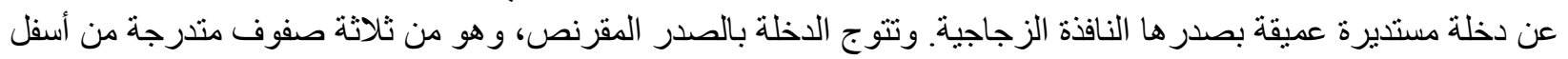
لأعلى من حيث اتساعها. ويمتد على جانبي واجهة القبة الضريحية ويُحددها إطار مستطيل من الجفت اللاعب، يحد الإطار الأيمن المدخل أيضًا

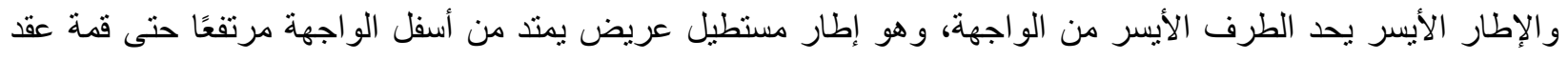

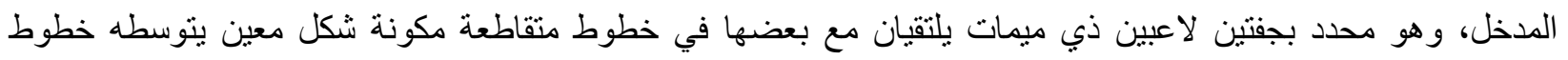

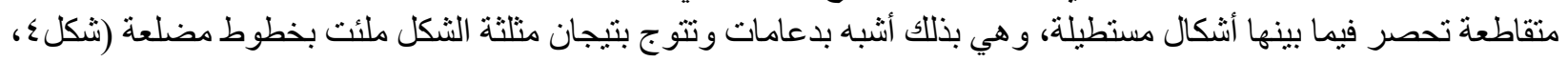

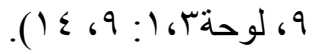

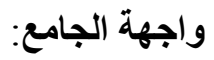

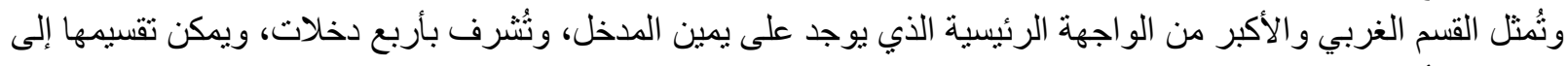

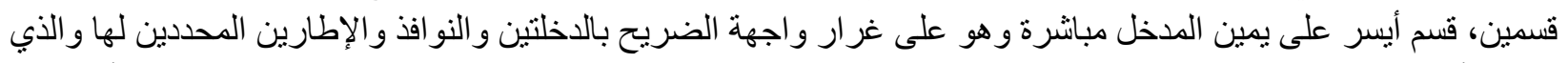

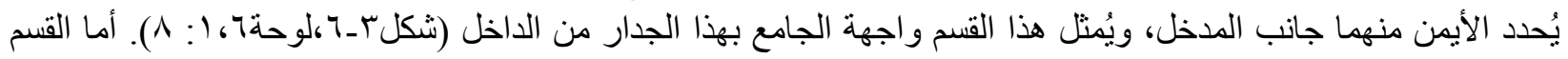




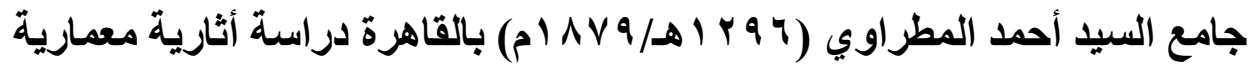

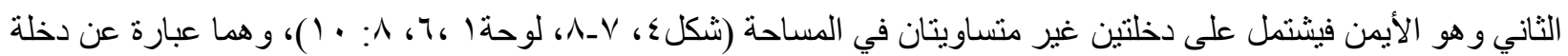

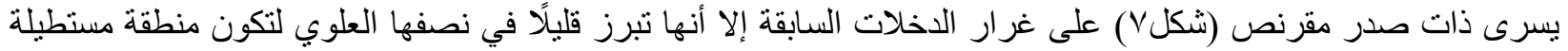
بارزة محددة بإطار من الجفت اللاعب ذي الميمات، و هي معقودة بعقد مدائني ثنلاثي بصفوف من المقرنصات ذات دلايات،

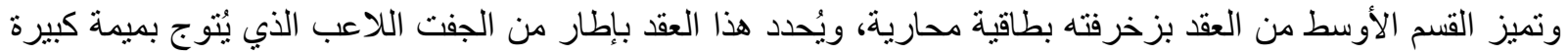

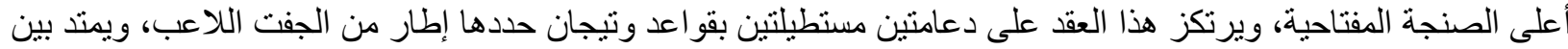
هاتان الدعامتان و أسفل العقد منطقة مستطيلة محددة بالجفت اللاعب ويتوسطها جامة مستديرة عميقة محددة بالجفت اللاعب

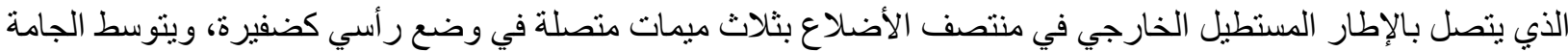

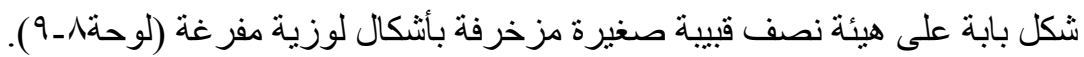

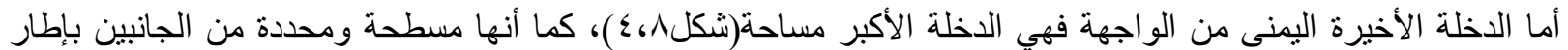

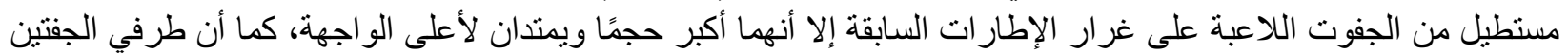

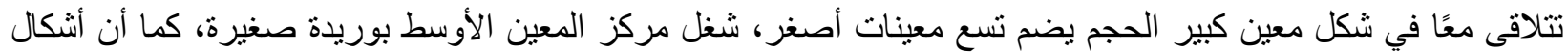

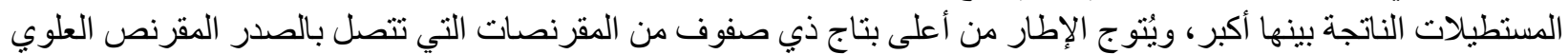
للو اجهة (لوحةا ، 7 ، ، • (1). ويحتوي القسم العلوي من هذه الدخلة على فتحة مزغل مسنطيلة وعميقة كنافذة تفتح على سلم المئذنة من الداخل، وهي

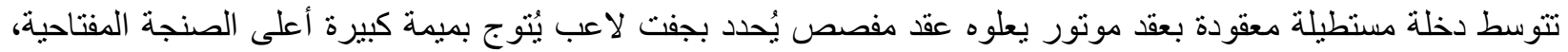

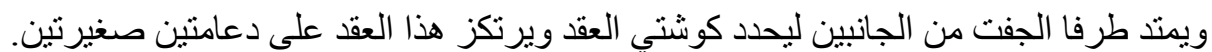

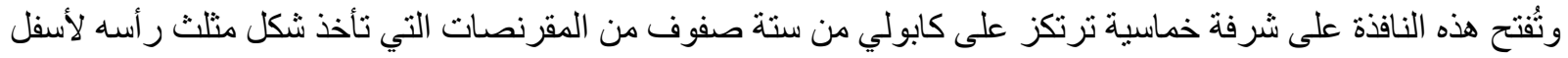

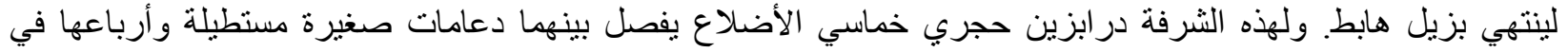

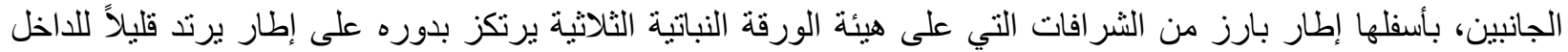

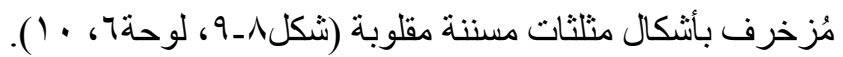

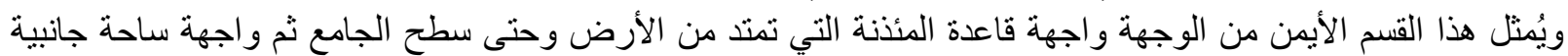

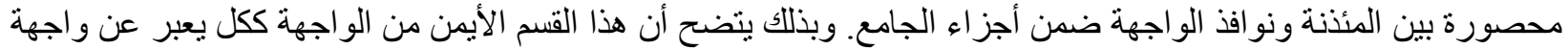

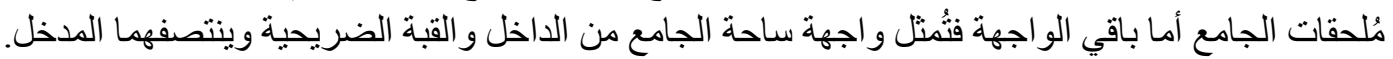

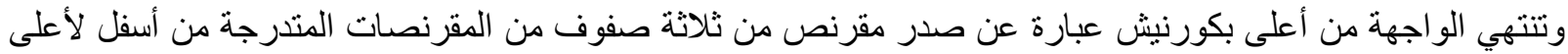

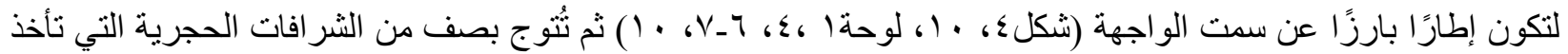

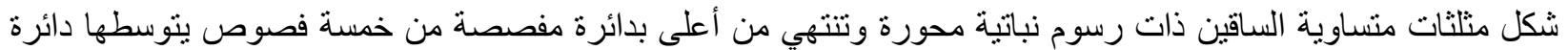

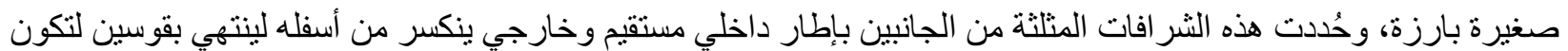

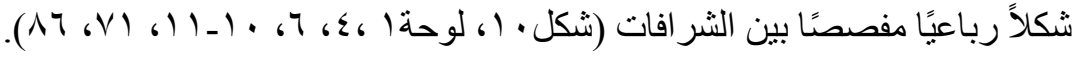

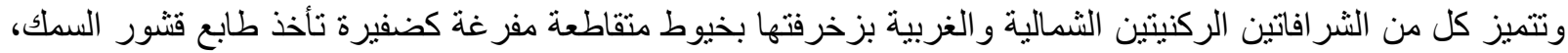

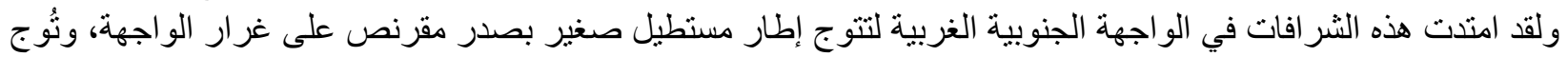

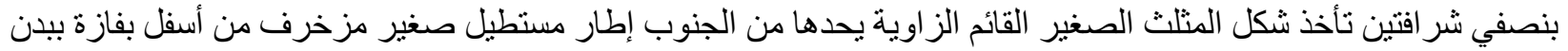

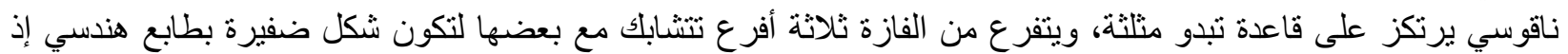

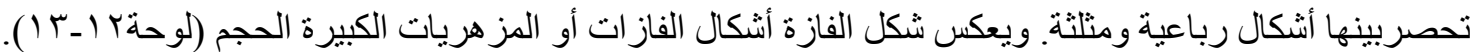

المدخل:

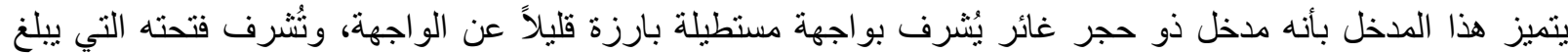

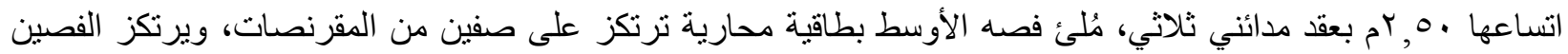

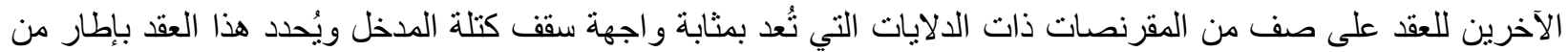

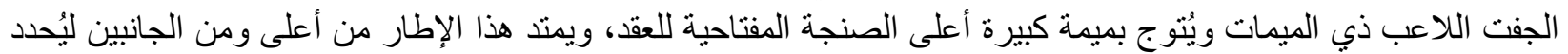

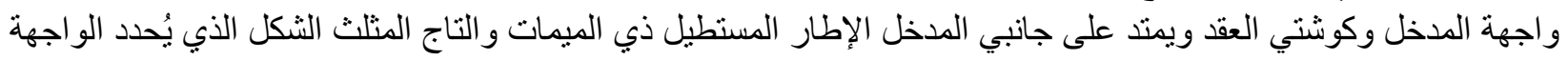

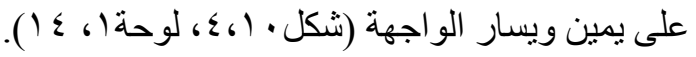


ويبلغ عمق المدخل أو طول ضلعيه الجانبيين الجنوبي الغربي و الثمالي الثرقي • V, Yم، ويتوسط كل منهما دخلة ذات صدر

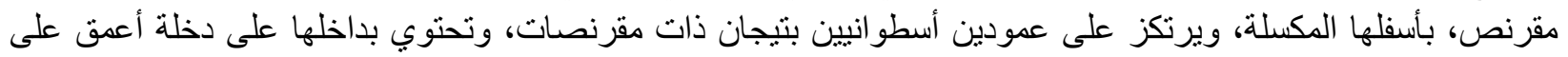

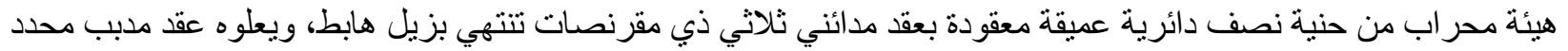

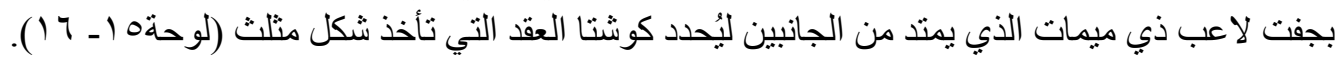

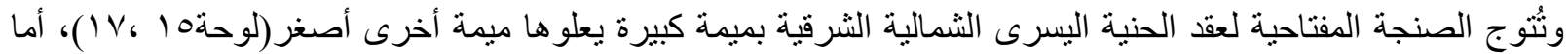

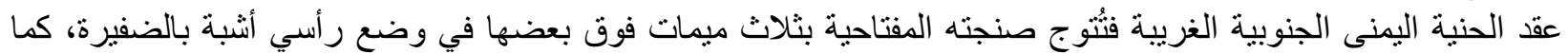

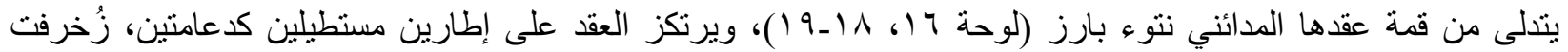

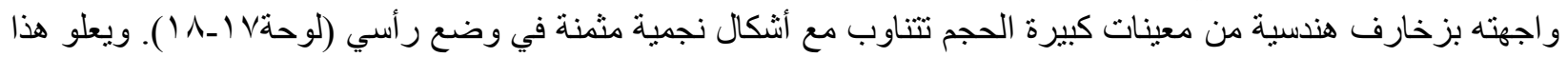
العقد الصدر المقرنص المكون من أربعة صفوف من المقرنصات المتدرجة العمق حتى ينتهي الصف العنى العلوي وكأنه مساوٍ

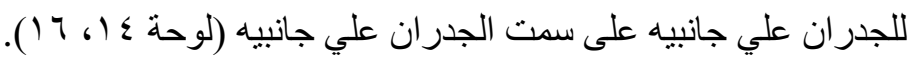

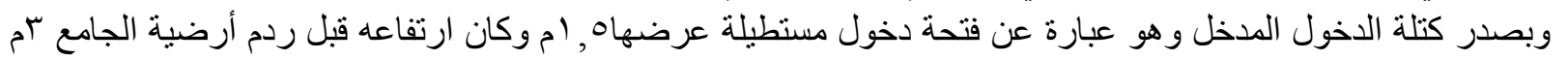

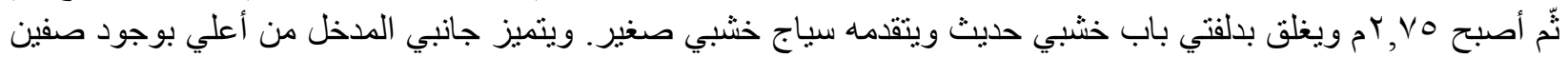

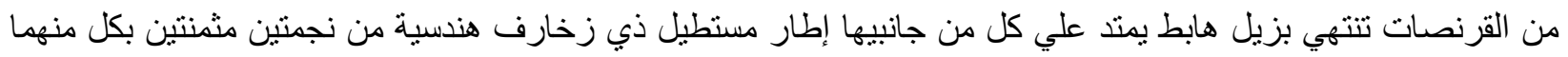

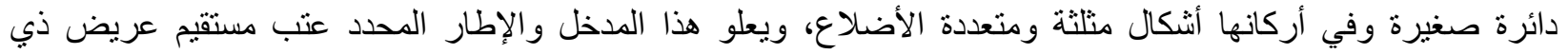

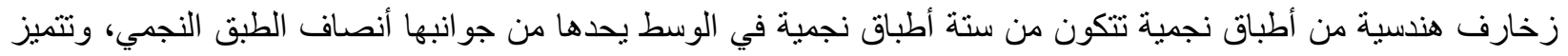

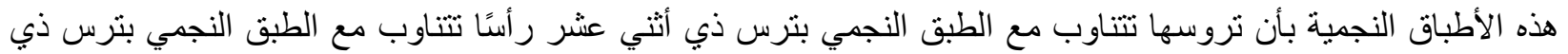

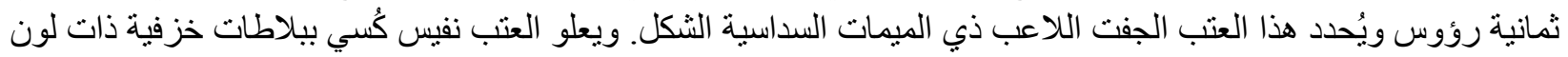

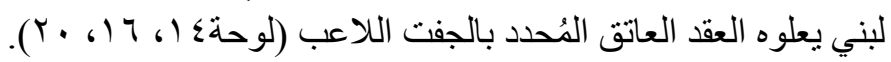

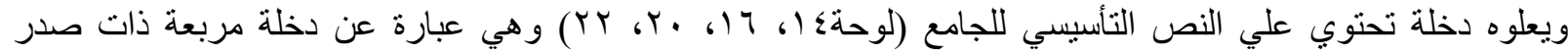

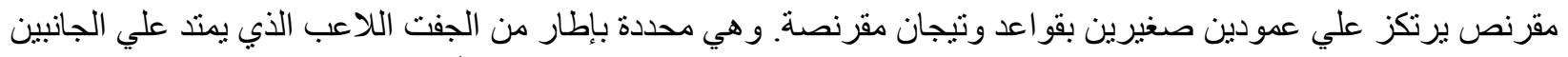

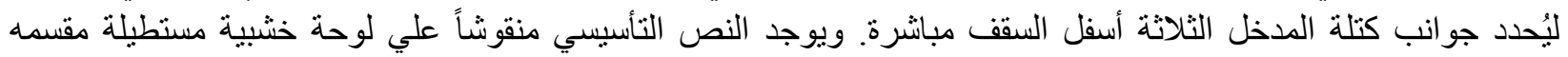

بإطارين أفقيين إلي ثلاث مناطق مستطيلة قُسمت بدور ها إلي ست بحور كتابية بالخط التركي نصها:

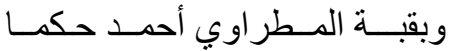

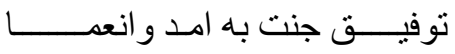

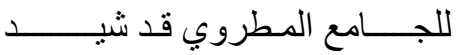

\section{1 97}

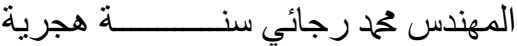

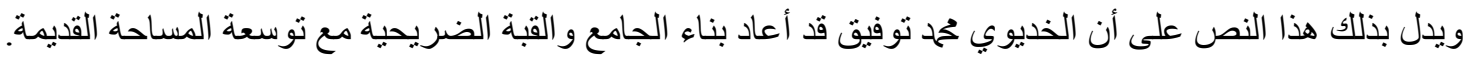

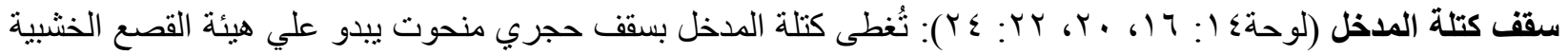

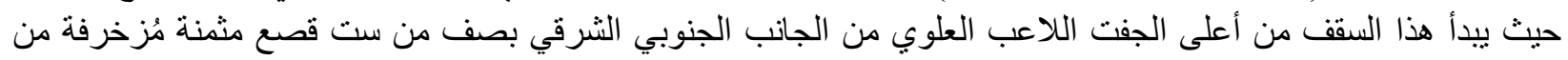

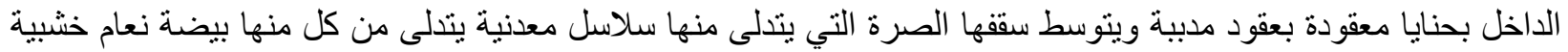

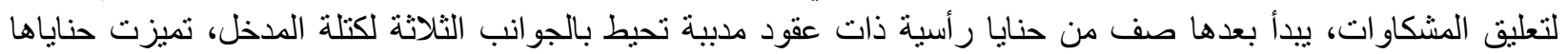

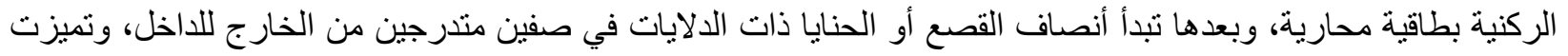

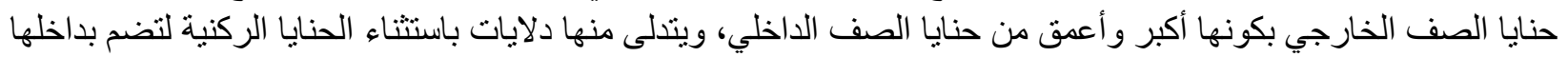

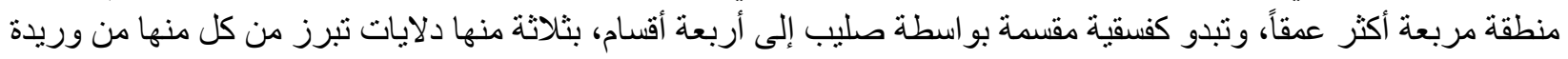

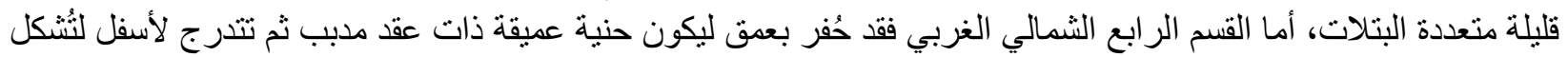

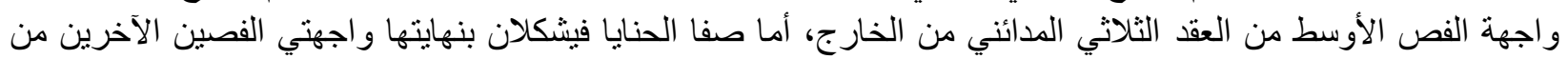

الواجهة الجانبية الشمالية الثرقية: تنقسم هذه الواجهة إلي قسمين، واجهة القبة الضريحية وواجهة الجامع (لوحةه : و آ)، وذللك على النحو التالي: 


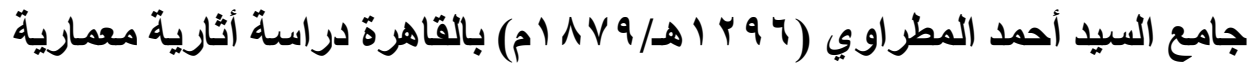

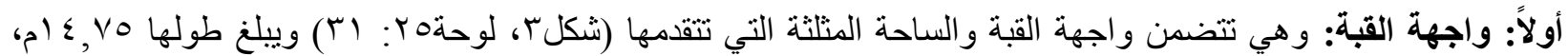

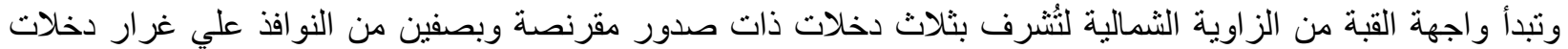

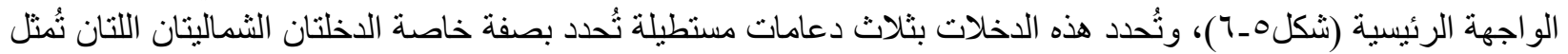

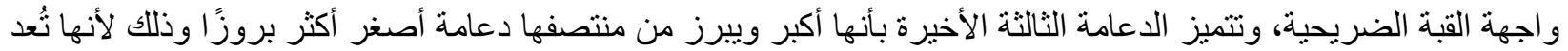

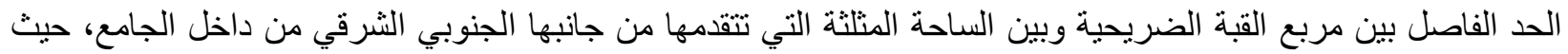

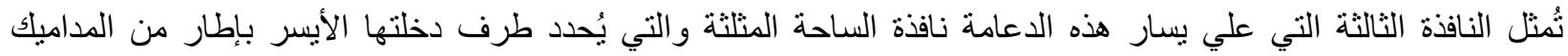

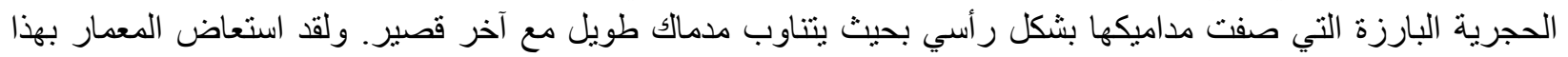

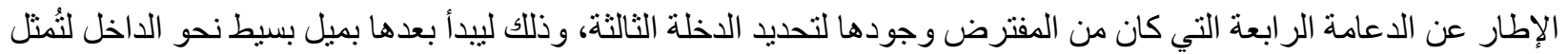

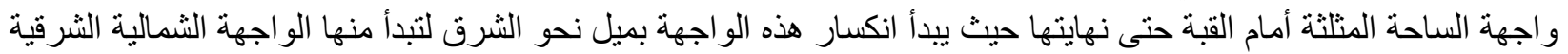

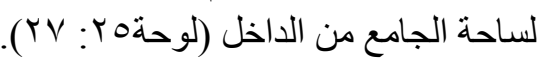

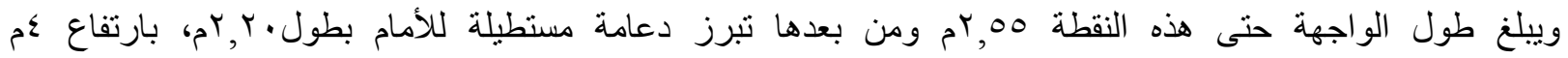

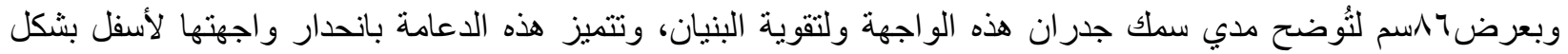

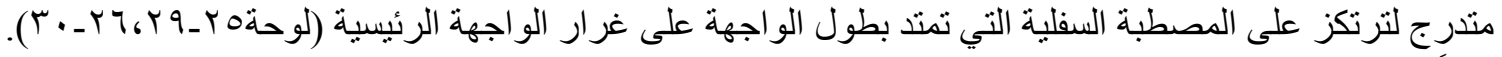

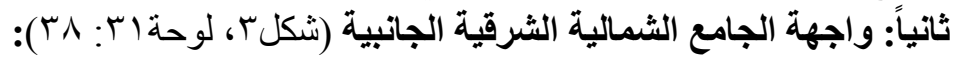

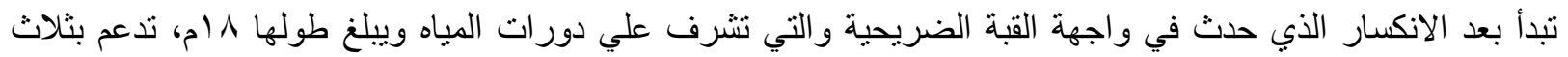

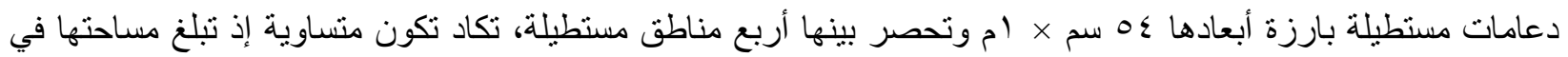

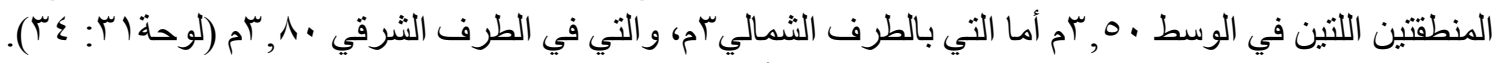

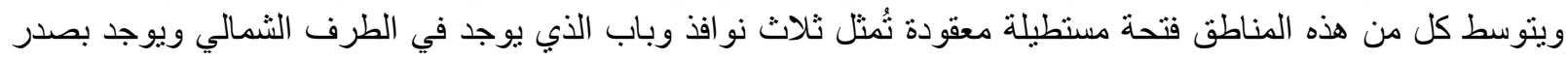

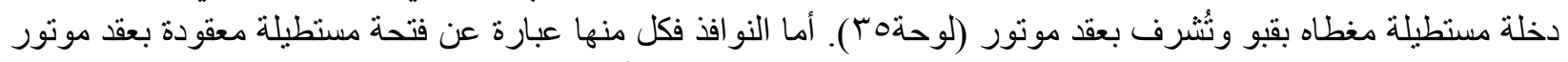

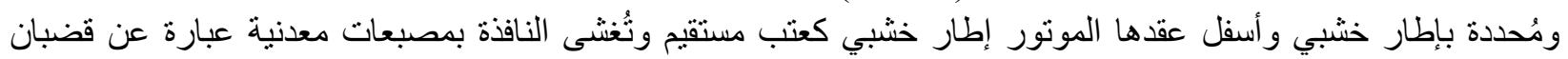

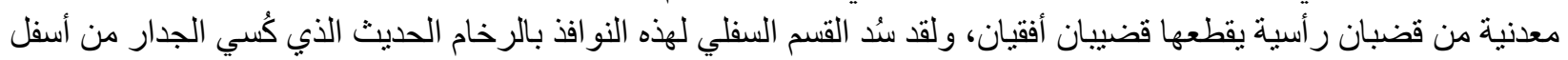

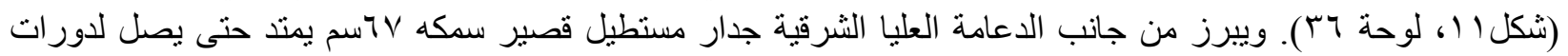

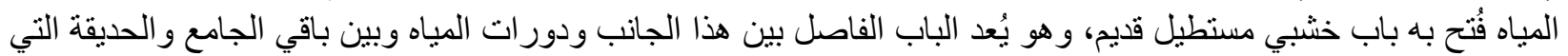

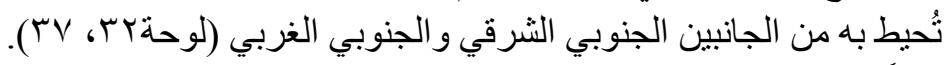

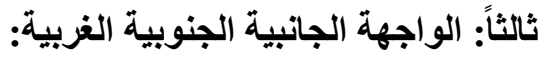

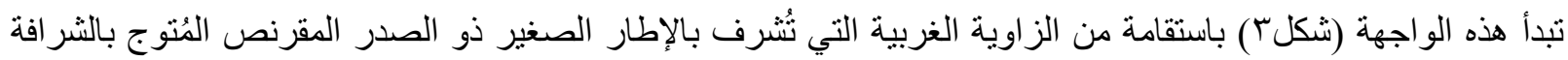

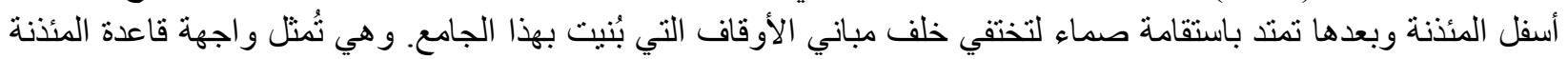

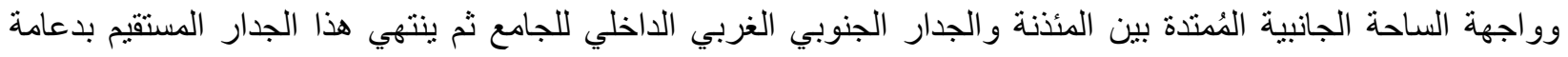

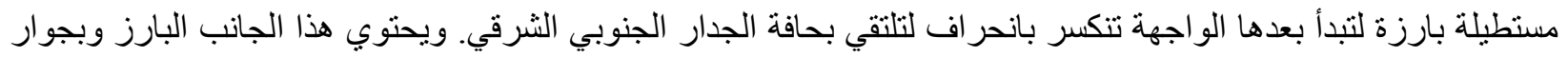

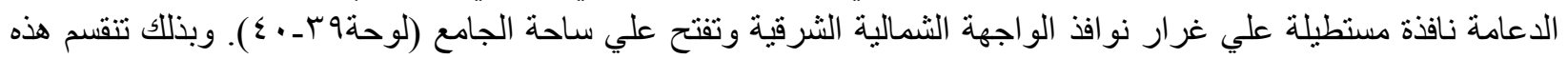

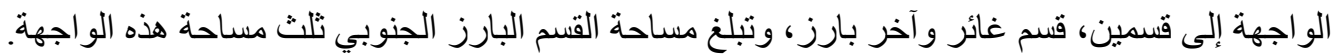
رابعاً: الواجهة الجنوبية الشرقية:

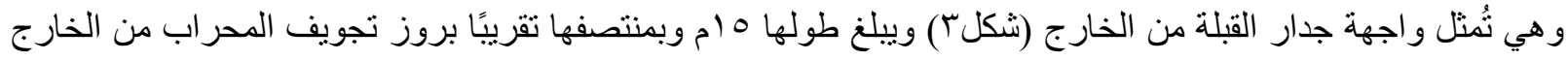

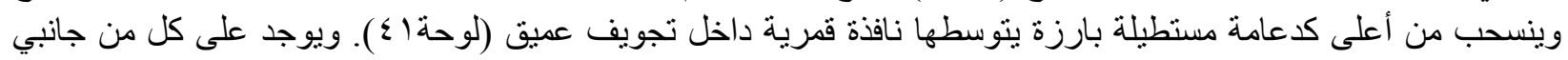

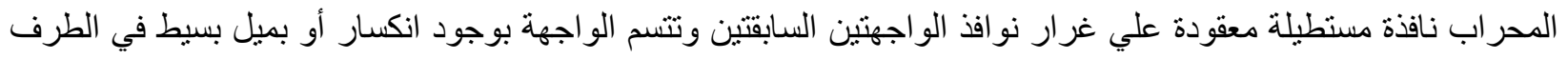

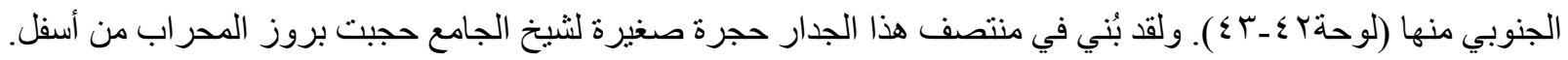

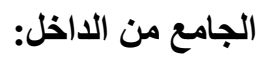

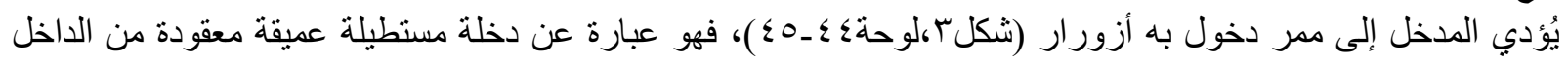

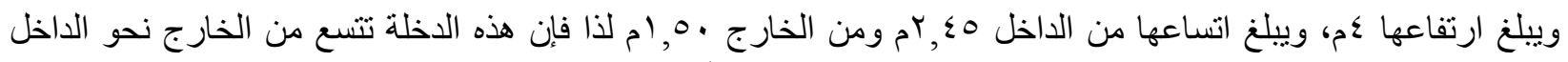

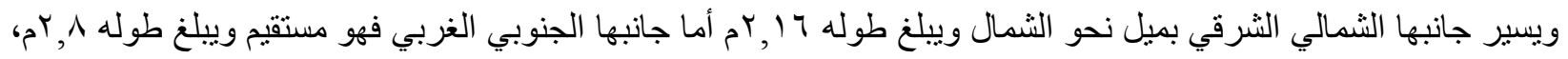


ولقد أدى ذلك إلى ارتداد الجانب الثمالي الأيسر من الجدار عن جانبه الغربي الأيمن و الذي أدى بدوره إلي عدم تساوي مساحة

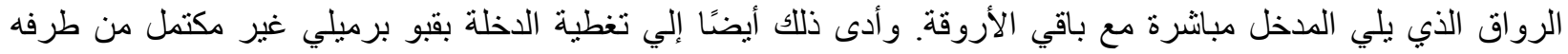
الجنوبي لذا تأخذ فتحة عقده الموتور شكل ثناثنة أرباعها.

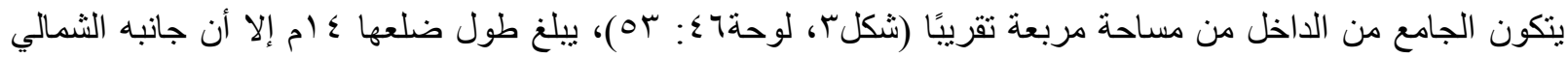

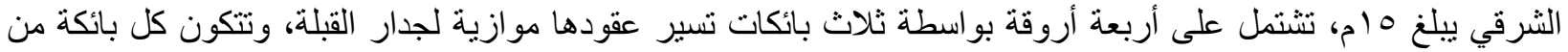

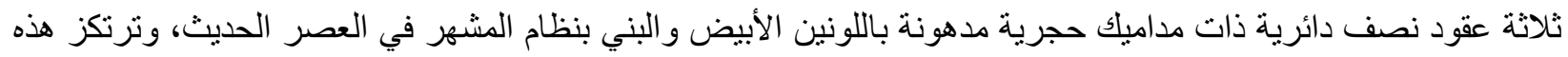

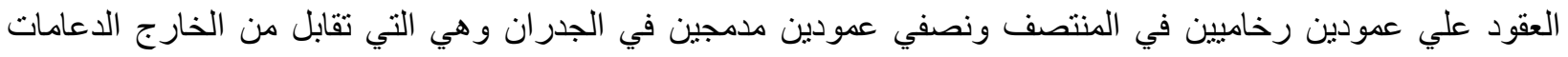

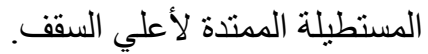

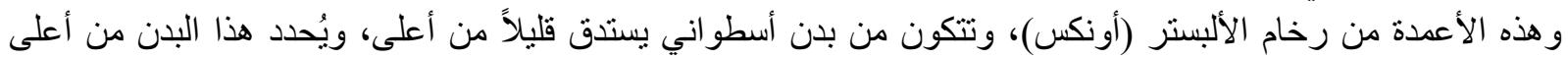

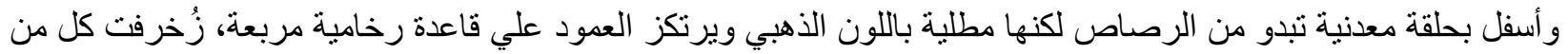

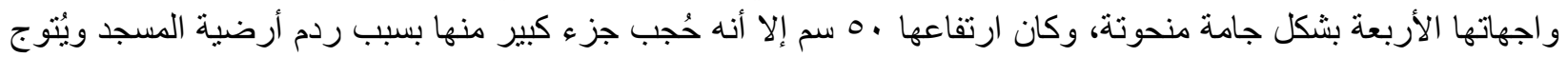

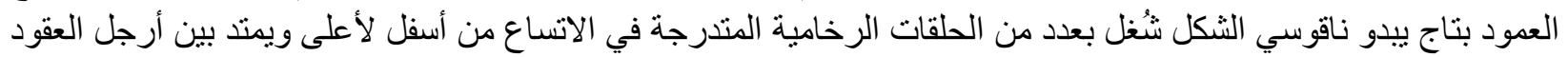

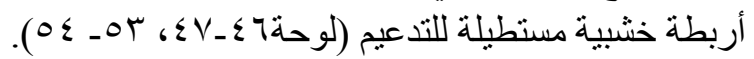

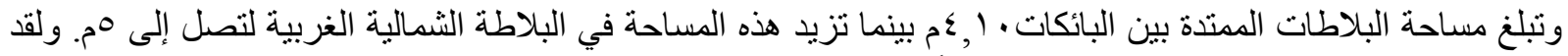

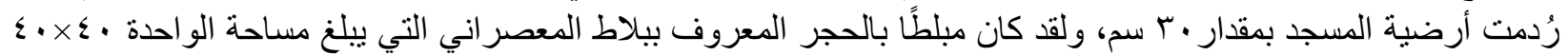

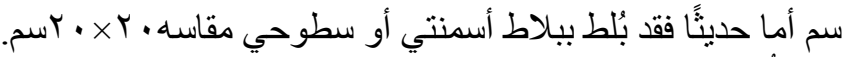

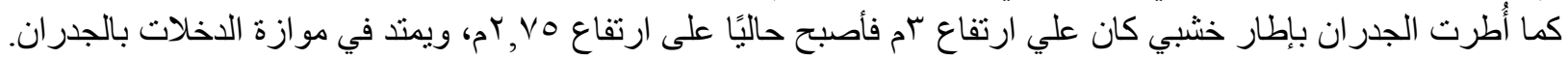

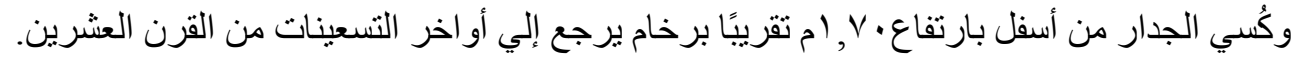

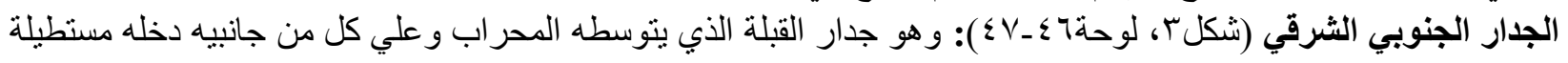

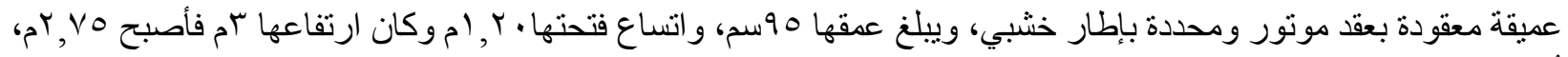

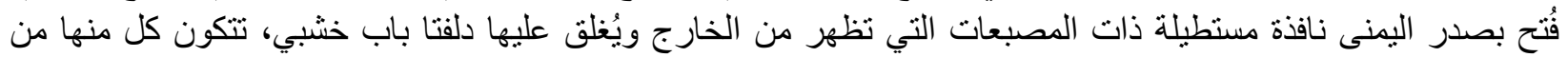

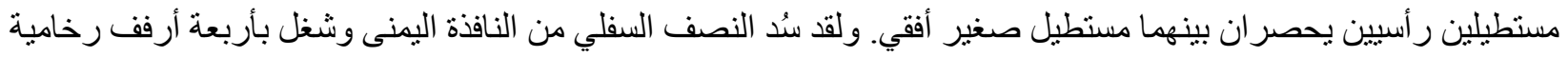

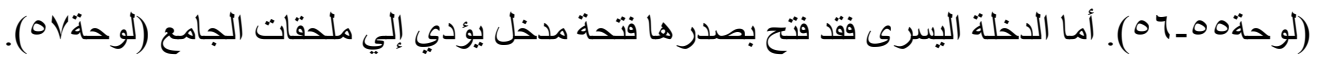

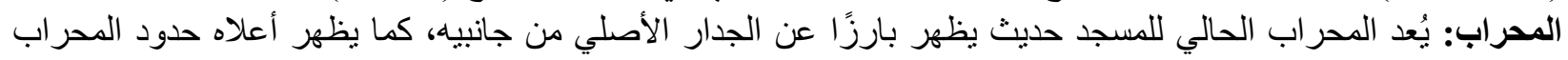

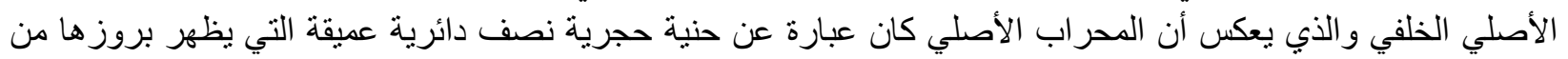

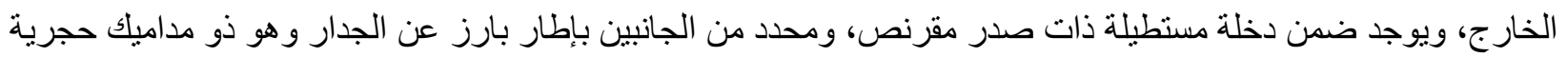

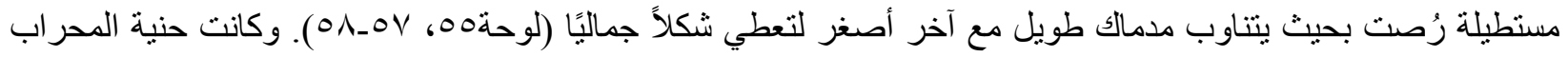
الأصلية المعقودة مُحددة بجفت لاعب ذاحت ذب ميمات يمتد لأعلى ليحدد إطار مستطيل أعلى المحراب يتوسطه ميمة كبيرة الثكل

ويعلو هذا الإطار نص تأسيسي ضمن دخلة مستطيلة مُحدده بإطار بارز من الجفت اللاعب ذي الميمات (لوحةهم). ونُقش الونش

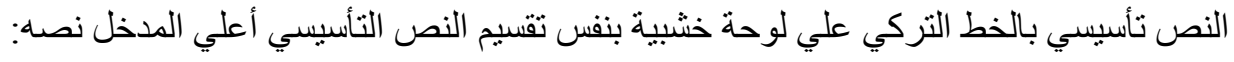

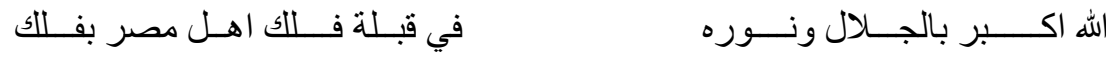

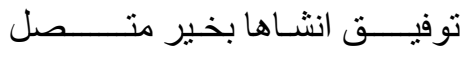

$$
\begin{aligned}
& \text { بمن احمد المولي الخديو حمحد }
\end{aligned}
$$

1T. or

$$
\text { واحب السـود بها فقلت خـامور }
$$

المهندس محمد رجائي في سنـــــة هجرية تحمد رجائي 


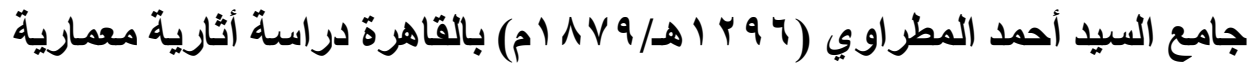

وذُكر في هذا النص تاريخ البناء مرتين الأولي المسجلة أسفل النص مسبوقة بكلمة سنة والثانية نُقتت كأرقام تجمع معا وهي: ويعلو النص التأسيسي نافذة قمرية مستديرة هُحاطة بإطار دائري من المداميك الحجرية وتُخطيى هذه النافذة بغطاء زجاجي

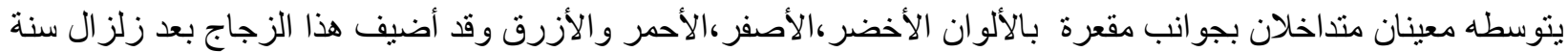

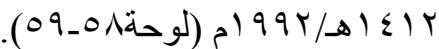

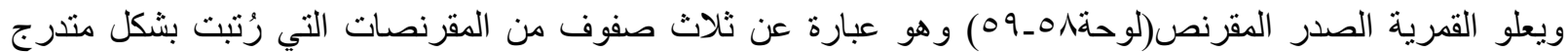
لتستدق من أعلى، حيث يتكون الصف السفلي من ثمان حنايا مسطحة بعقود منكسرة وحنية واحدة بجانبي الدخلة، ويعلو هذا

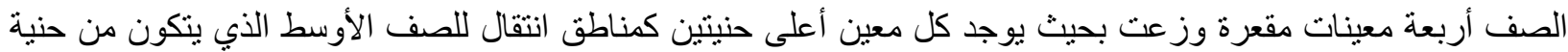
بجانبي الاخلة يحصر ان بينهما ست حنايا أودخلات صغيرة عميقة منكسرة وهي أثباه ببائكة ذات عقود منكسرة، ورُتبت هذه

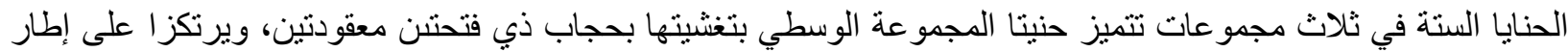
مستطيل، أما المجموعتان الآخريتان فيرتكز عقدا كل منهما من الوسط علي ثناثة إطارات صغيرة مستطيلة، أما الحنيتان

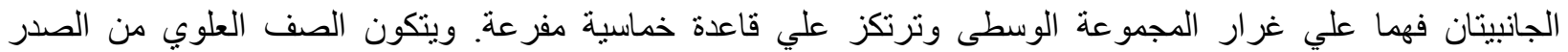
المقرنص من ثلاث حنايا عميقة منكسرة بعقود تبدو مسطحة، و على كل من جانبيها حنية مغثاه على غرار حنايا النى المجموعة

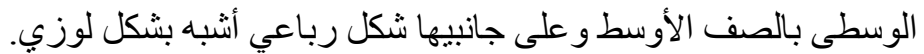

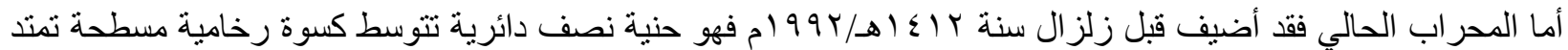
لأعلى حتى جوسق المنبر.

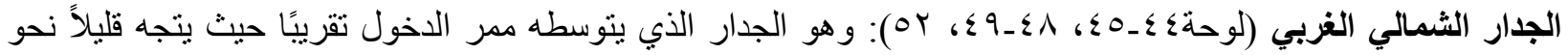

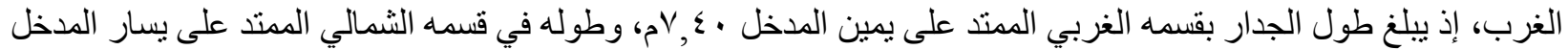

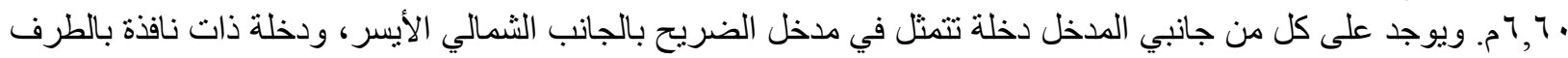

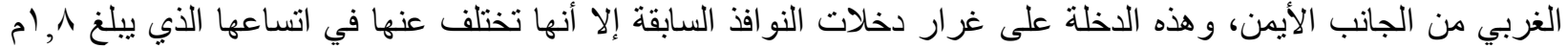

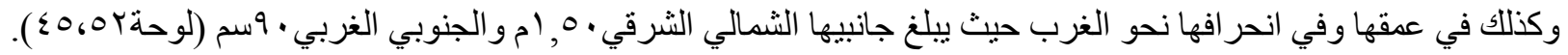
ويرجع هذا الاختلاف في العمق والميل أو الإنحر اف حتى تظهر النافذة بهذه الدخلة باستقامة في الواجهة الخارجية الثمالية

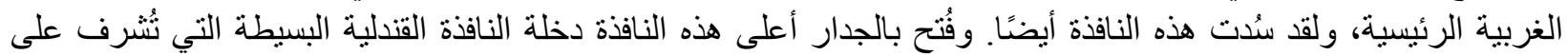

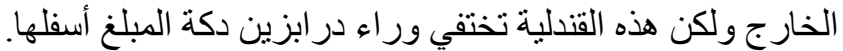

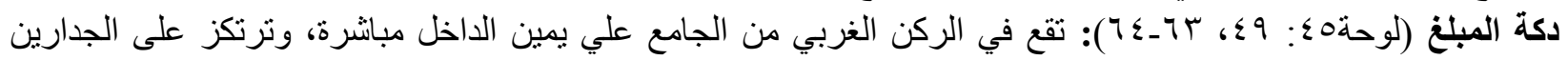

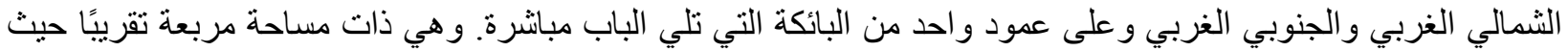

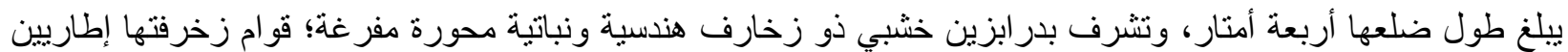

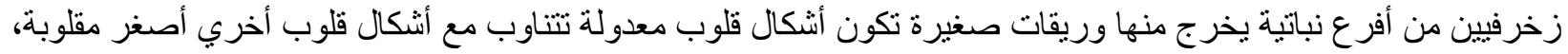

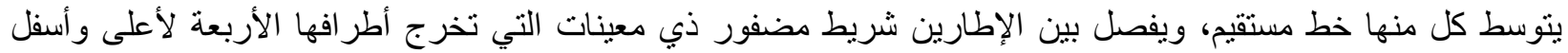
لتكون أثكال القلوب(شكل منه ( ) ).

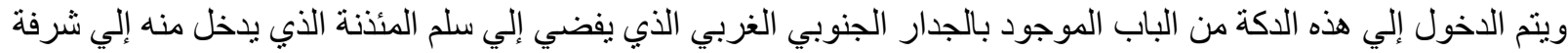
خشبية مستطيلة ذات درابزين تصل بين سلم المئذنة وجدار المسجد الذي فتح به فتحة باب مستطيل معقودة بعقد موتور يفتح على الدكة. الجداران الجانبيان (الجنوبي الغربي والثمالي الثرقي) (شكله، لوحةج ع: به): ينقسم كل من هذين الجدارين إلي أربعة

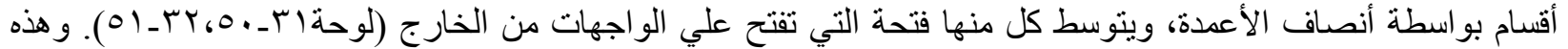

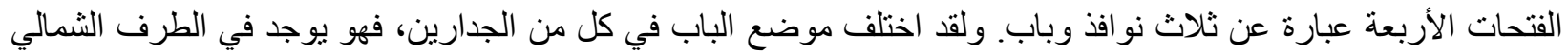

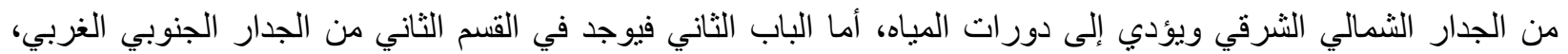
ويؤدي إلى سلم دكة المبلغ و المئذنة.

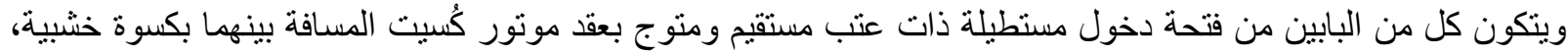
كما حُدد الباب بإطار خشبي، ويُخلق الباب بدلفتي باب خشبي ويفتح هذا الباب في دخلة عميقة تمثن خارج ساحة المسجد الداخلية 


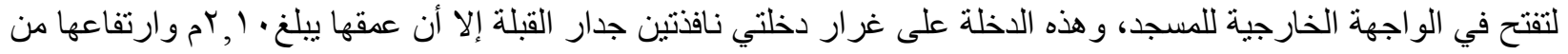

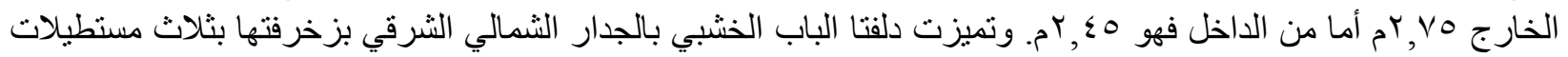

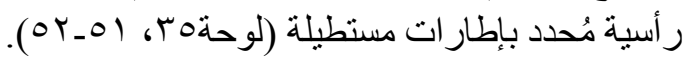

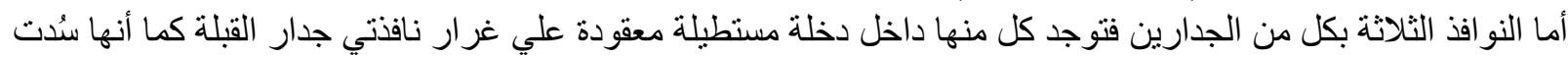

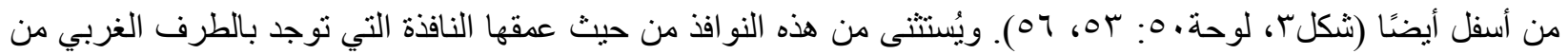

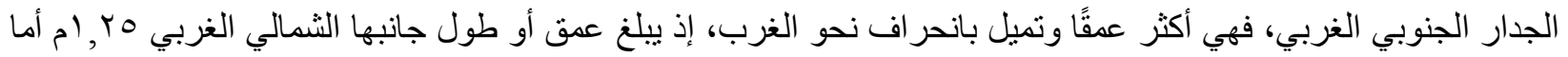

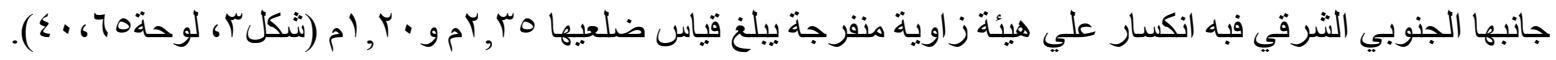

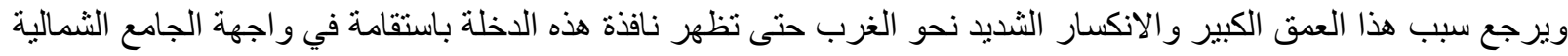
الغربية الرئيسية من الخارج؛ وذللك لأن هذه النافذة التي توجد في الطرف الناف الغربي من الجدار الجنوبي الغربي من الداخل تُمثل

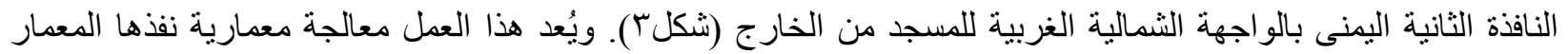

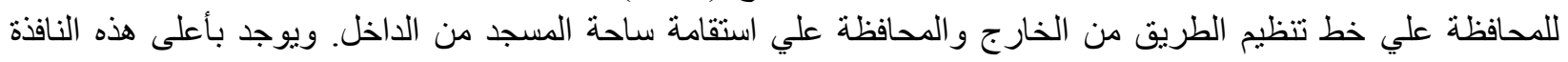

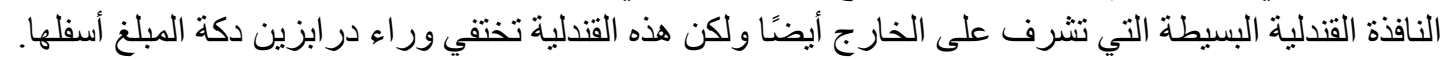

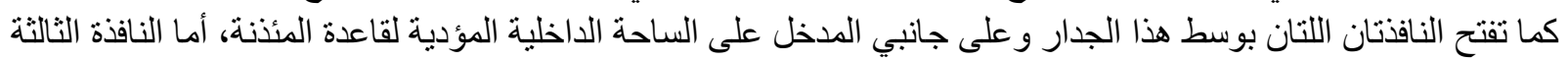

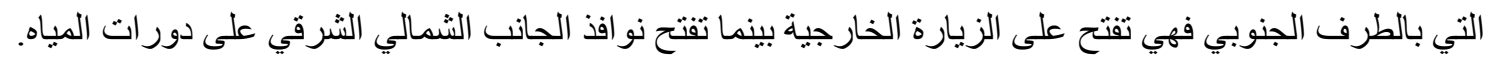

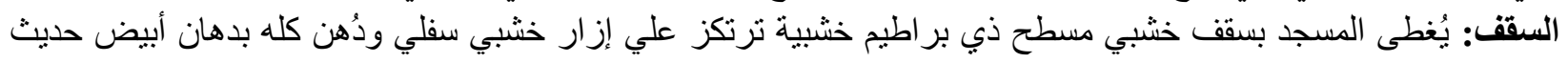

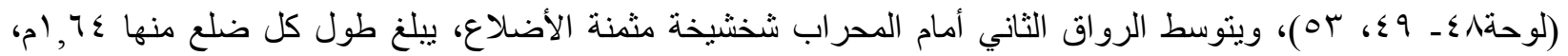

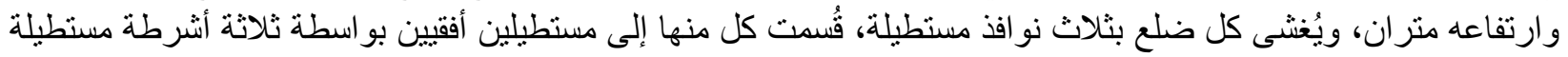

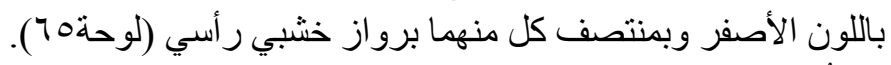

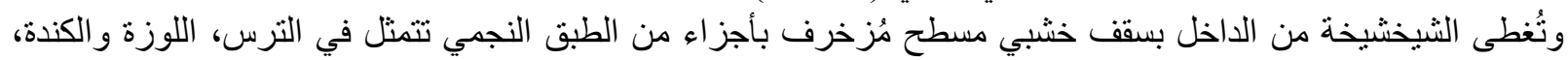

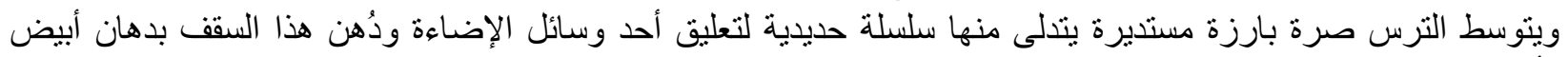

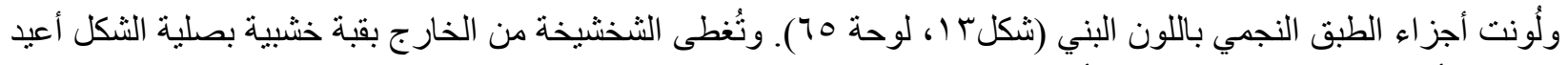

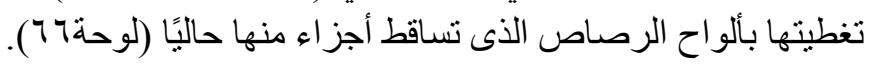

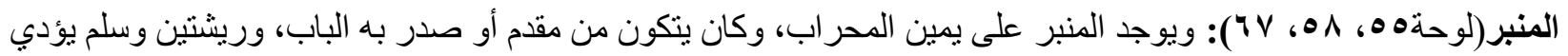

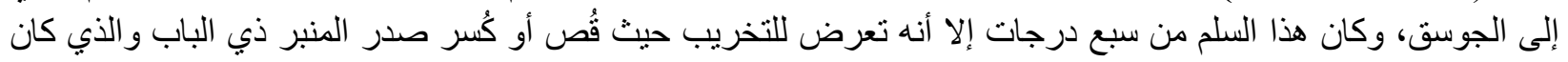

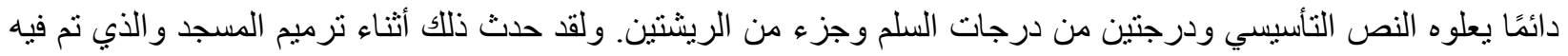

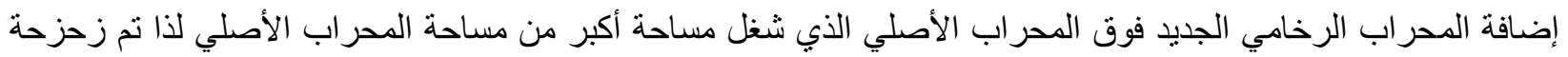

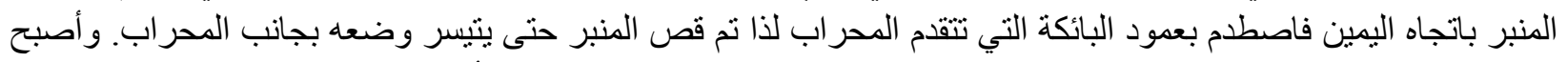
بذللك المنبر لا يحتوي على الصدر و اكتفى بتحديد جانبي ريشتيه بدعامة خشبية مسنطيلة ثُتوج من أعلى ببابه مستديرة الثكل.

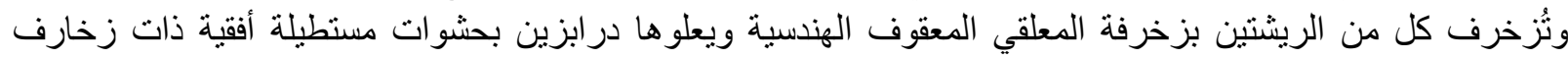

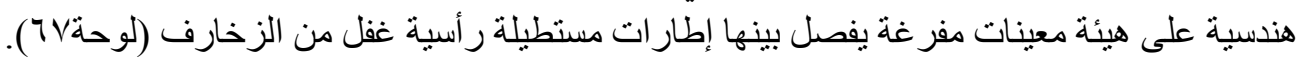

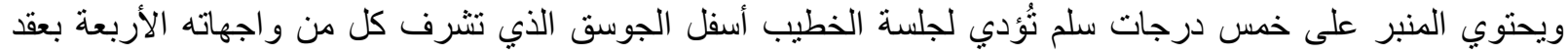

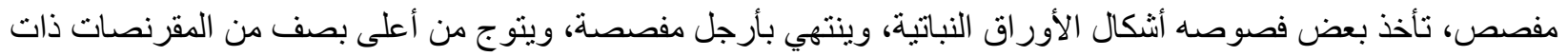

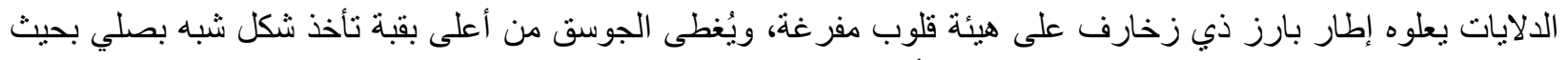

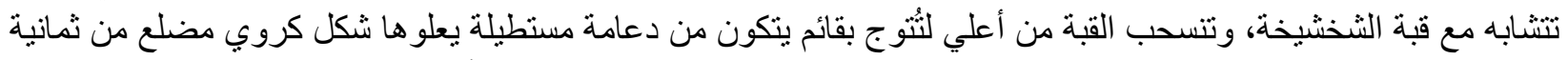

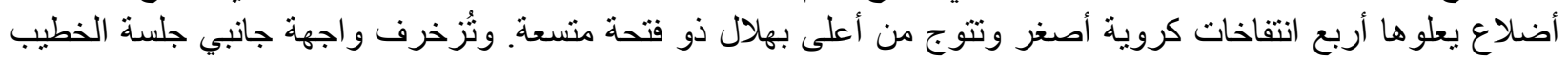

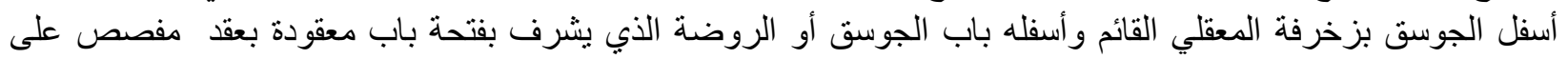

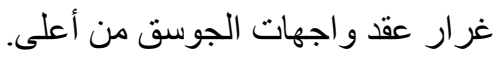

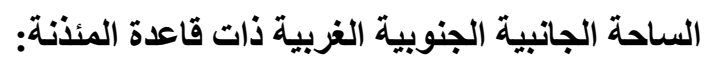

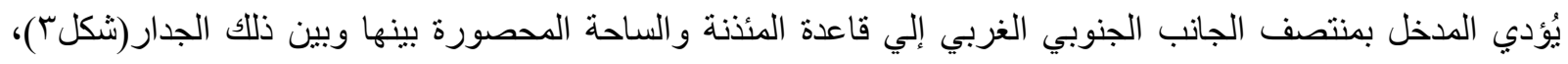
وتبدو هذه الساحة مقسمة إلي قسمين، قسم شمالي غربي على يمين الداخل وقسم جنوبي شرقي على يسار الداخل، ويتكون القسم 


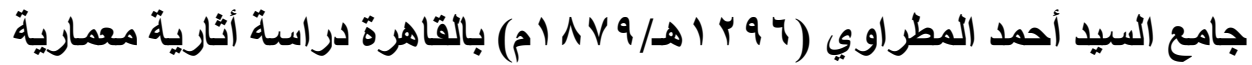

الأيمن من ساحة تبدو مستطيلة لكنها غير منتظمة الأضلاع، فهي محدده بخمسة أضلاع لأن الجانب الجنوبي الغربي يتكون من

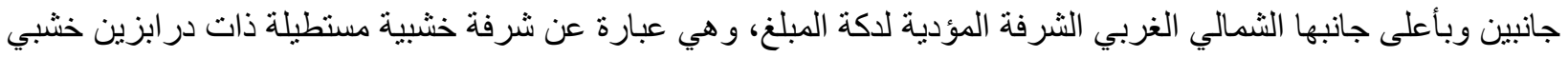

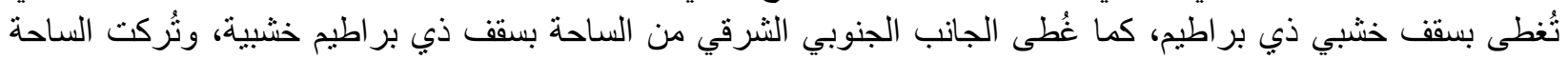

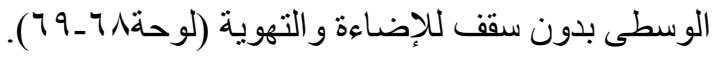

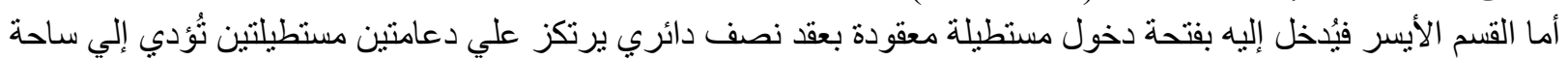

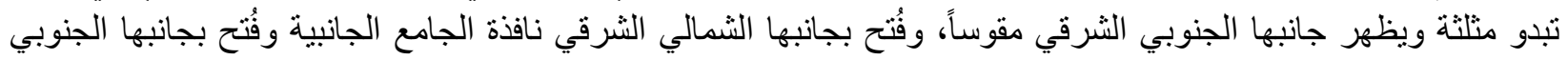

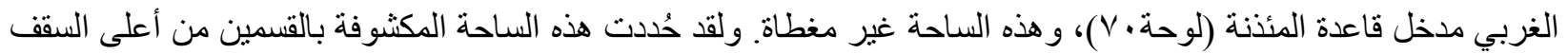

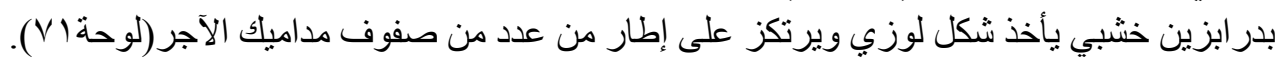

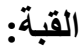

تُشخل القبة أو الضريح القسم الثمالي من الجانب الثمالي الغربي للجامع ومن الو اجهة الرئيسية للجامع أيضًا (شكلب)، ويُشخل

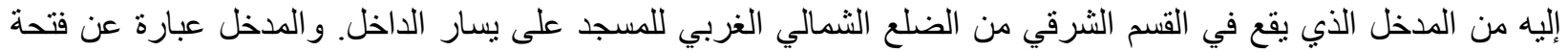

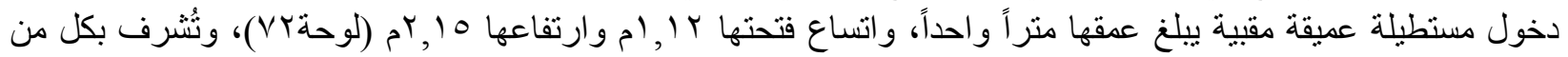

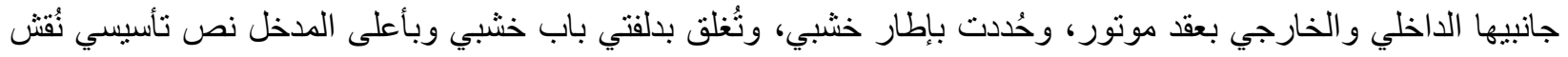

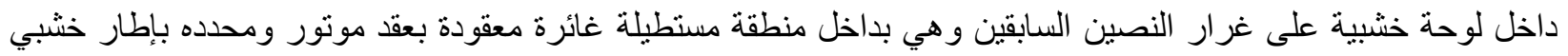

$$
\begin{aligned}
& \text { في قبـــة هـي منبــع الأفضـــــال }
\end{aligned}
$$

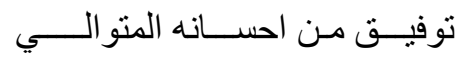

$$
\begin{aligned}
& \text { نادى الرضا فيهاوقتال خـامور } \\
& \text { I Y97 }
\end{aligned}
$$

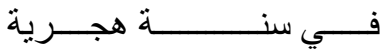

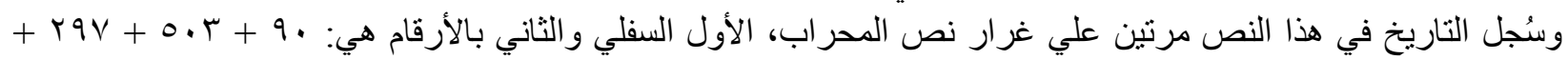

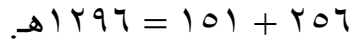

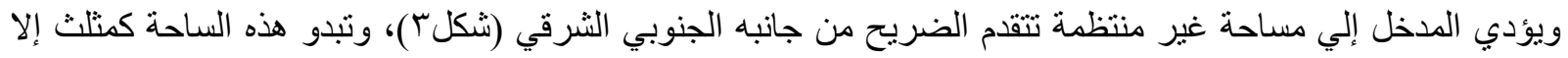

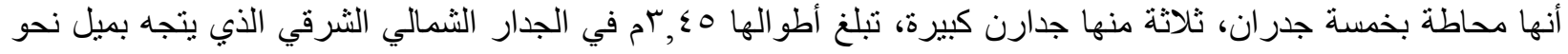

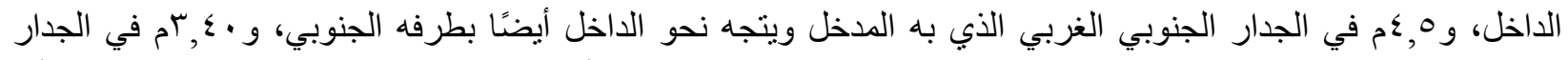

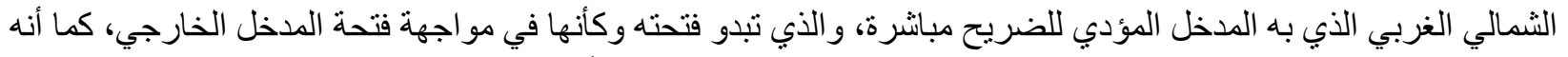

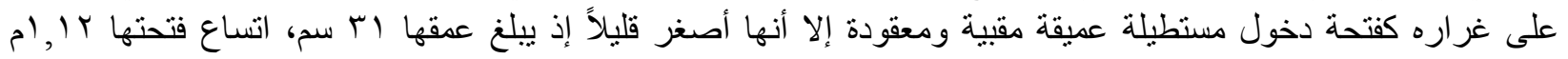

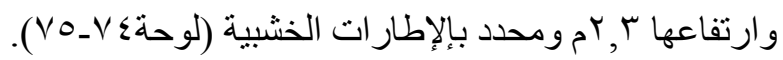

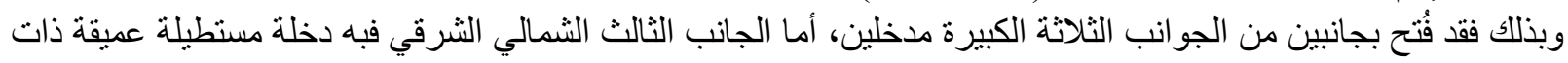

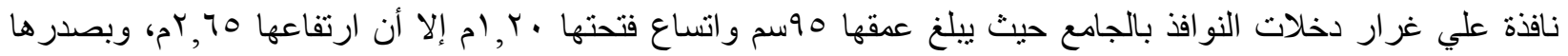

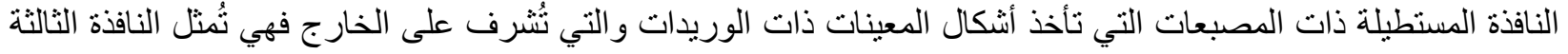

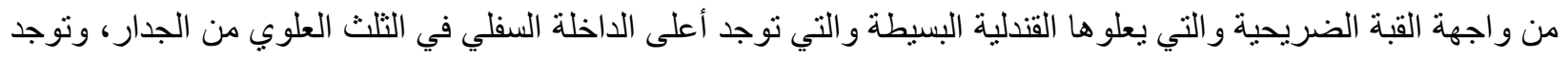

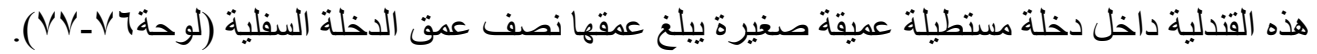

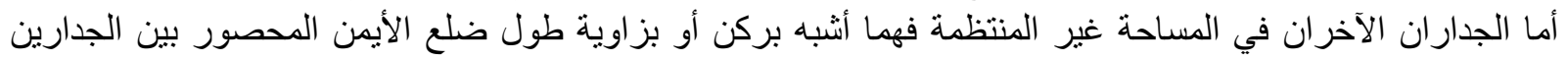

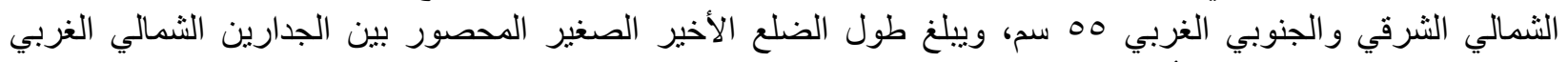

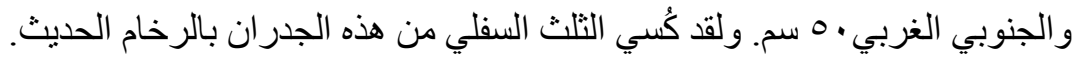

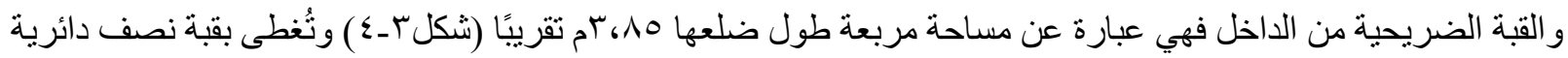

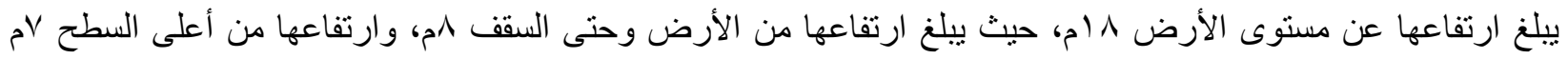


وثلاثة أمتار للقائم ذي الهلال الذي يتوجها. وترتكز القبة على رقبة أسطوانية ترتكز على أربع حنايا ركنية تتصب على

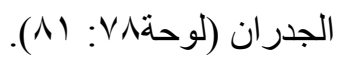
ويمكن تقسيم هذه الجدران إلى قسمين منساويين تقريبًا في الارتفاع، يمثل القسم السفلي مربع القبة السفلي، ويتوسط جدار ها

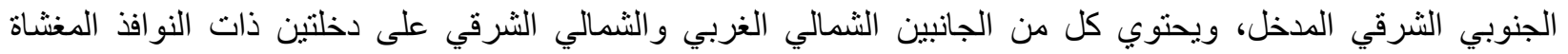

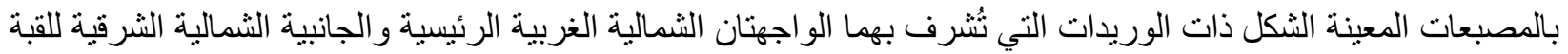

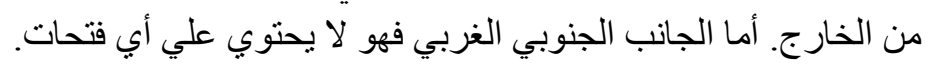

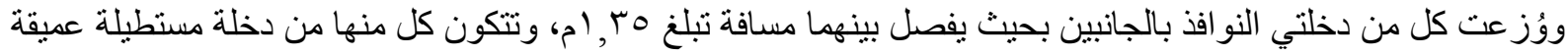

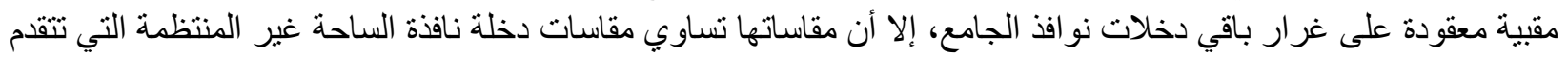

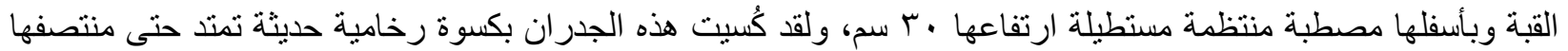

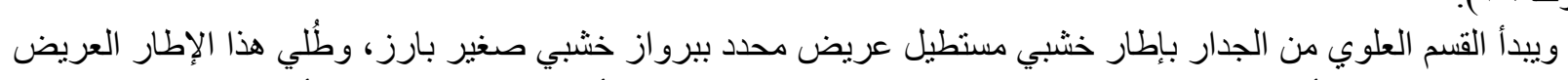
حاليًا بالزيت باللون الأخضر ، وربما كان هذا الإطار يحتوي على آيات قر آنية أو زخارف متنو عة إلإن أنها طمست بهذا الطلاء

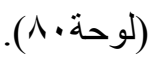
و ويمتد الجدار بعد هذا الإطار لأعلى حتى منطقة الانتقال مرتدًا قليلاً للداخل، ويحتوي كل من الجدارين الثمالي الغربي

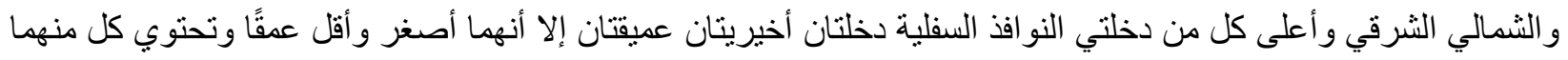

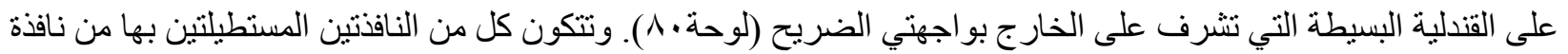

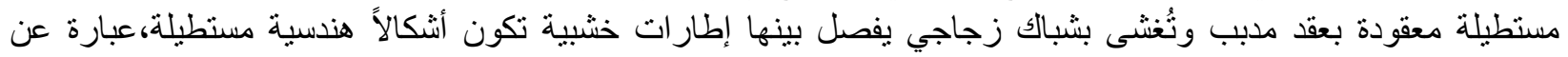

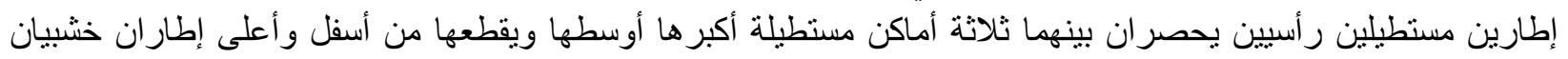

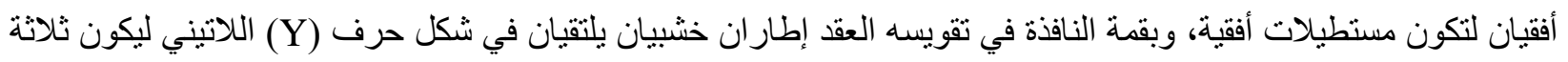

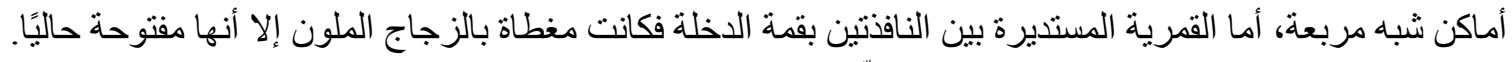

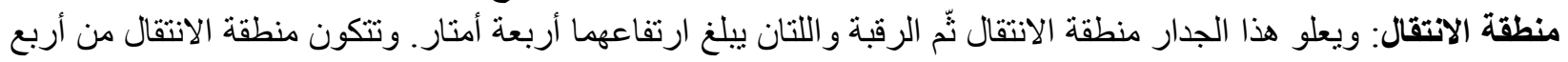

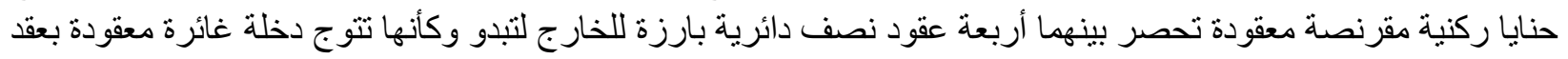

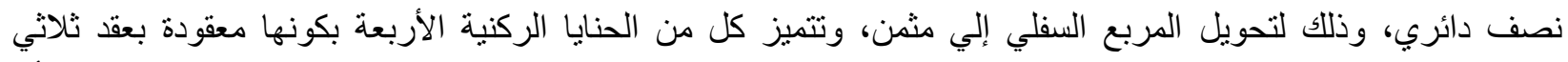

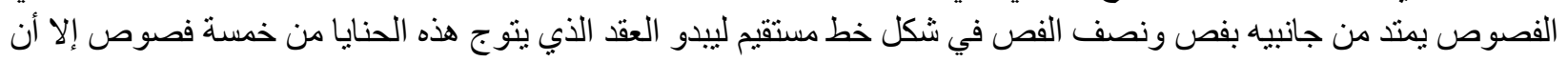

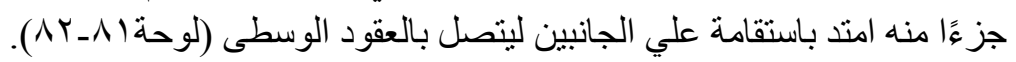

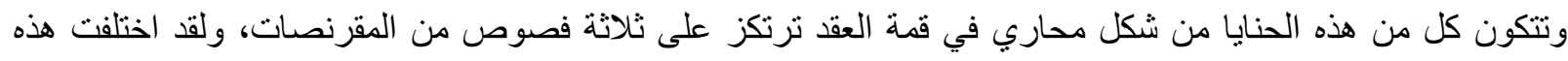

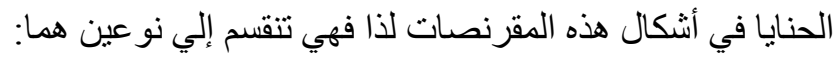

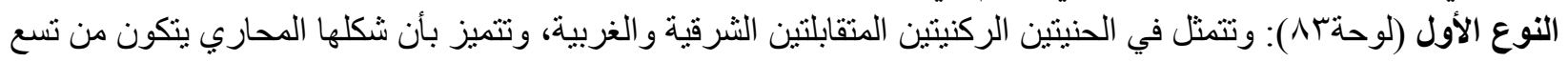

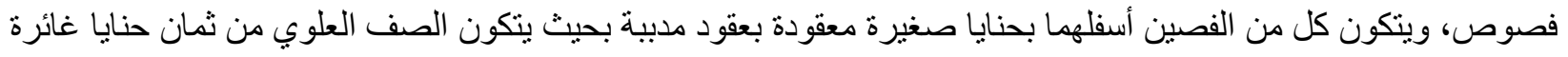

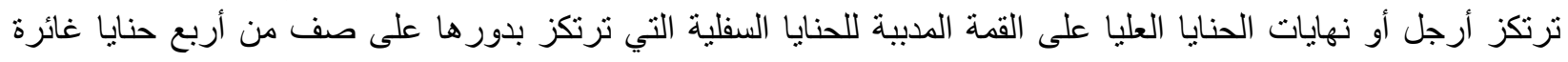

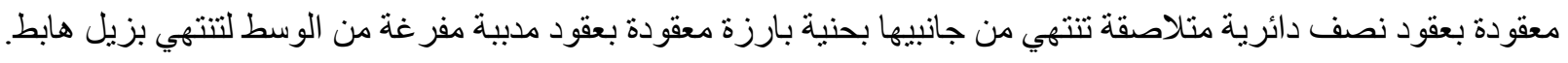

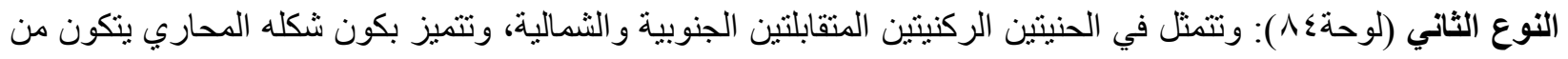

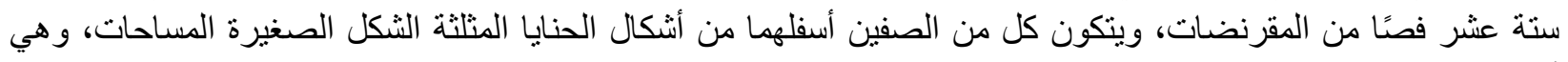

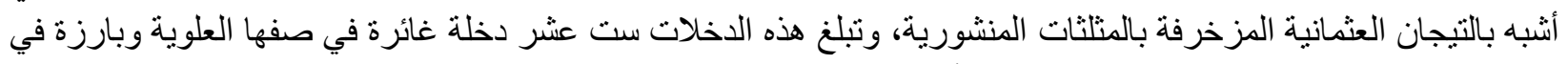

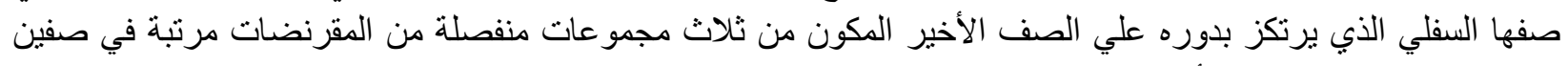

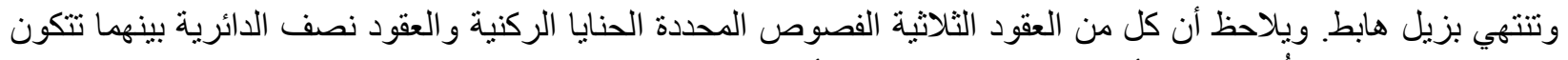

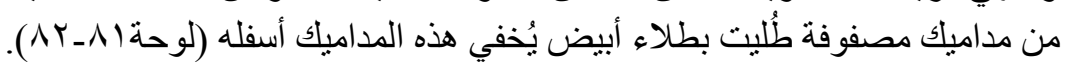

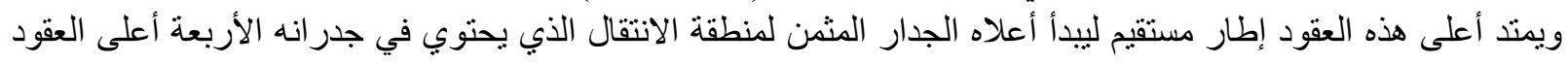

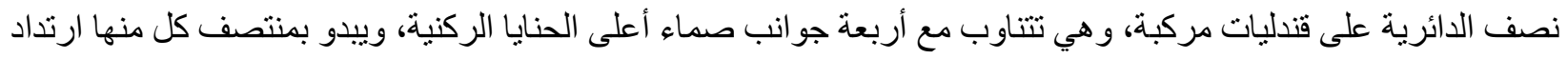

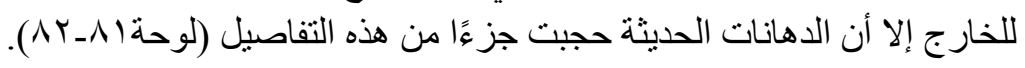




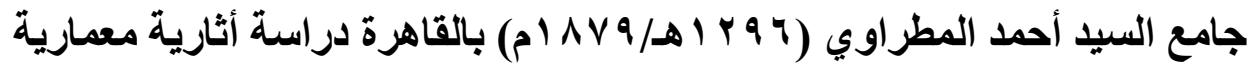

وتتكون كل من القندليات المركبة الأربعة من ثلاث نو افذ مسنطيلة معقودة بعقود موتورة، مغطاة بشباك زجاجي به إطارين

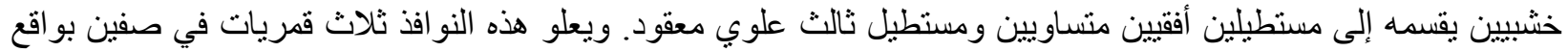

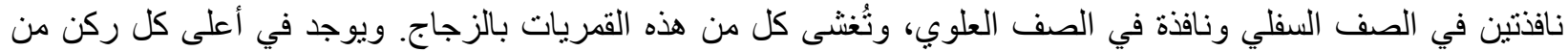

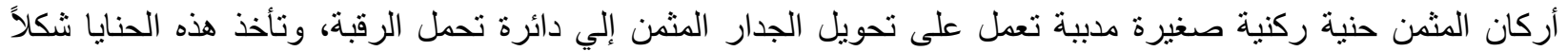

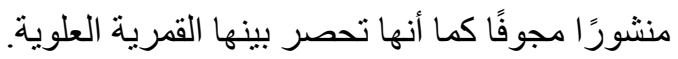

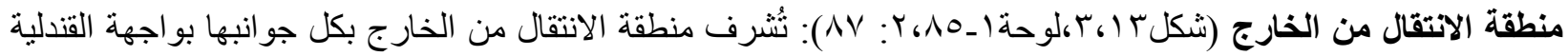

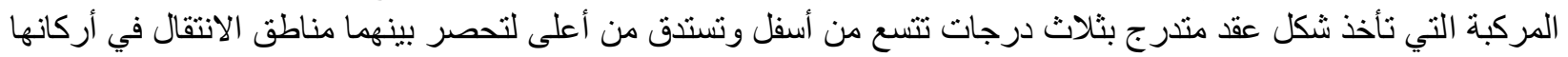

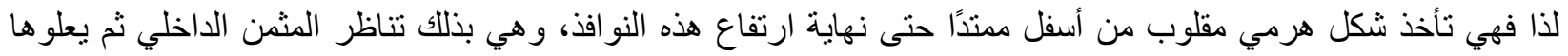

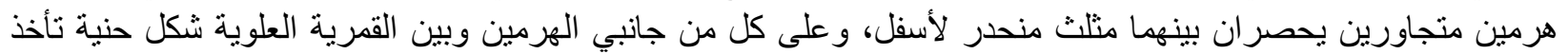

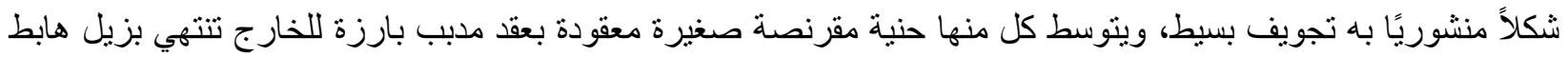

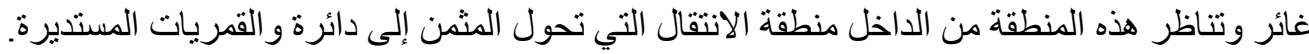

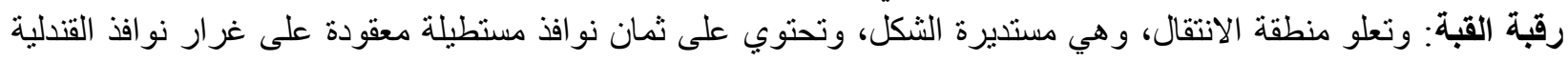

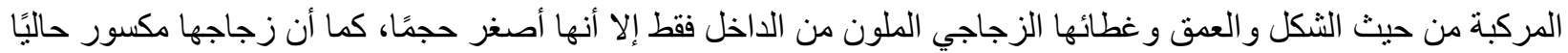

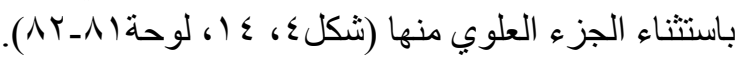

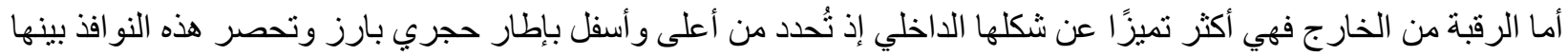

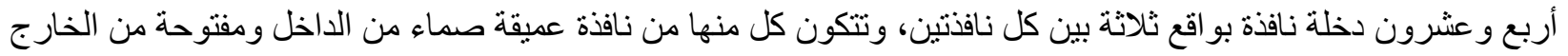

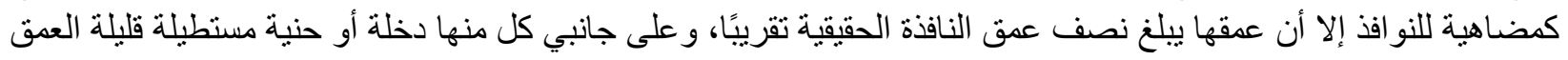

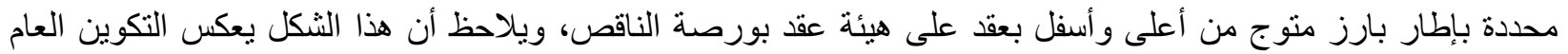

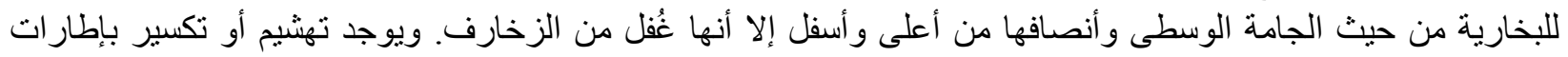

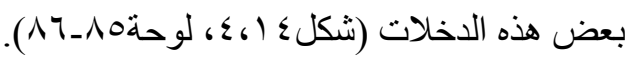

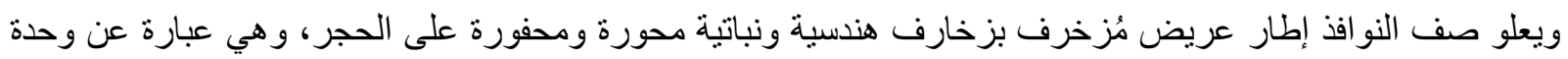

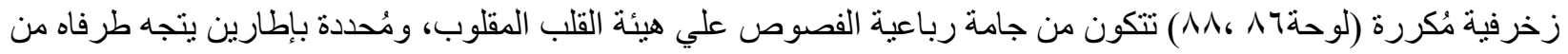

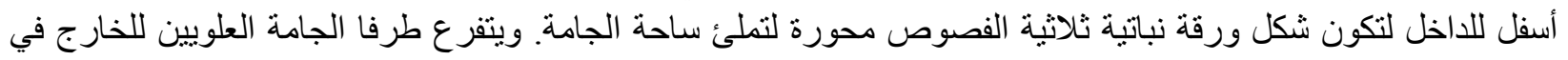

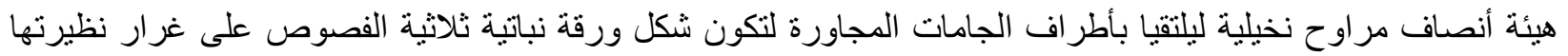

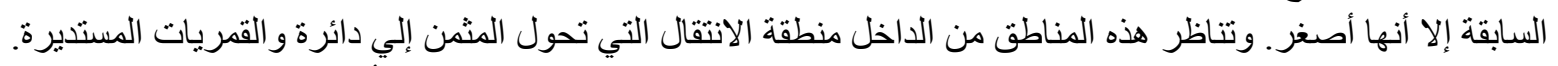

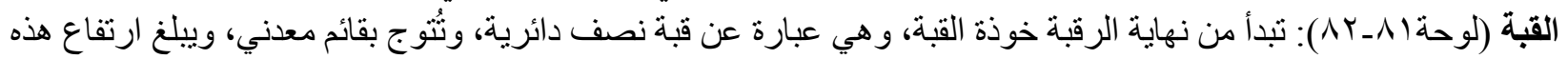

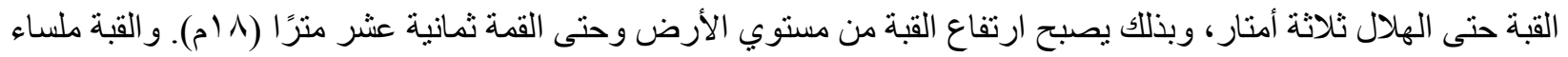

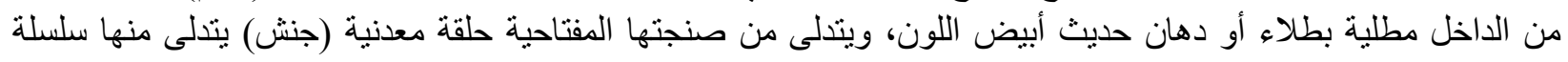

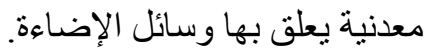

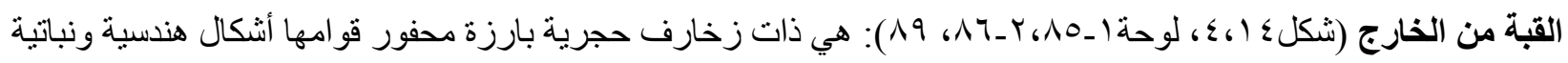

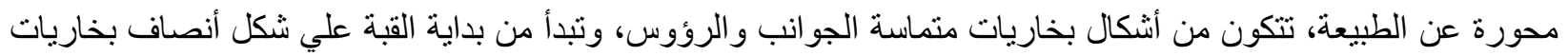

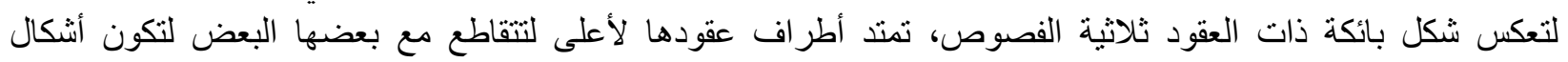

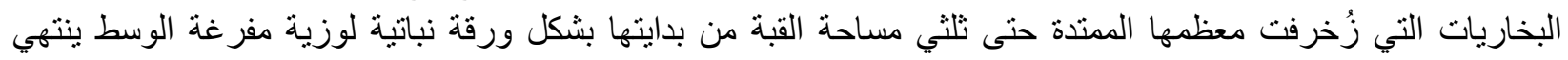

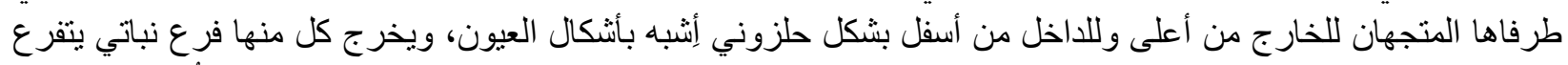

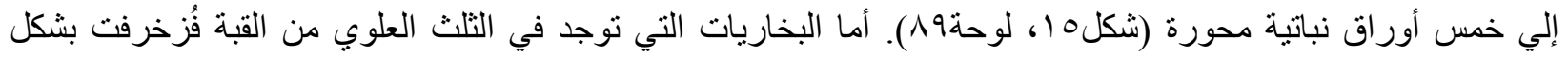

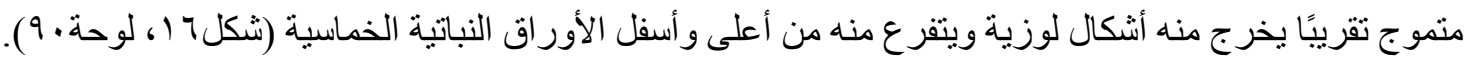

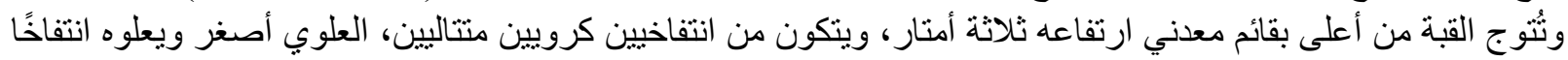

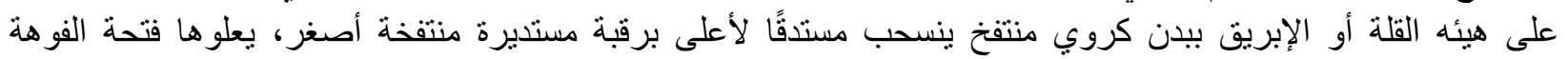

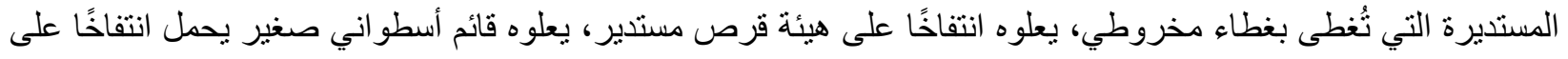


شكل كأس بفو هة مستديرة مسطحة بارزة للخارج، يحمل قائم أسطواني يتوسطه انتفاخ كروي كبير، ويتوج من أعلى بشكل

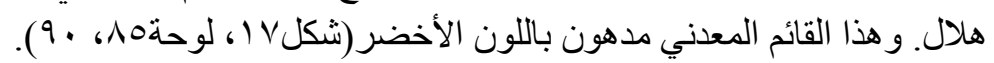

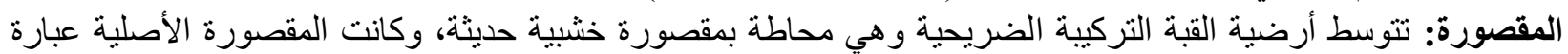

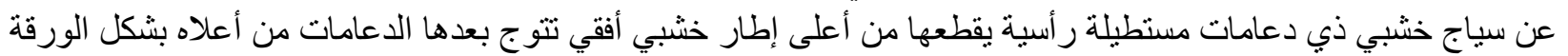

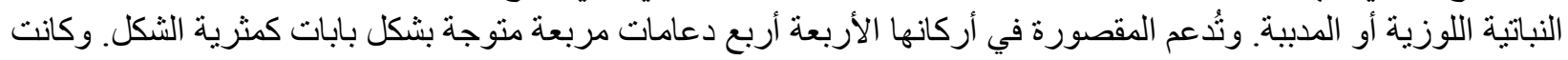

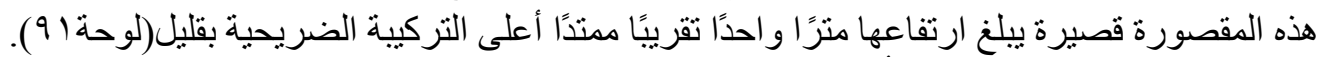

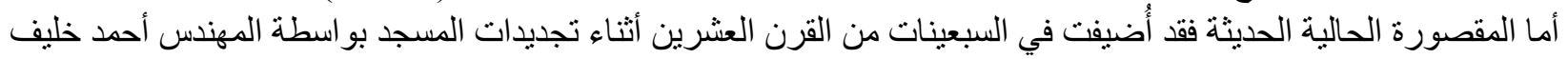

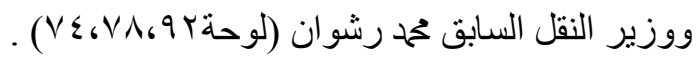

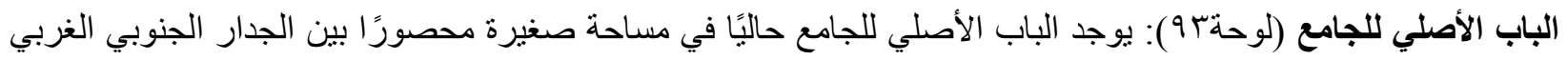

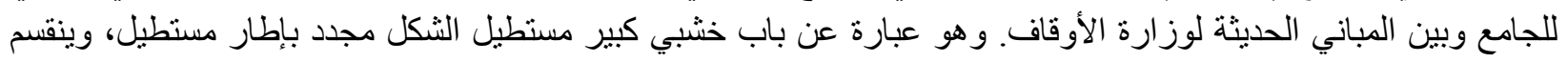

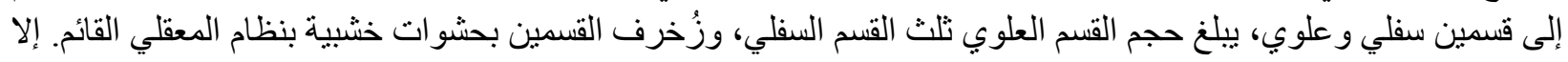

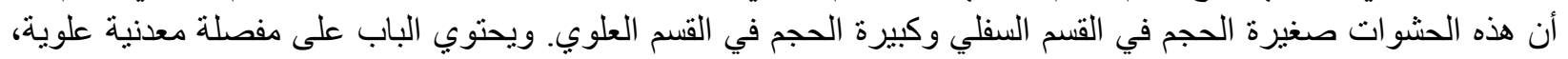

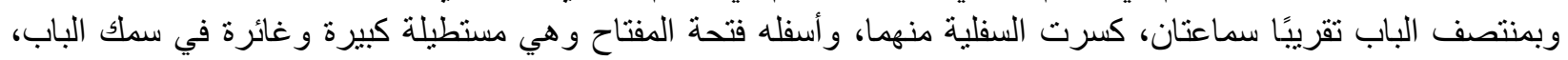

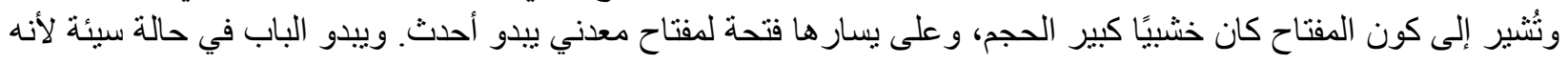
يحتاج إلي الترميم وللحفظ في مكان آمنان.

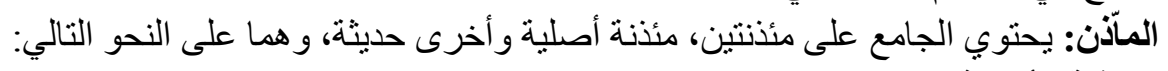

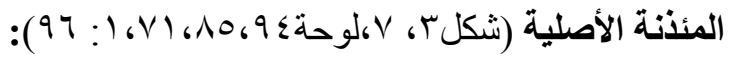

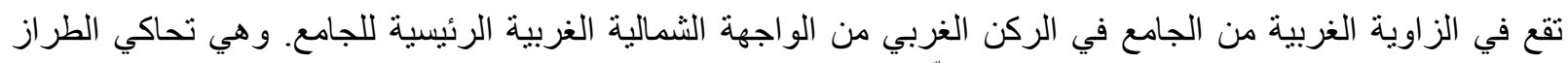

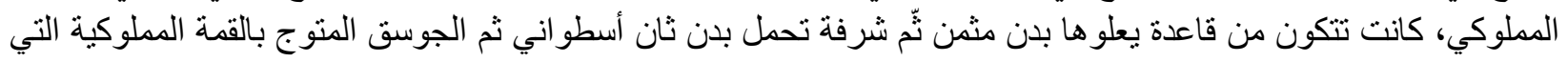

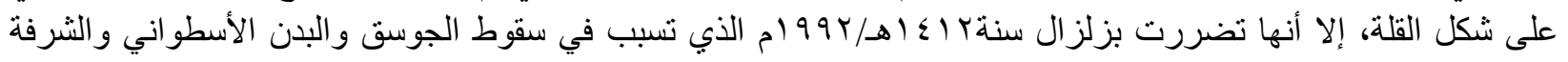

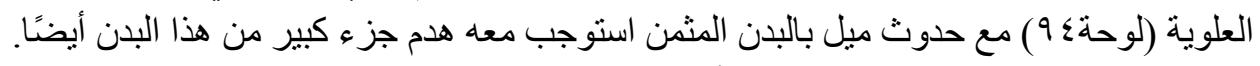

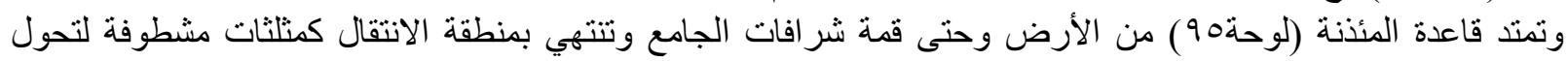

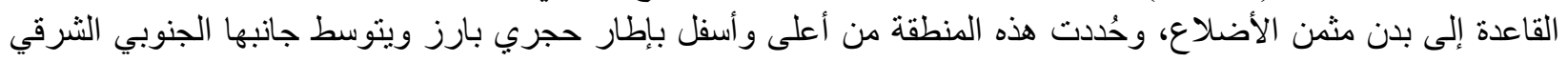

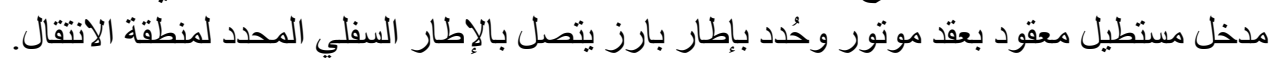

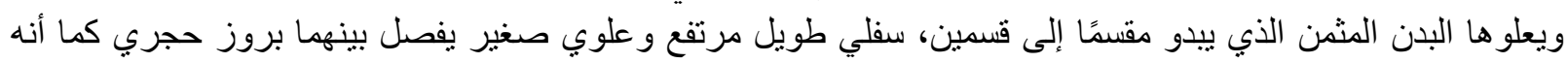

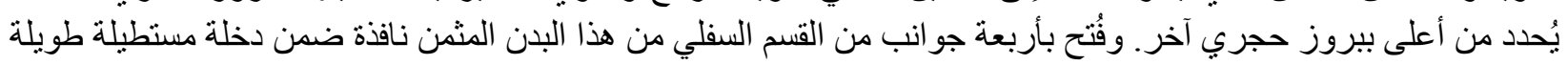

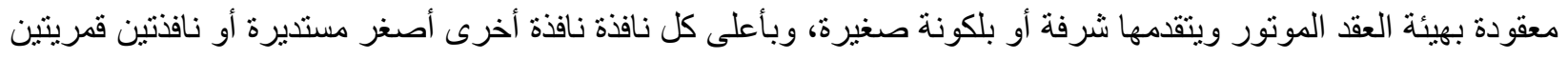

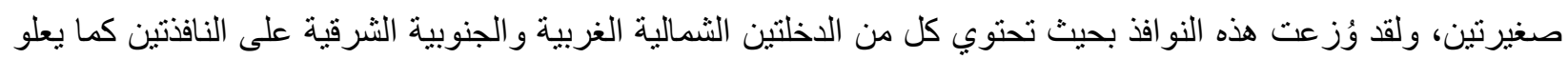
كل من هاتين الدخلتين نافذة صغيرة مستطيلة. أما الدخلتان الجانبيتين الثمالية الثرقية والجنية الثنوبية الغربية الثربية فتحتوي على نافذة

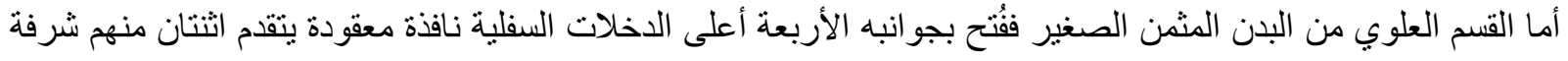

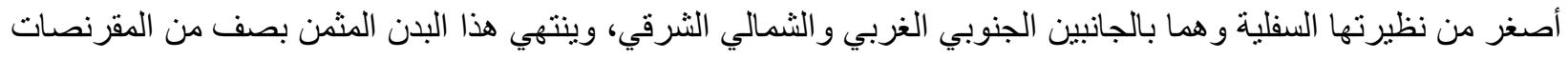

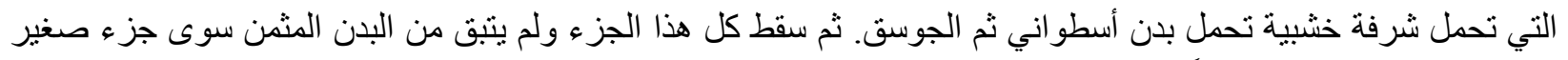

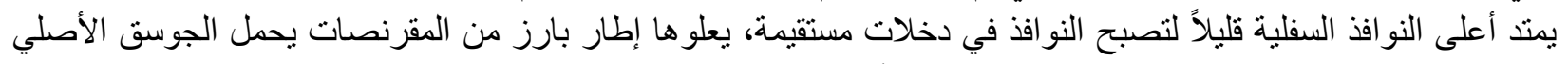

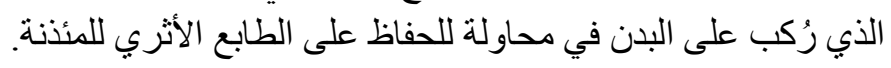

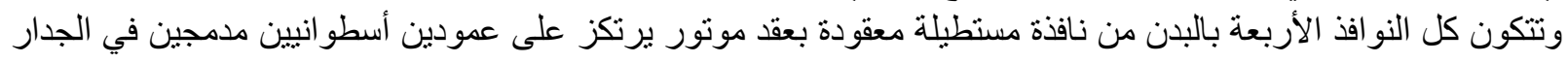

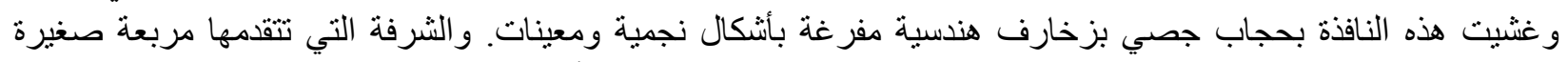

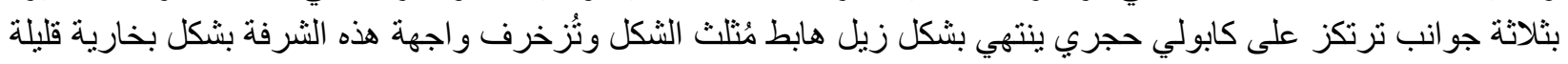

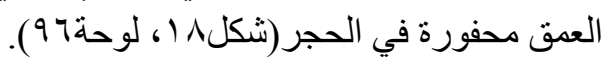




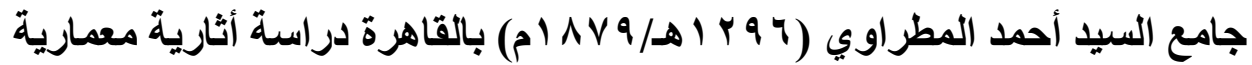

أما الجوسق فهو أسطو اني، فُتح به ثمان نو افذ مستطيلة معقودة بعقد موتور وغُشيت بأحجبة جصية بزخارف هندسية ذات

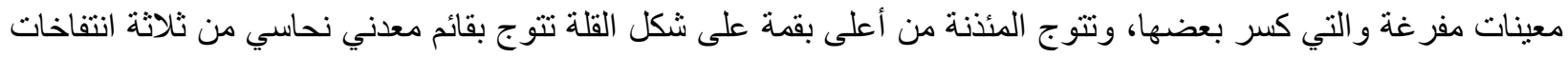

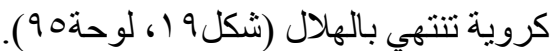

وتحتوي المئذنة على سلم حلزوني يؤدي إلى قمة المئذنة، و إلى دكة المبلغ وسقف الجامع، كما فُتح بجانبها الثها الثمالي الشرقي

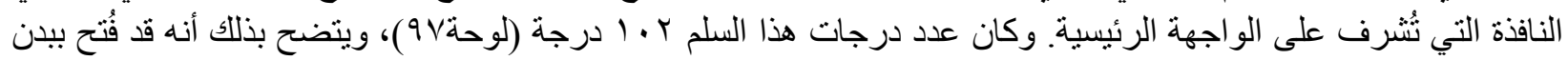

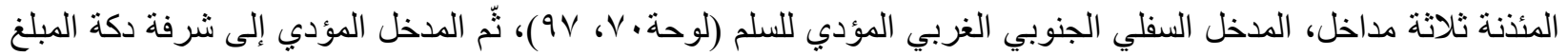

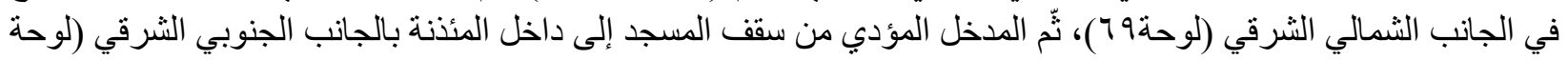
( ( $(1)$.90

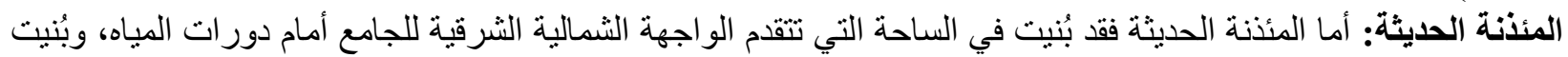

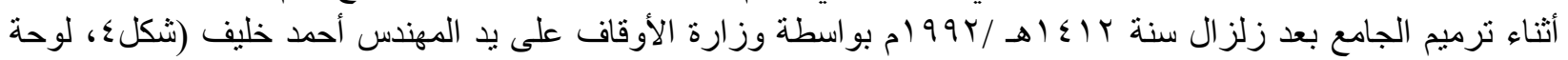

و هي التي تتمثل في حديقة ذات أثنار في الجانبين الجنوبي الثرقي والجنوبي الغربي ودورات المياه وممر الدخول إليها في

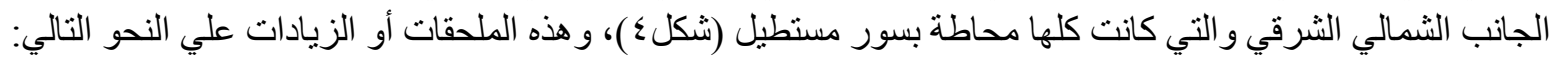

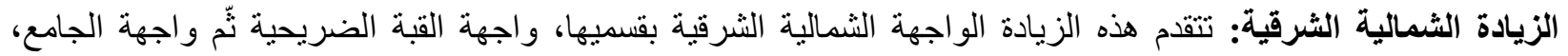

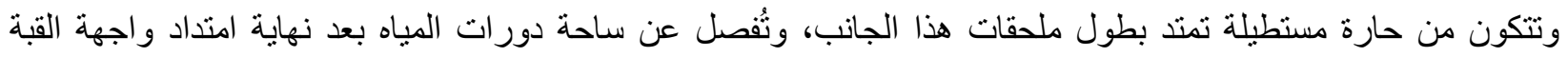

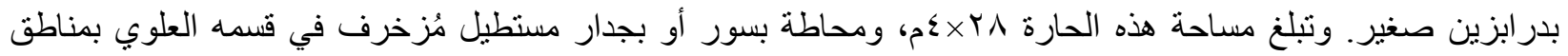

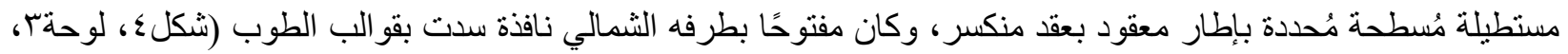

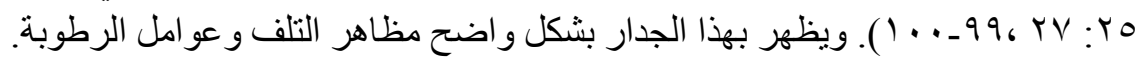

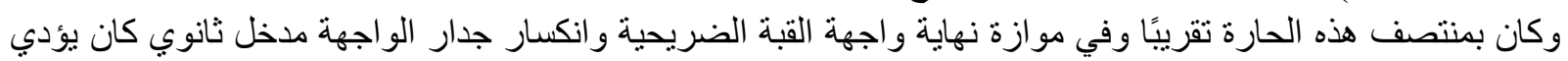

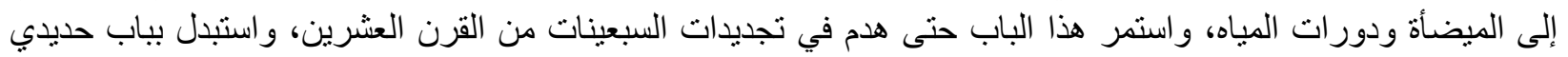

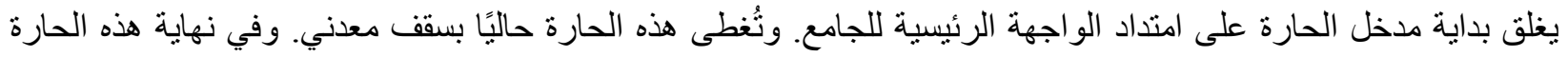
بُني سلم بؤدي إلي دور علوي بُني فوق دورات المباه كمصلي للسيدات وهو مستطيل ويُغطى بسقف مسطح يتوسط شخشيخة

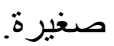
وبجانب و اجهة الجامع الثمالية الثرقية تمتد ساحة مستطيلة يتو سطها مئذنة حديثة ويمتد على يسار ها دورات مياه حديثة. وفي

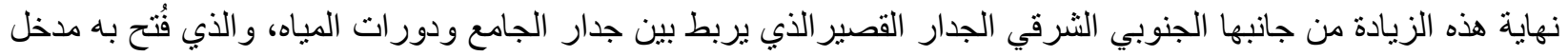

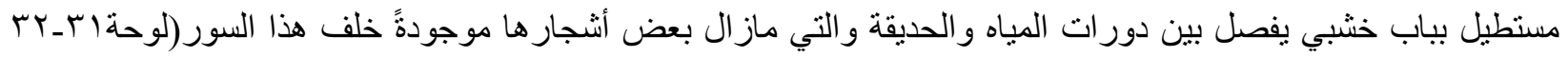

( $\left(r V_{6}\right.$

الزيادة بالجانبين الجنوبي الثرقي والجنوبي الغربي: كانت بمثابة حديقة أو جنينة مُلحقة بالمسجد أو كانت جزءًا من المساحة

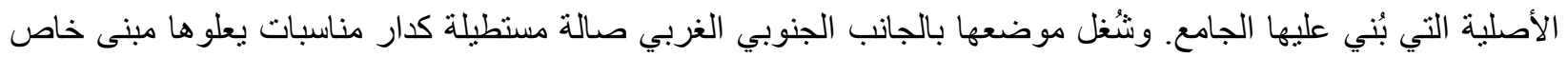
بوزارة الأوقاف يُصعد إليها من سلم محصور بين الجامع ومدخل دار المناسبات بالواجهة الرئيسية الثمالية الغربية، كما أن الن النيات

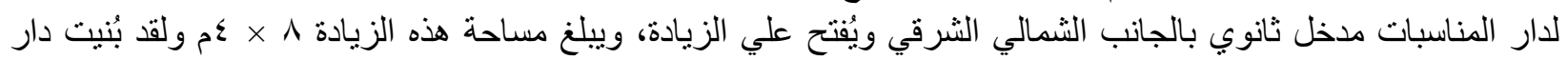

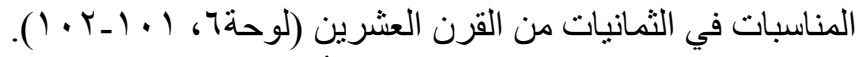

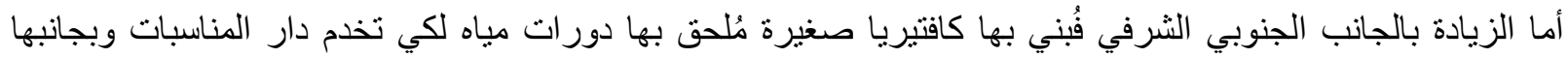

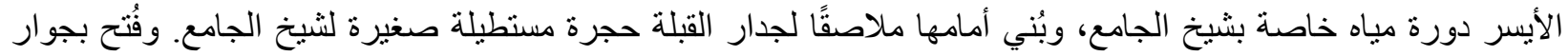

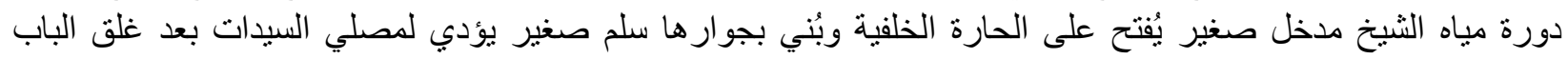

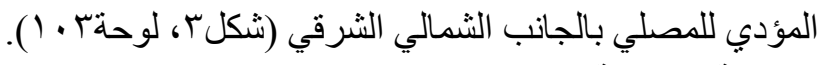

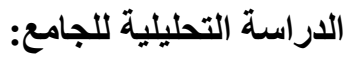

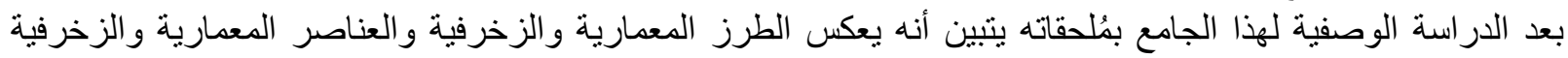
و المعالجة المعمارية للموقع التي كانت سائدة في عصر بناء الجامع والتي ترجع جذور ها إلى الطرز المصرية الإسلامية التي المئي 
تأصلت في مصر منذ العصر الفاطمي وتطورت بعد ذلك في العصور التالية من أيوبية ومملوكية وعثمانية ويتضح ذلك كما

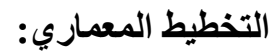

شيد هذا الجامع بتخطيط الجامع ذو الأروقة دون الصحن أو بطراز الجامع ذو السقف المرتكز على بائكات، والذي أطلق

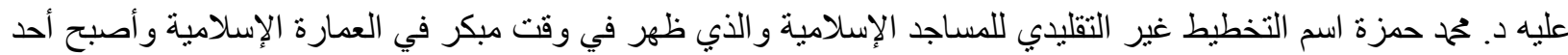

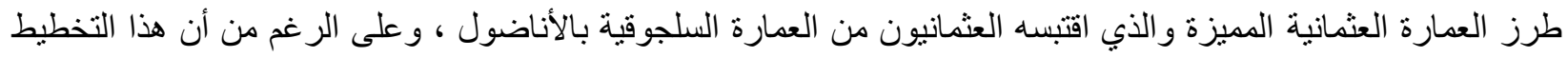

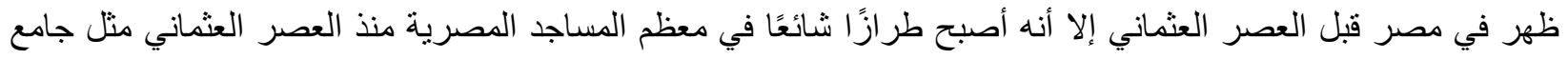

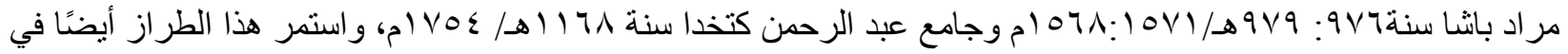

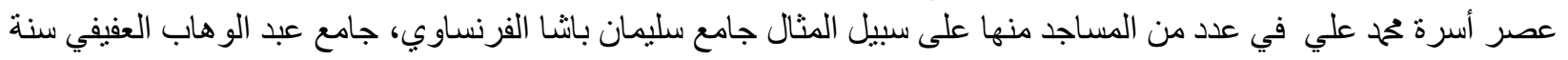

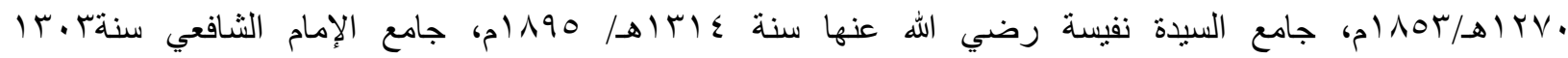

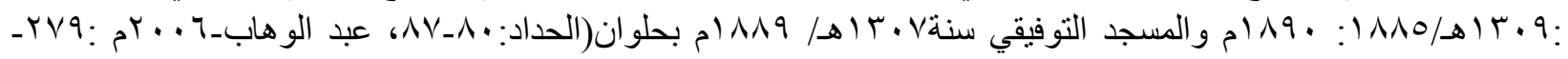

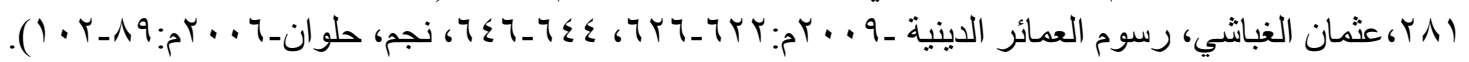

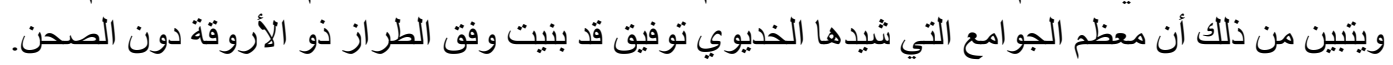

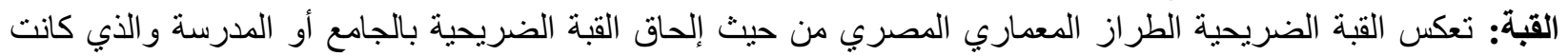

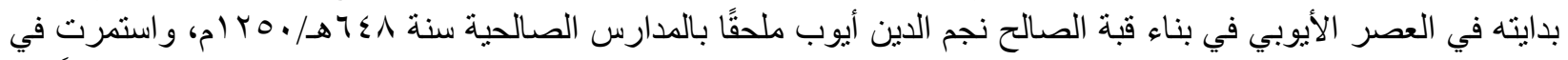

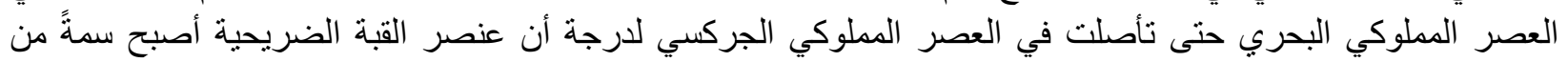

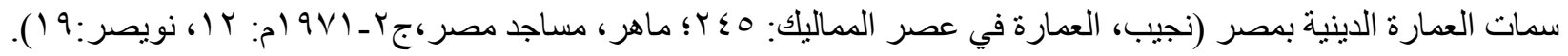

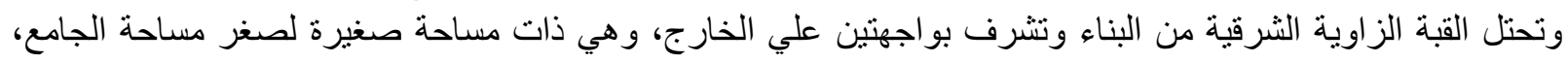

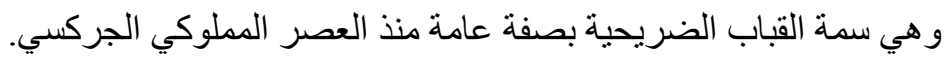

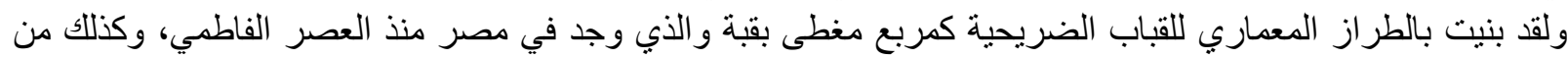

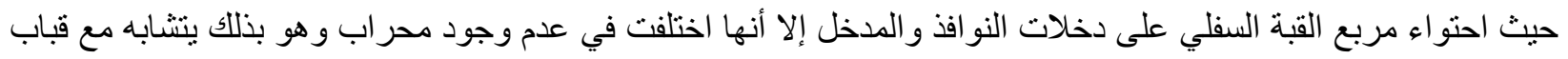

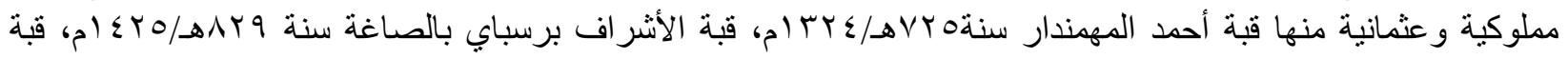

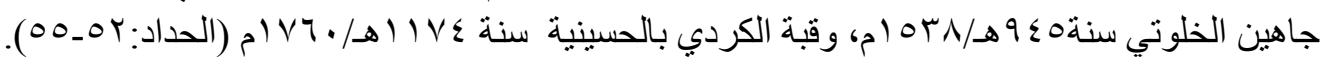

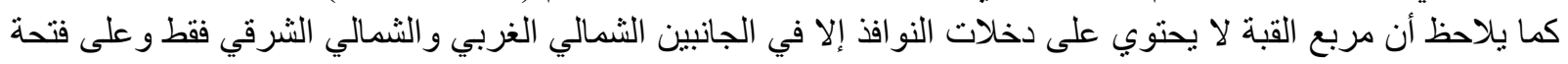

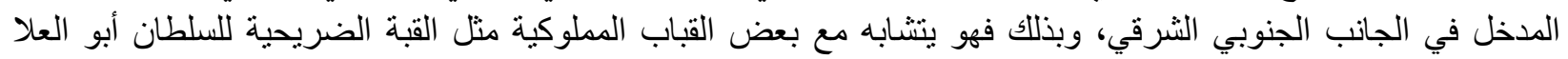

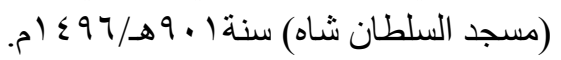

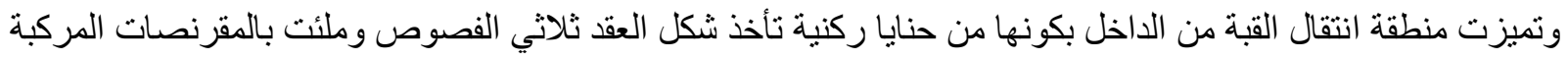

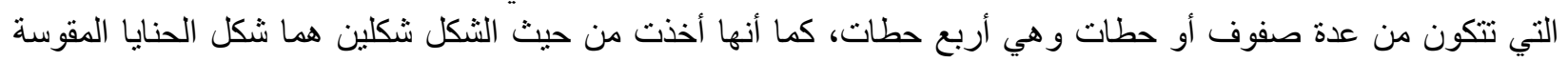

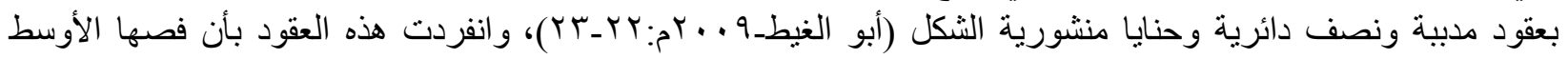

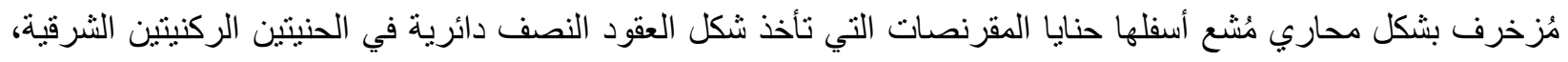

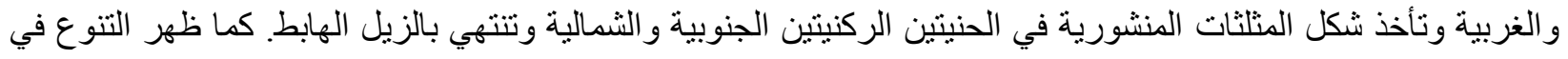

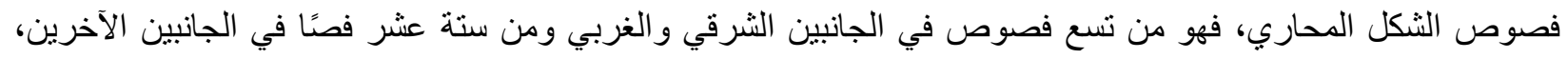

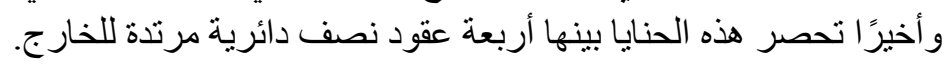

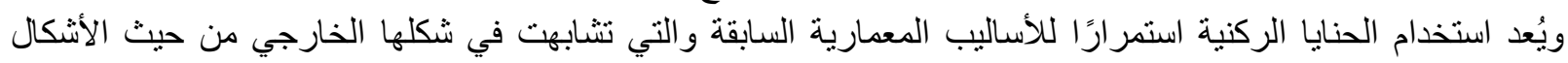

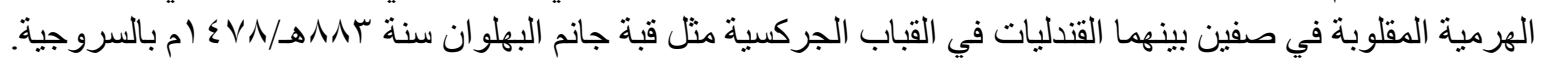

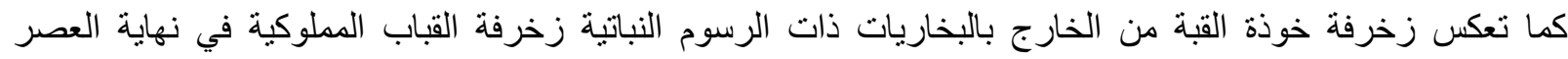

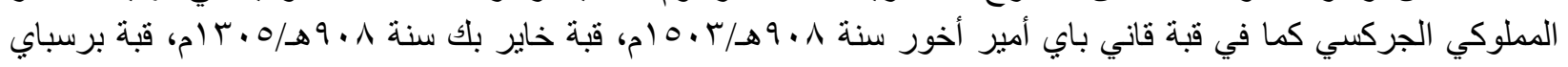

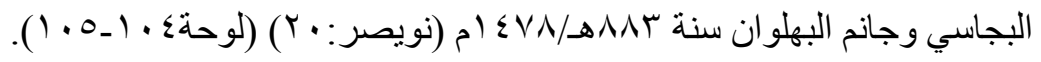

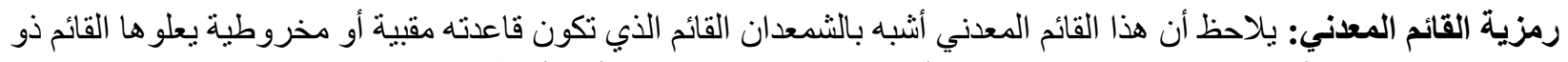
الانتفاخات الكروية أو اللوزية الثنكل وتنتهي من أعلي بييت الثمعة الذي يأخذ أحيانًا شكل الصينية التي تحمل الثنمعة في الثيان 


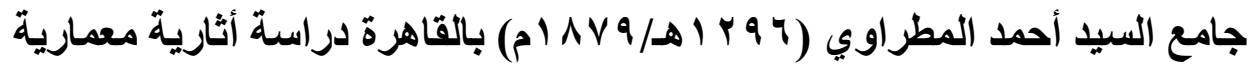

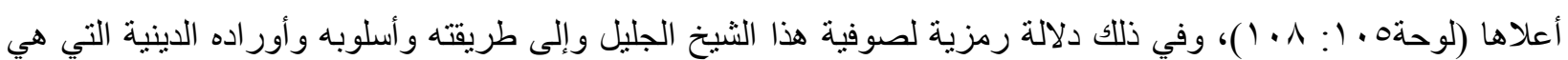

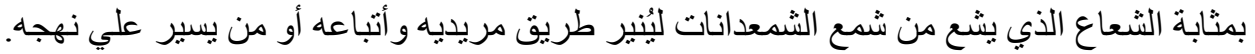

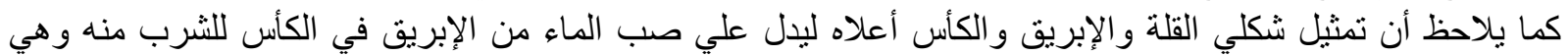

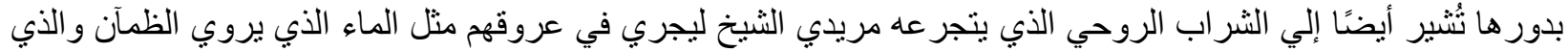

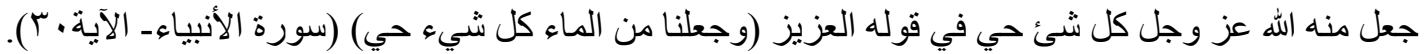

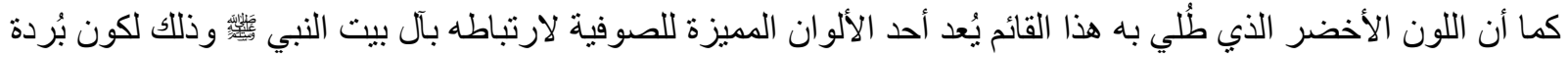

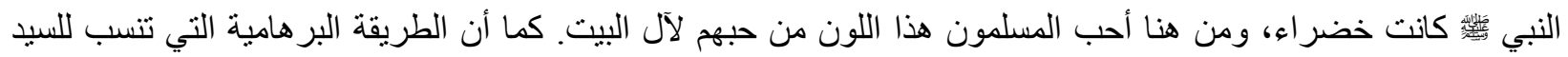

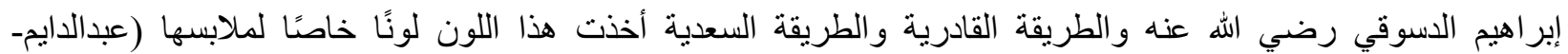

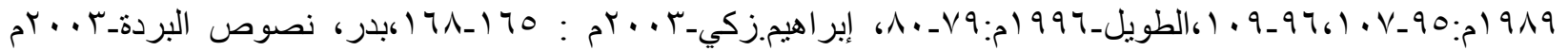

لذللك يُعد اللون الأخضر من الألوان التي تمتعت بمكانة سامية بين الألوان المستخدمة الفن الإسلامي بصفة عامة وارتبط

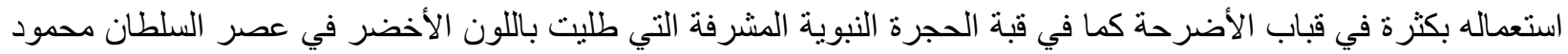

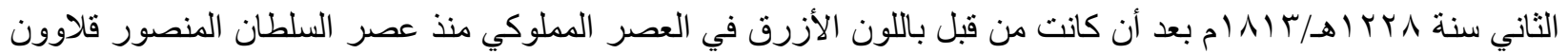

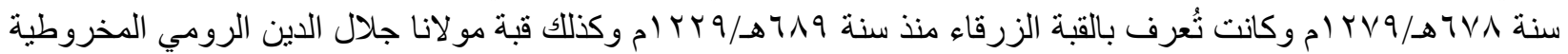

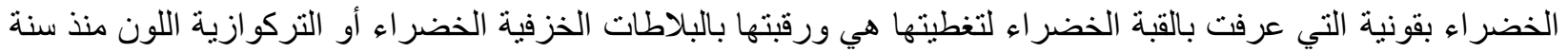
. . . . . ل

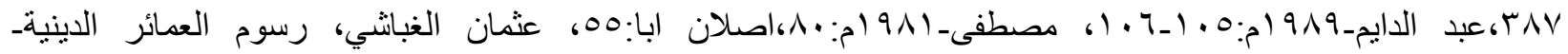

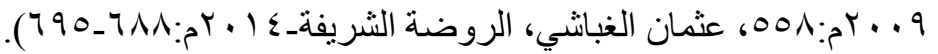

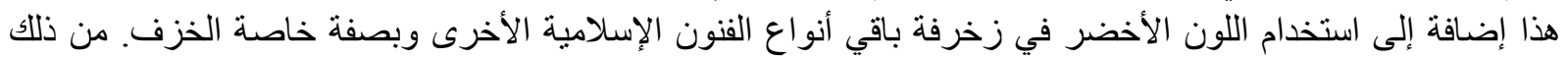

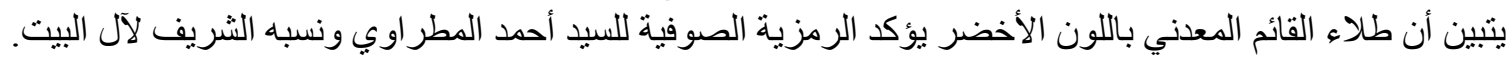

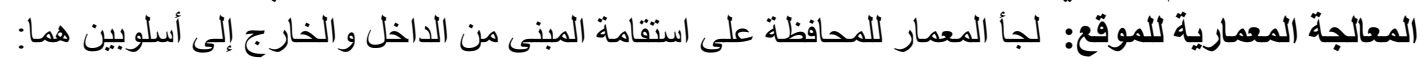

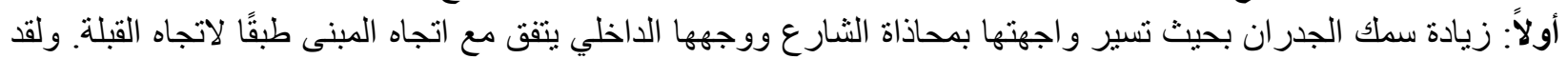

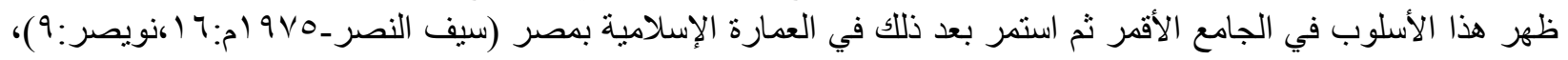

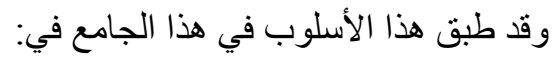

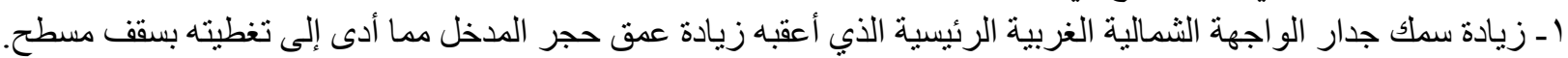
Y - زيادة عمق النو افذ وتفاوت سمكها و عمقها.

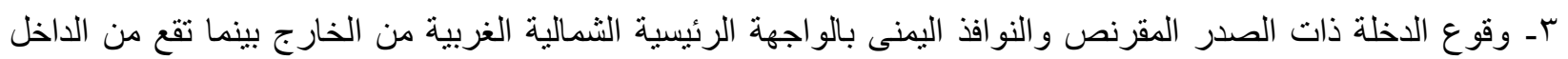
بالجانب الجنوبي الغربي.

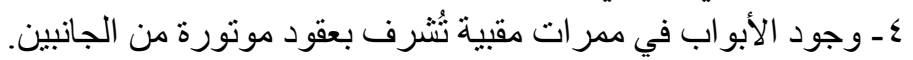

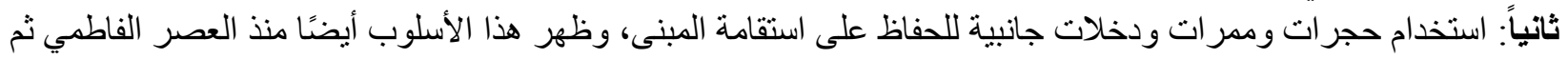

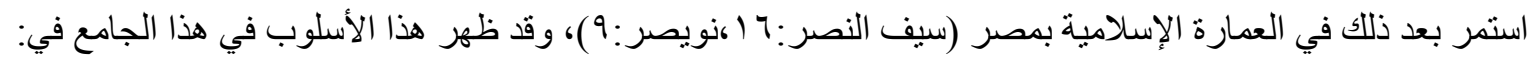

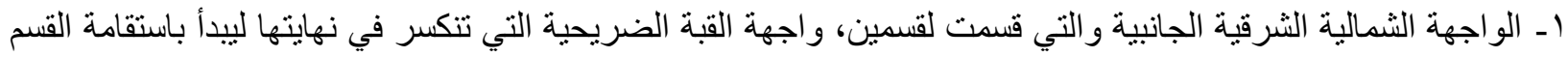

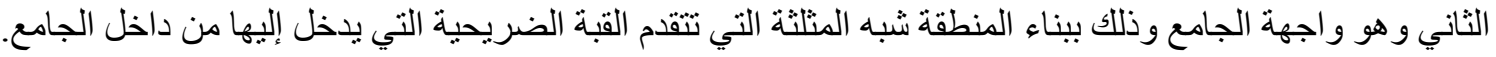

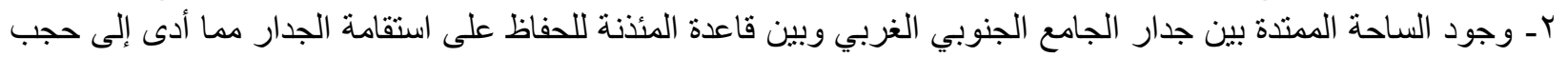
واجهة الجامع داخل هذه الساحة. الواجهات:

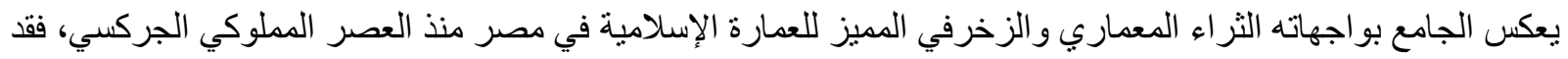

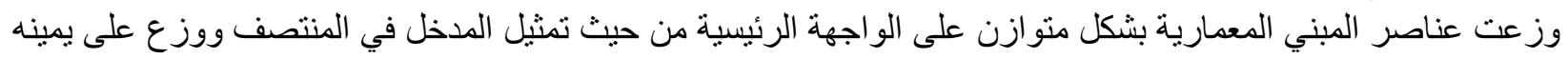
و اجهة الجامع و المئذنة و على يساره و اجهة القبة الضريحية (نويصر :Y ا l). 
ولقد قُسمت الو اجهات وخاصة الو اجهة الرئيسية الشمالية الغربية وواجهة القبة الضريحية الثمالية الشرقية إلى دخلات ذات

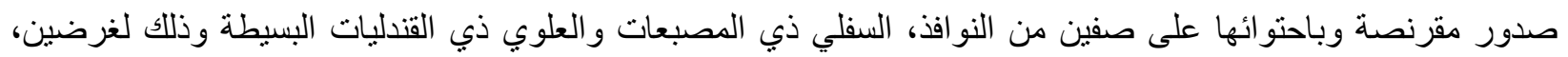

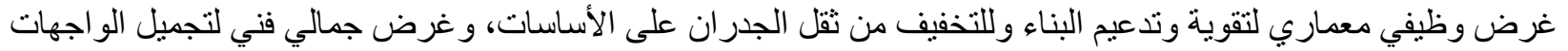

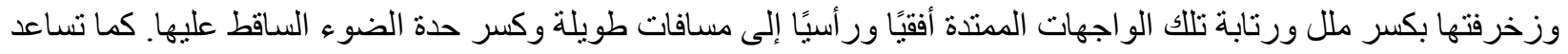

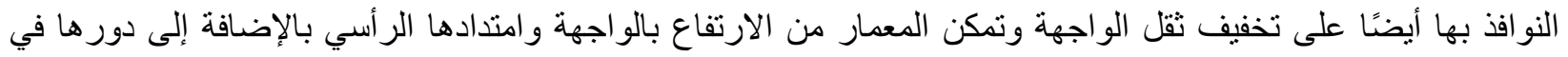

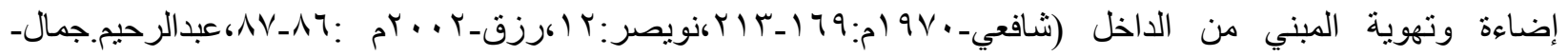
(199) ويُعد هذا التقسيم للواجهات إلى دخلات بات سمة من سمات عمارة مصر الإسلامية التي بدأت نظهر منذ العصر الفاطمي،

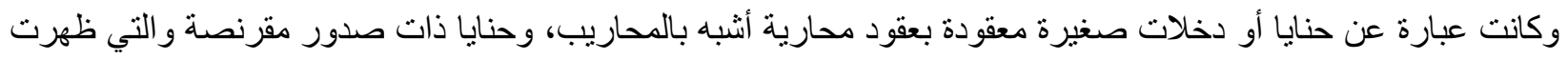

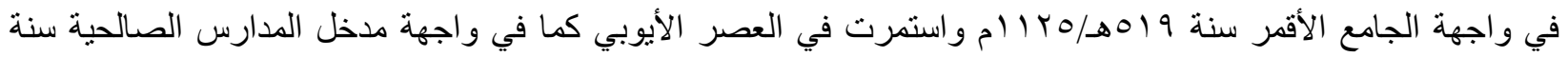

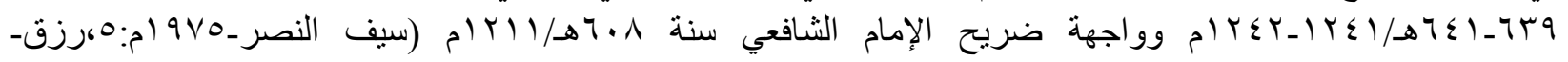

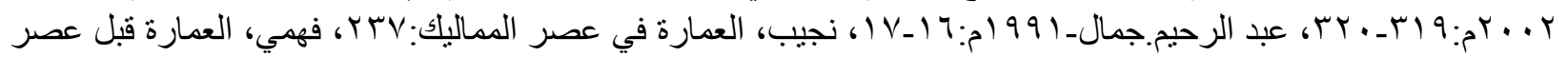

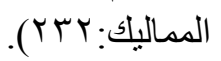

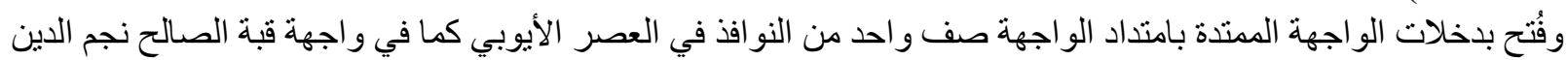

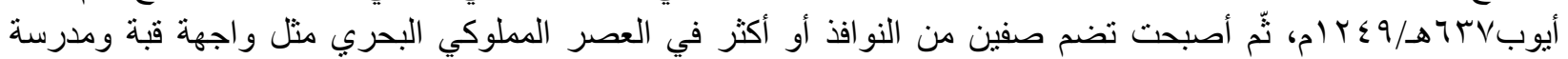

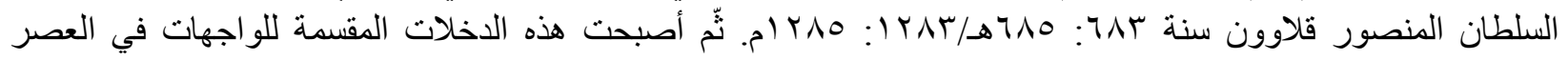

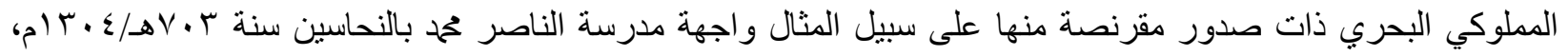

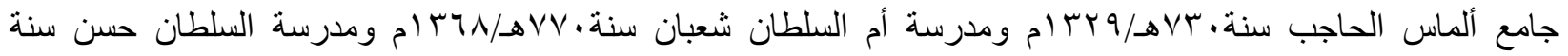

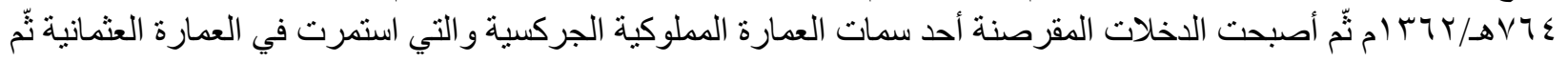

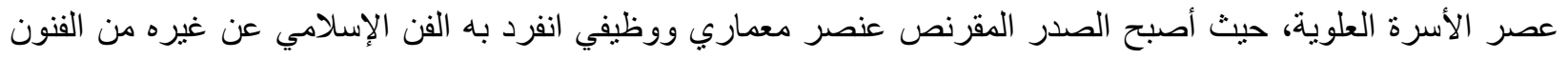

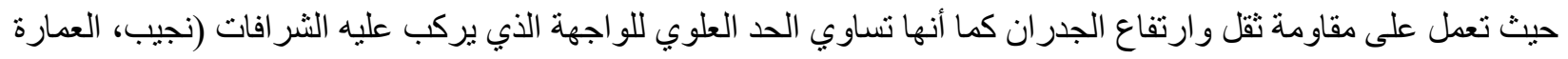

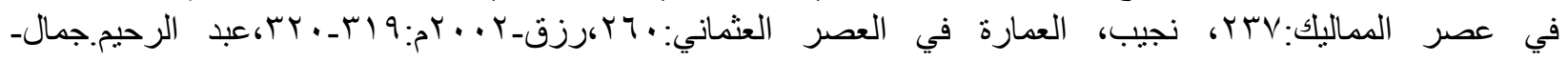

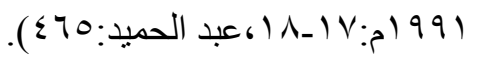

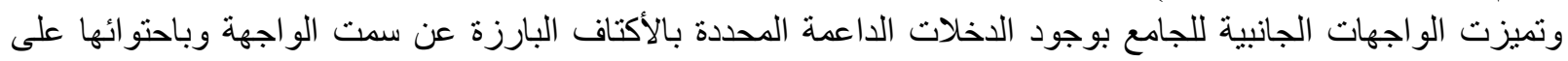

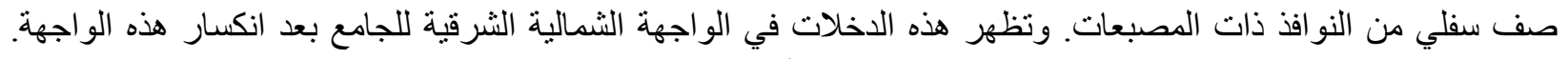

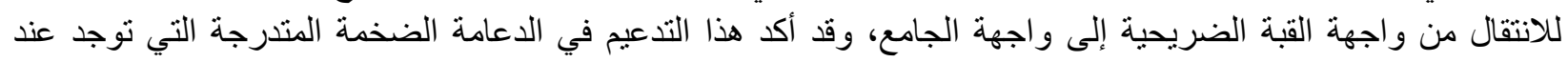

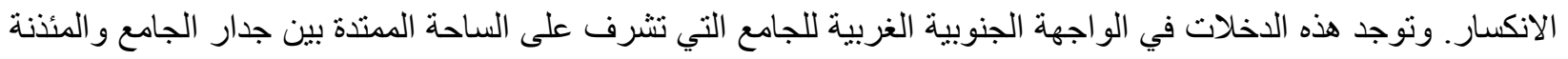
لذا لا نظهر في الواجهة الخارجية للمبني. ومما يؤكد هذا التدعيم ويقويه بالجانبين الثمالي الثرقي والجنية التوبي الغربي للجامع استخدم أنصاف الأعمدة المدمجة من

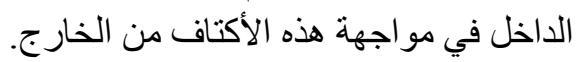

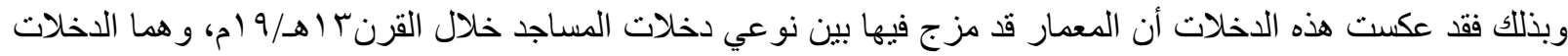

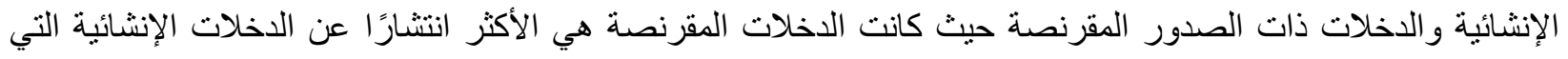

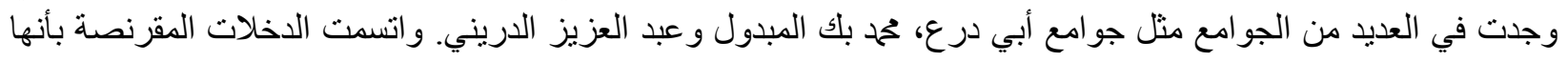

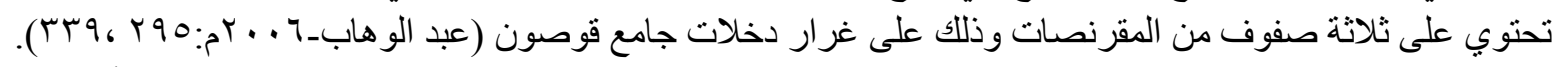

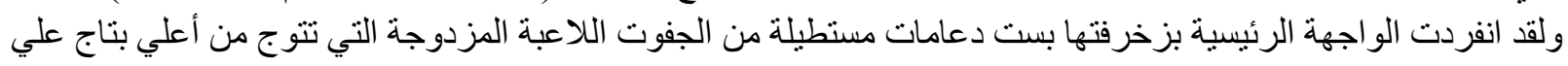

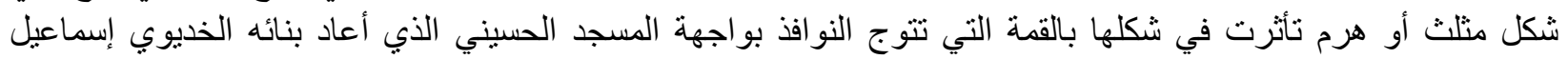

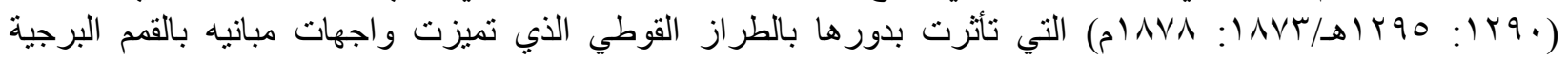

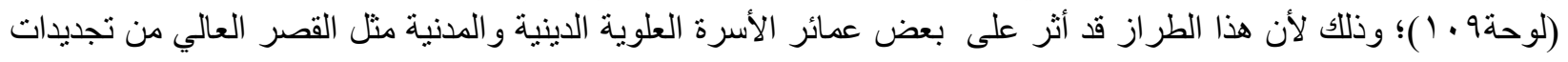

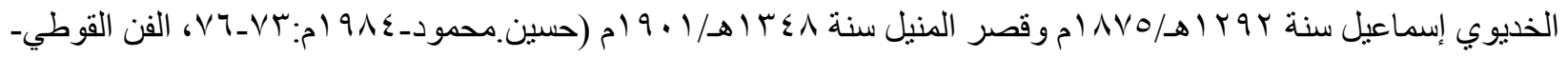

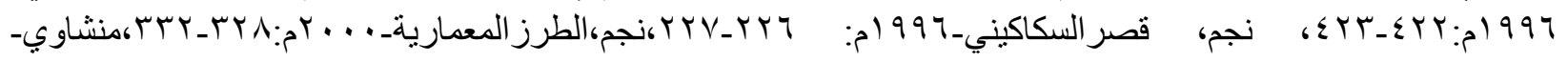




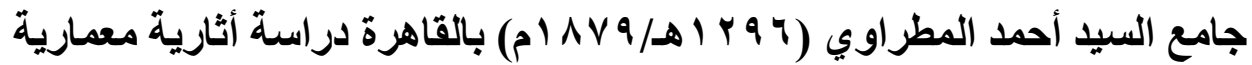

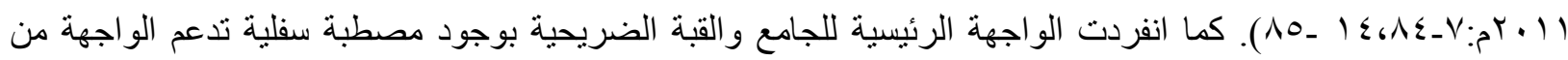

و وتميزت الو اجهة الرئيسية بوجود كورنيش من المقرنصات بأعلاها والذي ظهر في مصر في العصر المملوكي البحري في

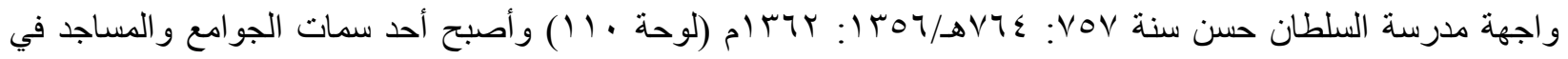

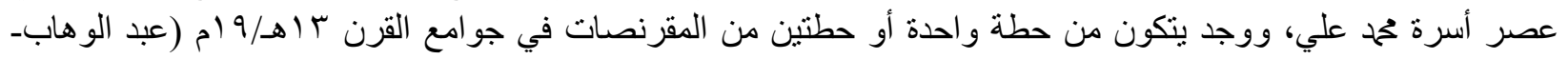

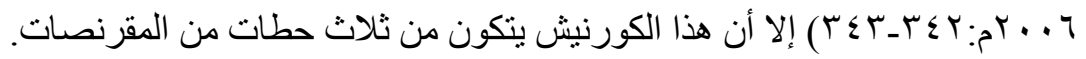

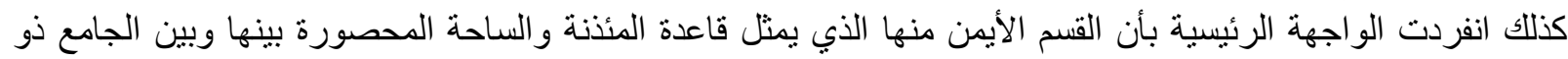

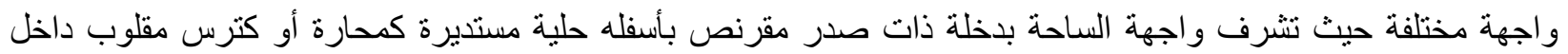

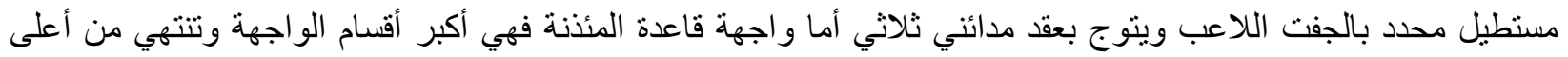

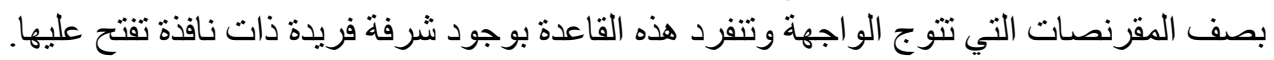

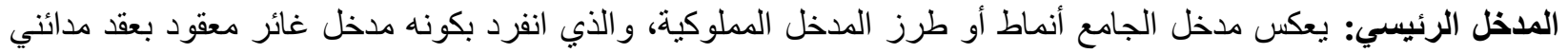

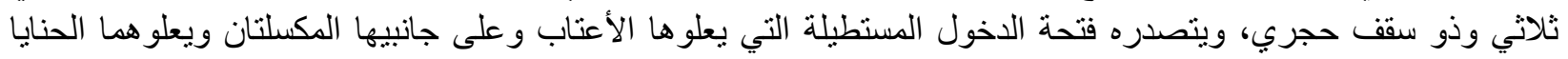

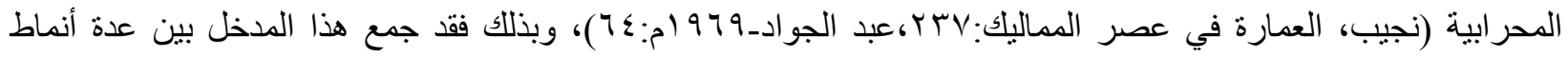

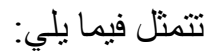

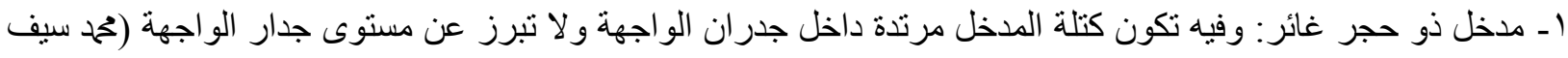

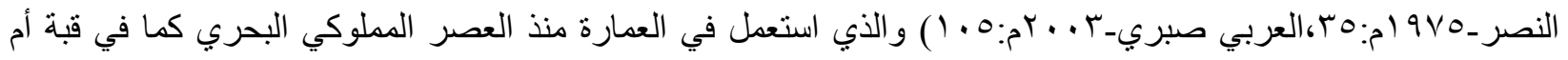

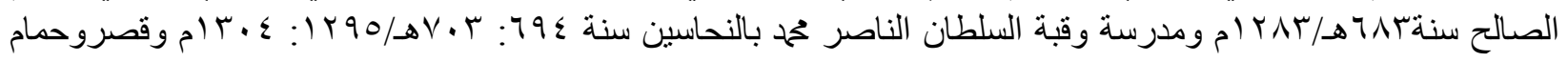

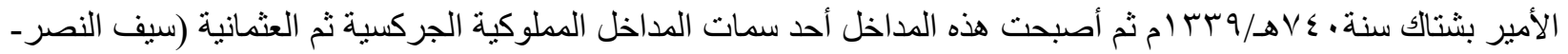

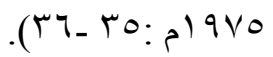
r- مدخل ذو حجر غائر معقود بعقد مدائني ثناثي: وهو الذي يتكون من طاقية مدببة بأعلى العقد وتتوجه وبأسفلها من الجانبين

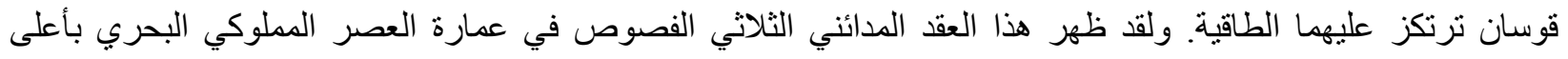

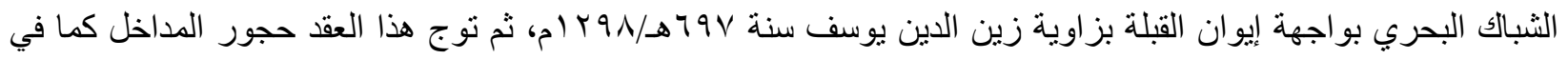

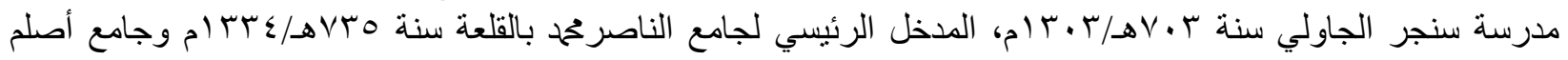

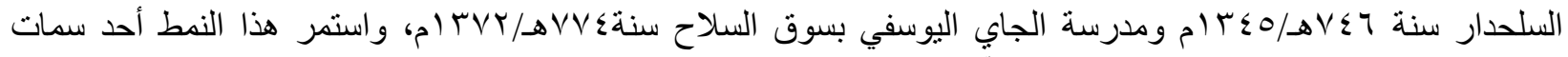

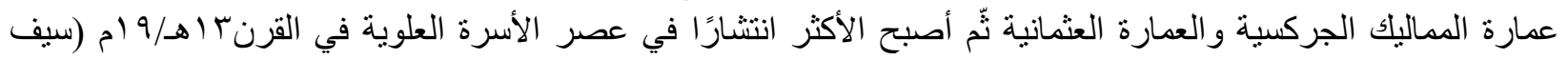

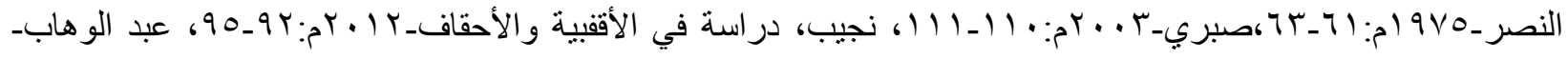

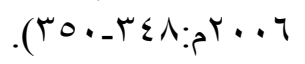

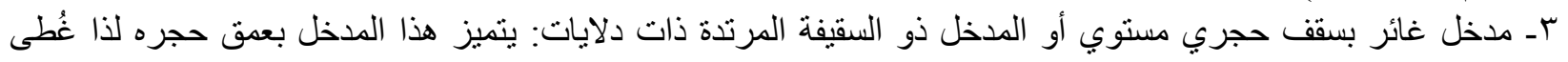

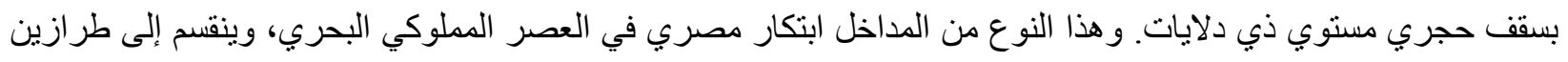
هما:

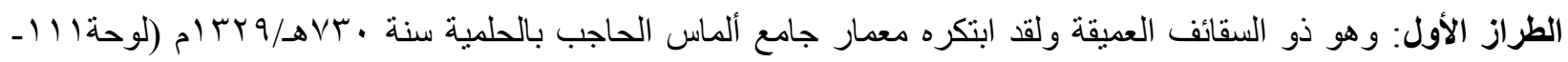

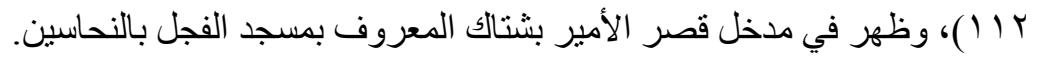

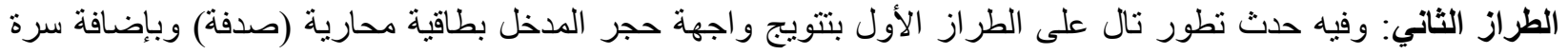

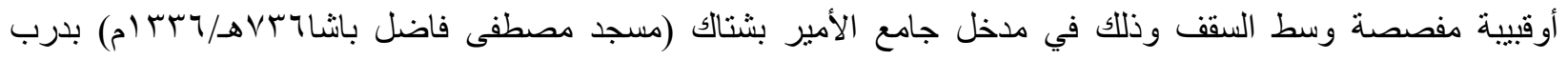

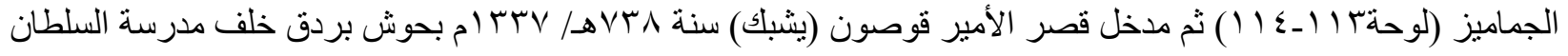

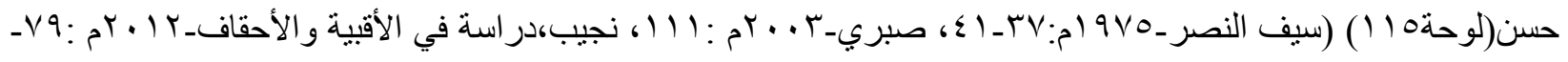

وبذلك يتشابه سقف هذا المدخل مع سقفي كل من جامع ألماس الحاجب وجامع الأمير بشتاك إلا أنه قد تميز بتتويج واجهته

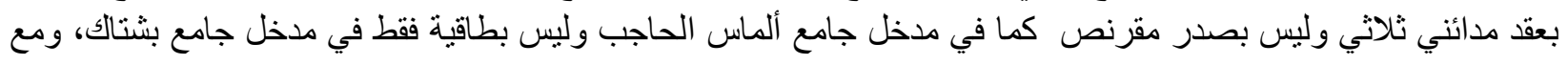
ذلك فهو يتشابه مع مدخل بثناك في الطاقية المحارية. 
ويلاحظ أن الثكل العام للسقف يتشابه مع سقف مدخل بشتالك في شكل الحنايا ذات الدلايات، وترتيب هذه الحنايا من الخارج

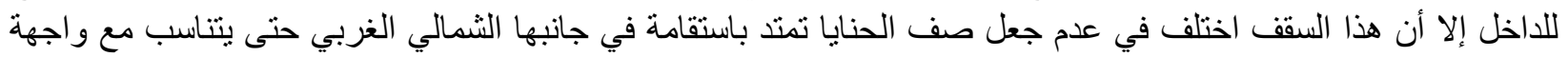
العقد من الخارج، وفي عدم وجود السرة أو السقيفة تتوسط السقف حيث جعلها في القسم الثمالي الغربي من السقف، وجعلها

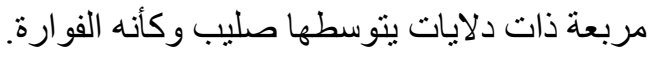

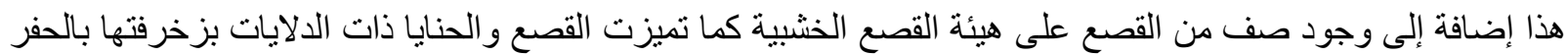

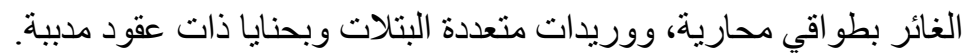
وبذلك فقد انفرد هذا السقف في الجمع بين سمات السقف ذي الدلايات وبعض سمات الأسقف الخثبية ذات القصع والسقف ذي ذي الفسقية. ويتميز جانبا كتلة المدخل بوجود دخلة بصدر مقرنص بها حنية محر ابية بعقد مدائني ثلاثي مقرنص و التي تعكس تشابهرها

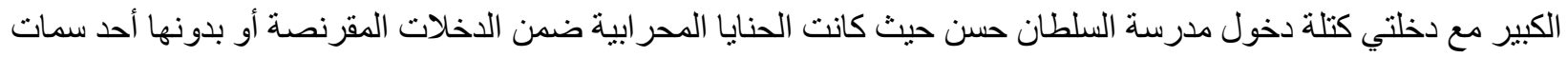

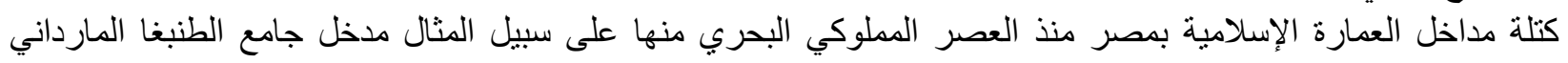

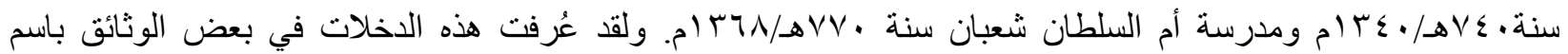

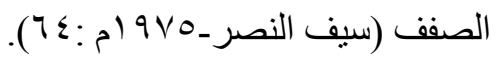

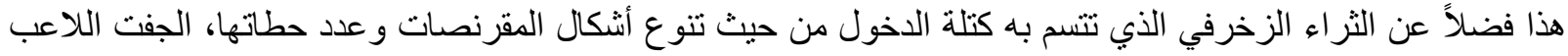
ذي الميمات المتعددة الأشكال، و الزخارف الزي الهندسية من الأطباق النجمية وأنصافها أعلبي المدخل، والأشكال النجمية و المعينات

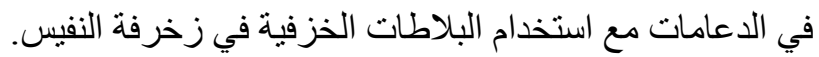

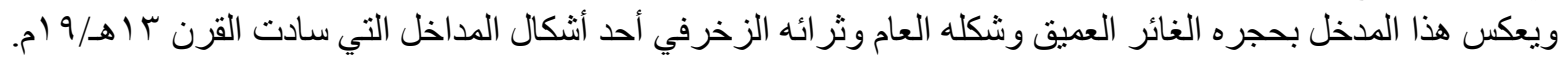

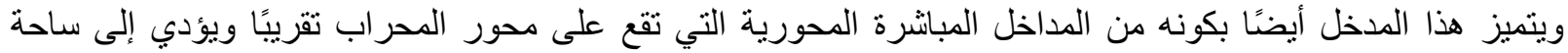

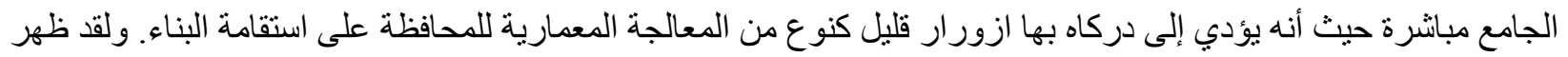

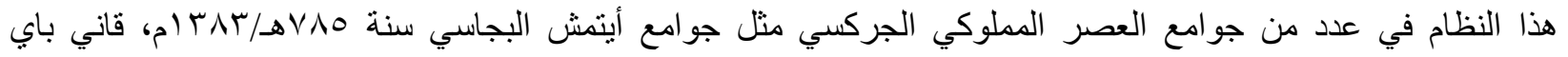

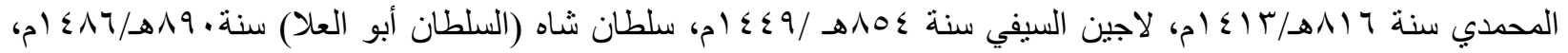

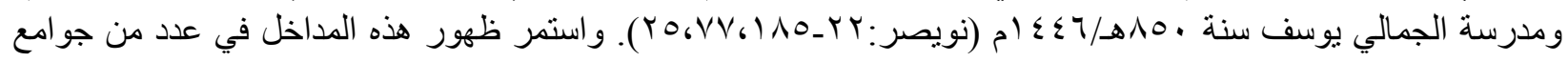

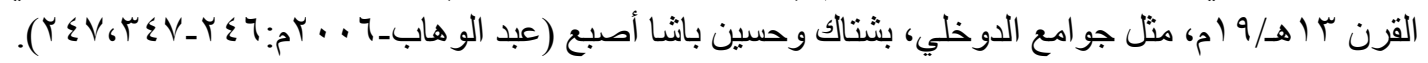

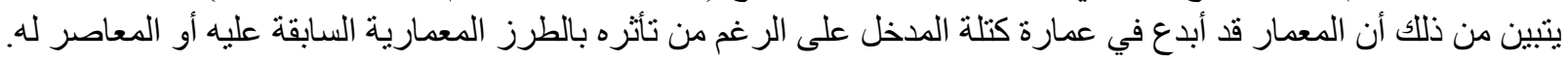

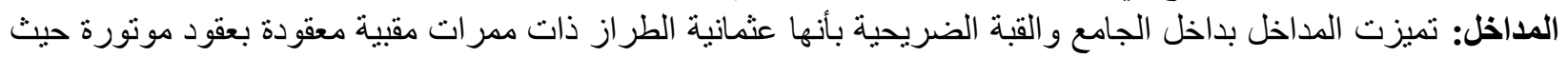

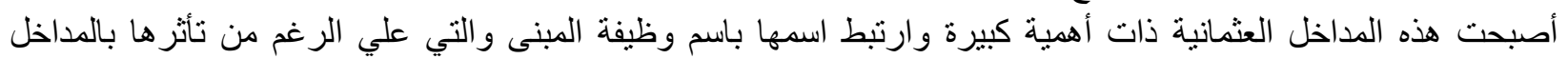

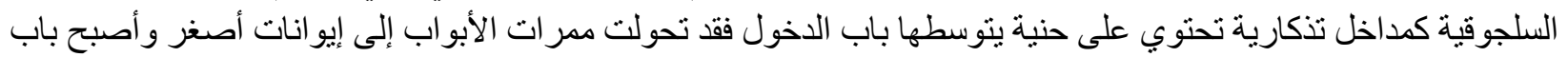

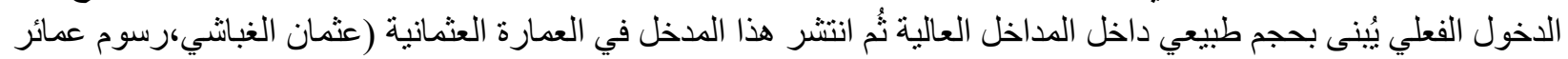

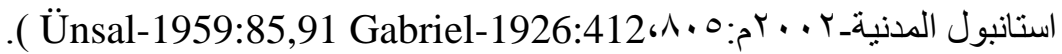

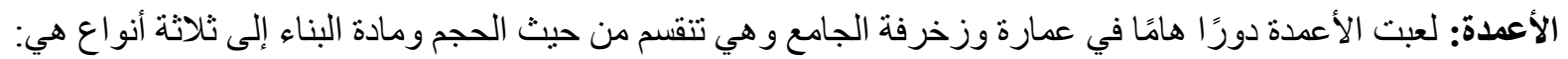

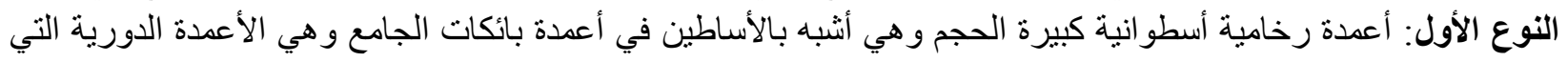

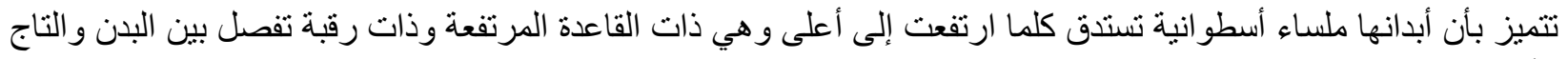

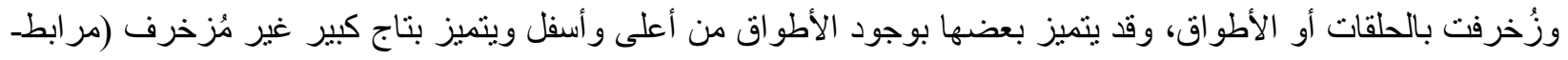

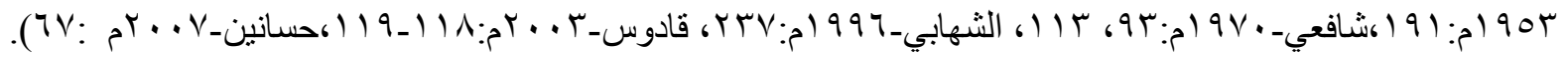

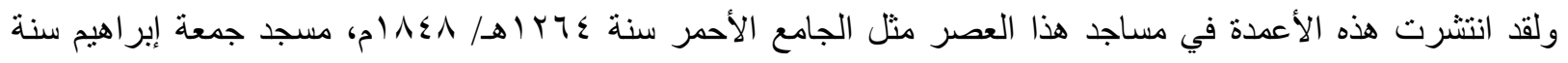

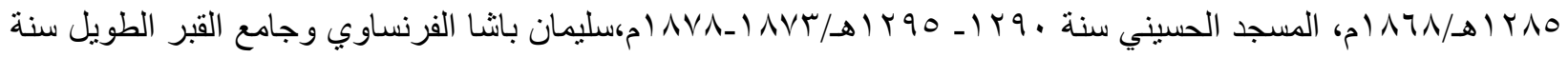

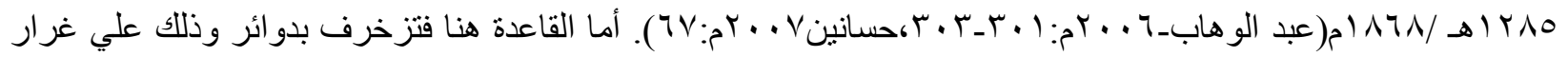

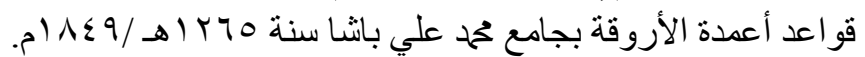

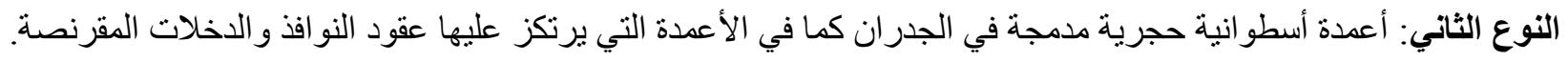

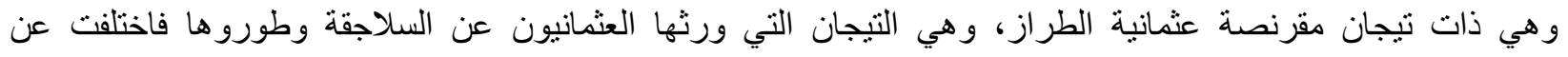




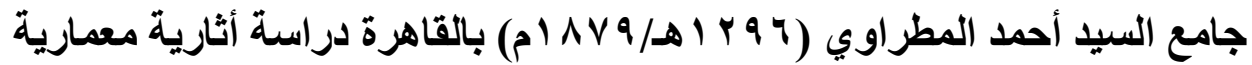

السلجوقية في تنوع نسب وتركيبات المنشوريات التي تكون التاج فأصبح من منشوريات ذات خطوط مستقيمة، وكانت أعمدة

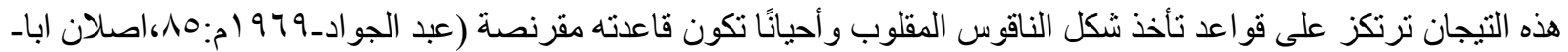

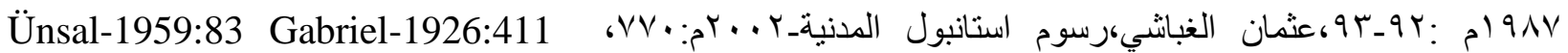
.(Arseven-1951:109 النوع الثالث: الأعمدة النصفية الحجرية الكبيرة المدمجة في الجدارين الجنوبي الغربي والثمالي الثرقي التي ترتكز عليها

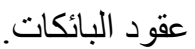

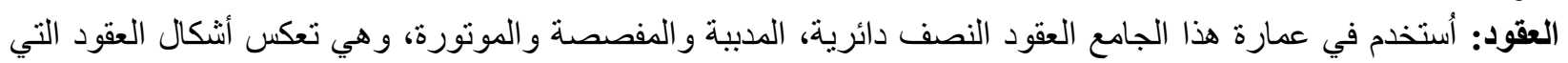

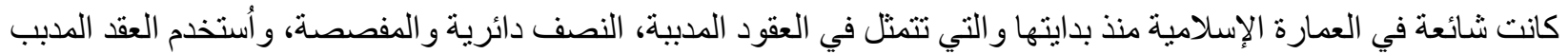

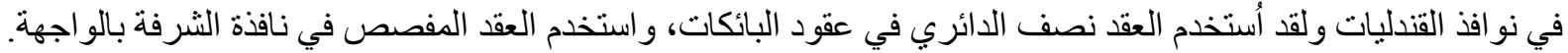

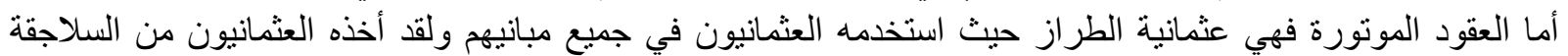

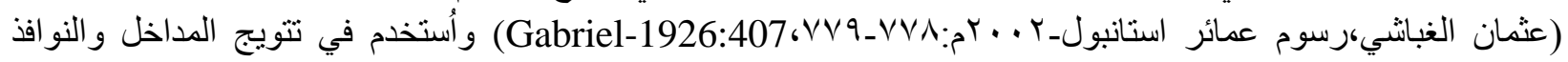

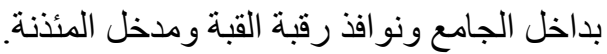
النوافذ: عكست النوافذ بترتيبها و أنواعها كنو افذ ذات مصبة الفيعات سفلية وقندليات علوية في الواجهة الرئيسية للجامع و القبة

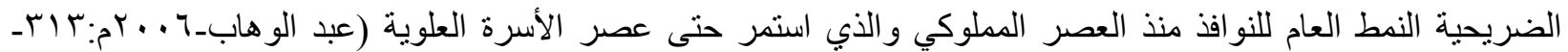

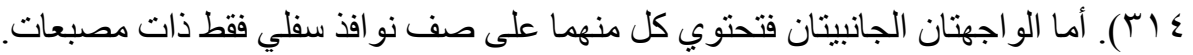

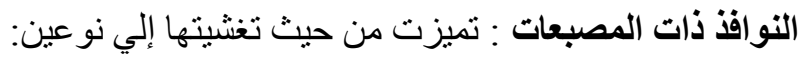

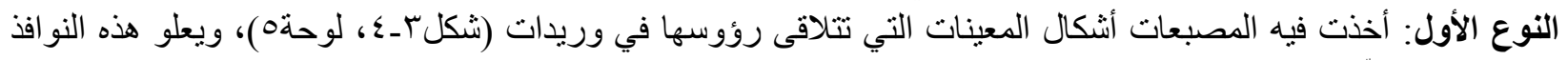

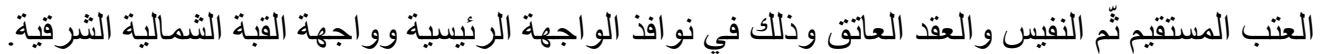

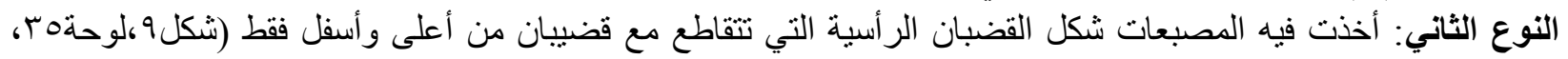

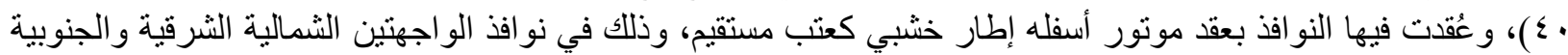

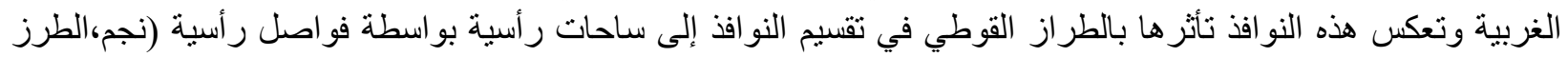

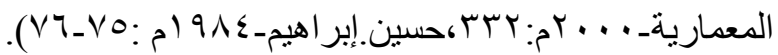

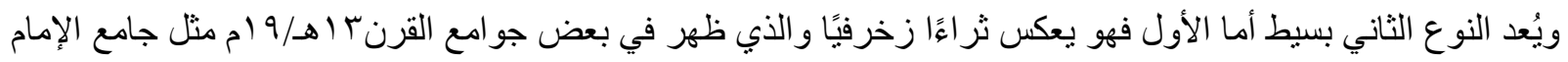

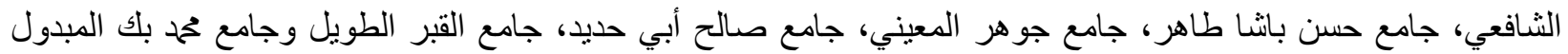

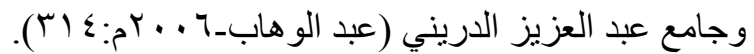
النوافذ القندلية: التي تعد أحد السمات المميزة للعمارة الإسلامية، وتتمثل في هذا الجامع في القندلية البسيطة التي تتكون من

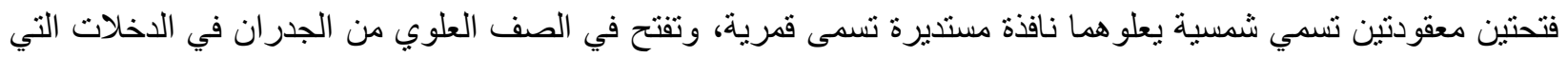

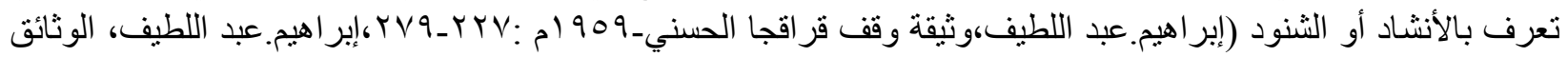

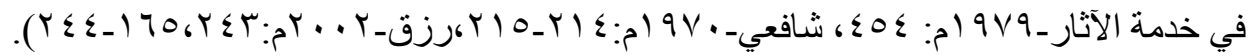

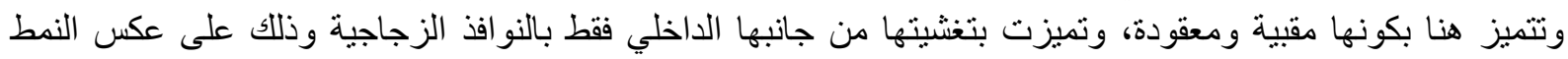

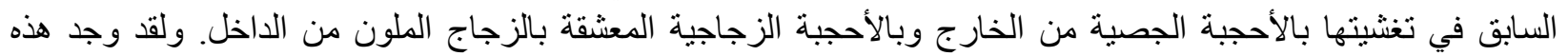

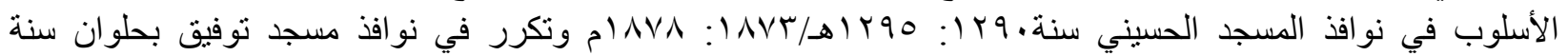

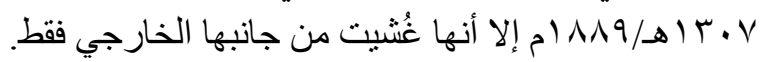

وتنقسم هذه القندليات إلي نوعين، الأول عبارة عن قندليات بسيطة من نافذتنين مستطيلتين بعقود مدببة يعلو ها قمرية وذللك في

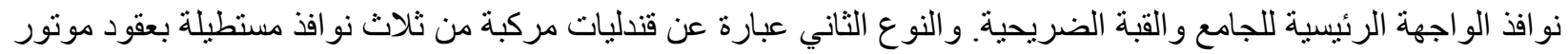

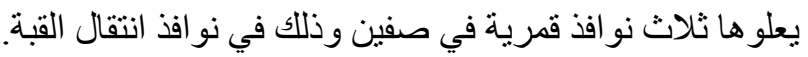

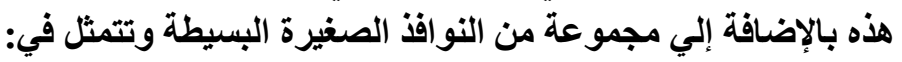

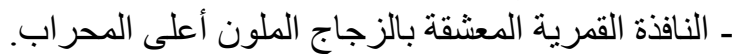

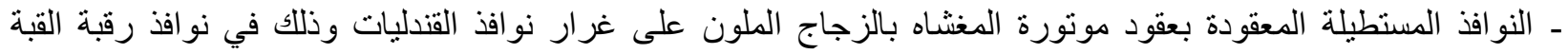


ـ النو افذ المستطيلة المعقودة بعقود موتورة المغشاة بأحجبة حجرية بزخارف هندسية في نو افذ المئذنة.

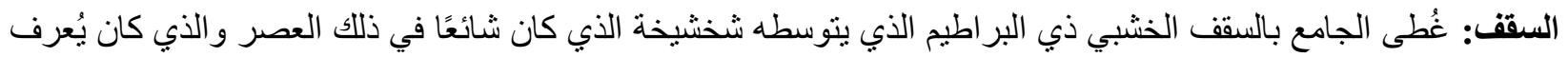

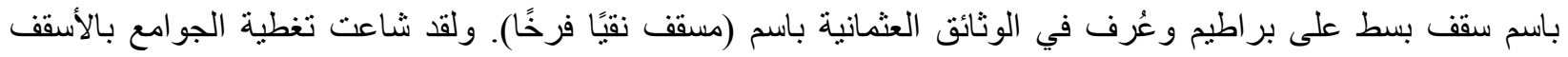
الخشبية التي يتوسطها الثخشيخة منذ العصر المملوكي الجركسي مع تصغير مساحة الجوامع والذي الذي أعقبه تصغير مساحة

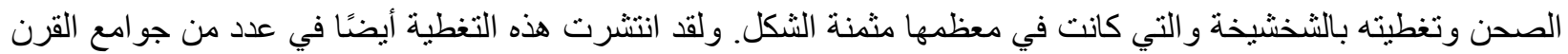

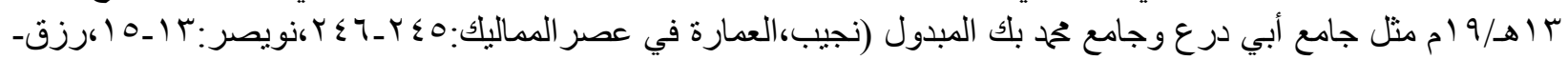

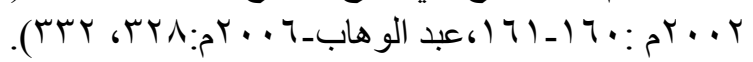

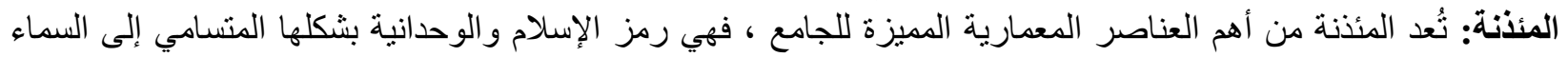

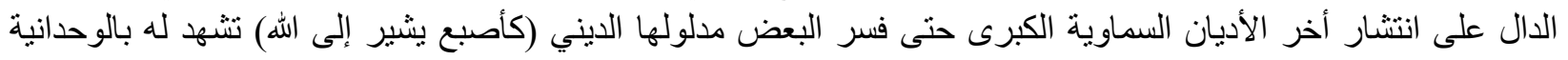

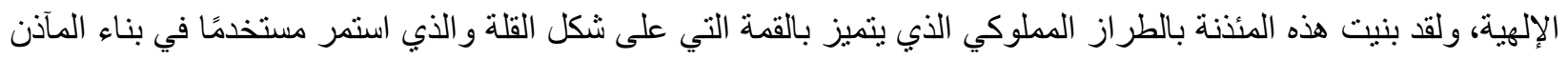

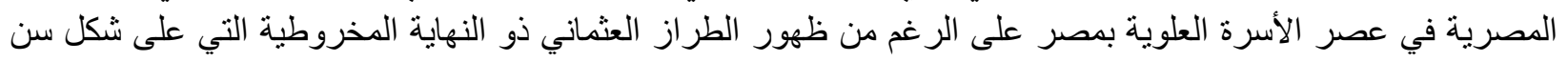

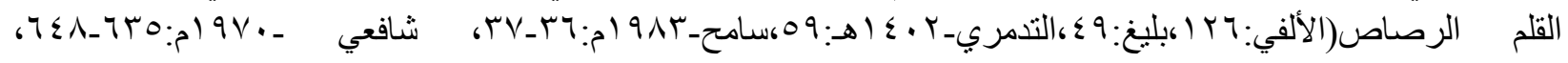

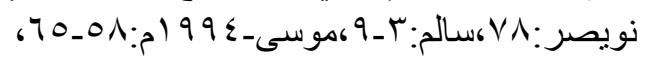

Petersen-1996:36-37,Goodwin-1993:79,Briggs-1974:134,Martin:56,Bloom-1989:175-177, .Hillenbrand:164, Burckhardt-1966:159)

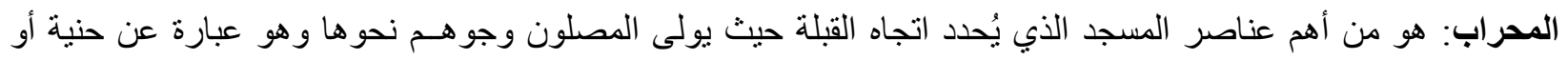

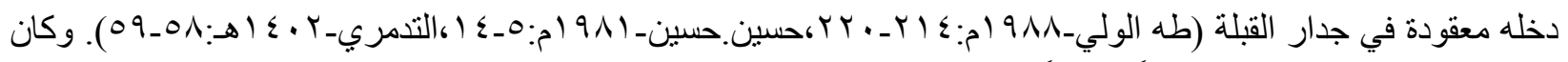

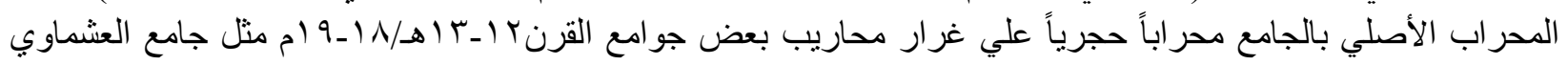

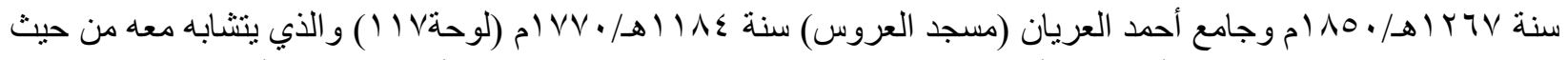

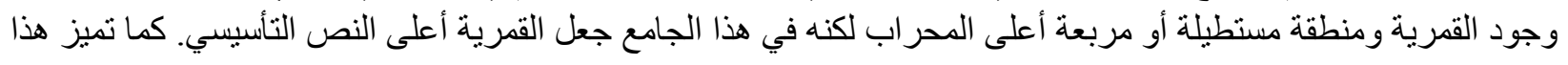
المحر اب بكونه ضمن دخلة محددة بإطارين من مداميك سميكة.

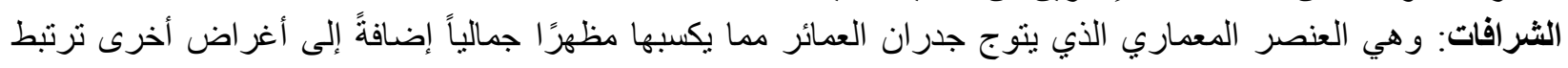

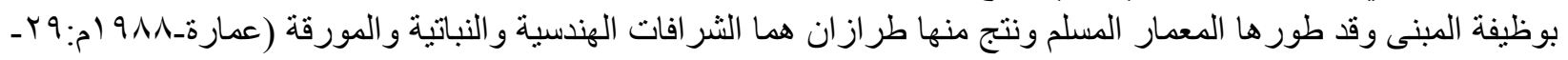

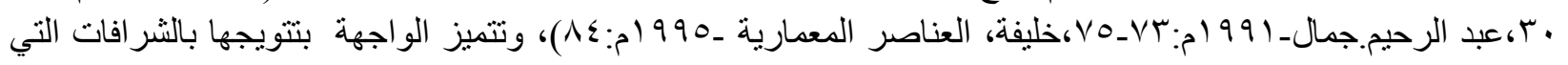

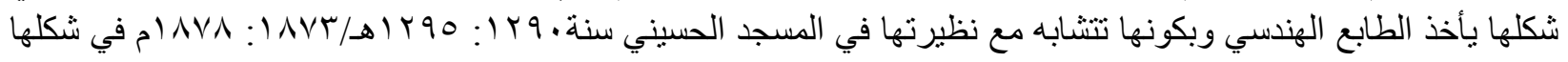

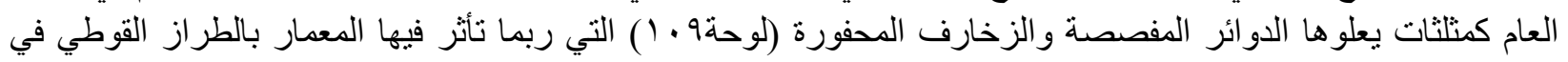

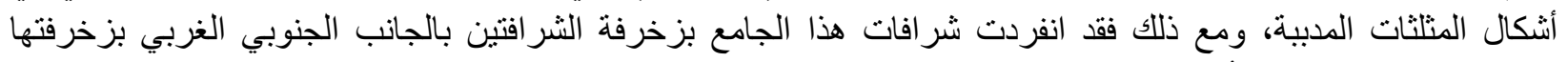
بخطوط منقاطعة كضفيرة تُعطى طابع قشور السمك.

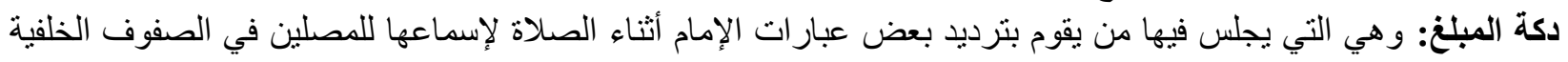

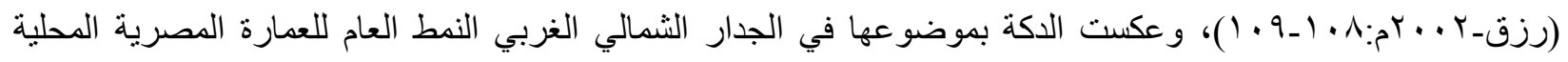

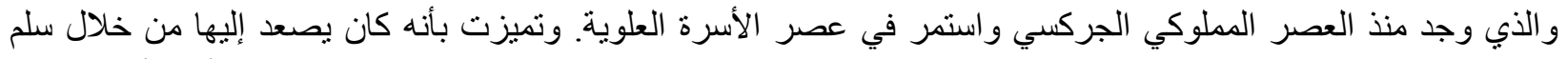

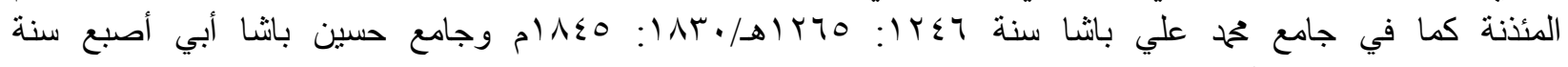

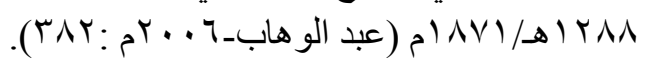

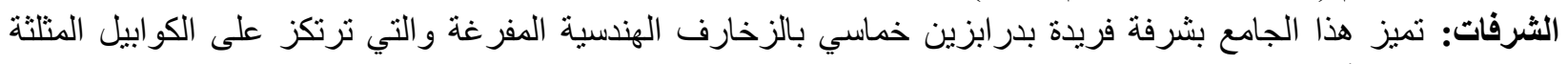

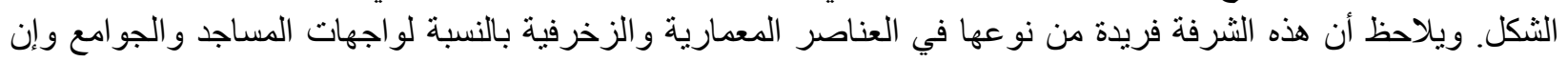

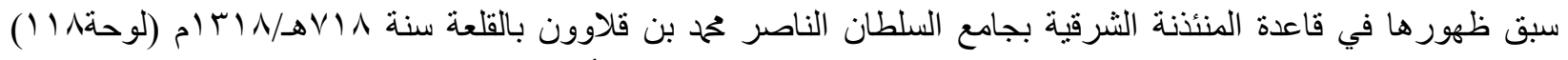

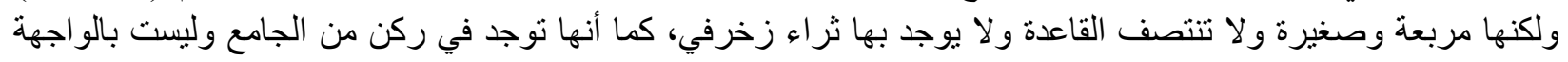

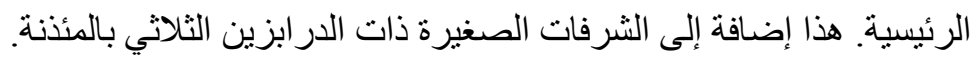




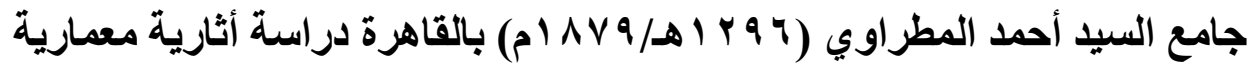

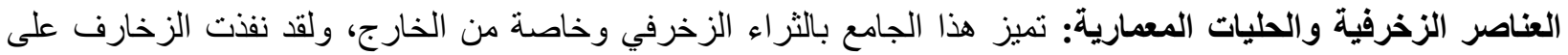
الحجر، الخشب والبلاطات الزخرفية، وتمركز هذا الثراء الزخرفي في العناصر الزخرفية و الحليات المعمارية الزخرفية، وذلك على النحو التالي:

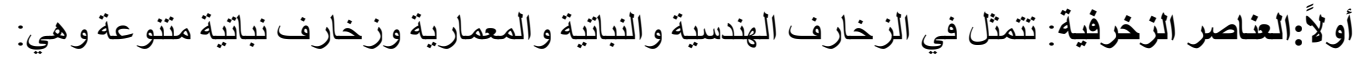

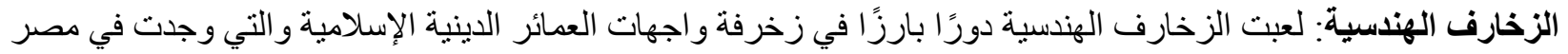

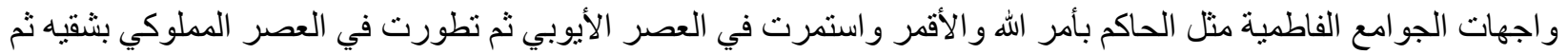
استمرت في العصر العثماني وعصر الأسرة العلوية. تتمثل الزخارف الهندسية في هذا الجامع في الأشكال النجمية، الأطباق

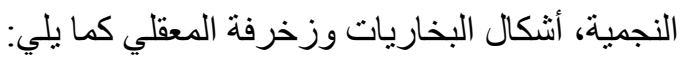

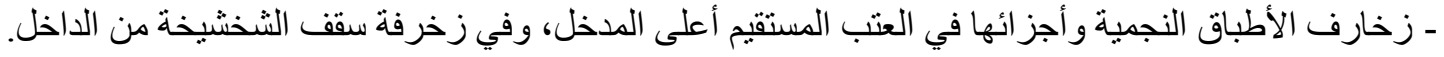

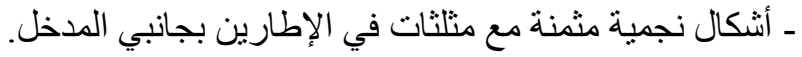

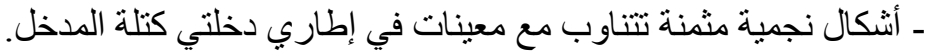

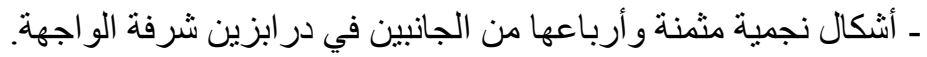

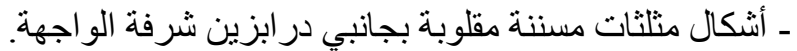

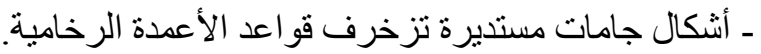

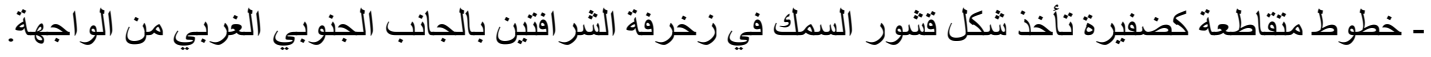

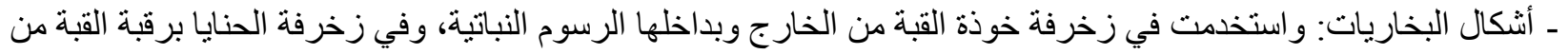

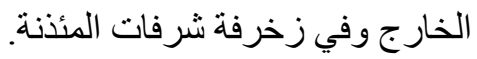
- زخرفة المعلقي الخشبية: هي أحد الزخارف الهندسية التي شاعت في زخرفة التهف التحف الخشبية في مصر في العصر العثماني،

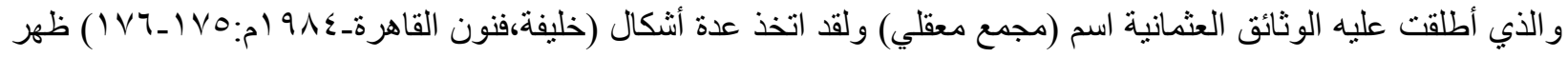

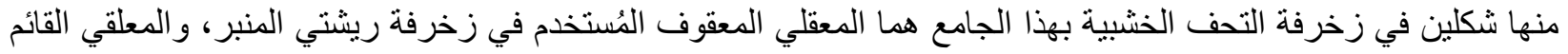

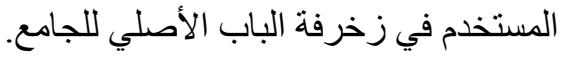

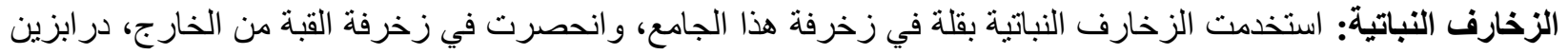

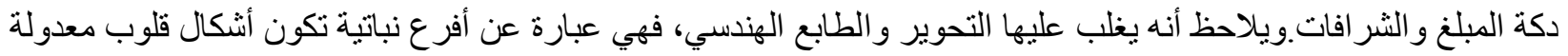

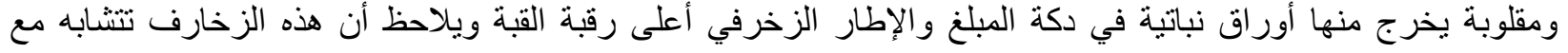

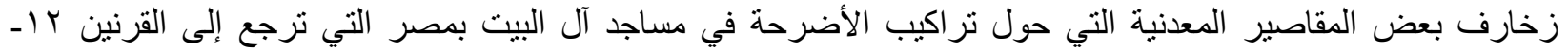

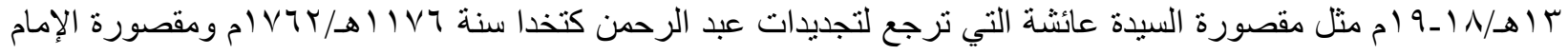

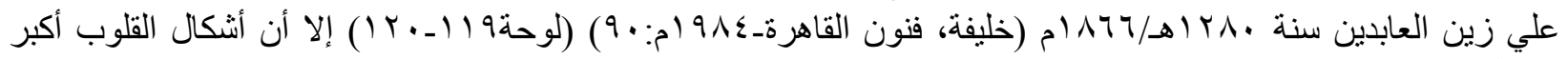
حجماً مع صغر الأوراق النباتية. أما خوذة القبة فُتزخرف بخاريتها بالأور اق النباتية اللوزية و الخماسية الثكل، أو تُزخرف بأنثكال الأوراق النباتية التي تنتهي

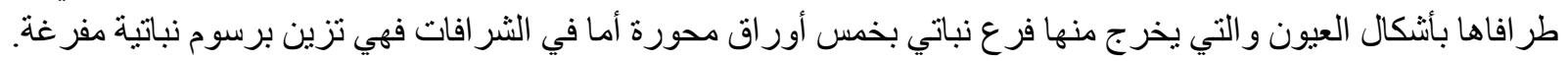

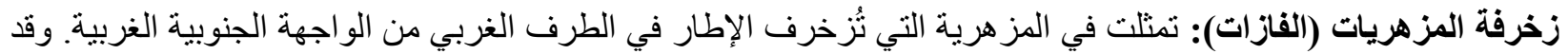

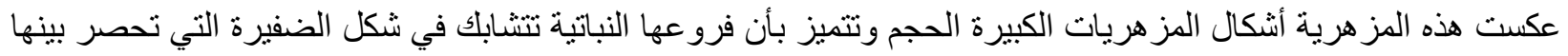

الأشكال الرباعية و المنلثة.

ولقد كانت المزهريات أحد العناصر الزخرفية ذات التأثثر الهلينستي على الفنون الإسلامية والتي شاع استعمالها منذ بداية التهاية

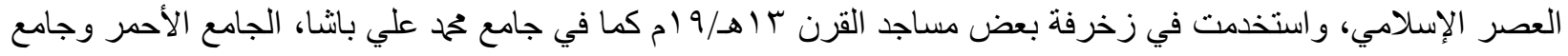

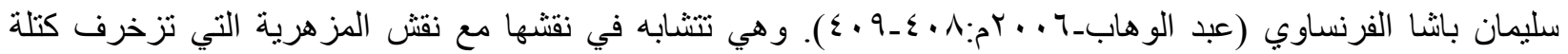

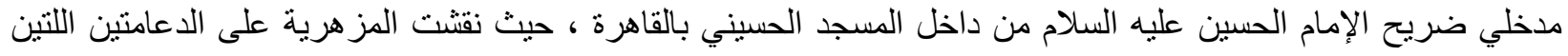

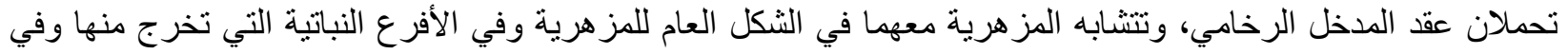

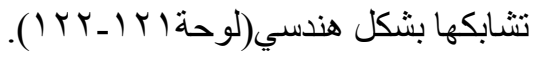
الزخارف المعمارية: وتمثلت في أثنكال الثر افات التي علي هيئة الورقة النباتية الثلاثية في زخرفة شرفة الواجهة. 


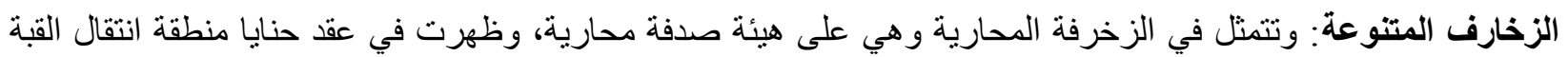

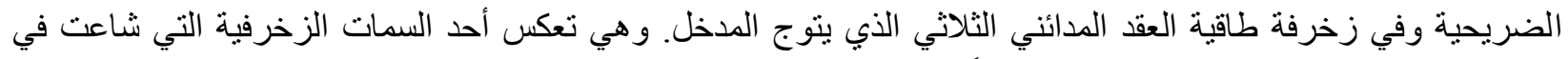

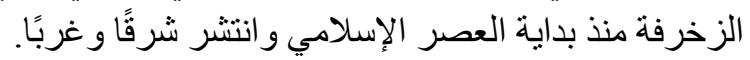

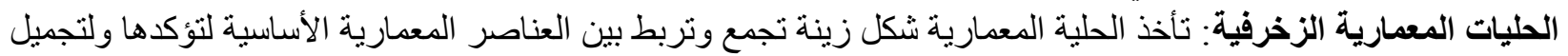

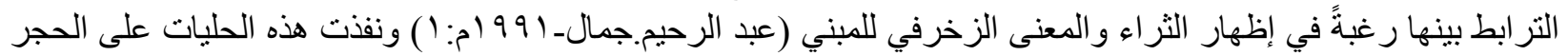

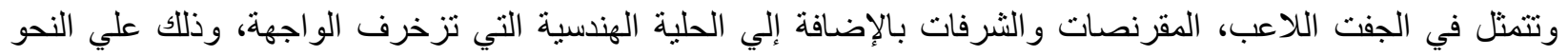

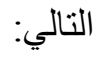

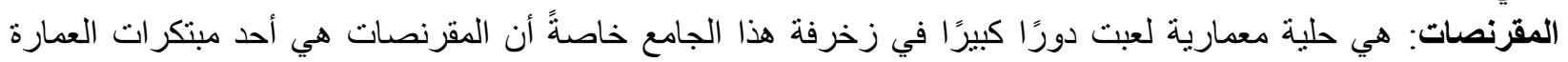

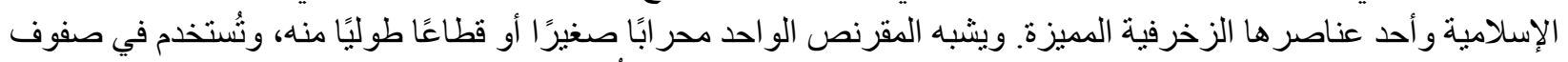

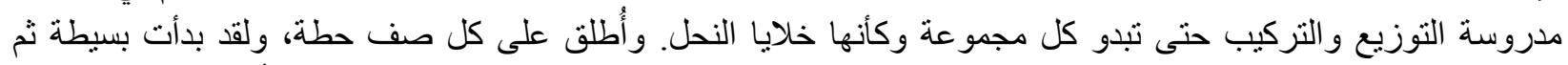

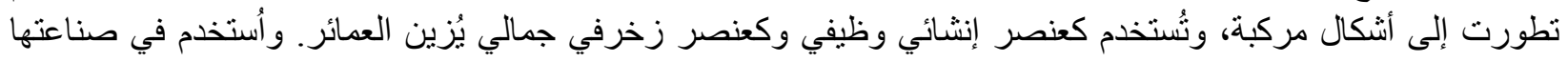

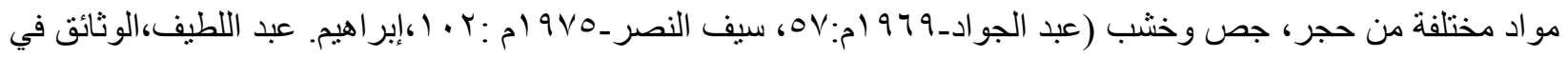

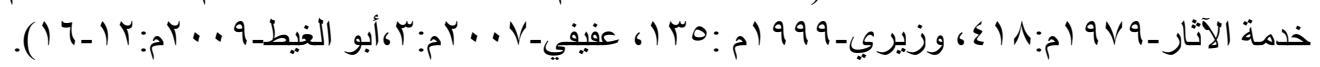

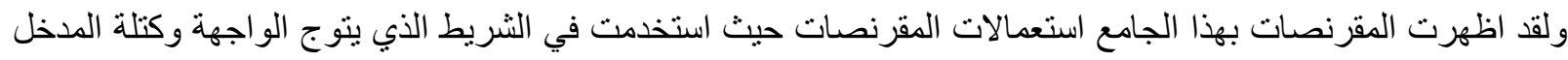

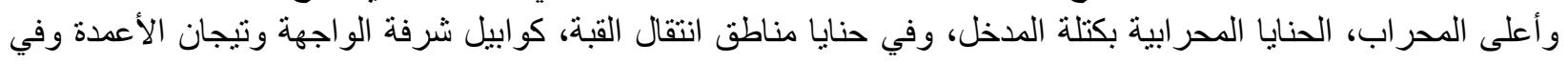

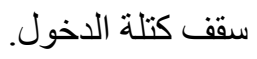

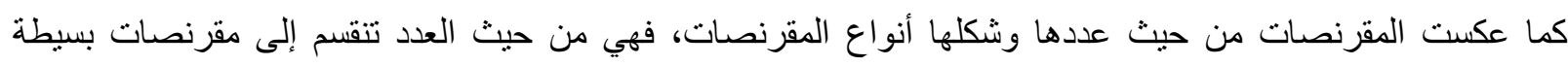

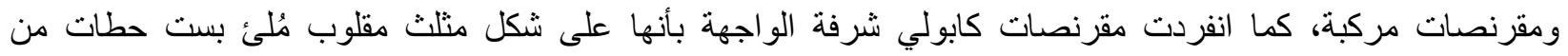

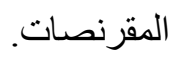

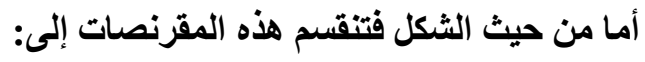

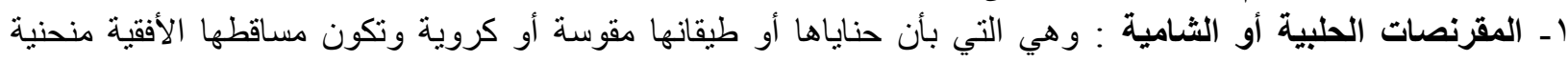

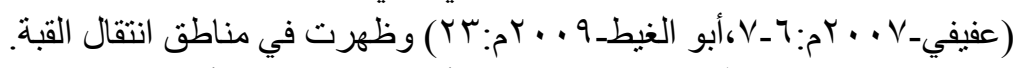

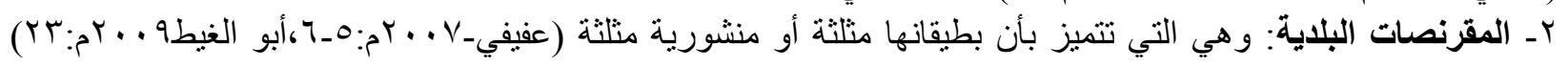
وظهرت في مناطق انتقال القبة.

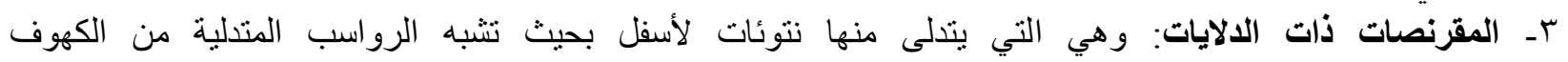

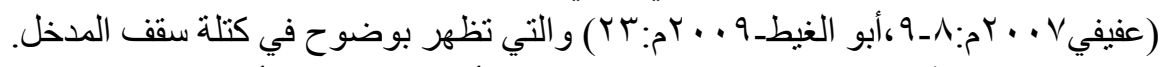

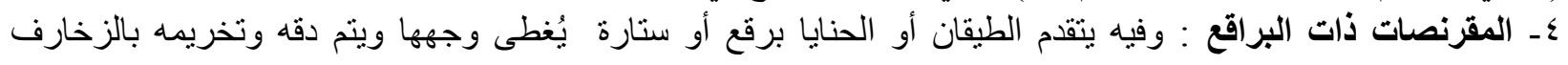

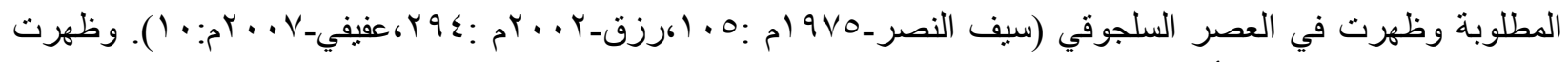
في مقرنصات صدر الدخلة أعلى المحراب.

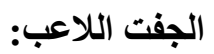

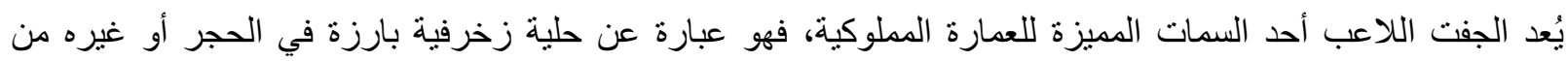

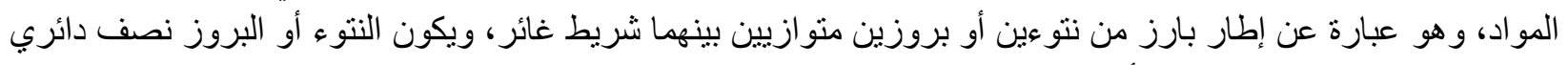

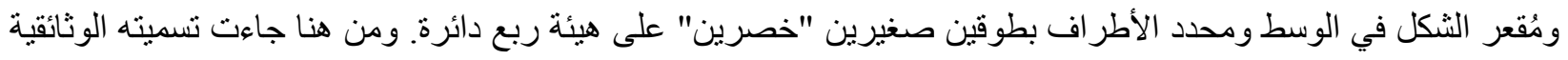

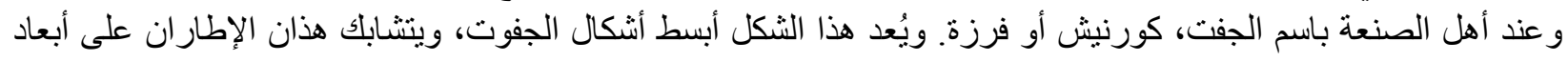

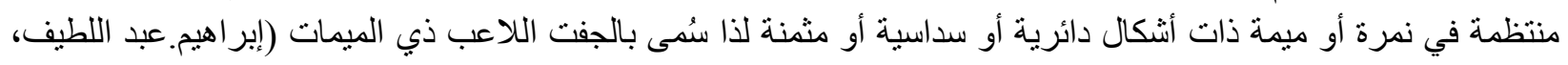

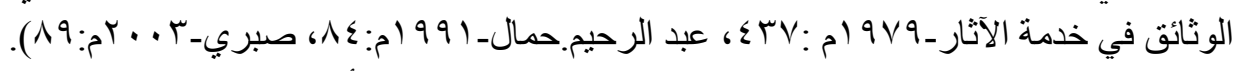

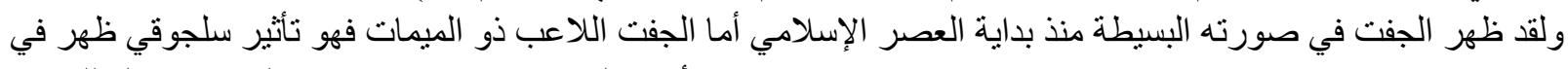

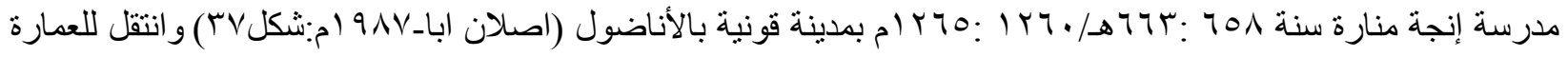

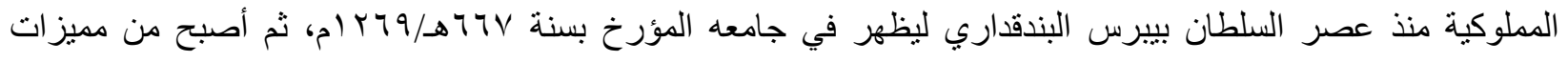

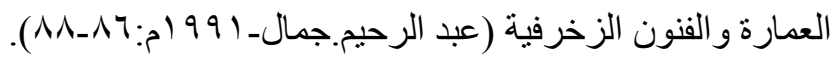




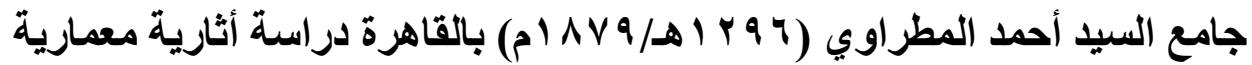

ولقد استخدم الجفت اللاعب في هذا الجامع في تحديد دخلات الواجهة، المدخل، النوافذ، الدعامات، الحنايا المحر ابية بكتلة المدخل و المحر اب الأصلي. وينقسم الجف اللاعب في هذا الجامع إلى ثناثة أشكال هي: ا - جفت لاعب ذي ميمة مستديرة: ويمكن تقسيمها إلى نو عين هما:

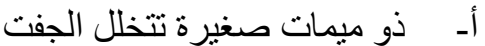

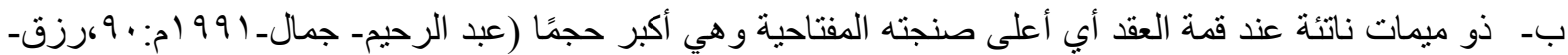
(TV.

r - جفت لاعب ذي ميمة على شكل الضفيرة: وهي أعلى عقود النو افذ القندلية وعقود حنيتا المحر اب بكتلة المدخل.

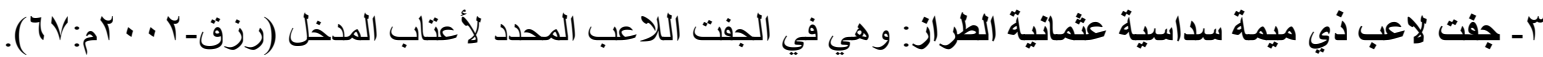

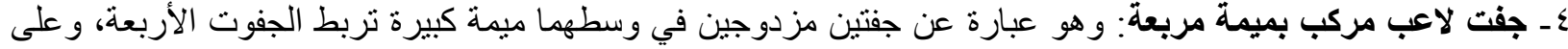

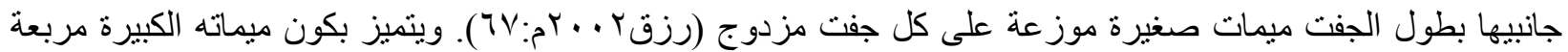

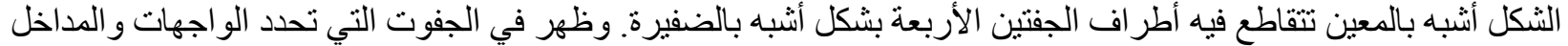

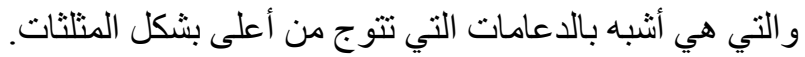
مواد البناء: استخدم في بناء هذا الجامع عددًا من مو اد البناء تتمثل في الأحجار ، الأخشاب المعادن، الزجاج و البلاطات الخزفية

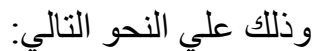
الأحجار: لقد استخدم الحجر الجيري المُسمى بالدبش في بناء هذا الجامع حيث كانت الأحجار هي مادة البناء الأساسية في

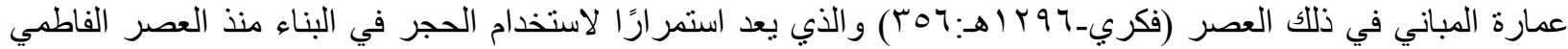

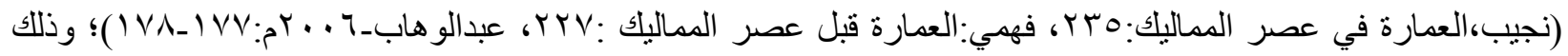

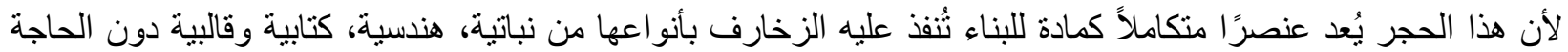

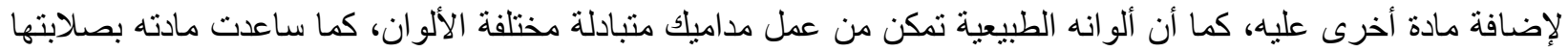

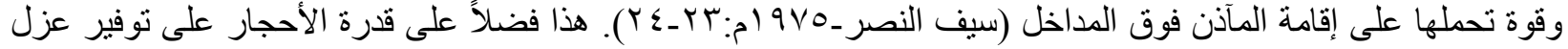

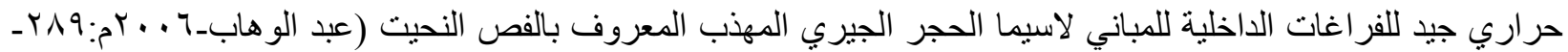

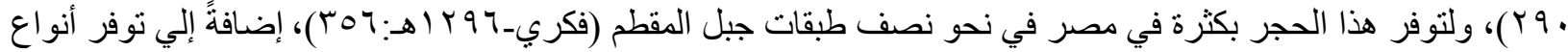

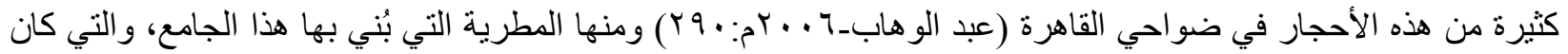

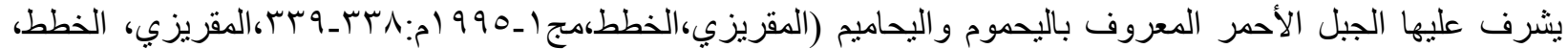

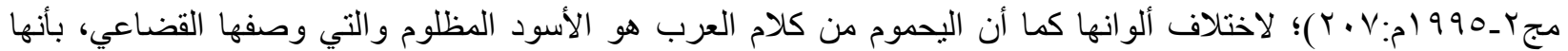

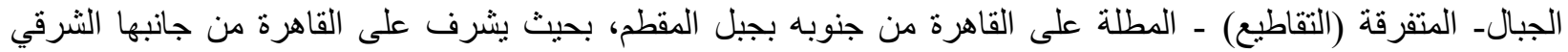

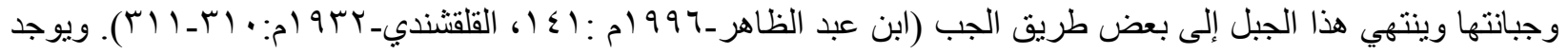

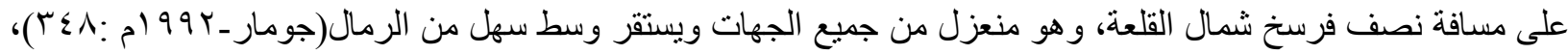

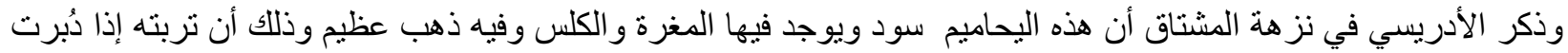

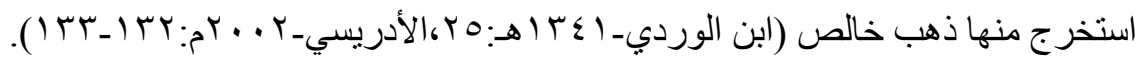

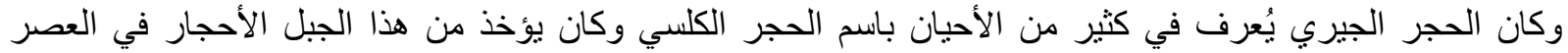

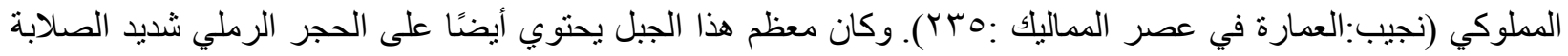

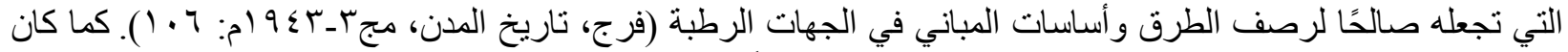

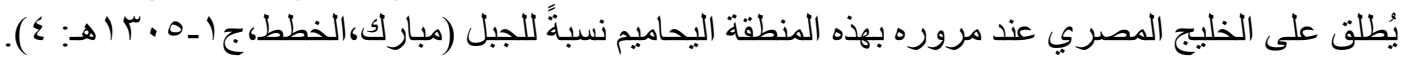

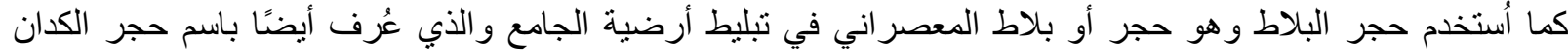

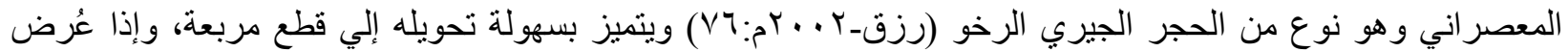

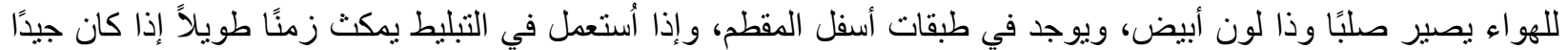

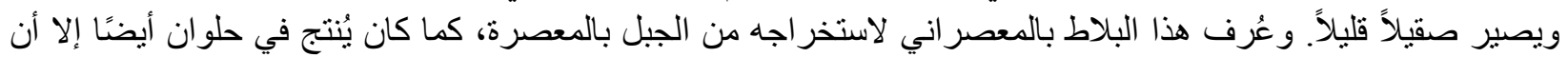

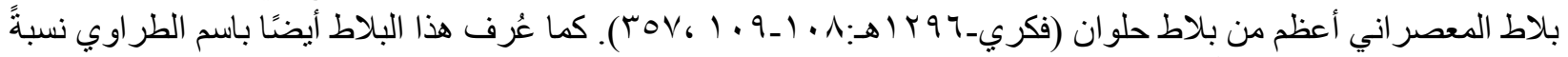

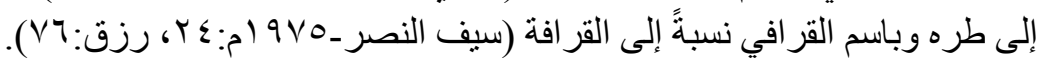




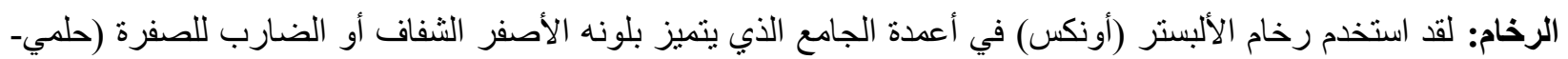

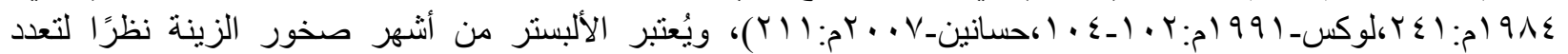

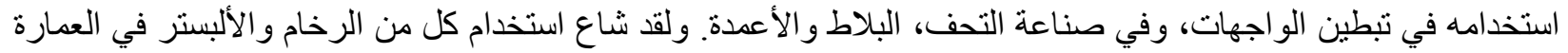

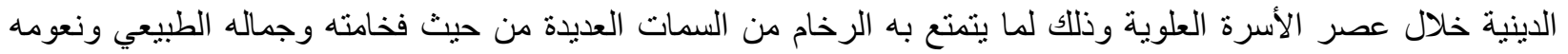

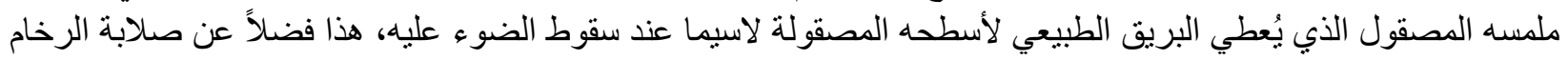

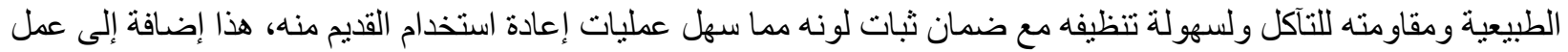

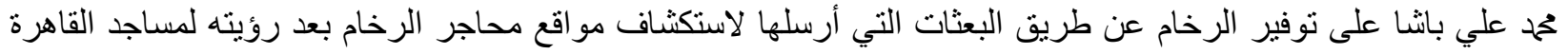

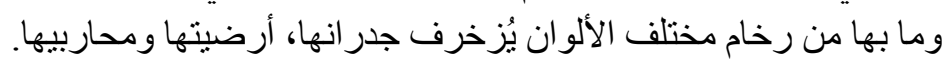

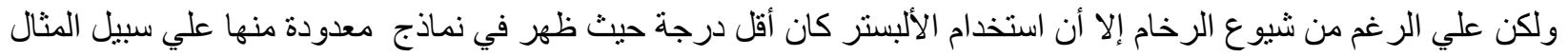

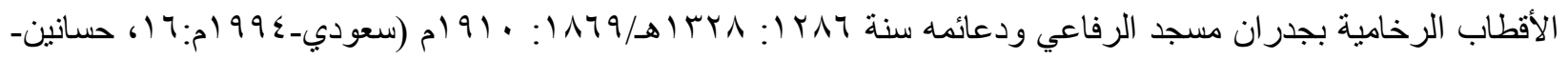

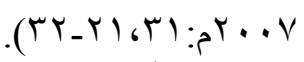

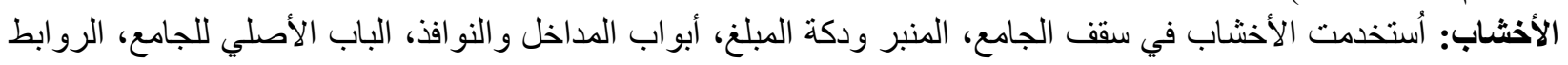

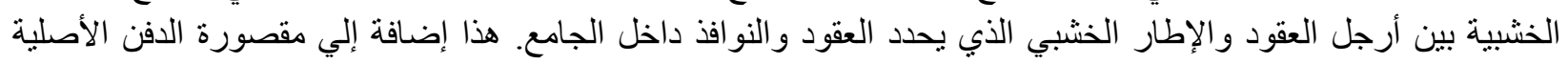

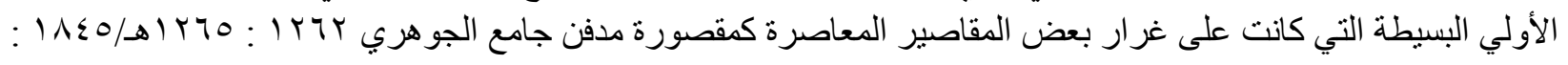

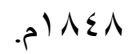

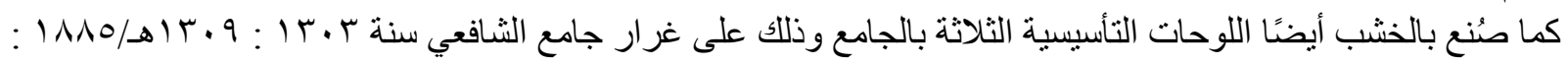

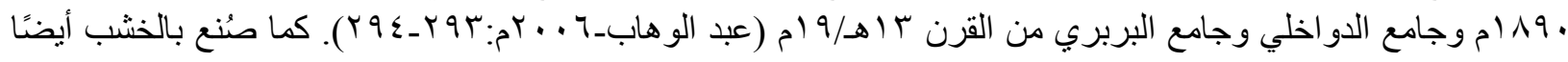

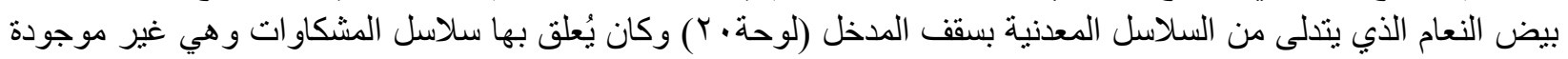
حاليَّا. الزجاج: لقا أستخدم الزجاج في أحجبة نو افذ الجامع من القندليات، القمريات نو افذ الثخشيخة ورقبة القبة وذلك على غرار كثير

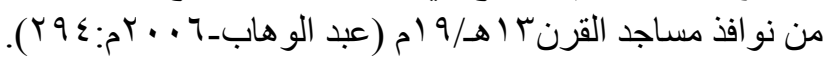

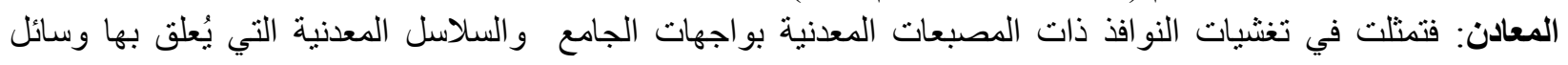

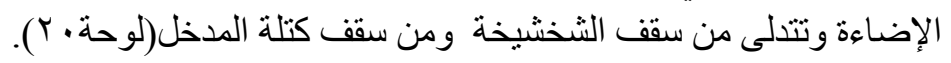

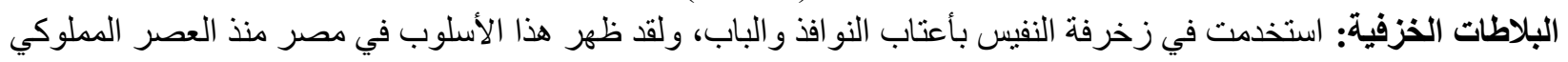

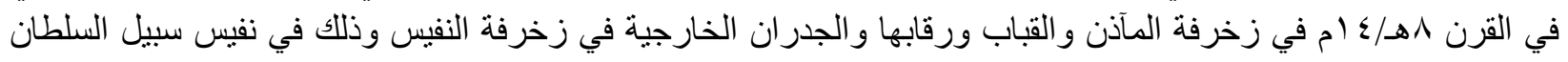

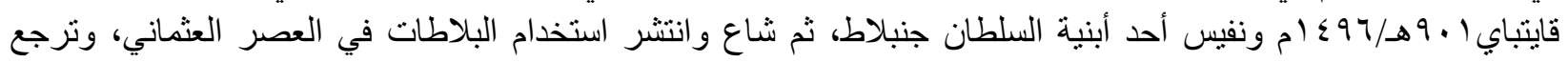

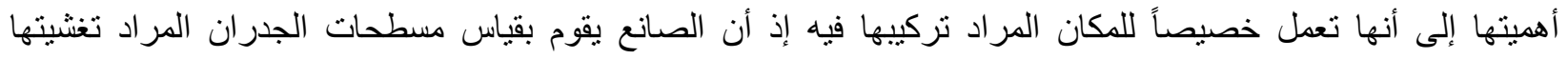

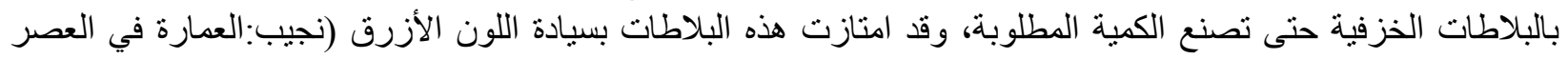

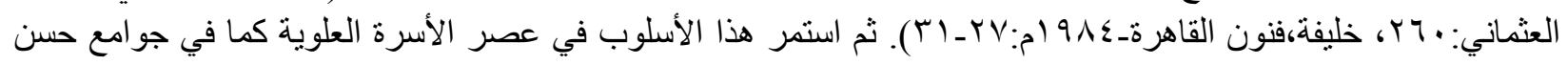

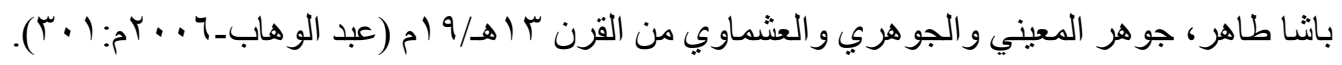

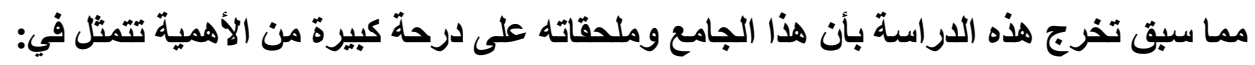

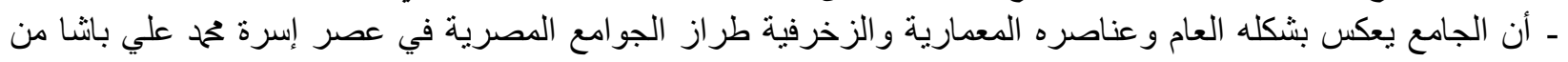

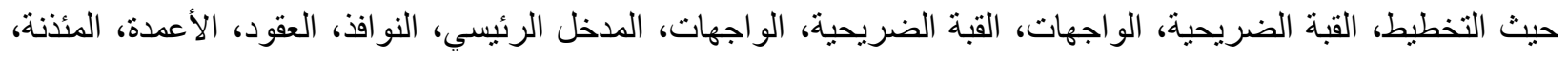

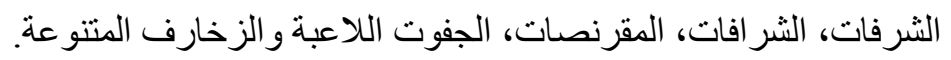

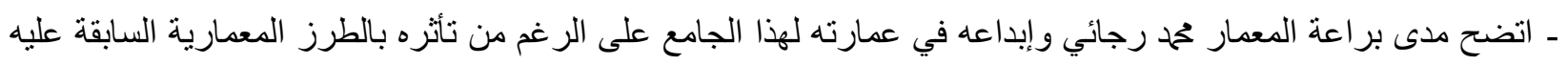

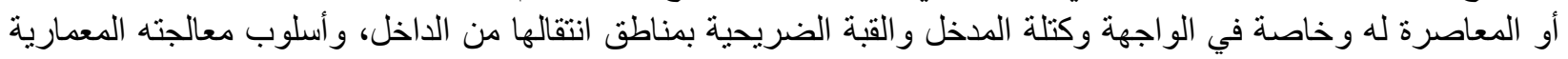
للموقع.

- يعكس الجامع أيضًا الثر اء الزخرفي خصوصيًا في الو اجهة الرئيسية و المدخل.

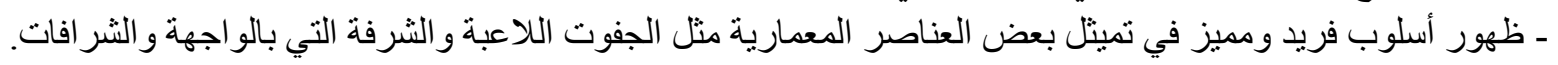

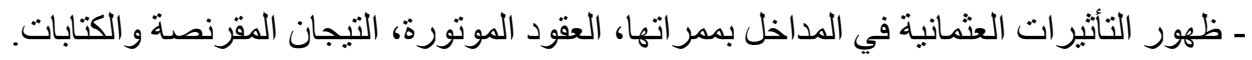




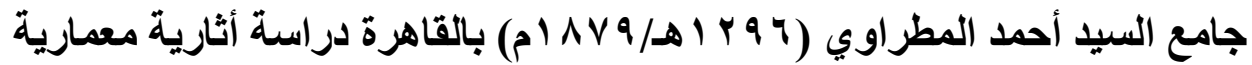

ـ ظهور تأثير ات من القرن با اهـ/9 (م في بعض الزخارف مثل الزهريات وظهور تأثير الطراز القوطي في الأشكال البرجية

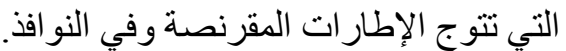

- يساعد على إظهار التطور المعماري و الزخرفي المتو اصل للعمارة في مصر منذ بدايتهاوحتى عصر إسرة محمد علي باثنا. ـ توصي هذه الدر اسة بتسجيل هذا الجامع ضمن قائمة الآثار المار الإسلامية.

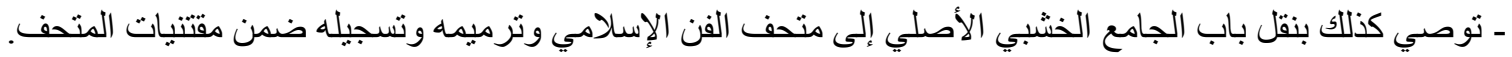

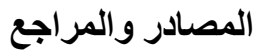

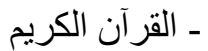

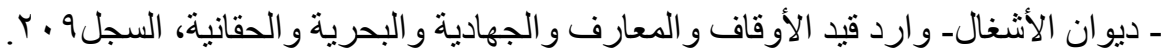

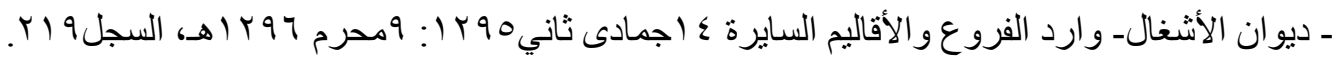

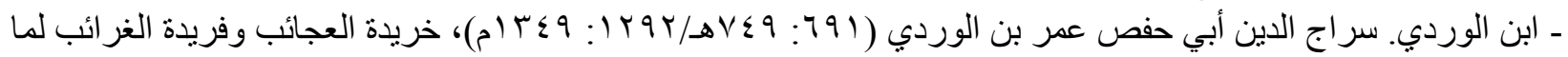

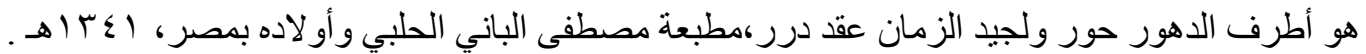

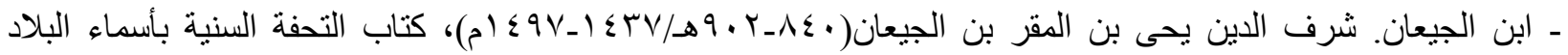

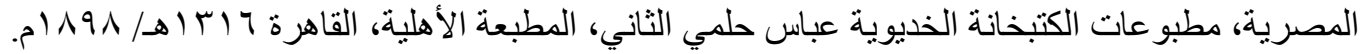

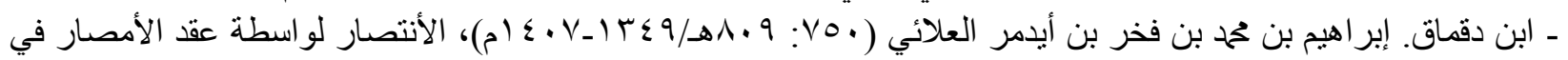

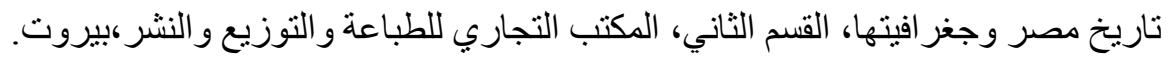

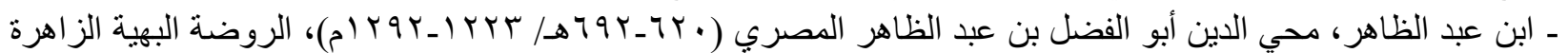

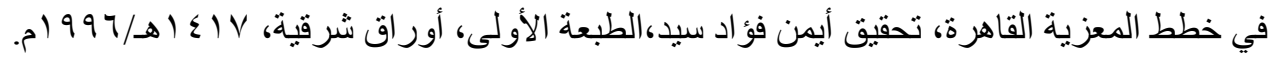

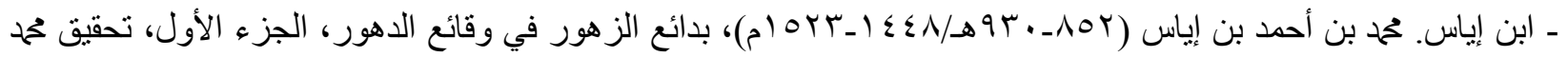

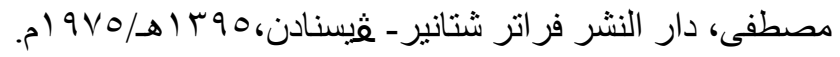

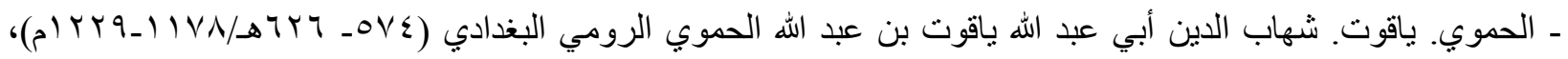

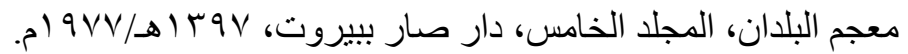

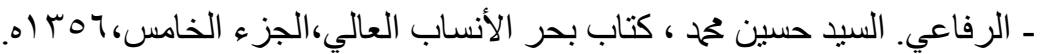

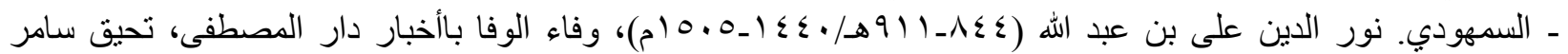

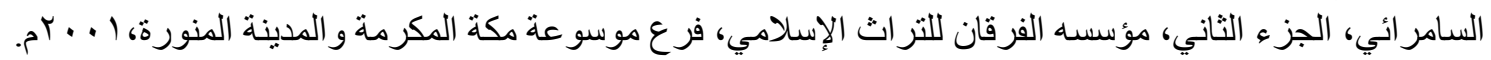

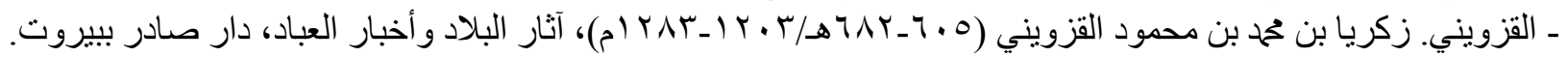

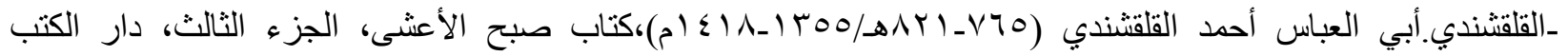

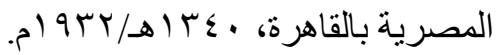

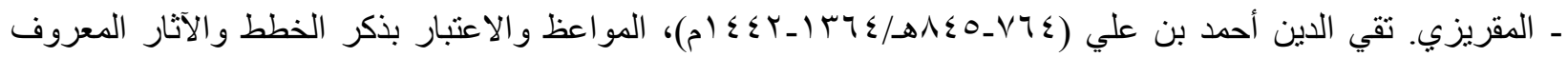

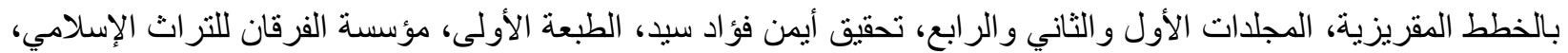

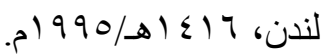

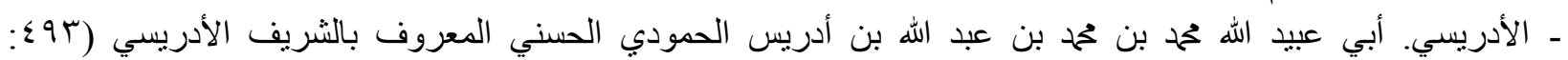

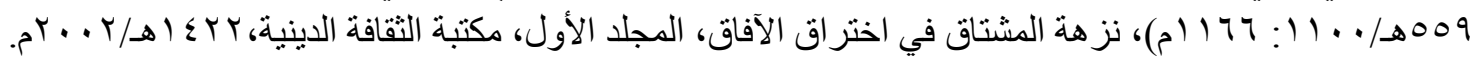

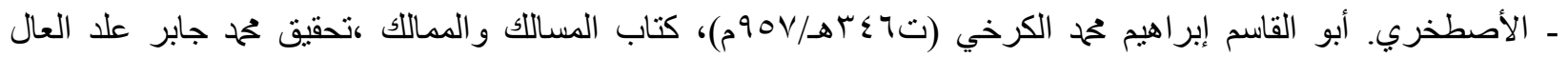

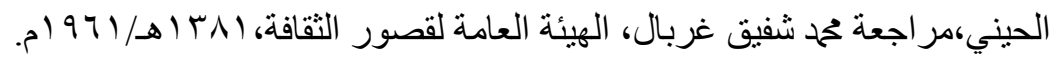

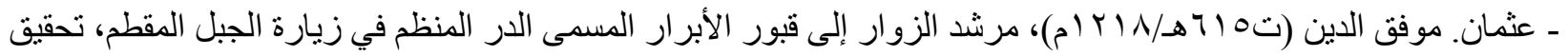

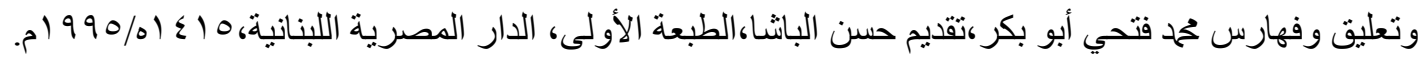

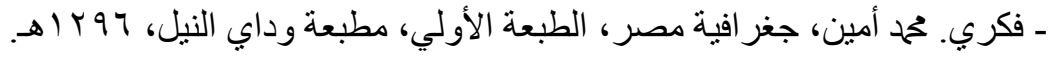

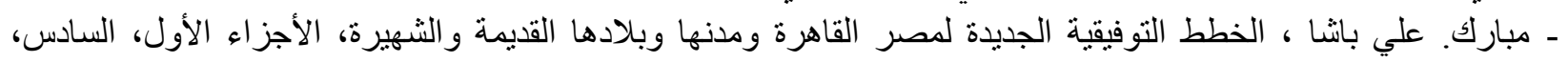

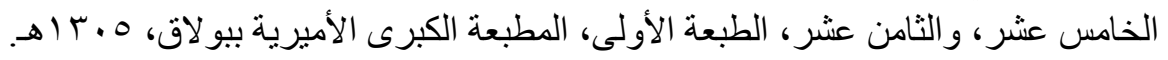

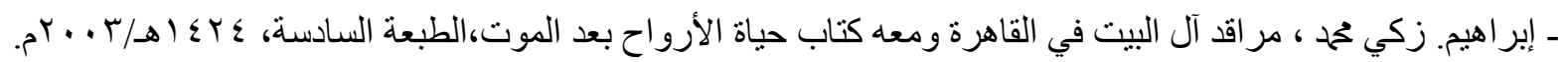




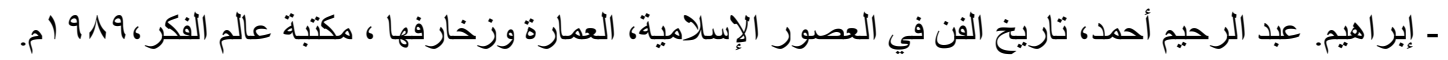

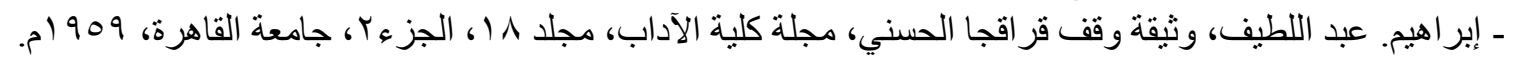

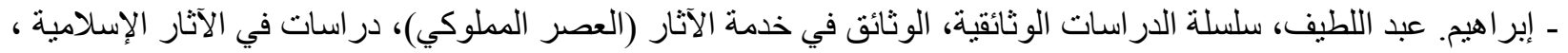

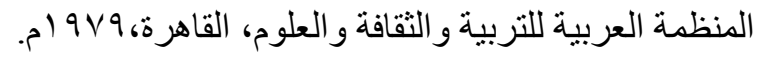

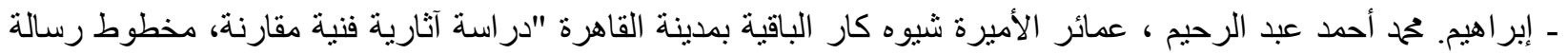

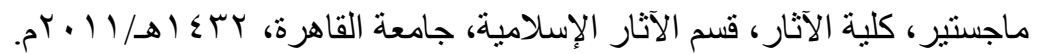

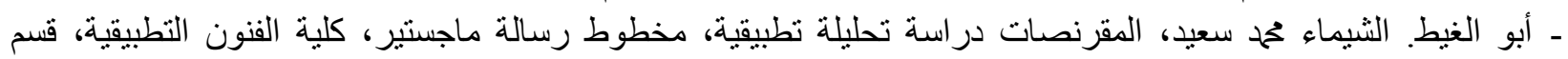

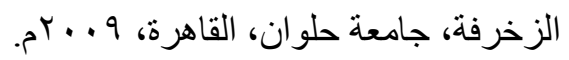

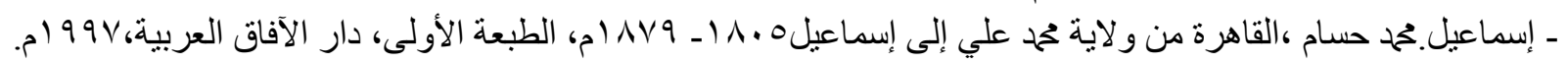

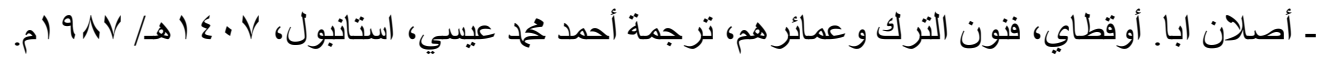

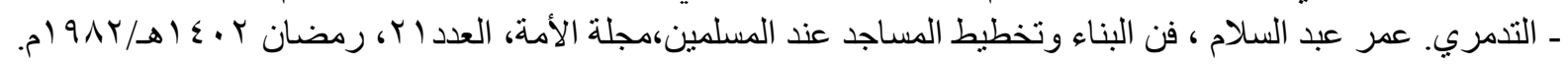

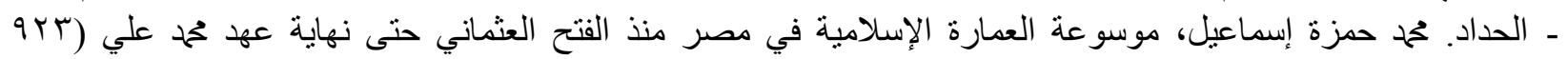

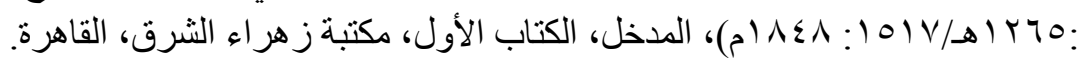

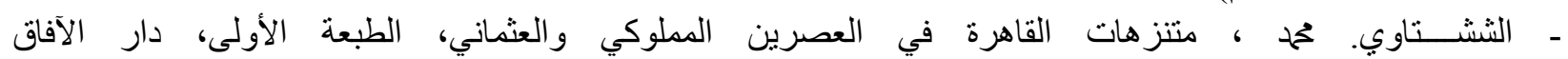

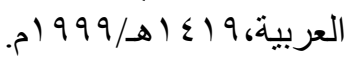

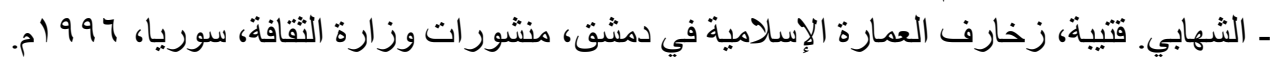

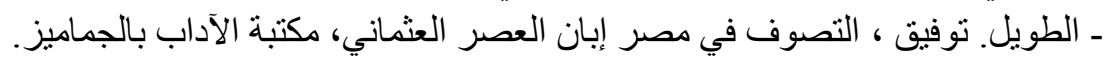

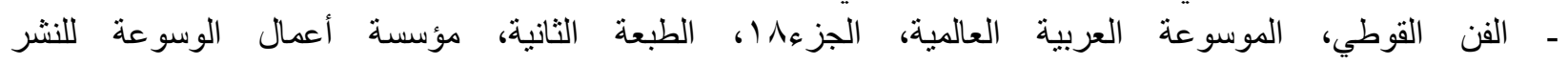

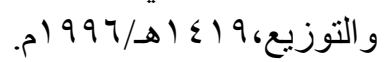

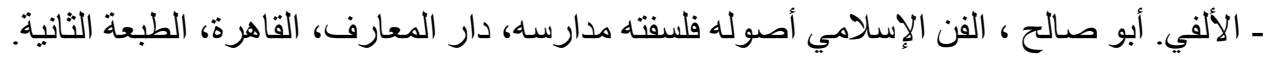

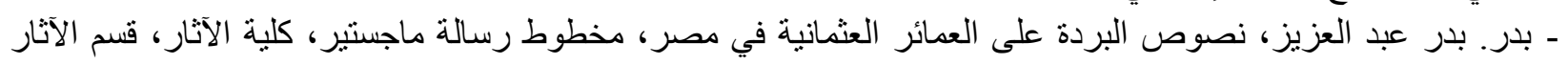

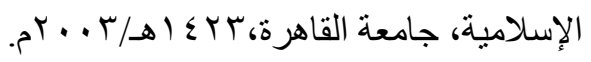

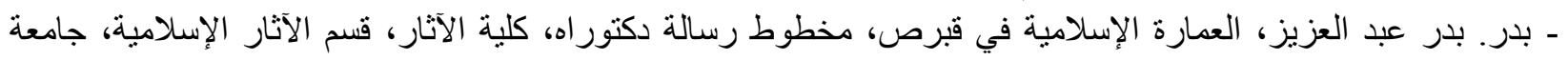

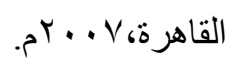
- بعض وثائق تاريخية من عهدي ساكني الجنان إسماعيل باثنا وتوفيق باثـا خديوي مصر ، انتقاها وأمر بترجمتها وطبعها

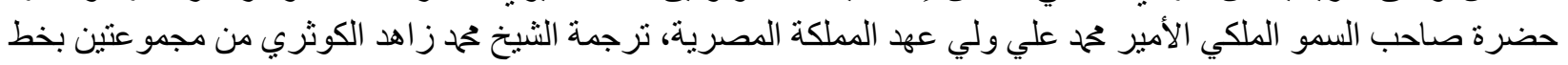

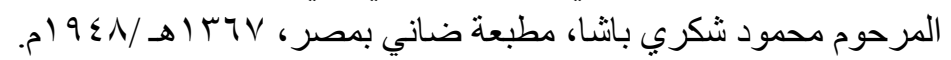

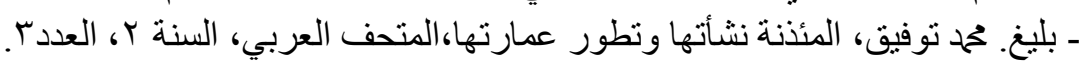

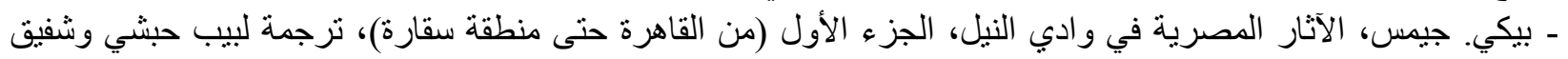

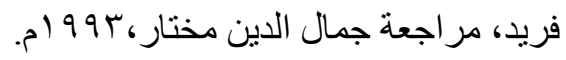

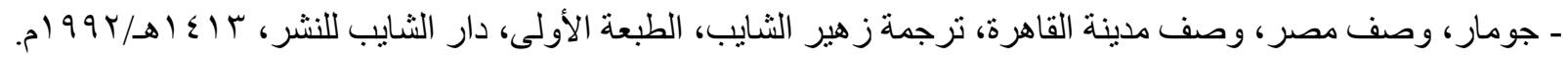

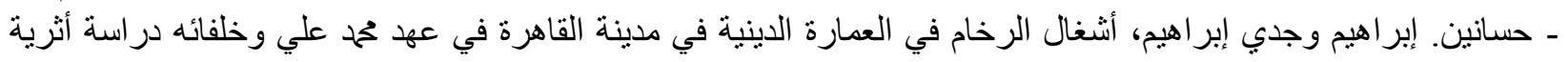

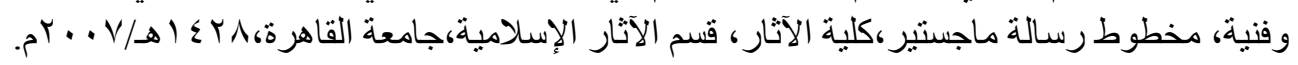

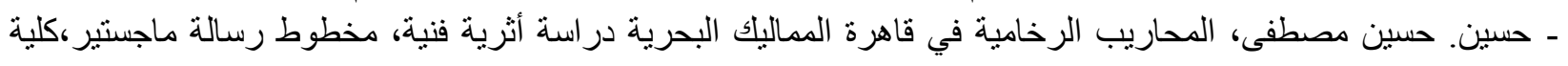

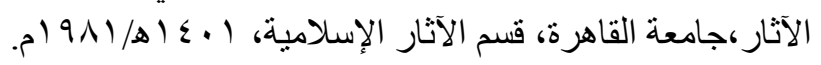

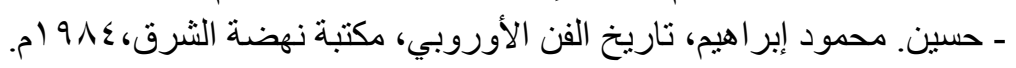

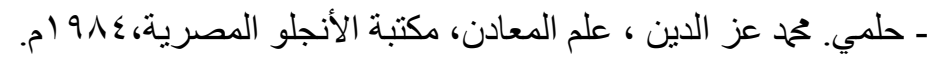

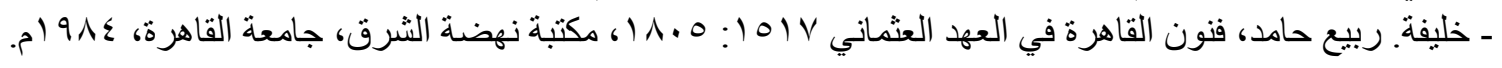

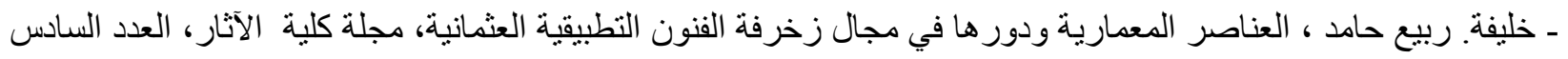

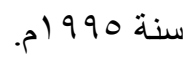




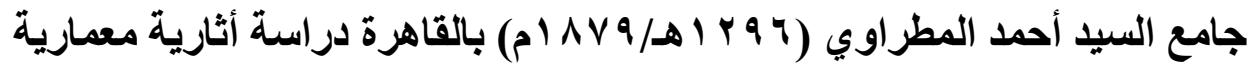

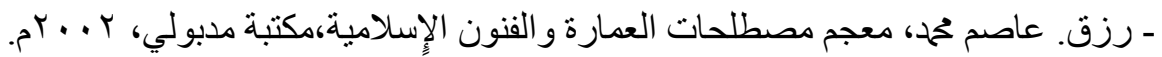

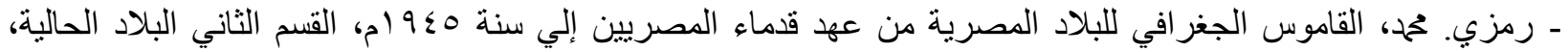

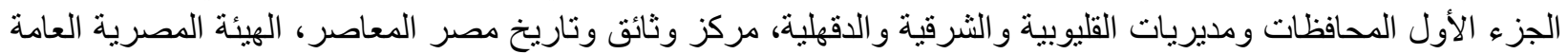

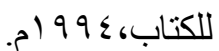
- رياض. مححد ، القاهرة نسيج الناس في المكان و الزمان مشكلاتها في الحاضر و المستقبل، دار الثروق، الطبعة الأولى،

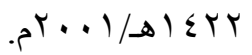

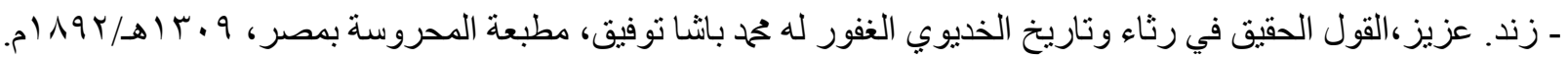

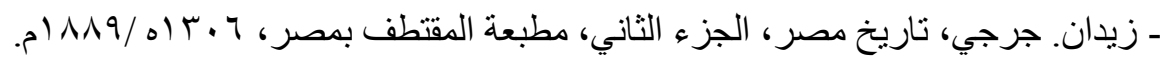

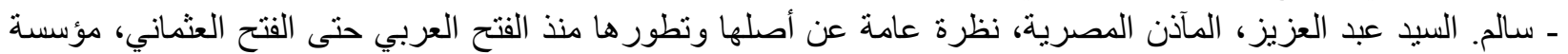
سباب الجامعة، الإسكندرية.

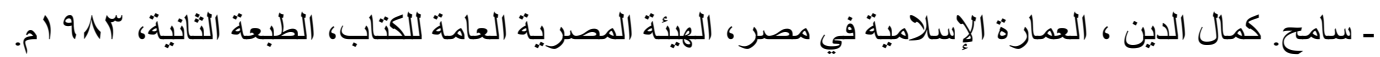

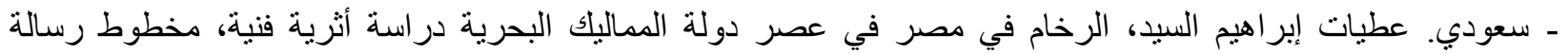

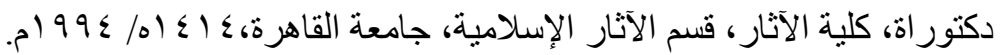

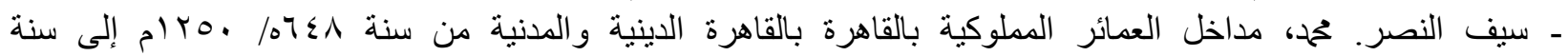

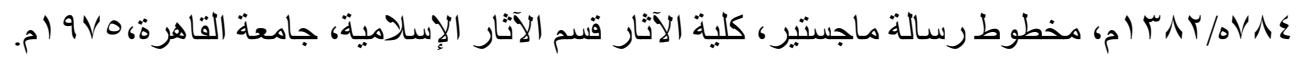

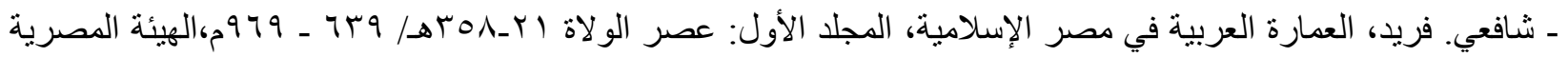

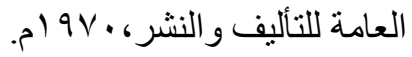
- صالح. عبد العزيز، الشرق الأدنى القديم، الجزء الأول، حضارة مصر القديمة، الطبعة الرابعة، مكتبة الأنجلو المصرية، م) 99.

ـ صبري. العربي، دراسة مقارنة لطراز العمائر الدينية الباقية بمدينتي دمثق و القاهرة، مخطوط رسالة دكتور اه، كلية الآثار،

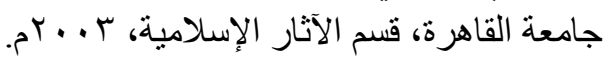

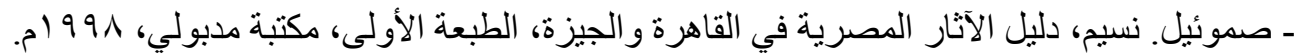

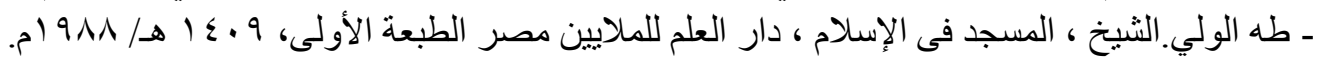

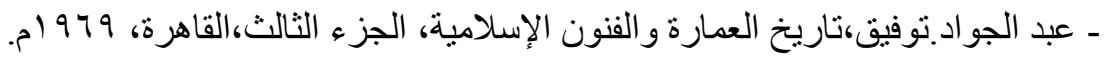

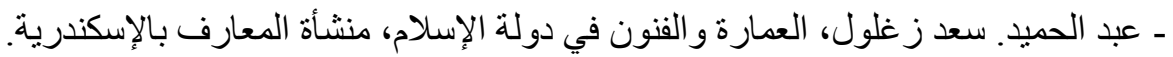

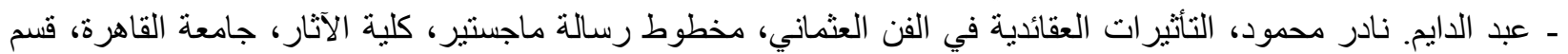

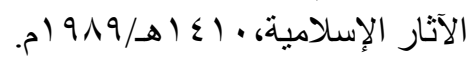

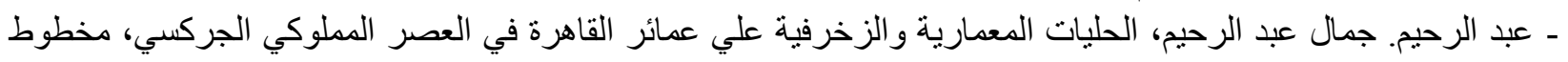

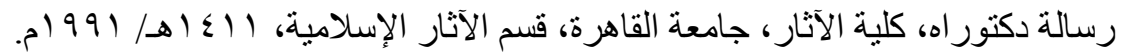

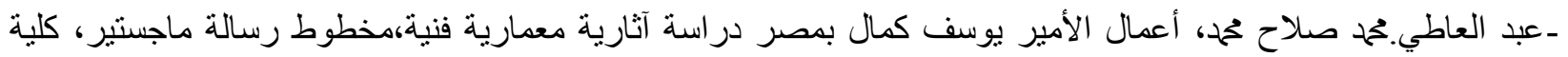

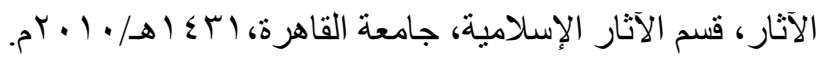

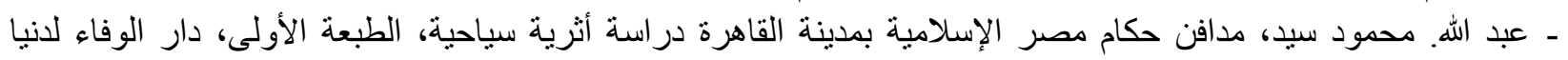

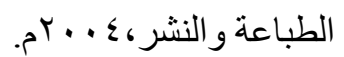

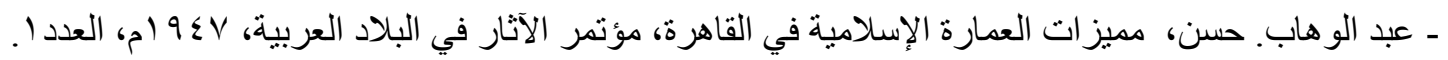

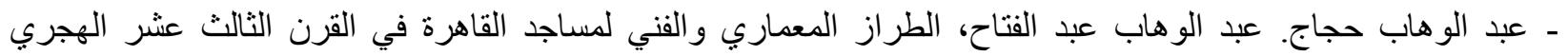

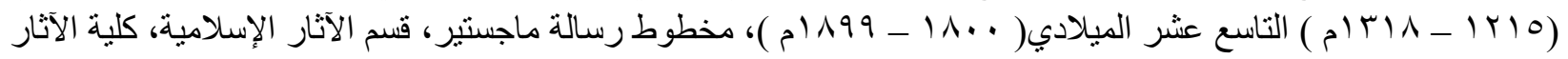

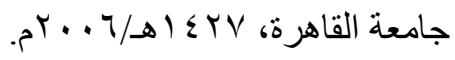

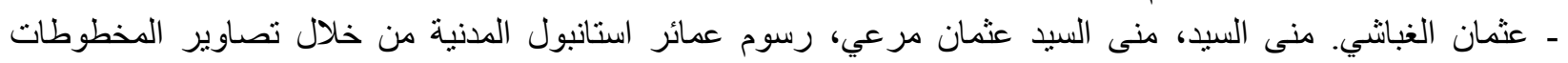

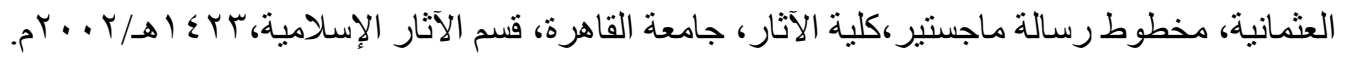


ـ ـ عمان الغباثي. منى السيد، رسوم العمائر الدينية في تصاوير المخطوطات العثمانية، مخطوط رسالة دكتور اه، كلية

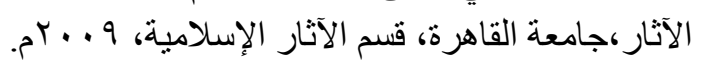

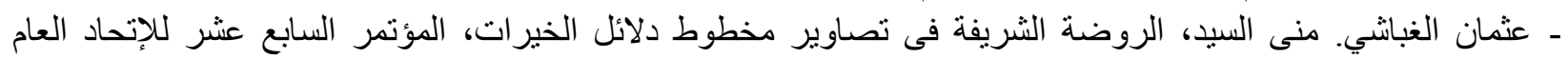

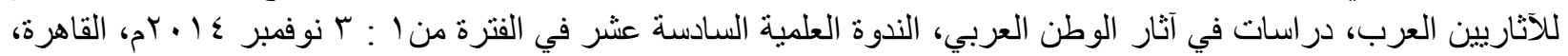

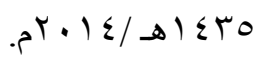
ـ عفيفي خليفة. غدير دردير ، الدور المعارئ الدماري والفني للمقرنصات في العمارة المملوكية بمصر و الثشام "دراسة أثرية فنية

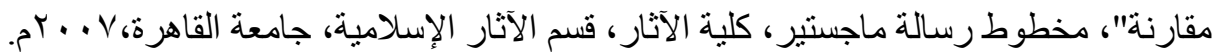

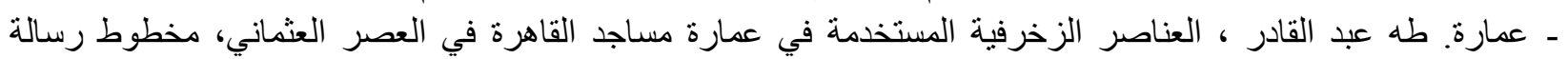

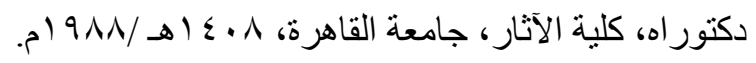
ـ فرج. فؤاد، تاريخ المدن القديمة ودليل المدئة جاهينة الحديثة، المجلد الثالث، القاهرة (1)، مطبعة المعارف ومكتبتها

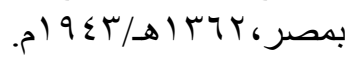

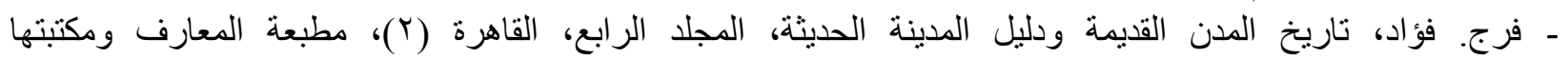

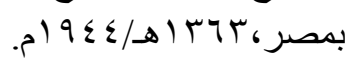
ـ فهمي. عبد الرحمن ، العمارة قبل عصر أمر المعاليك، القاهرة تاريخها فنونها آثار ها، مؤسسة الأهر ام.

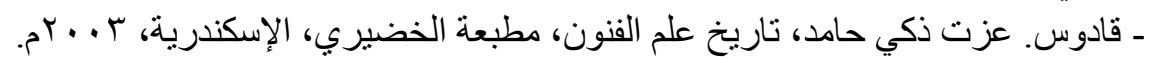

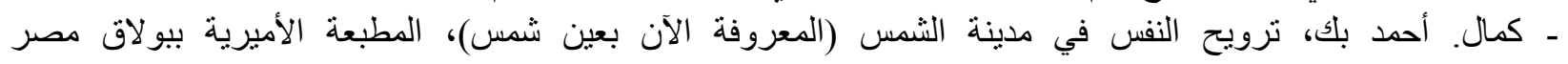

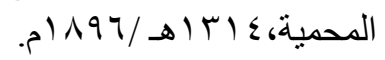

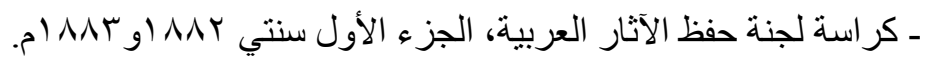

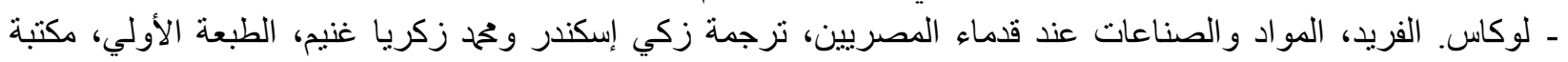

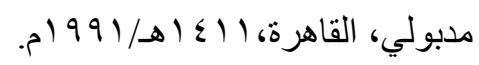

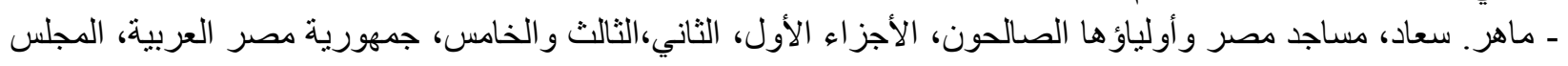

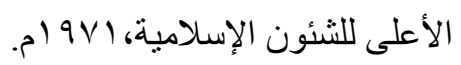
ـ محمود. هاني ححمد رشدي، قصور الإدية الأمر اءو والباشوات في منطقتي المطرية و المرج در اسة تاريخية سياحية، مخطوط رسالة

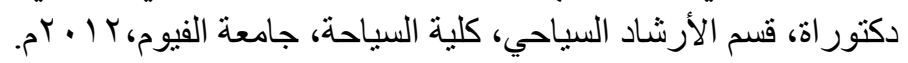

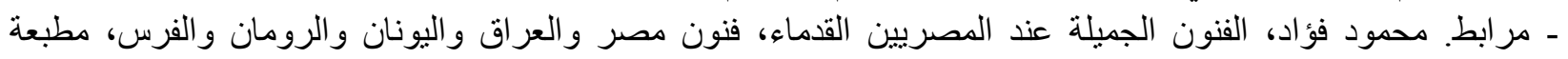

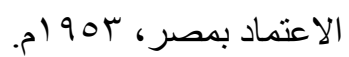

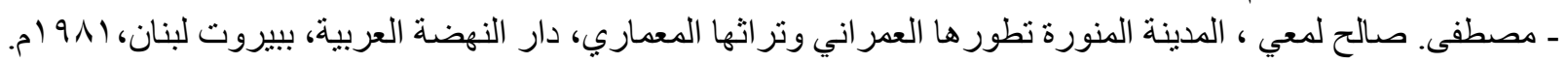

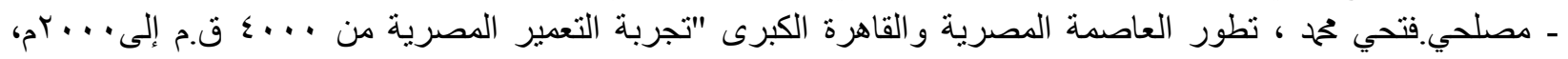

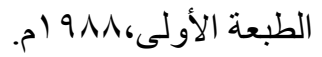
ـ منشاوي. أمنية أحمد مجاهد، التأثيرات القوطية على العمائر الإسلامية و القبطية بمدينتي القاهرة والإسكندرية خلال القرن التاسع عشر وحتى العقد الأول من القرن العشرين، مخطوط رسالة ماجستير، كلية الآثار قسم الآثار الإسلامية، جامعة القاهرة، الإنة rا

ـ موسى. عبد الله كامل، تطور المئذنة المصرية بمدينة القاهرة من الفتح العربي وحتى نهاية العصر المعلوكي. دراسة معمارية

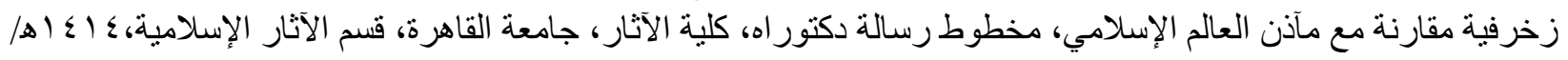
م) $99 \leq$

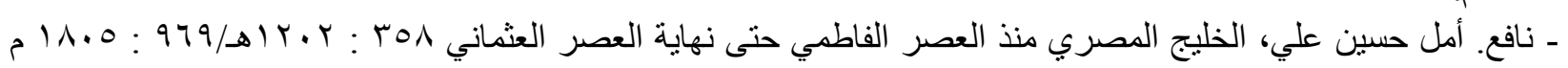

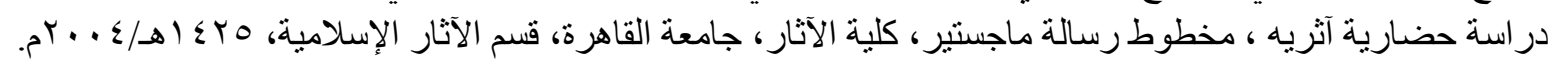
ـ نجم. عبد المنصف سالم حسن ، قصر السكاكيني دراسة معمارية فنية، مخطوط رسالة ماجسير، كلية الآثار ، قسم الآثار

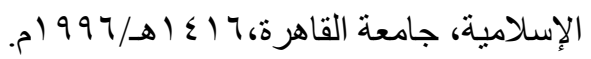




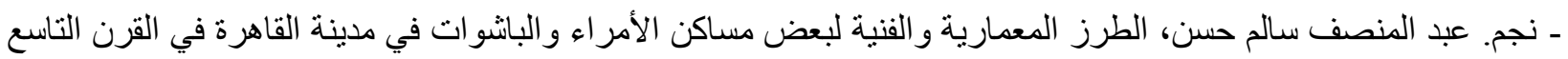

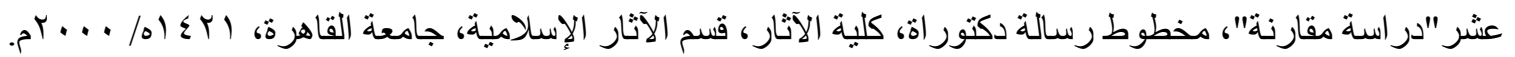

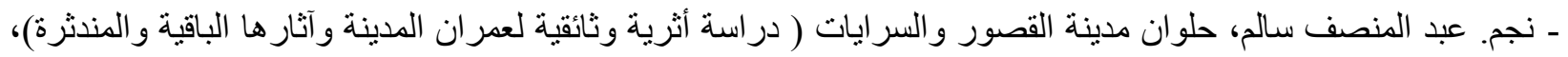

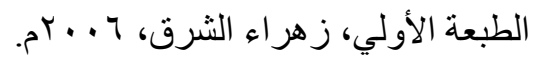

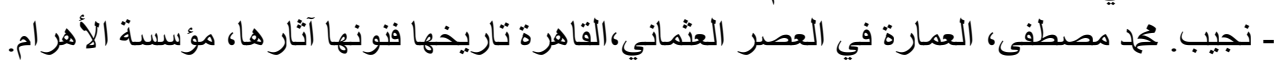

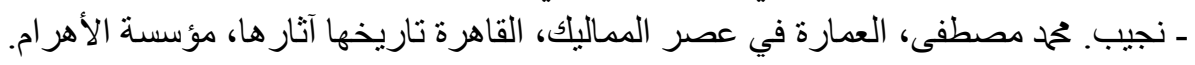

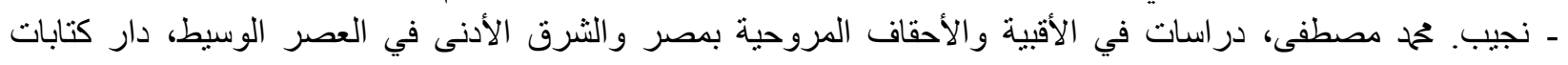

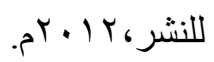

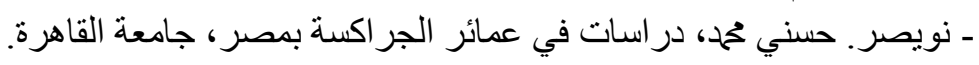

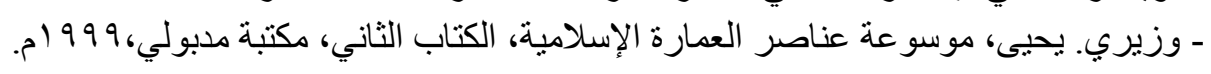
- Arseven.(C.E), Les Decoratifs Turcs, Istanbul,1951.

- Bloom. (J), Minaret Symbol of Islam, Oxford Studies in Islamic Art, Oxford University press,

1989.

-Burckhardt. (H), Art of Islam Language And Meaning. World of Islam festival,1966.

- Briggs. (M), Muhammadan Architecture In Egypt and Palastine,1974.

- Gabriel. (A), Les Mosquée De Constantiople, Syria, Revue d'Art , Tome VII, Paris, 1926.

- Goodwin.(G), Sinan Ottoman Architecture and Its Values Today,Great Britian,1993.

- Hillenbrand.(R), Islamic Architecture Form, Function and Meaning, Edinburgh University press.

- Martin. (H), L' Art Musulman,La Grammaire Des Style-Collection De P recis sur L' Histoire

-Petersen.(A), Dictionany of Islamic Architecture, London and de L'Art, Paris (V I). New York, 1996.

- Ünsal.(B),Turkish Islamic Architecture in Seljuk and Ottoman Times 1071- 1923, London,

1959. 


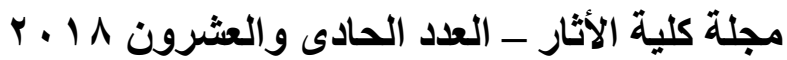

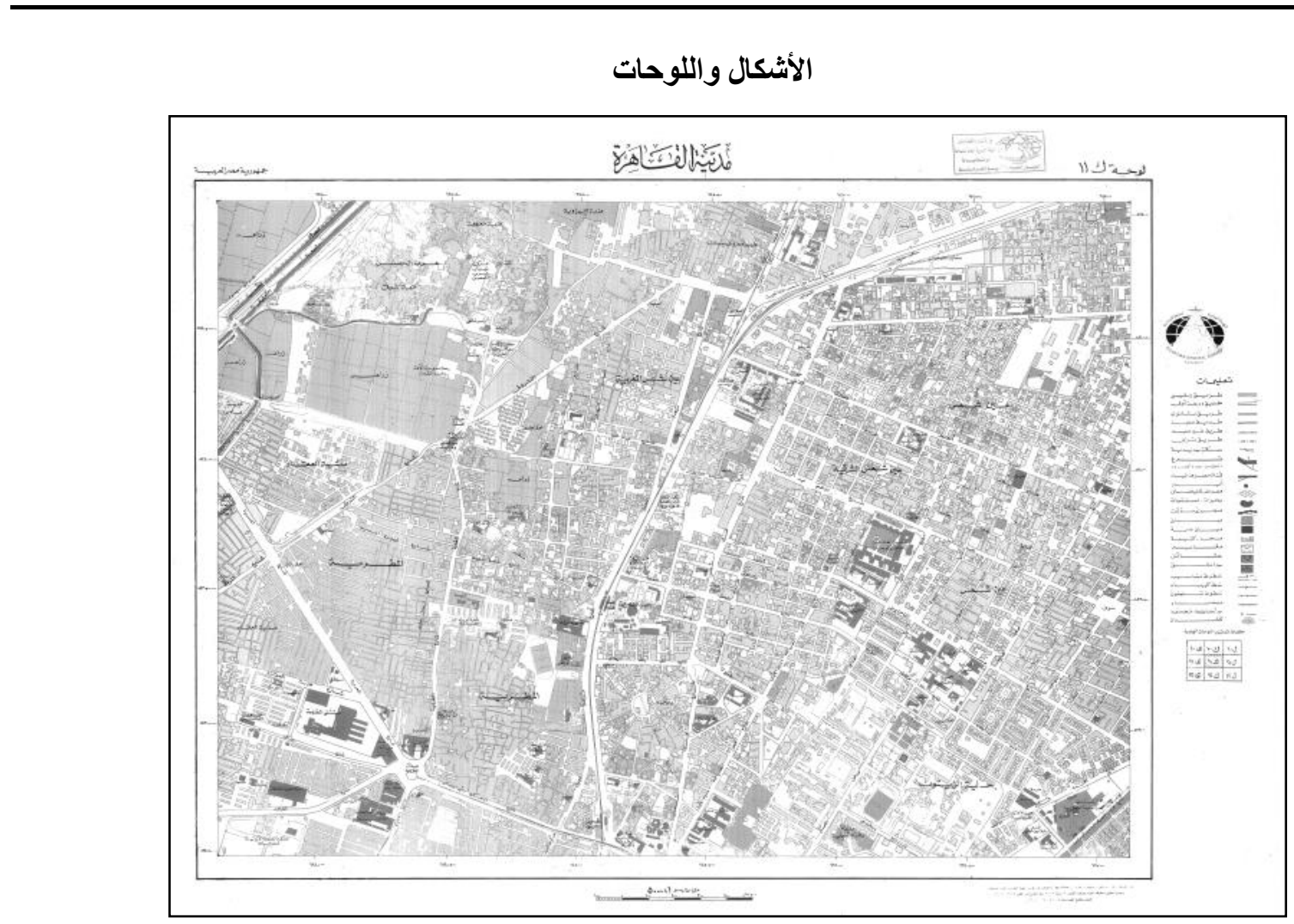

(شكل ا ) خريطة لمدينة القاهرة بمقياس رسم ا : . . 0 توضح حي المطرية موقع عليها جامع السيد أحمد المطراوي، عن:

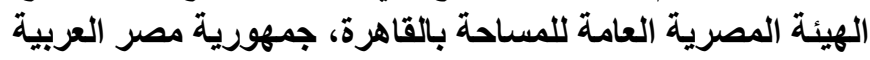

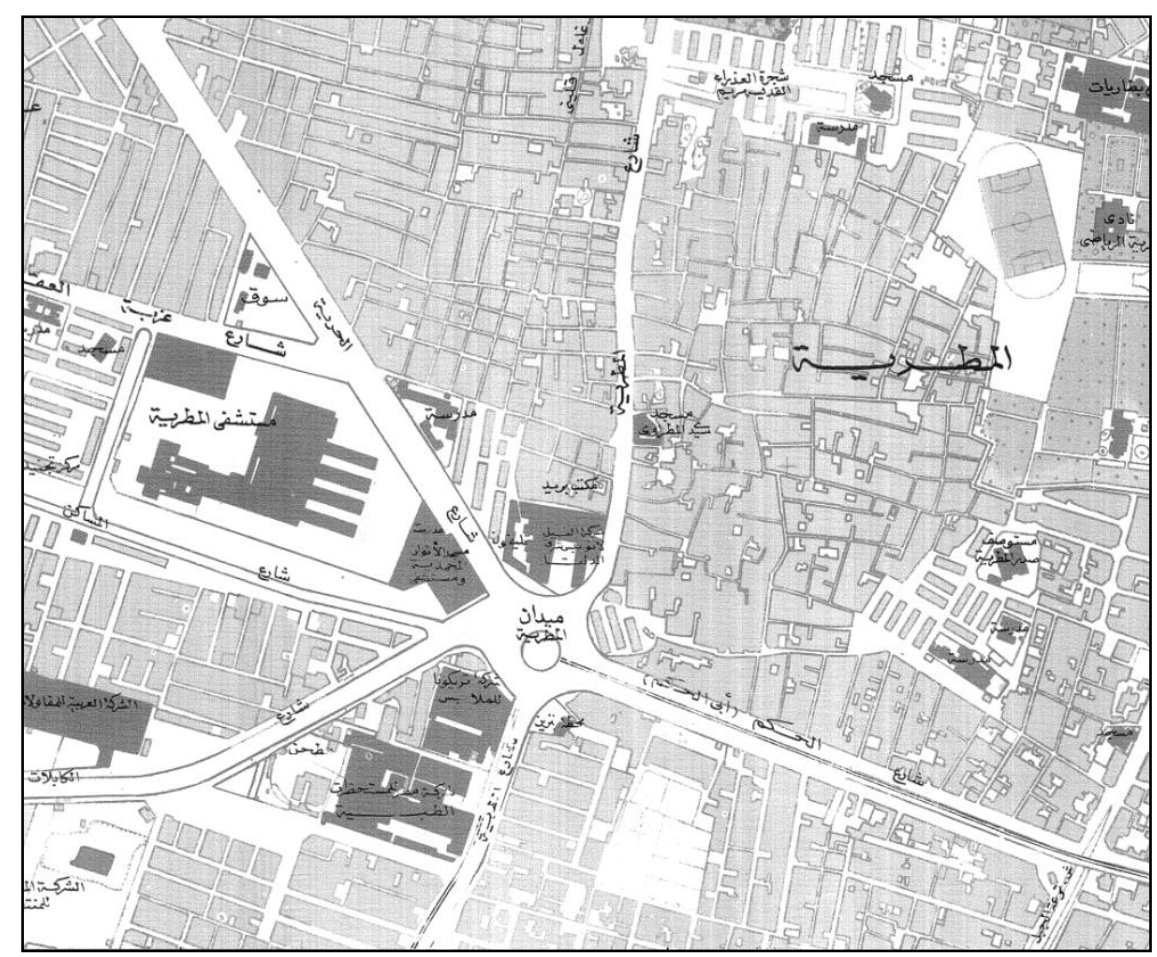

(شكلץ) جزع تفصيلي من الخريطة السابقة توضح جامع السيد أحمد المطراوي موقع بحي المطرية 


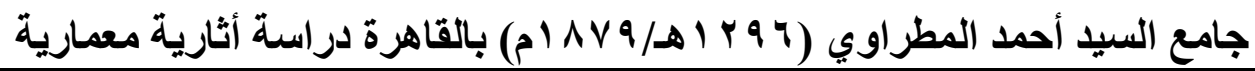

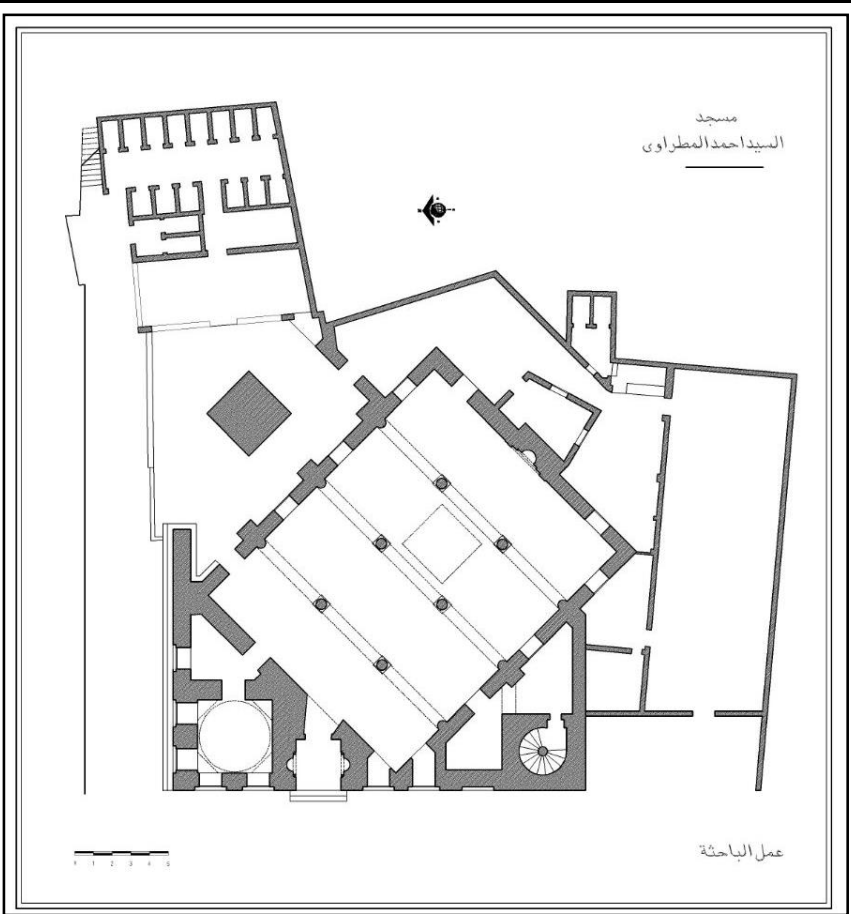

(شكلץ) تخطيط جامع السيد أحمد المطراوي

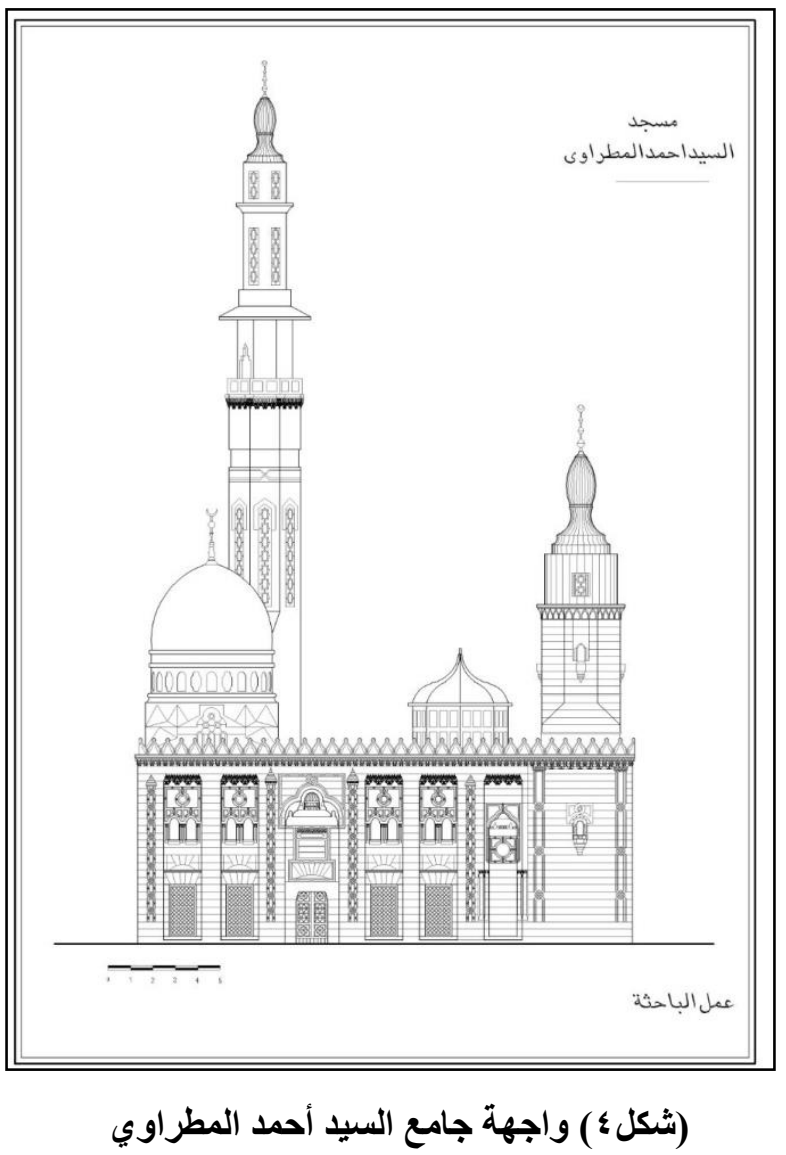




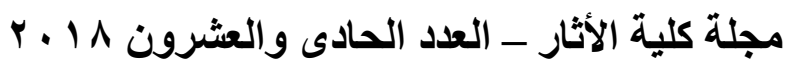

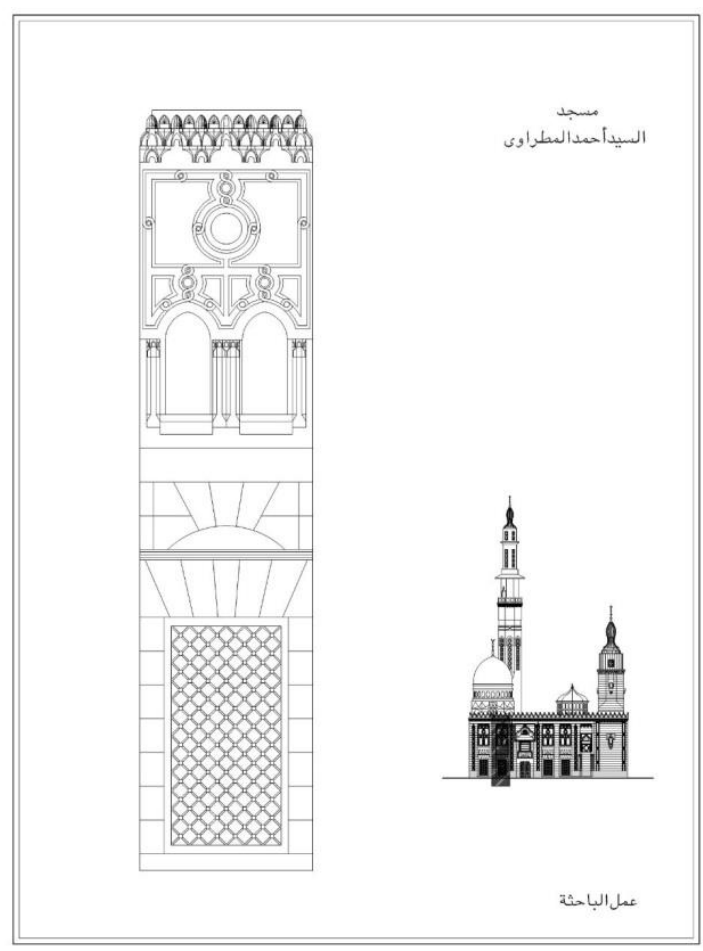

(شكله) دخلة القبة الضريحية ذات المقرنصات

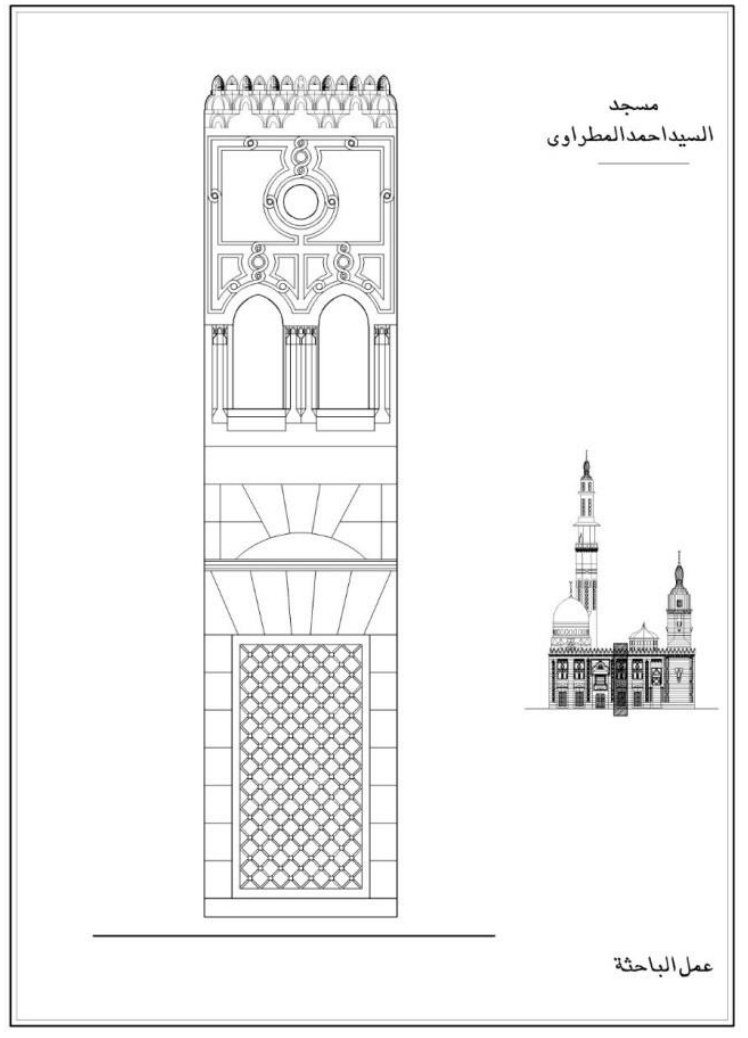

(شكلج) دخلة الجامع ذات المقرنصات

118 


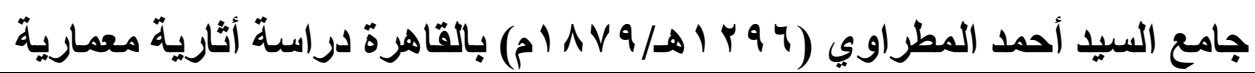

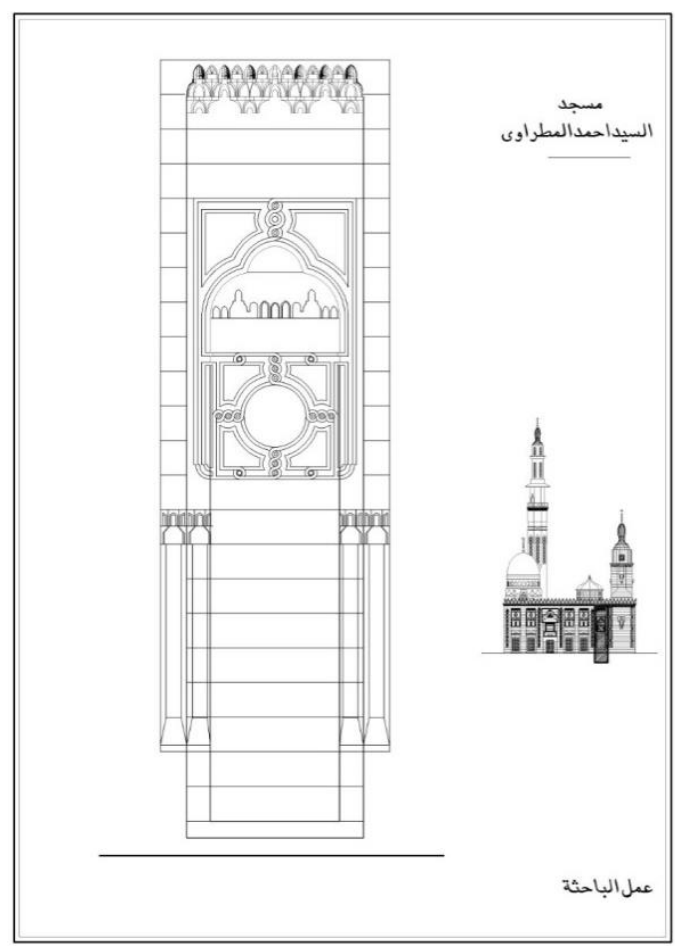

(شكل V) الاخلة ذات المقرنصات التي تمثل واجهة المنطقة المحصورة بين الجامع والمئذنة

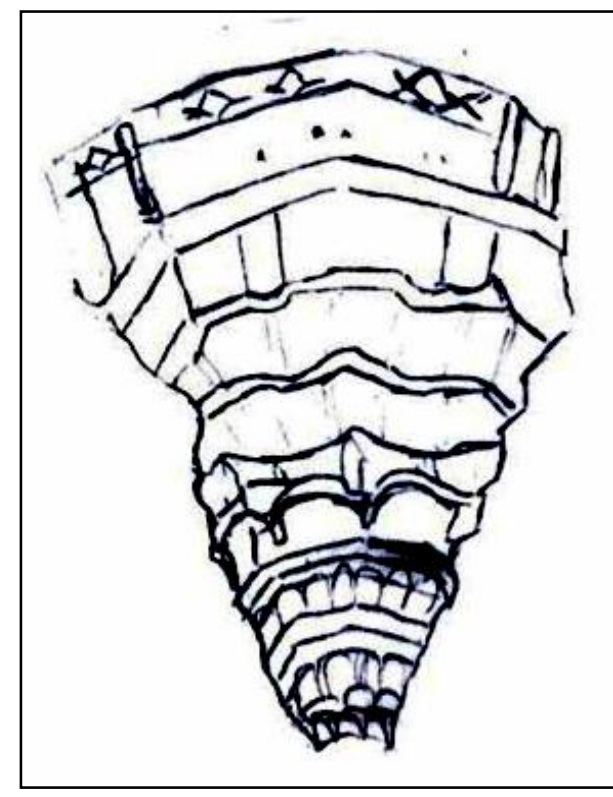

(شكل 9 ) شرفة ناقذة قاعدة المئنتة

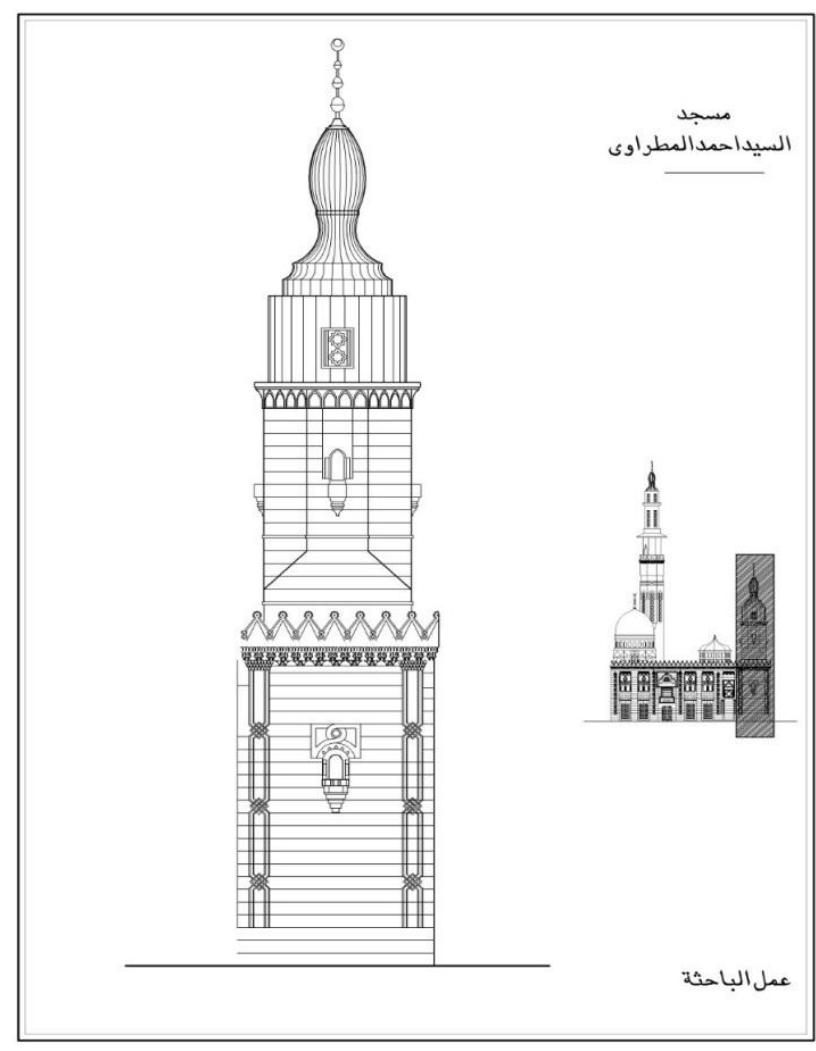

(شكل^) الاخلة ذات المقرنصات التي تمثل واجهة قاعدة المئذنة 
مجلة كلية الأثار - العدد الحادى والعثرون 1 1 ـ r

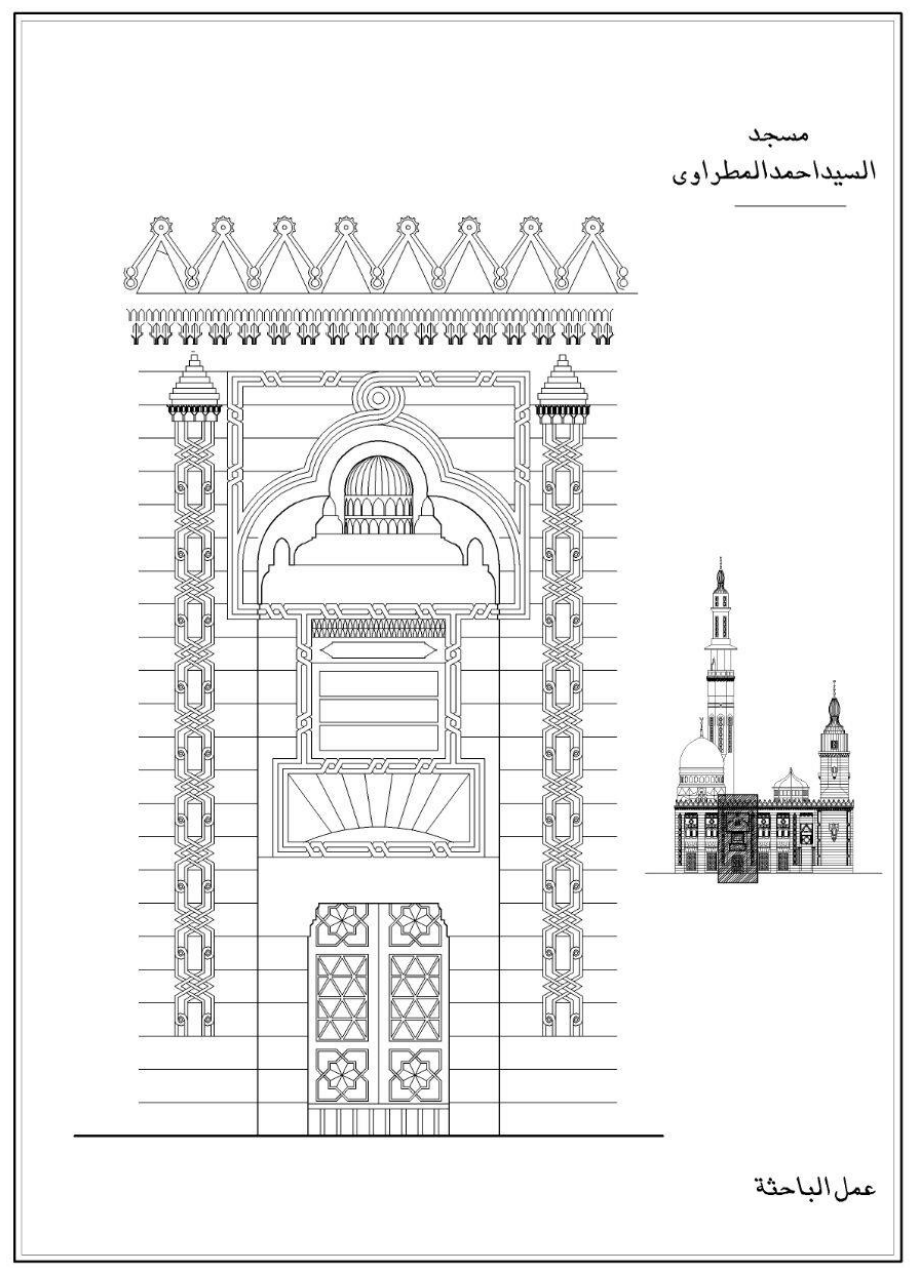

(شكل · 1 ) واجهة المدخل

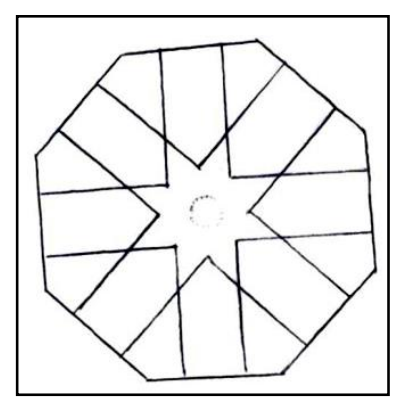

(شكلب ا ) زخرفة سقف الثخشيخة الاخلي

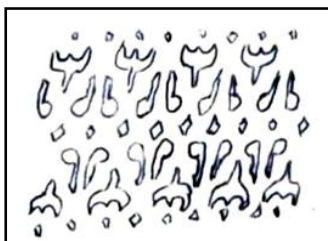

(شكل r ا ) زخرفة درابزين دكة المبلغ

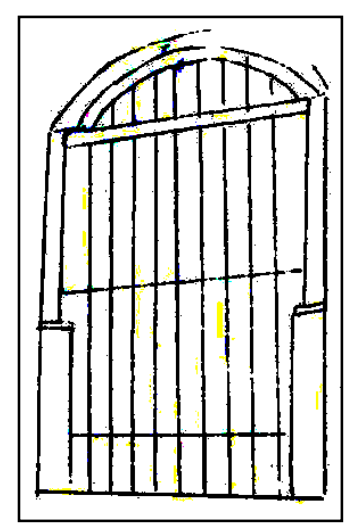

(شكل 1 1) ا التكسية ذات

المصبعات 


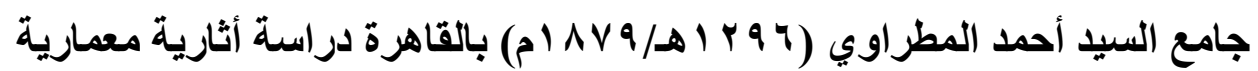
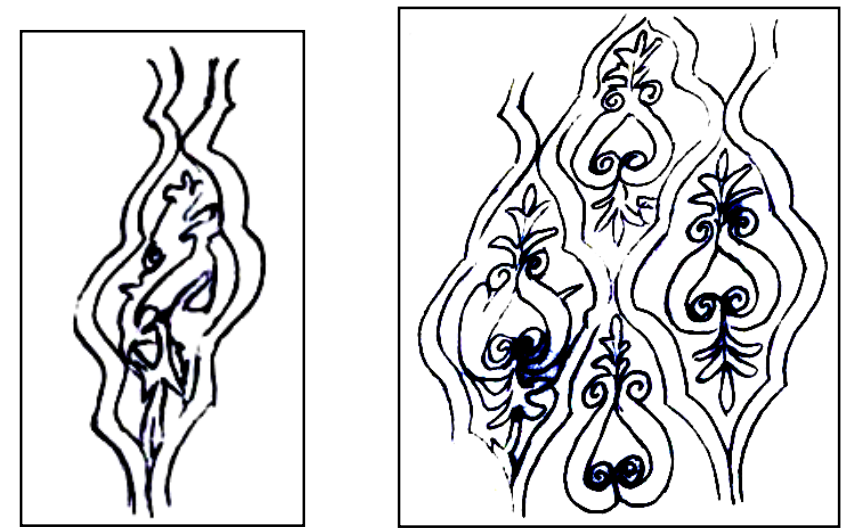

(شكله 1) زخرفة القبة من أعلى (شكله 1) زخرفة القبة من أسفل

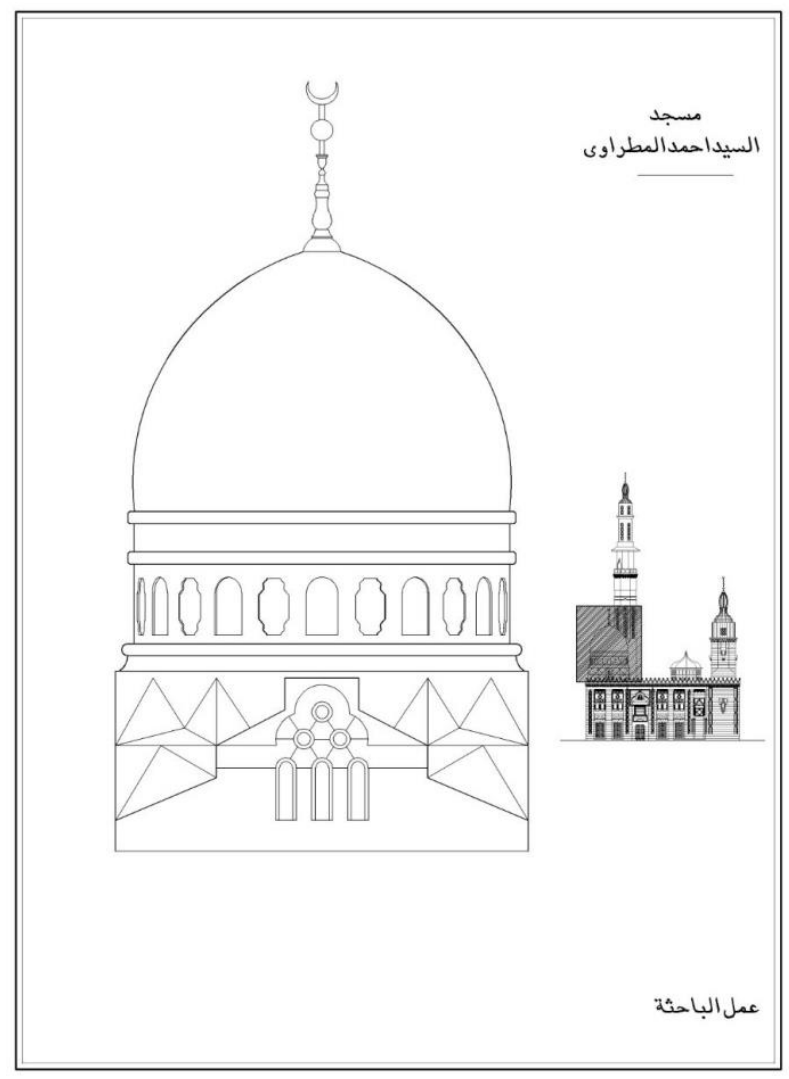

(ثكل \& 1 ) القبة من الخارج

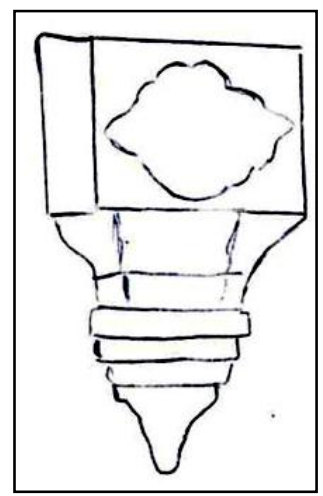

(شكلو 1 ) شرفة ناقذة المئذنة

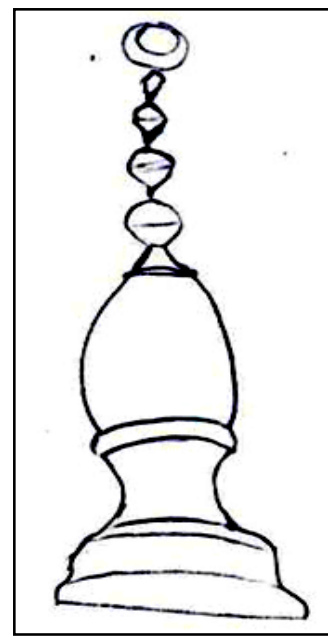

(شكل1 1 ) القائم المعدني

الأي يتوج المئذنة

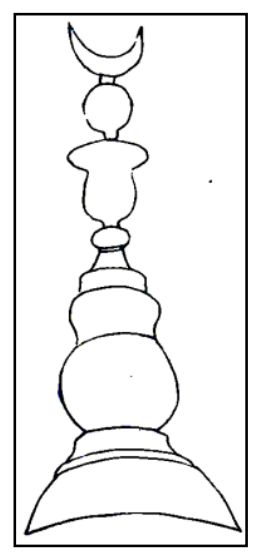

(شكل I V القائم المعدني

الأي يتوج القبة التمان المعن 


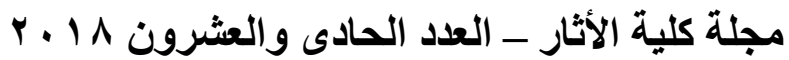

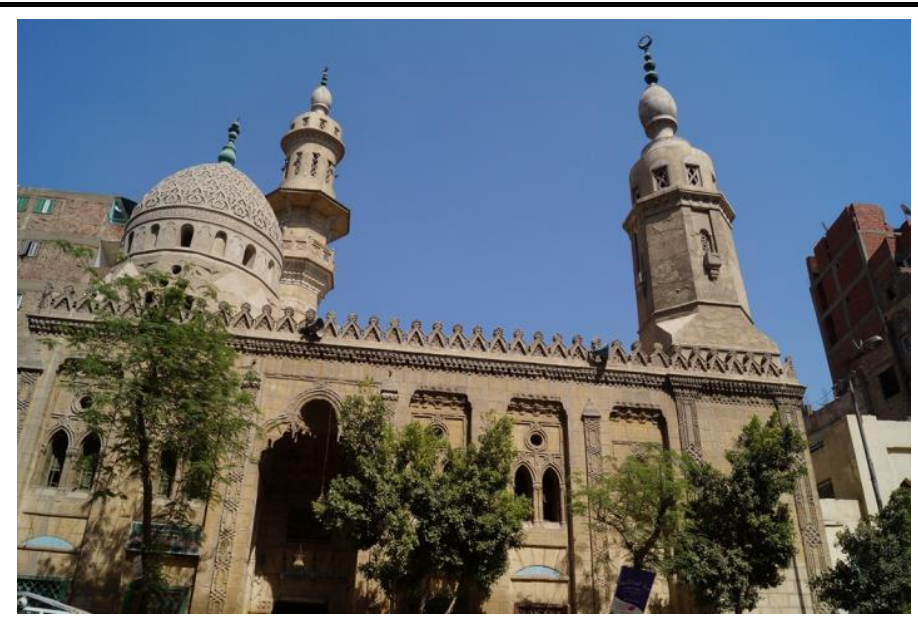

(لوحة ا) جامع السيد أحمد المطراوي من الواجهة الرئيسية

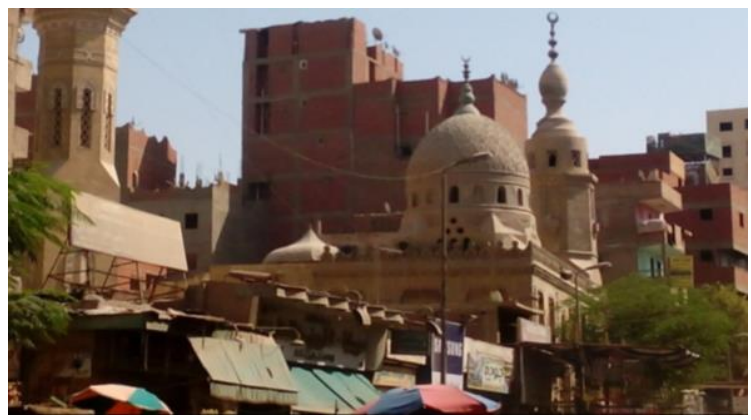

(لوحةץ) جامع السيد المطراوي من الزاوية الثرقية

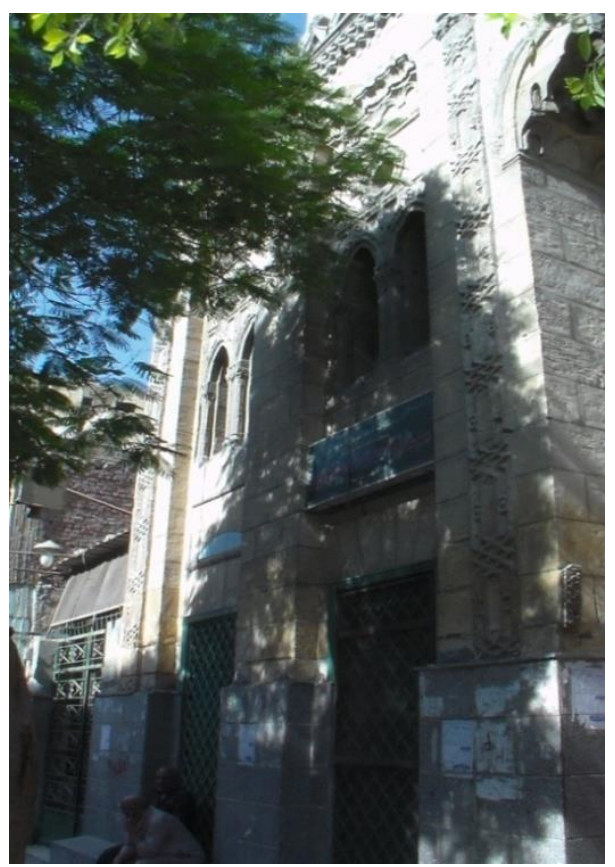

(لوحة ؛ ) القتلية بواجهة القبة الضريحية الرئيسية

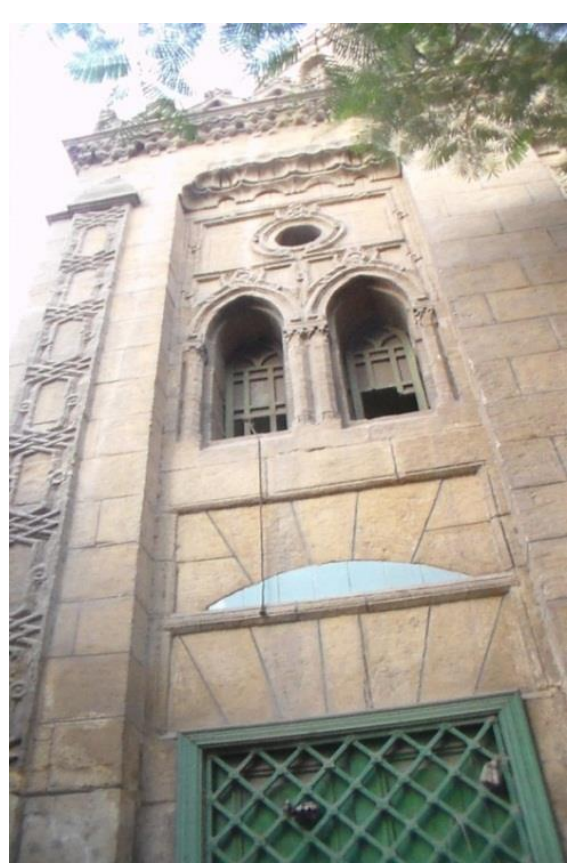

(لوحةب) واجهة القبة الضريحية الرئيسية على يسار المدخل 


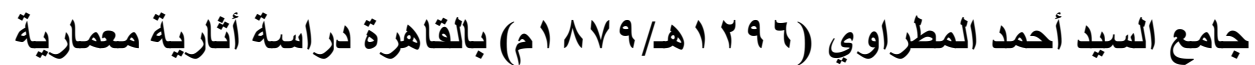
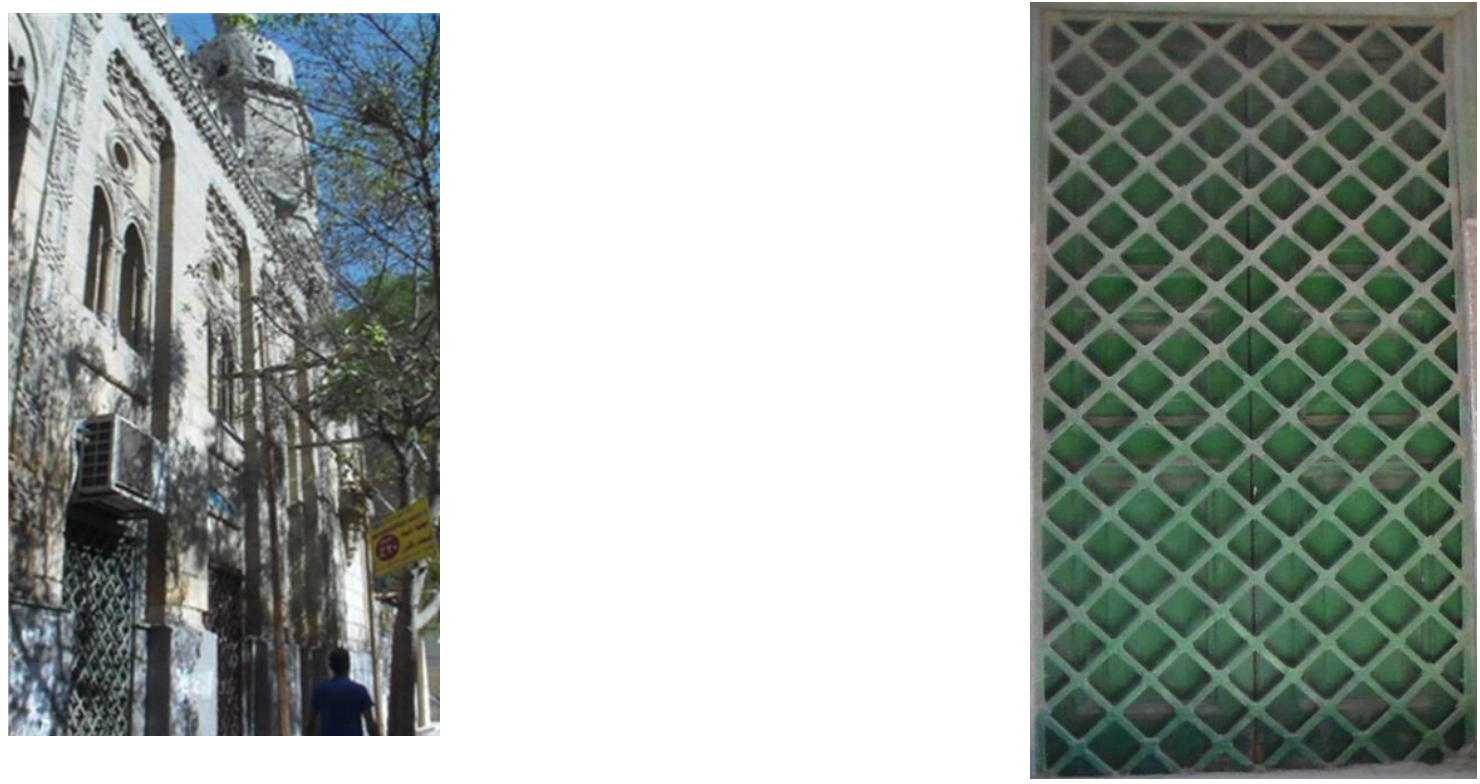

(لوحة) واجهة الجامع الرئيسية على يمين المدخل

(لوحةه) النافذة ذات المصبعات المعدنية

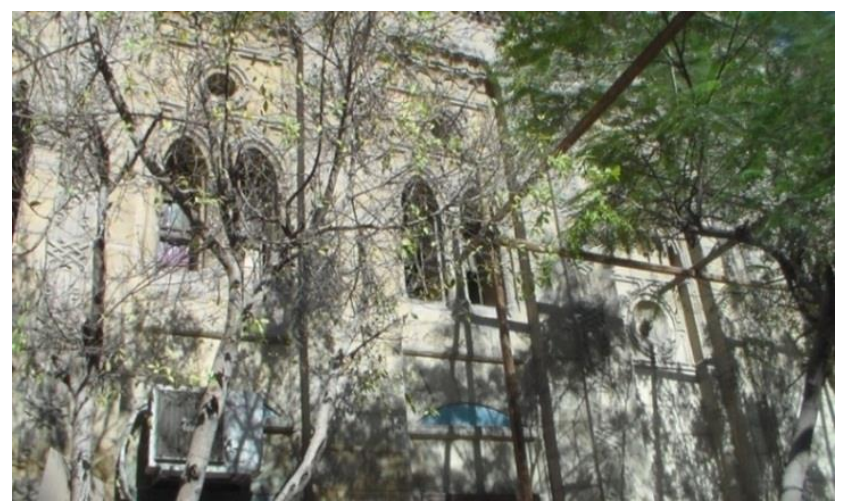

(لوحة (لقسم العلوي من واجهة الجامع الرئيسية

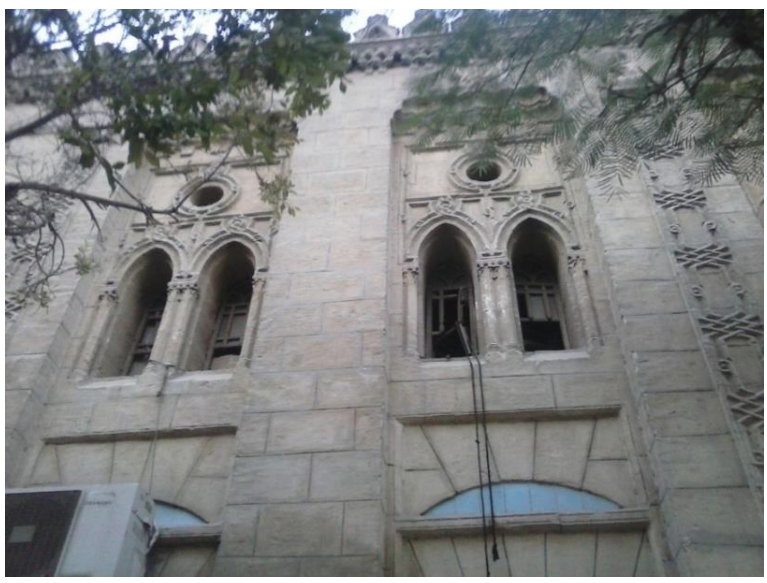

(لوحةه) و واجهة الجامع الرئيسية 
مجلة كلية الأثار - العدد الحادى والعشرون 1 1 ـ r

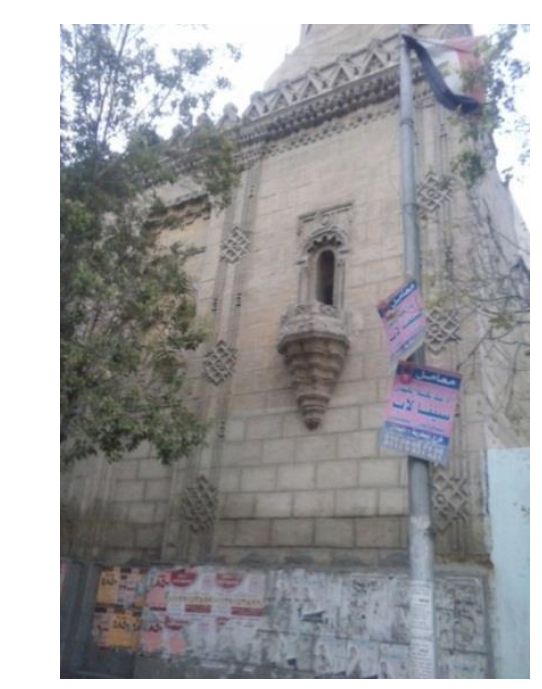

$$
\text { (لوحة ، 1 ) الطرف الأيمن من واجهة الجامع }
$$

الرئيسية وهي قاعدة المئننة

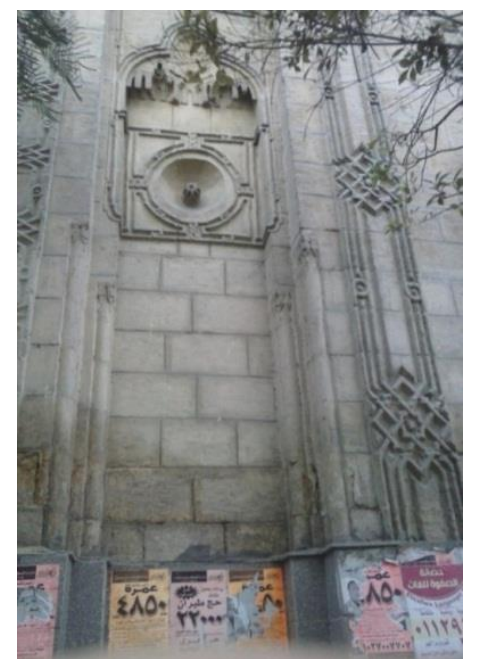

(لوحة9) واجهة الجامع الرئيسية موضحة

الاخلة ذات الحلية الزخرفية الزئة

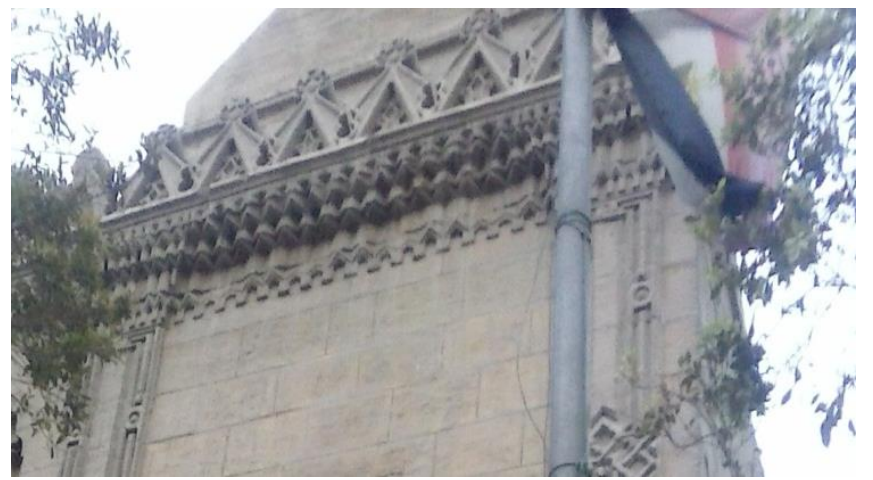

$$
\text { (لوحة ا ( ) الثرافات أعلى الواجهة }
$$

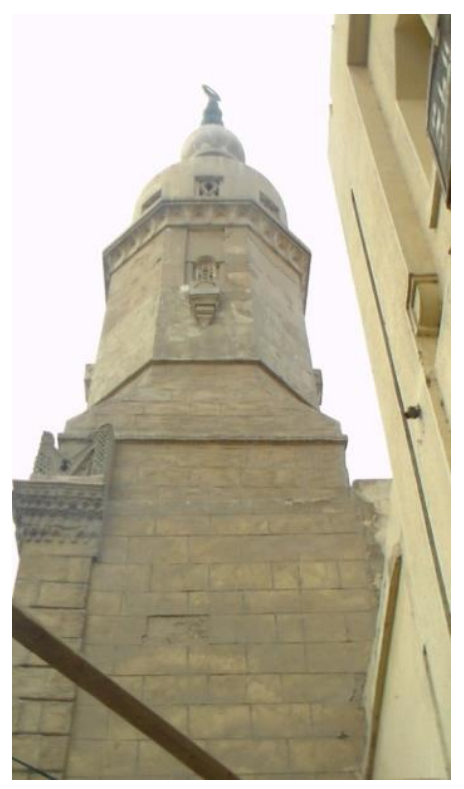

(لوحة ץ 1) المئنة والثر افات بالواجهة الجنوبية الغربية 


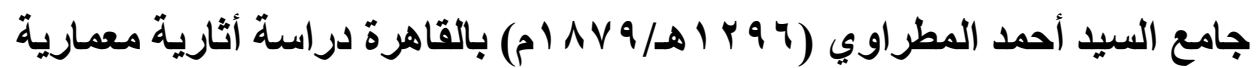

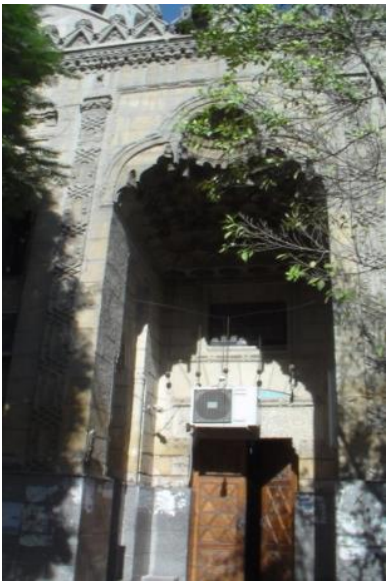

(لوحة ؛ ) المدخل الرئيسي بالواجهة

الرئيسية الثمالية الغربية

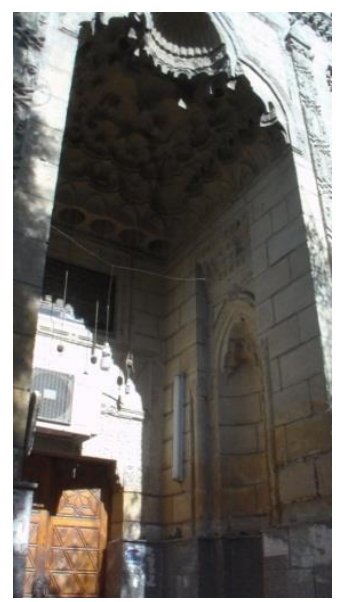

(لوحةه 1 ) الحنية المحر ابية

اليمنى بحجر المدخل

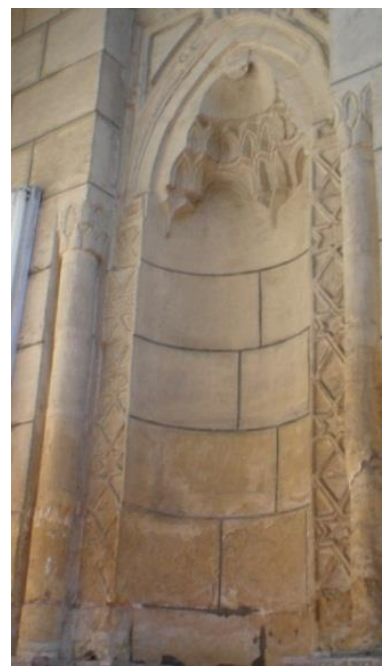

(لوحةه ا ) تفصيل للاخلة اليمنى بحجر المدخل

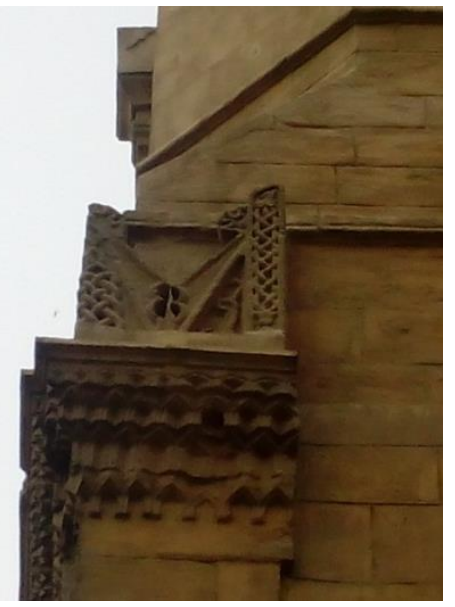

(لوحة ب ا ) تفصيل للثر افات بالواجهة الجنوبية

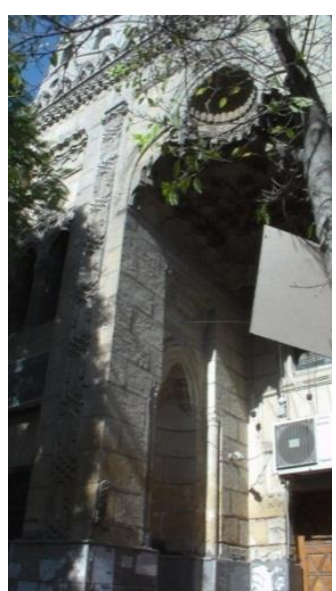

(لوحةه 1 ) الاخلة أو الحنية المحرابية

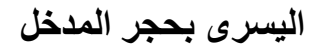

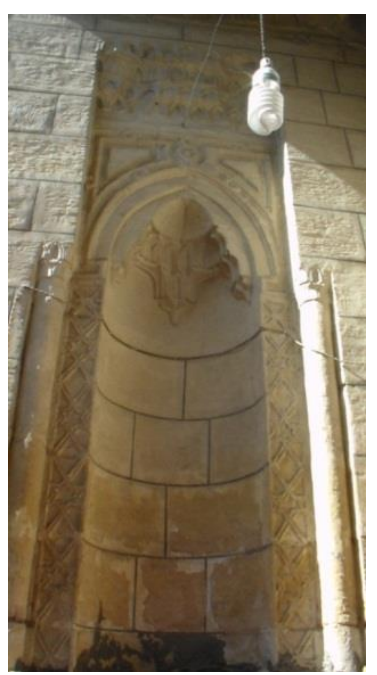

(لوحة V ) تفصيل للاخلة اليسرى بحجر المدخل 
مجلة كلية الأثار - العدد الحادى والعثرون 1 1 ـ r

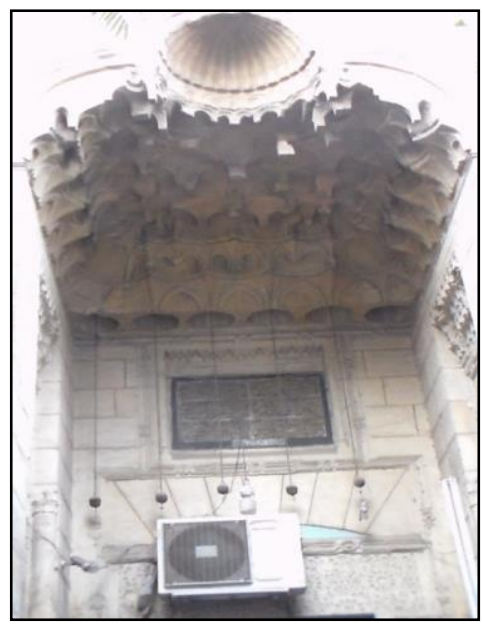

(لوحة + r) الأعتاب التي تعلو المدخل

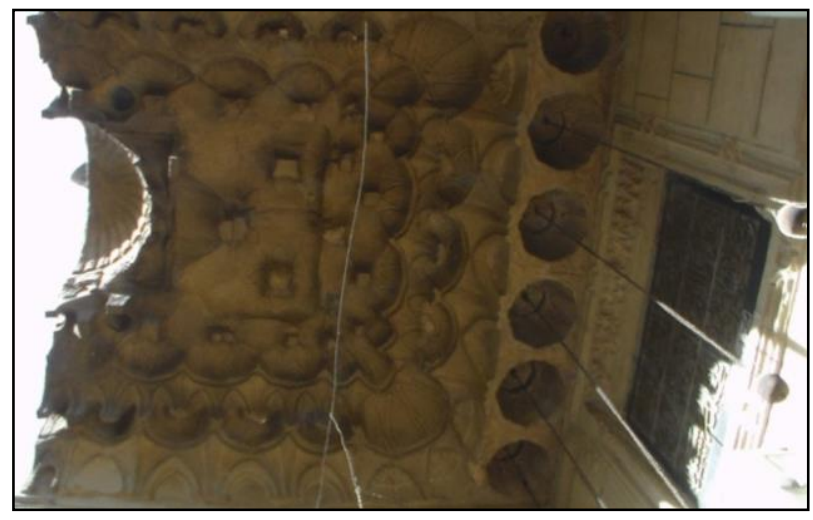

(لوحةץ ץ) النص التأسيسي وسقف حجر المدخل

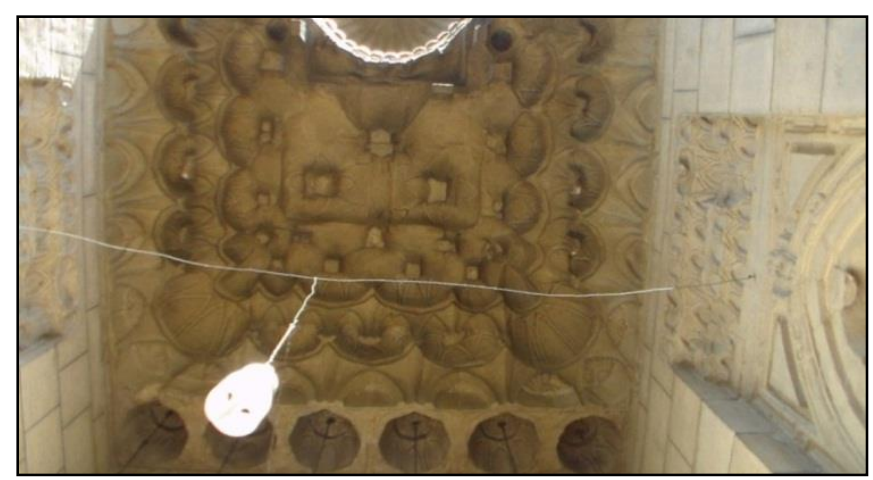

(لوحة ؟ ب) تفصيل لسقف حجر المدخل

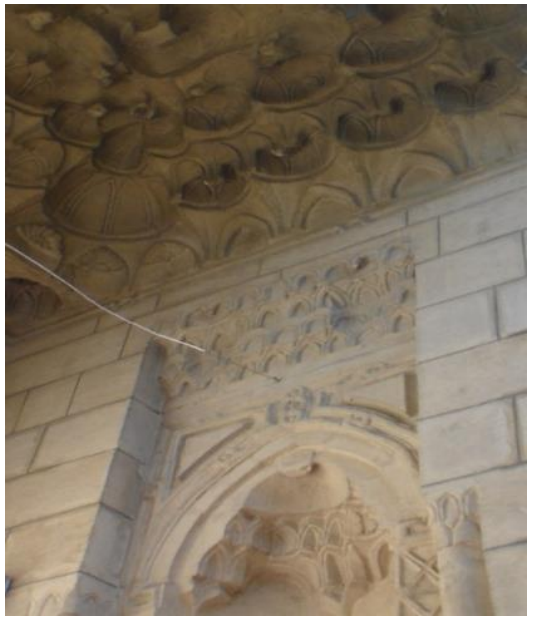

(لوحة 9 ( ) تفصيل للاخلة اليمنى بحجر المدخل

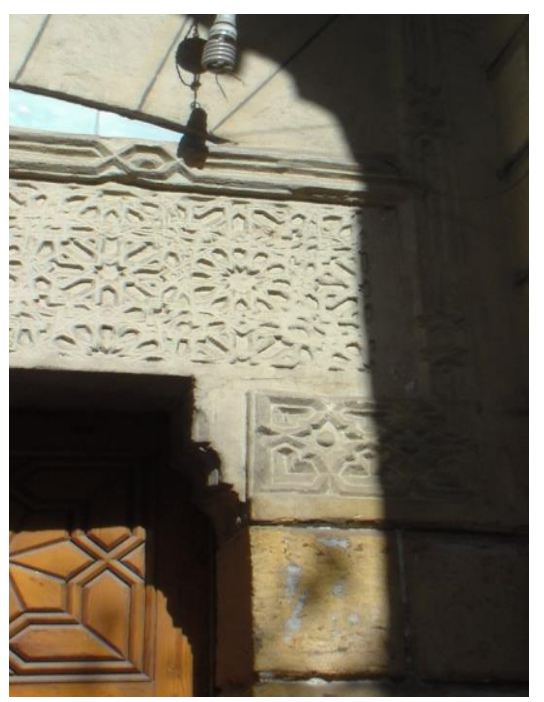

(لوحة / r ) تفصيل لزخارف الأعتاب التي تطو المدخل

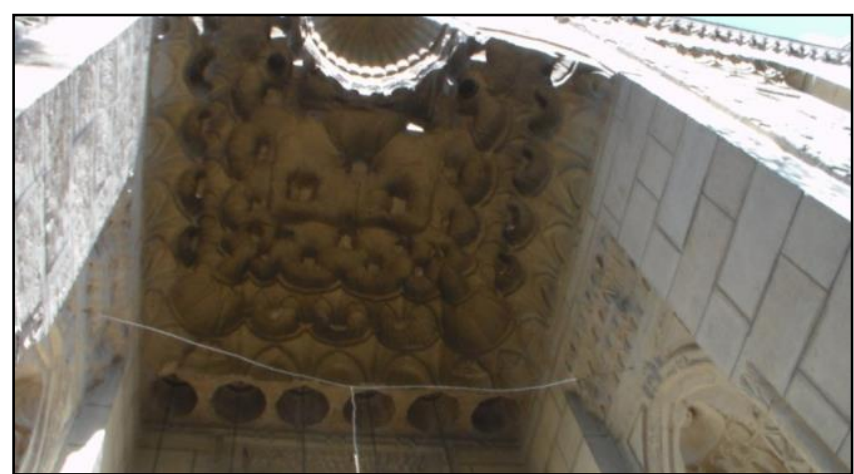

(لوحة r (ץ) سق حجر المدخل 

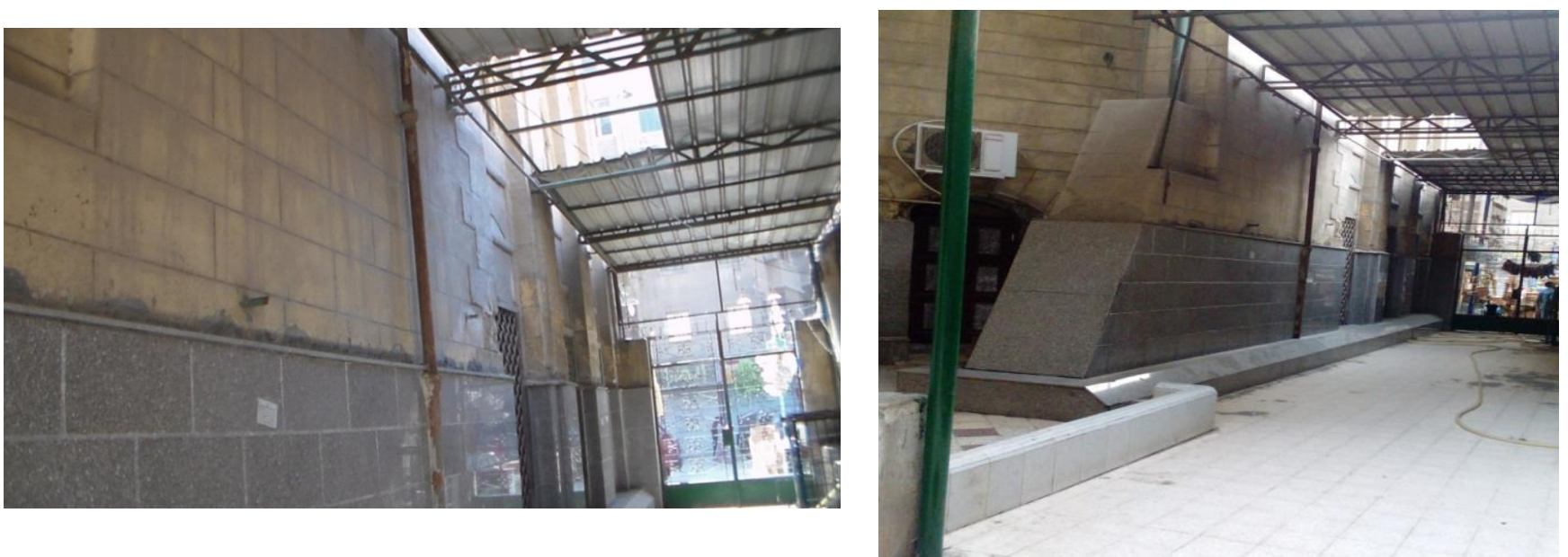

(لوحة r ب ) الواجهة الشمالية الشرقية للقبة

(لوحةه r) الواجهة الشمالية الثرقية للقبة الضريحية والمساحة غير المنتظمة التي تتقدمها من الجاتب الضريحية والمساحة غير المنتظمة التي تقدمها من الجاتب
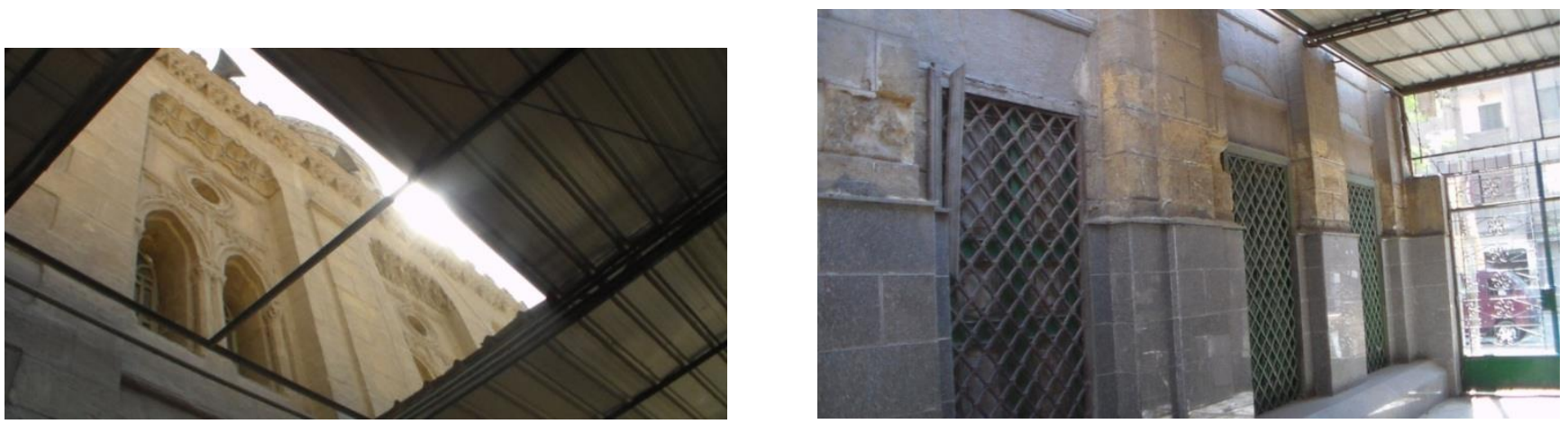

(لوحة人 ץ ) القسم العلوي من الواجهة الشمالية الشرقية للقبة الضريحية

(لوحة Y V الواجهة الشمالية الثرقية للقبة الضريحية
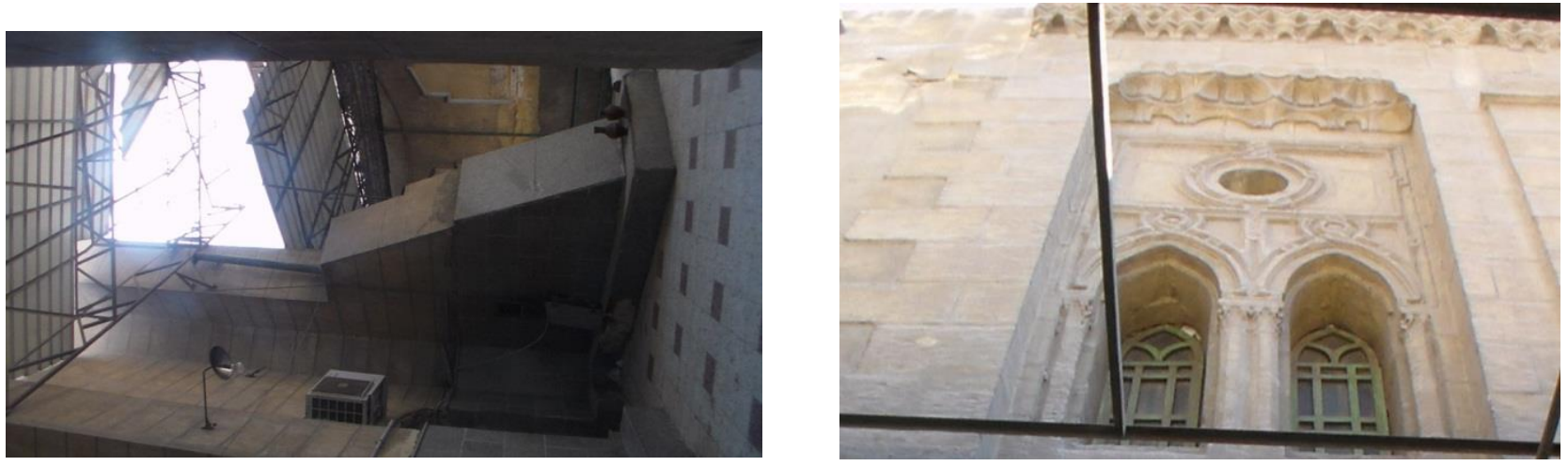

(لوحة • r) الدعامة البارزة والمتدرجة التي ينتهي بها واجهة القبة الضريحية والمساحة غير المنتظمة التي تتقدمها

(لوحة9 ( ) تفصيل لقندلية الواجهة )

الثمالية الثرقية للقبة الضريحية 


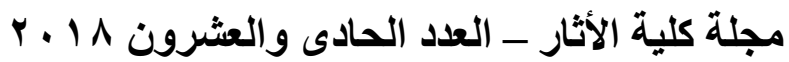

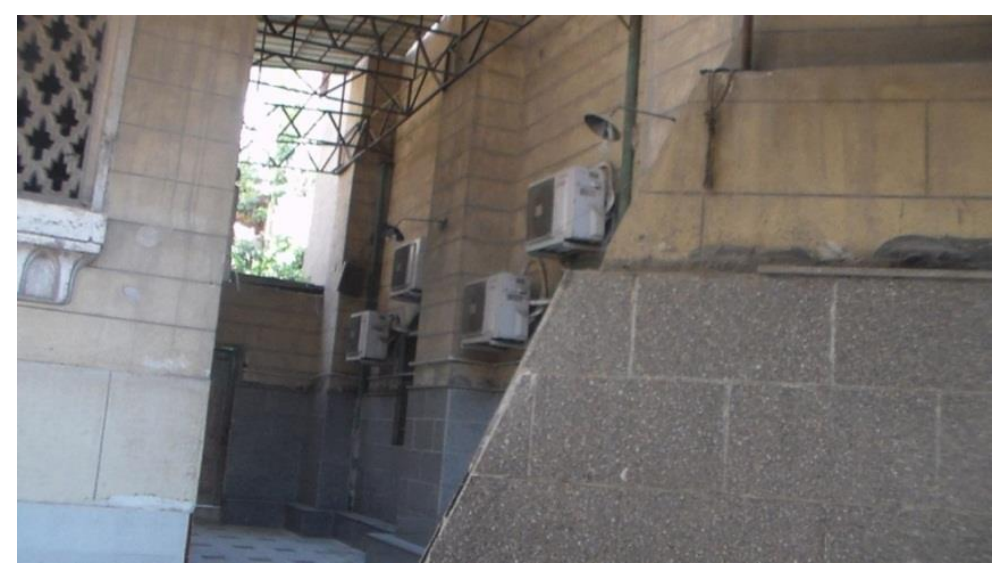

(لوحة اب) الدعامة البارزة والمتدرجة من أسفل وواجهة الجامع الثمالية الثرقية والزيادة الجانبية الثمالية الثرقية

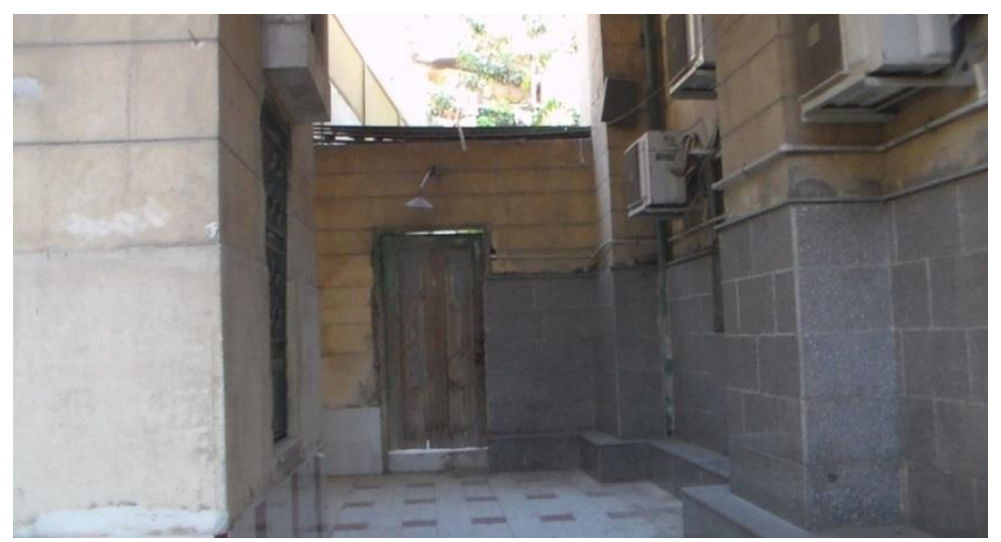

(لوحة r) الواجهة الثمالية الثرقية للجامع والزيادة الجانبية والجدار الصغير ذو الباب الذي يؤدي للزيادة الجنوبية الثرقية

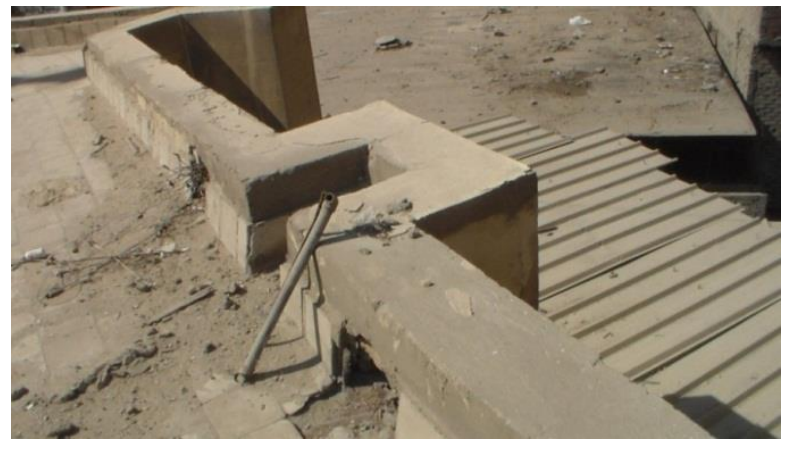

(لوحة ؟ س) الدعامات التي تدعم الواجهة

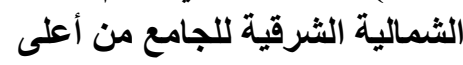

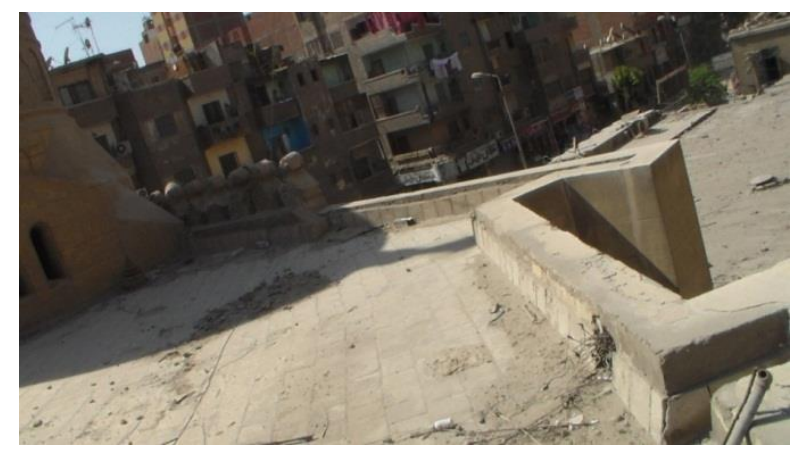

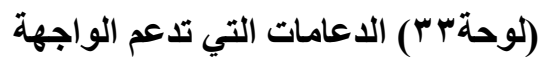

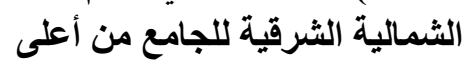



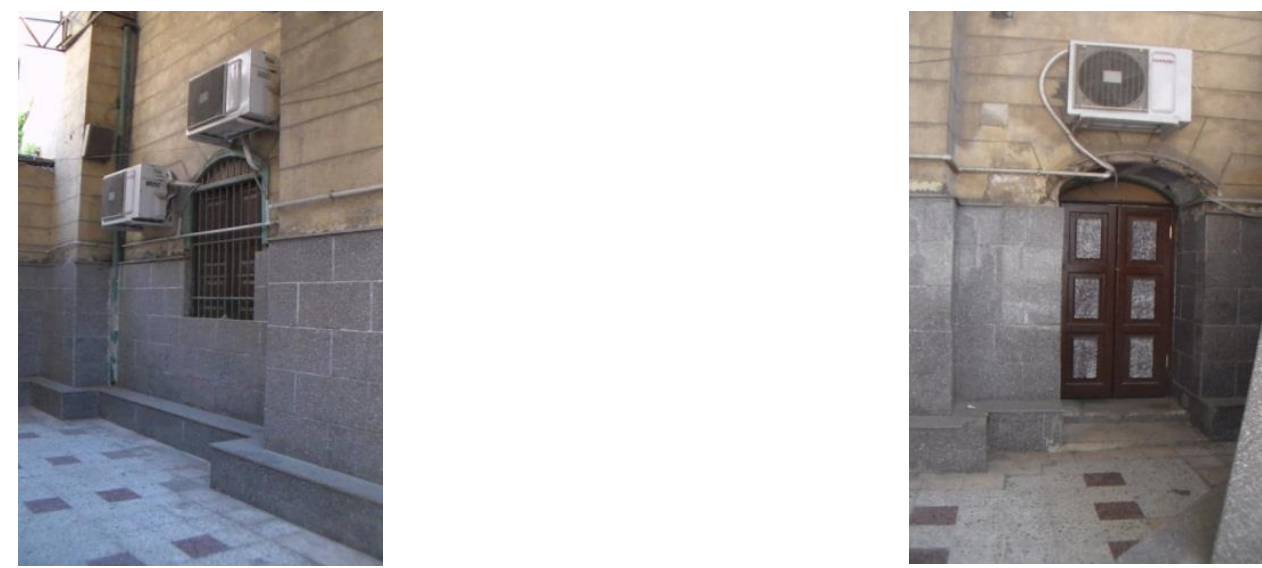

(لوحة آم) النافذة التي بالطرف الثمالي (لوحةه r) المدخل الذي بالطرف الثرقي

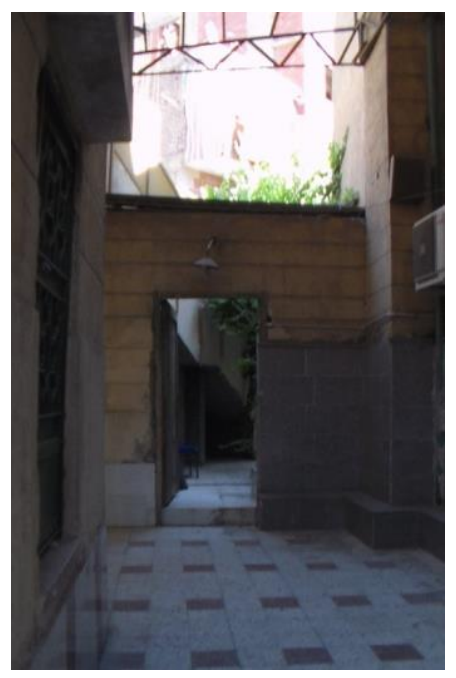

(لوحة الباب الذي يوجد بالزيادة الشمالية الشرقية ويؤدي إلى الحديقة التي توجد بالزيادة خلف المحراب

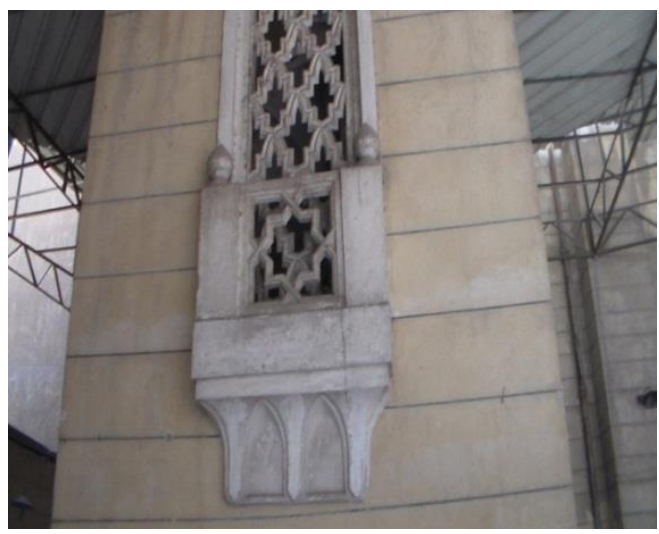

(لوحة/ץ) قاعدة المئنة الحديثة التي توجد في الزيادة الثمالية الثرقية بين جدار الجامع وبين دورات المياه 


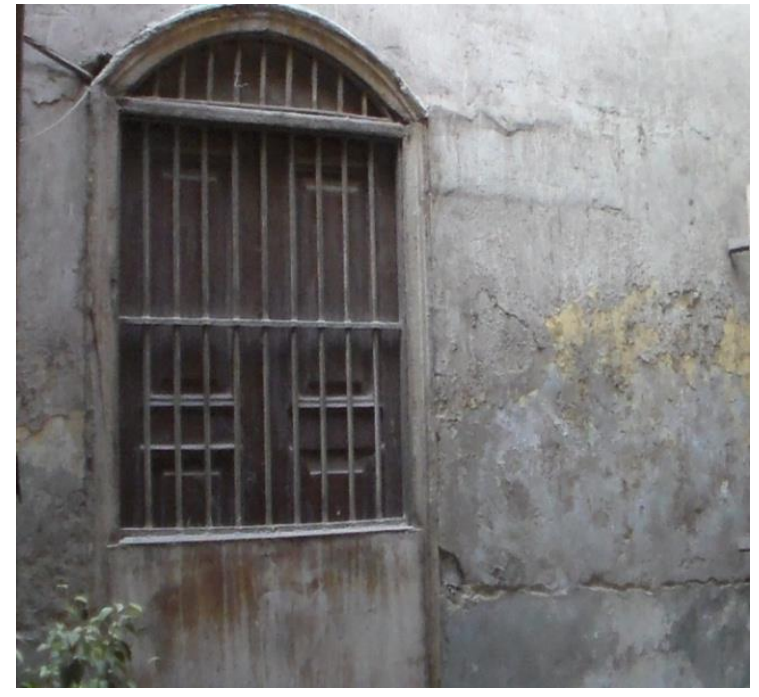

$$
\text { (لوحة ؛ ) النافذة التي بالطرف الجنوبي }
$$$$
\text { الواجهة الجنوبية الغربية النانية }
$$

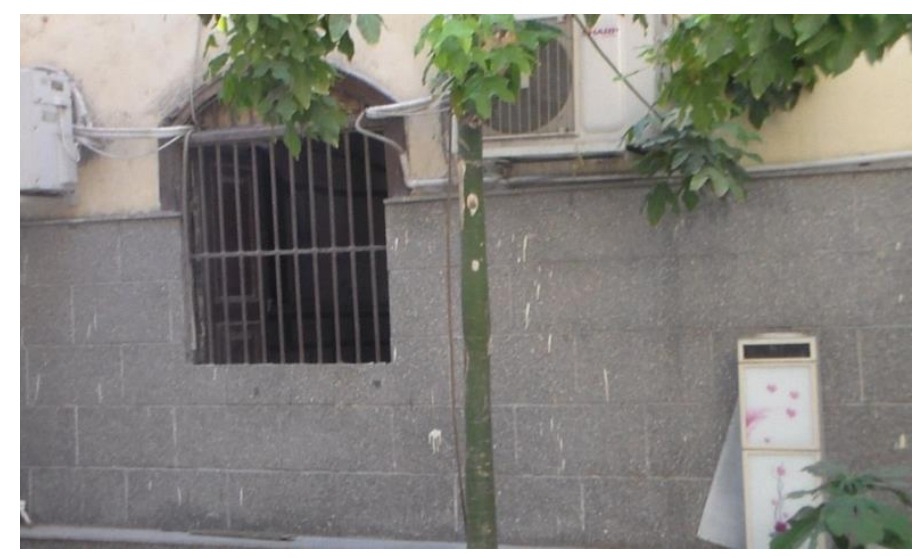

(لوحة ץ ؛) النافذة التي بالطرف الجنوبي من الواجهة الجنوبية الثرقية

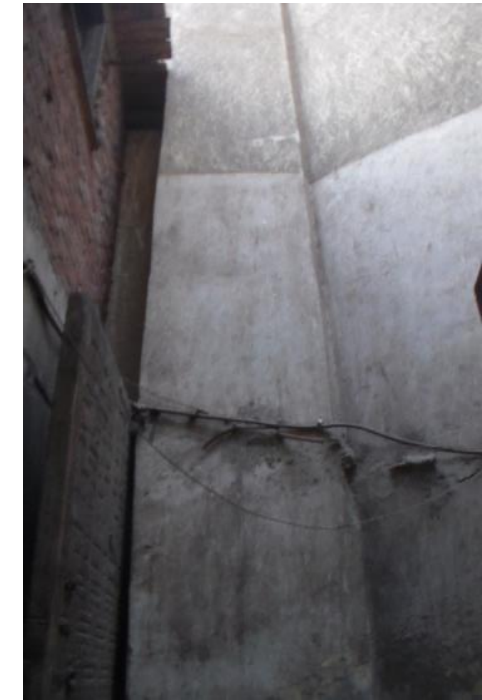

$$
\text { (لوحة (ب) الانكسار بالواجهة الجنوبية }
$$

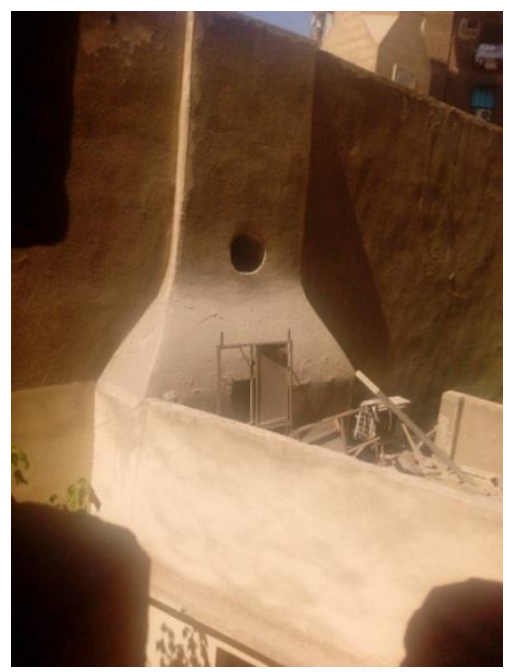

(لوحة ا §) واجهة جدار القبلة وبروز المحراب

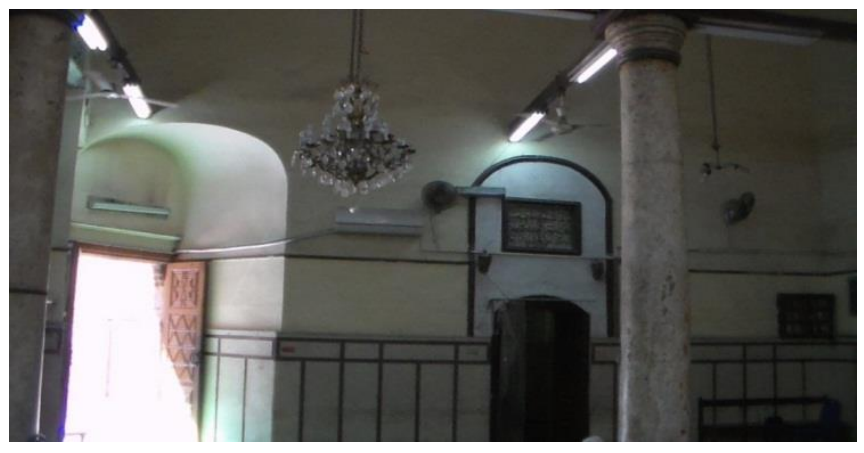

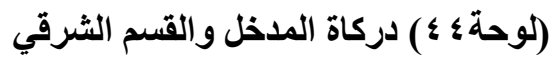

من الجانب الثمالي الغربي للجامع من الألخل

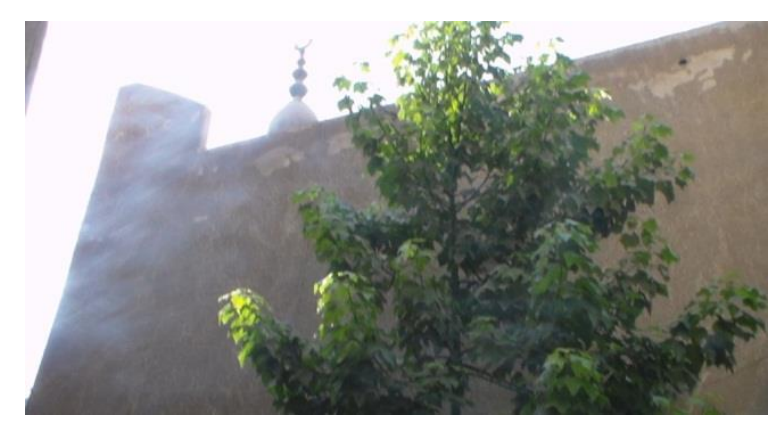

(لوحة ب \&) الجانب الجنوبي من الواجهة الجنوبية

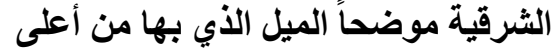




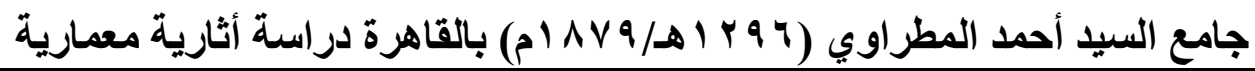

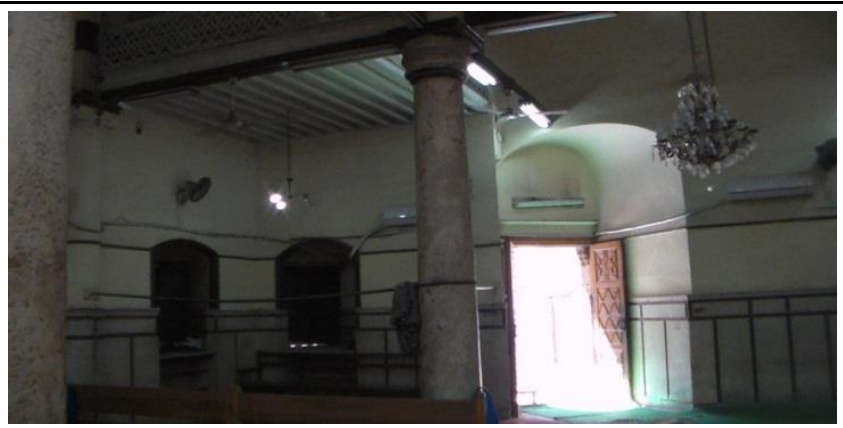

(لوحةه ؛ ) دركاة المدخل والجانب الثمالي الغربي للجامع من الداخل

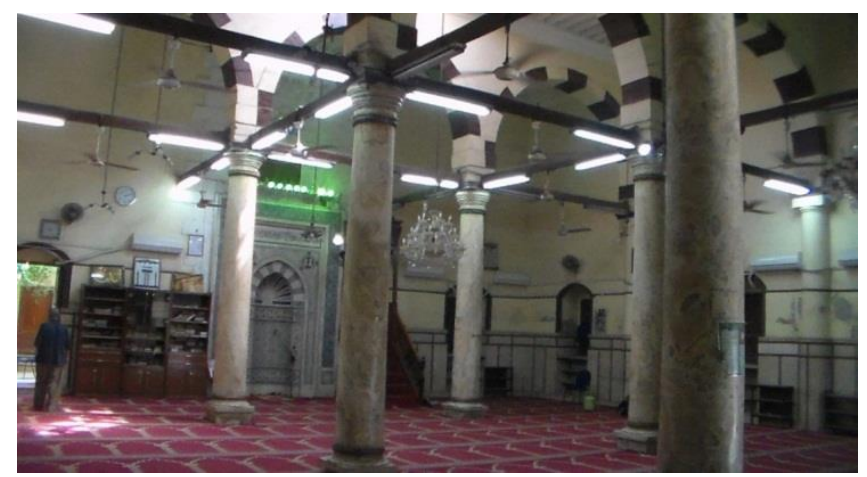

(لوحة" ؛ ) بائكات الجامع والجانبين الجنوبي الشرقي والجنوبي الغربي من الجامع

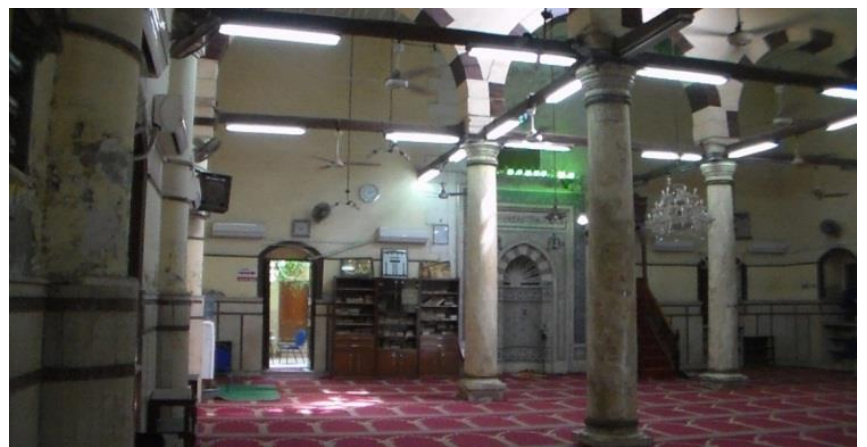

(لوحة V \& ) بائكات الجامع والجانبين الجنوبي الثرقي والجنوبي الغربي من الجامع والسقف الخثبي

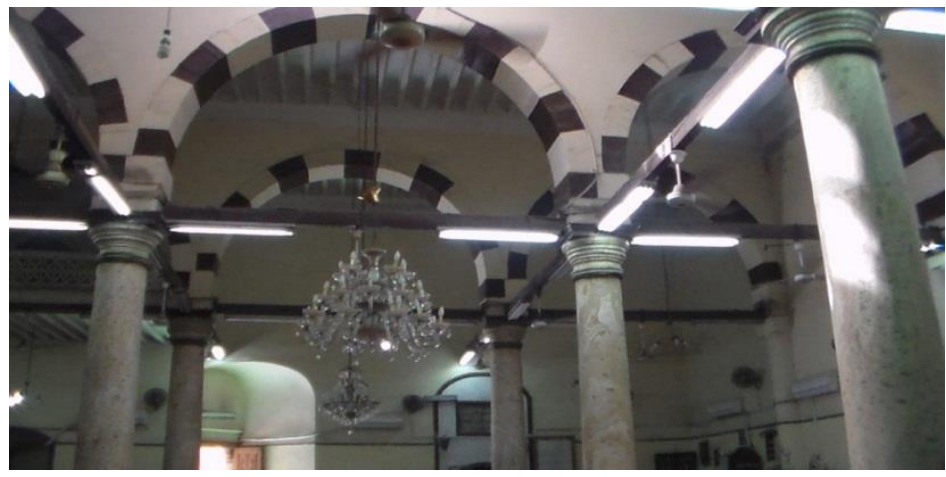

(لوحةد ؛ ) بائكات الجامع والجانبين الثمالي الشرقي والثمالي الغربي من الجامع 
مجلة كلية الأثار - العدد الحادى والعثرون 1 1 ـ r

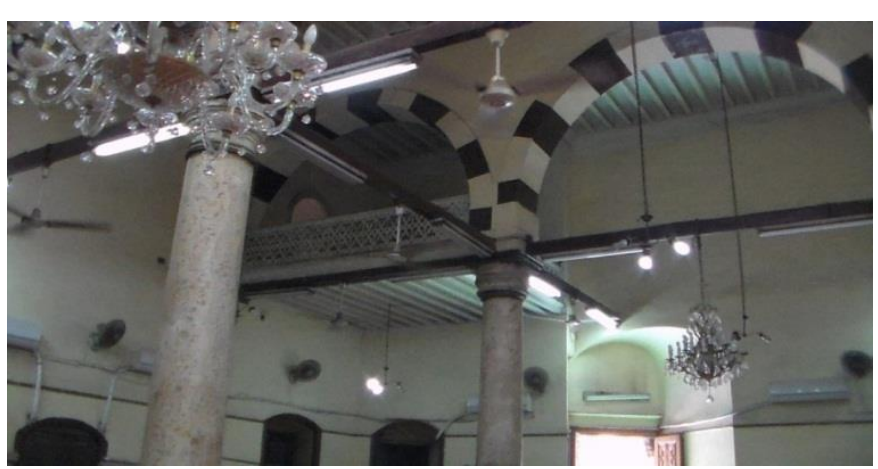

(لوحةq ؛ ) الجانبان الثمالي الغربي والجنوبي الغربي من الجامع

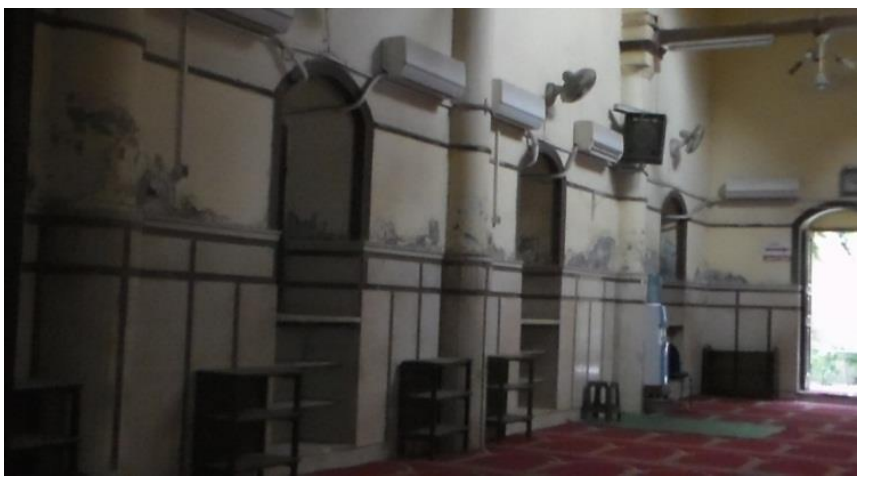

(لوحة ـ 0) الجاتب الثمالي الثرقي من الجامع

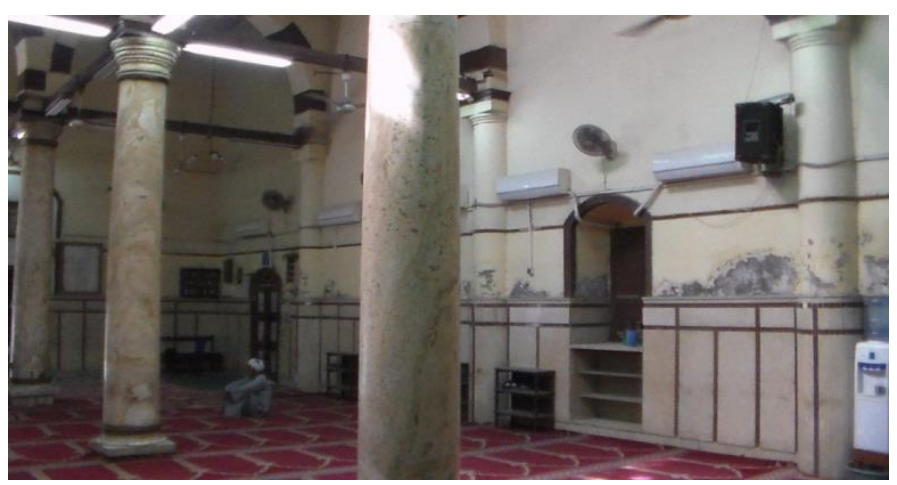

(لوحة اه) الجانبان الثمالي الثرقي والثمالي الغربي من الجامع

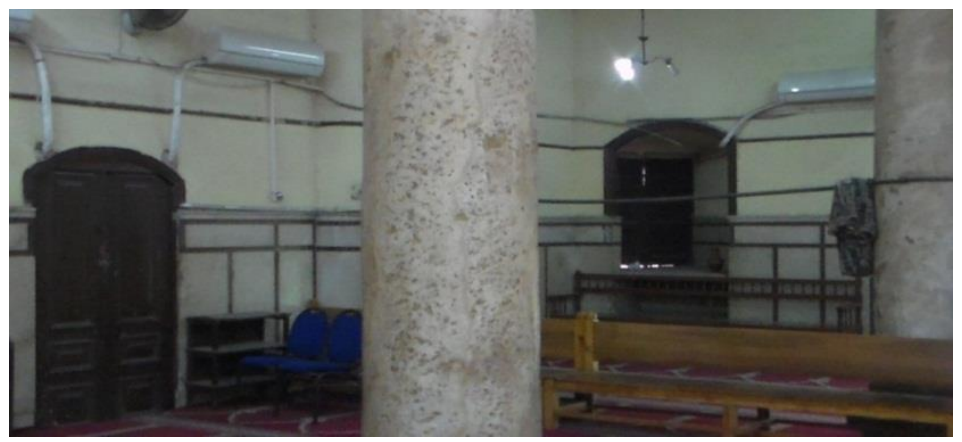

(لوحة ه ) الجانبان الثمالي الغربي و الجنوبي الغربي من الجامع 


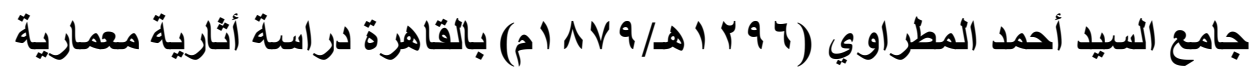
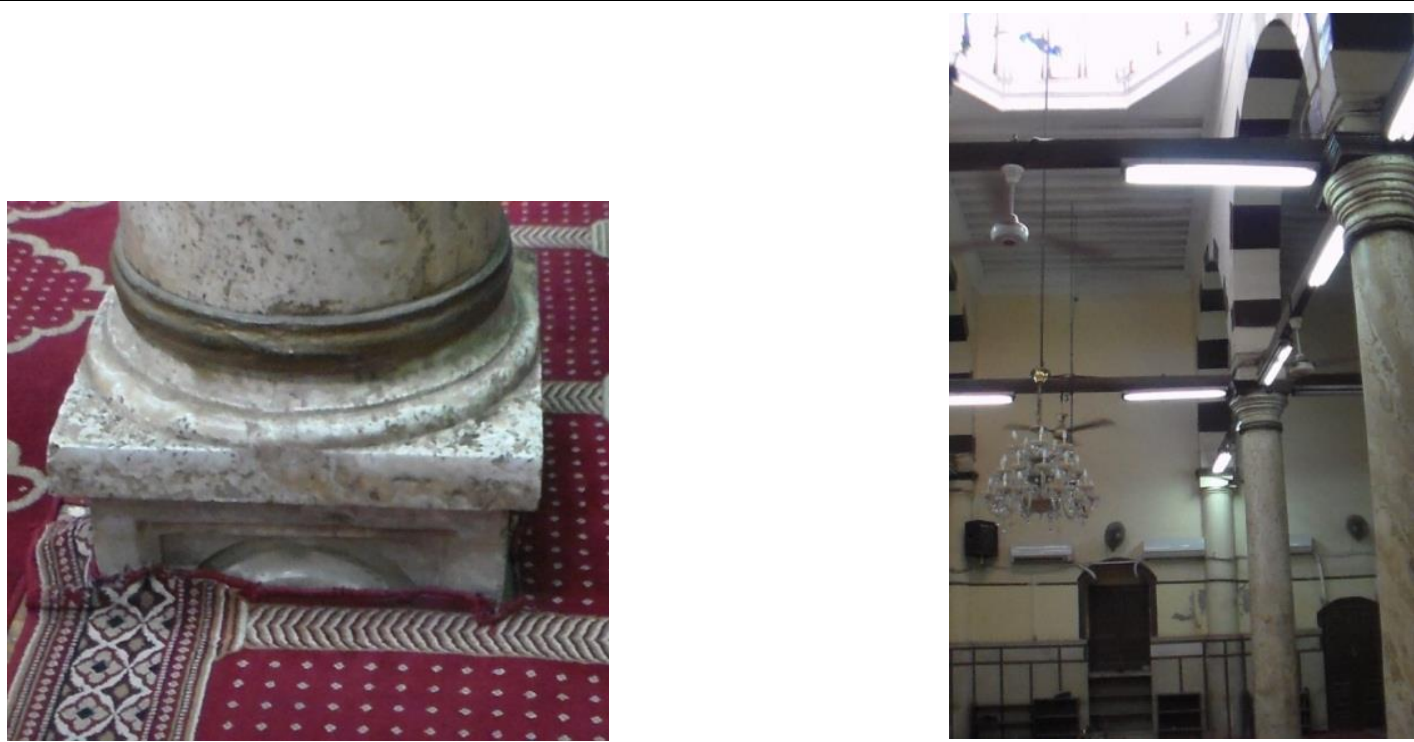

(لوحة ؛ 0) قاعدة العمود الرخامي

(لوحةrه) الجاتب الجنوبي الغربي من الجامع

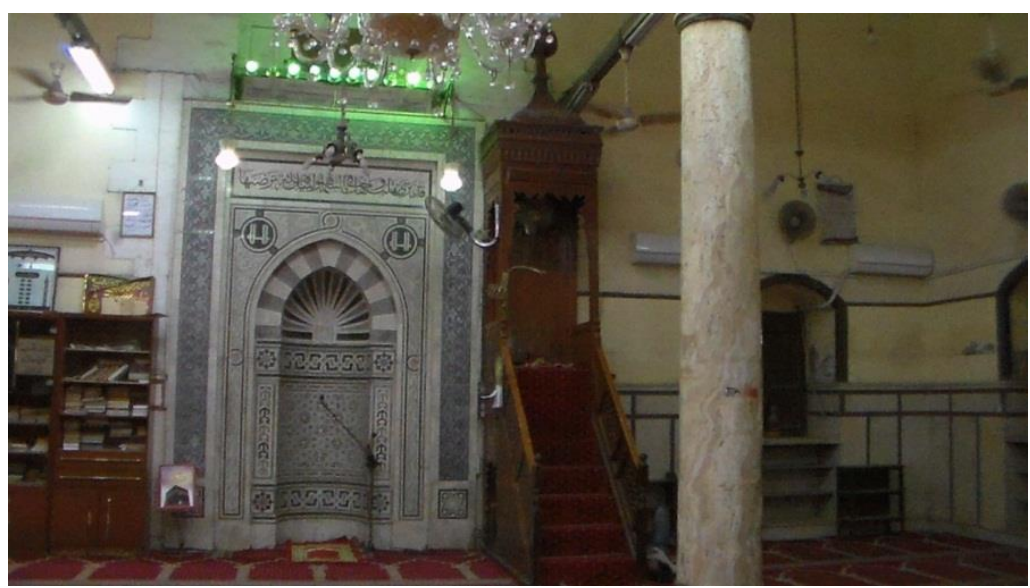

(لوحةه ه ) جدار القبلة

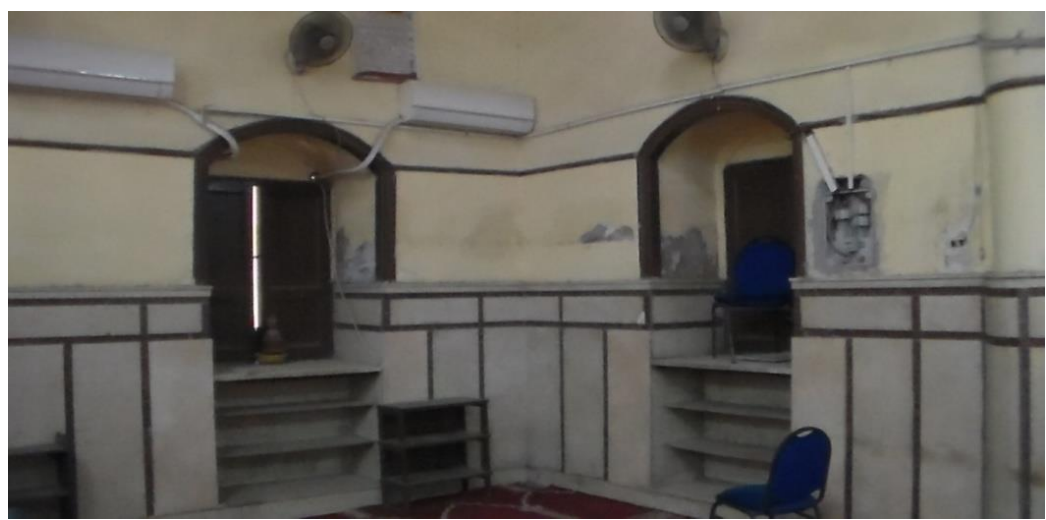

(لوحة ه ه) الركن الجنوبي من الجامع من الاخلل 

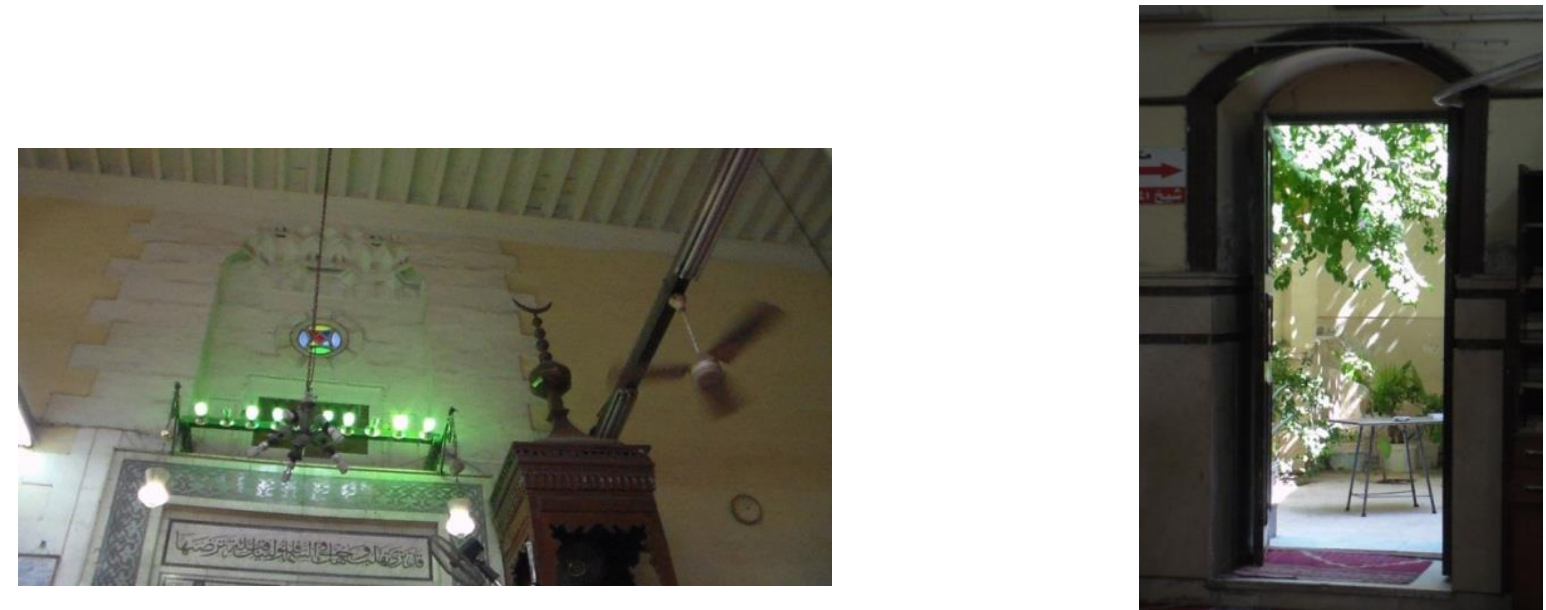

(لوحة Vه) المدخل على يسار المحراب بجدار القبلة (لوحةمه) الاخلة التي كاتت تعلو المحراب الأصلي والنص التأسيسي

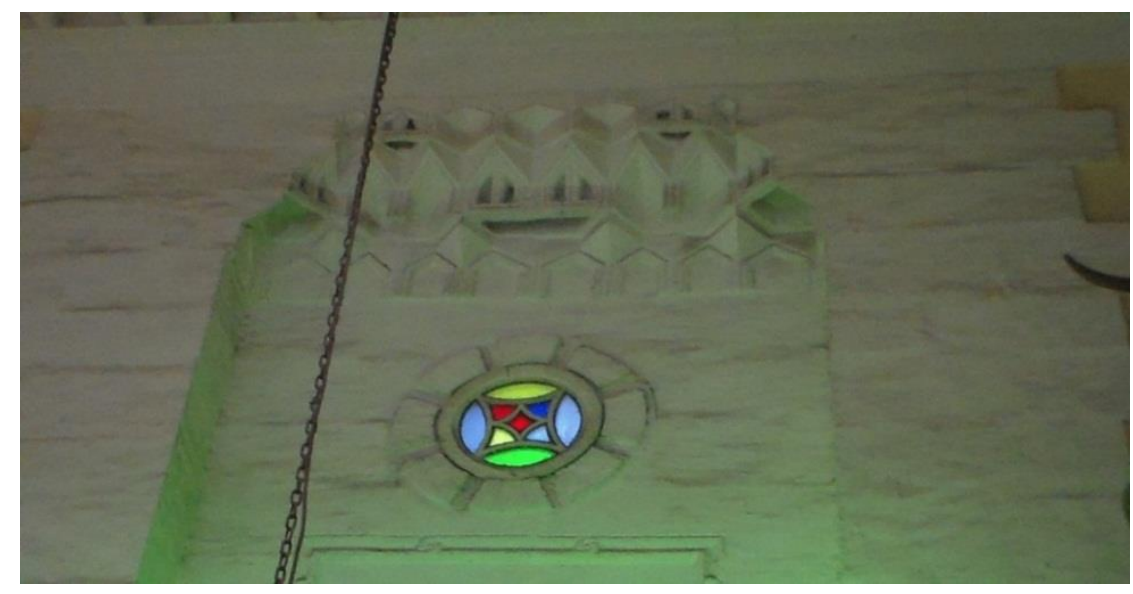

$$
\text { (لوحةهه) الاخلة التي تعلو المحراب الأصلي }
$$
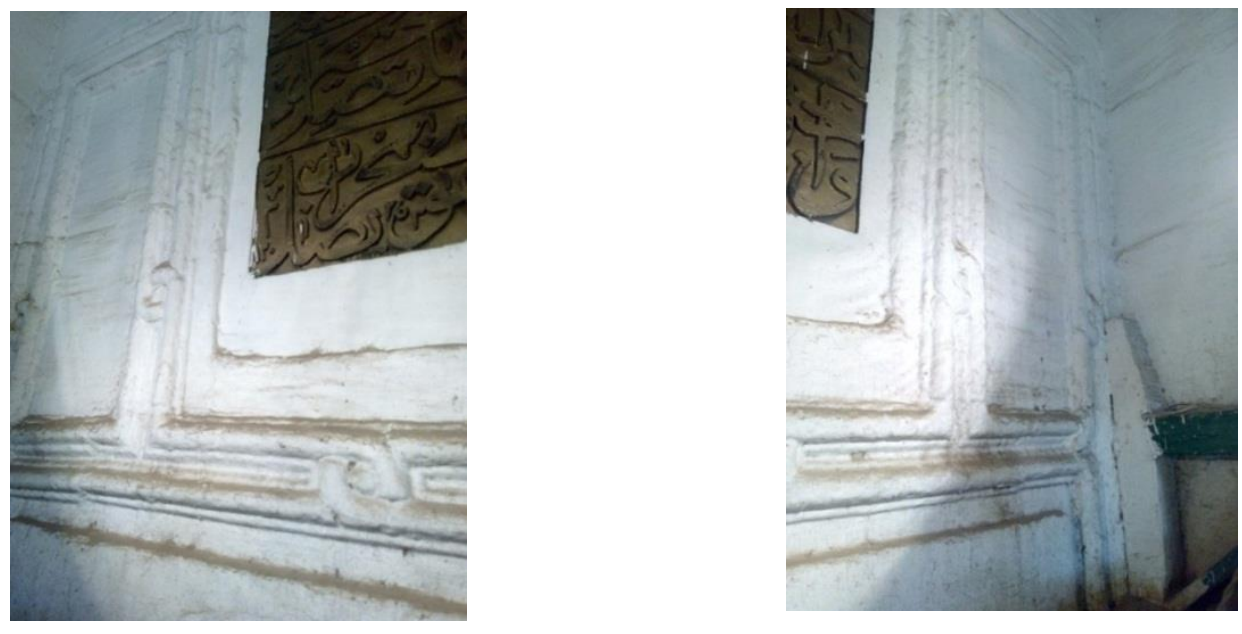

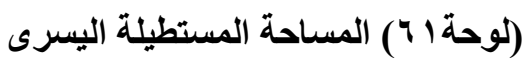

(لوحة ، ج) المساحة المستطيلة اليمنى المحدة بالجفت اللاعب ذي الميمات بالاخلة التي تعلو المحراب الأصلي 


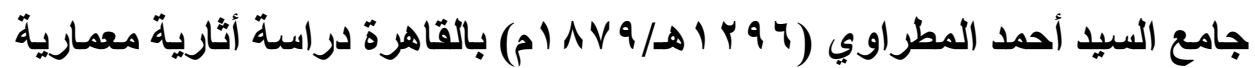

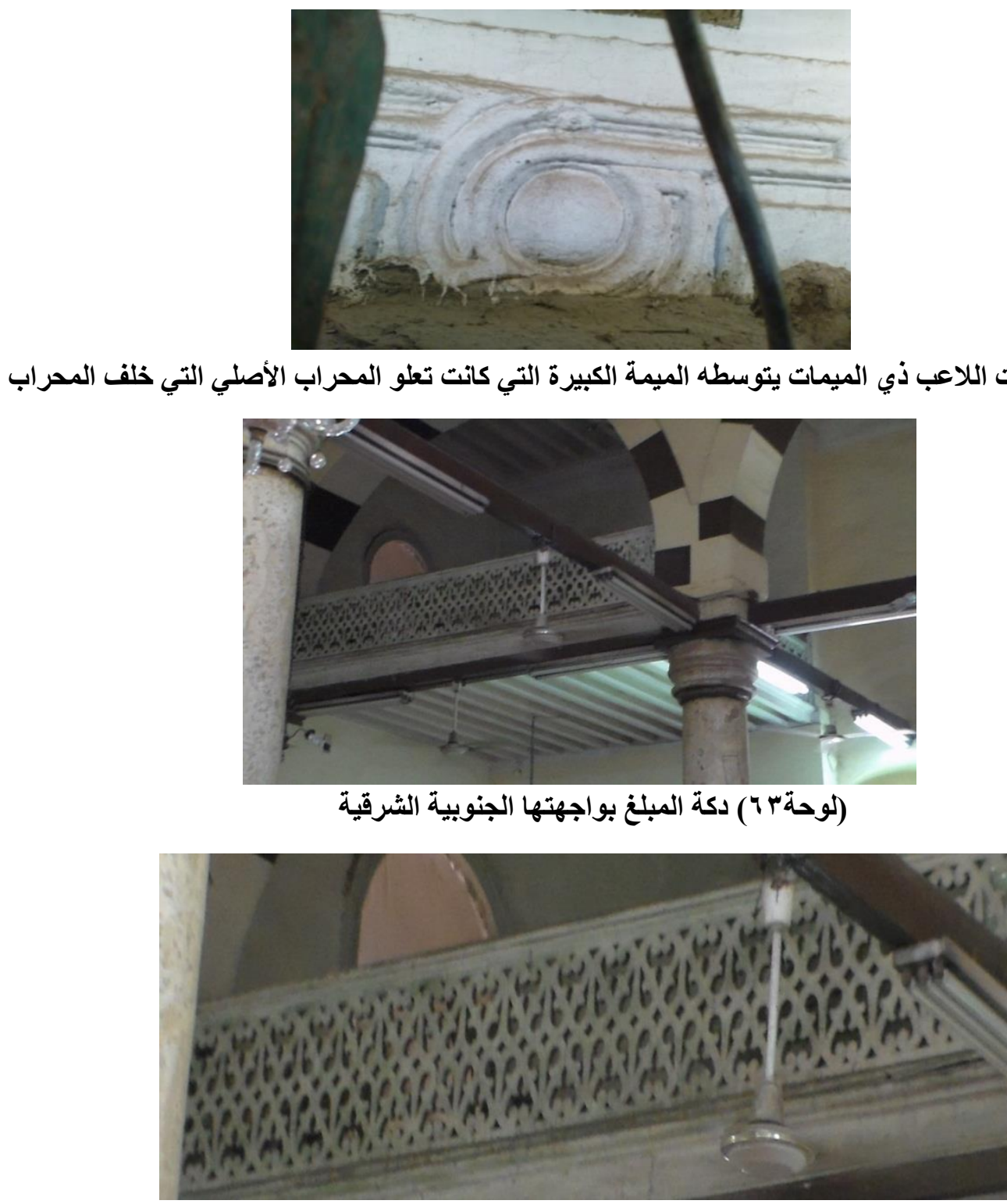

(لوحة ؛ ج) دكة المبلغ بواجهتها الجنوبية الثرقية

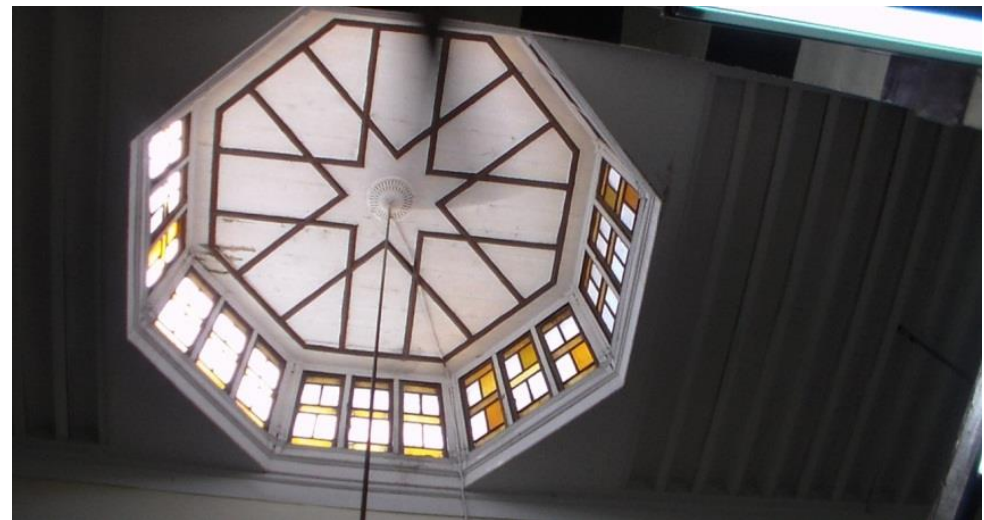

(لوحةه 7) الثخثيخة التي تتوسط البلاطة الثانية من جدار القبلة من الاخل 


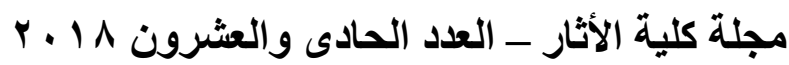
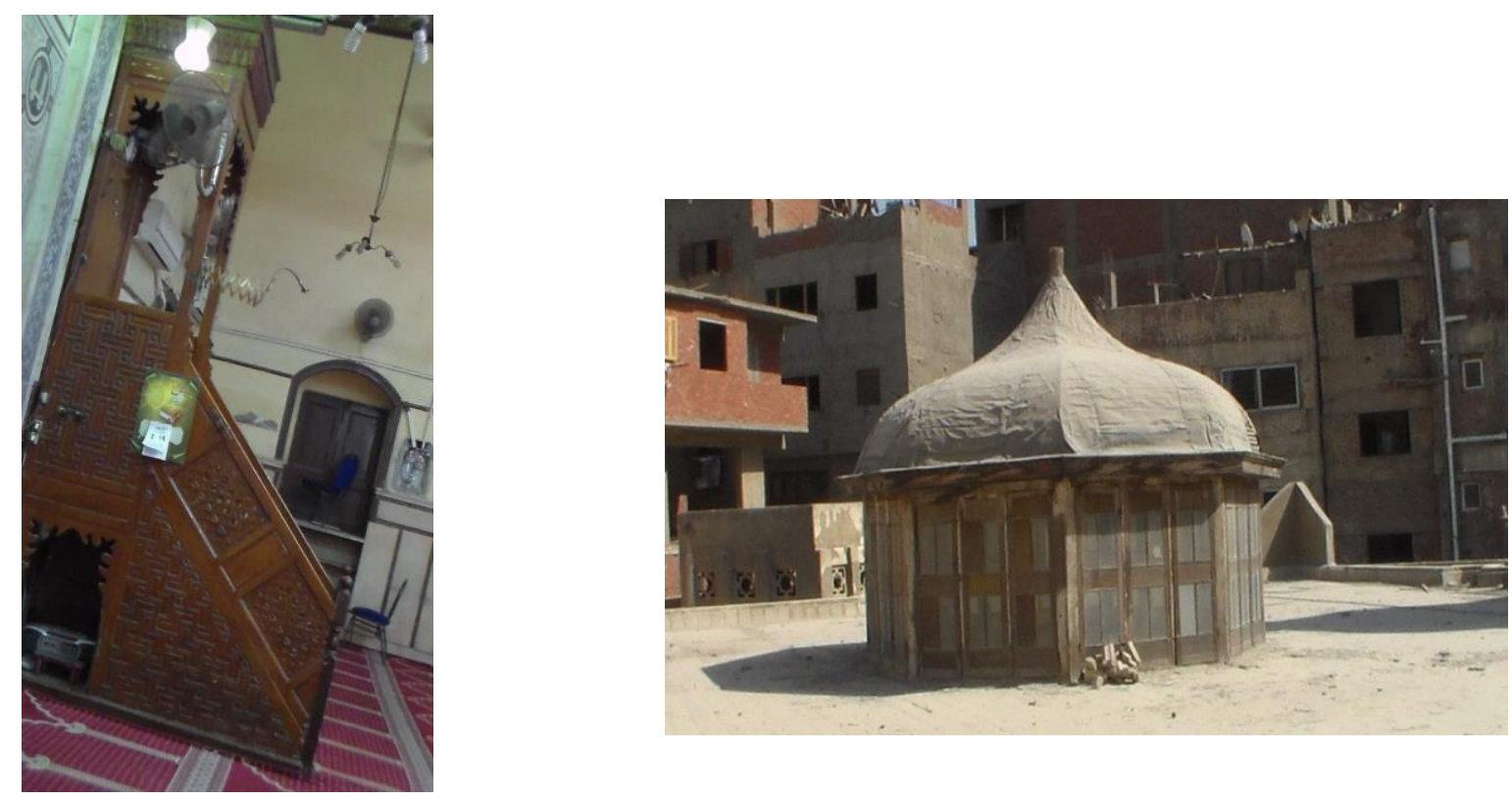

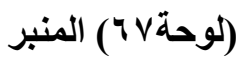

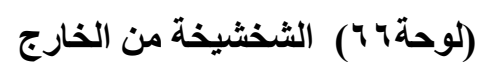

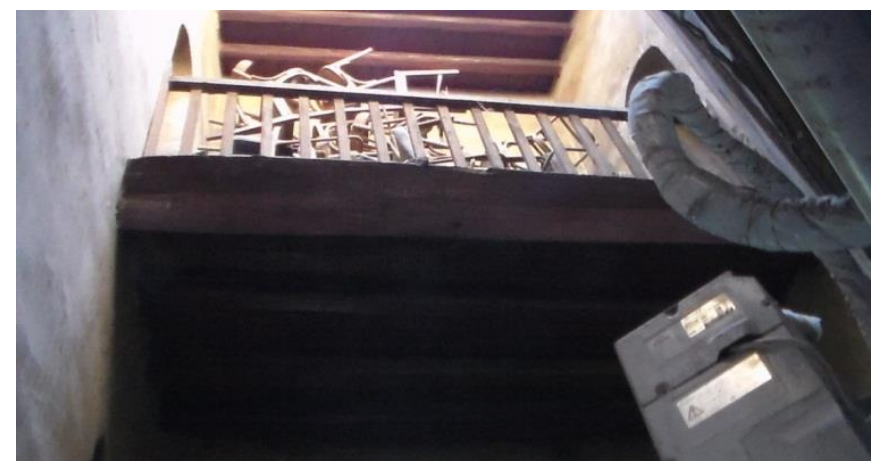

(لوحةم^ج) الشرفة المؤدية لدكة المبلغ في الساحة المحصورة بين الجدار الجنوبي الغربي للجامع والمئنة

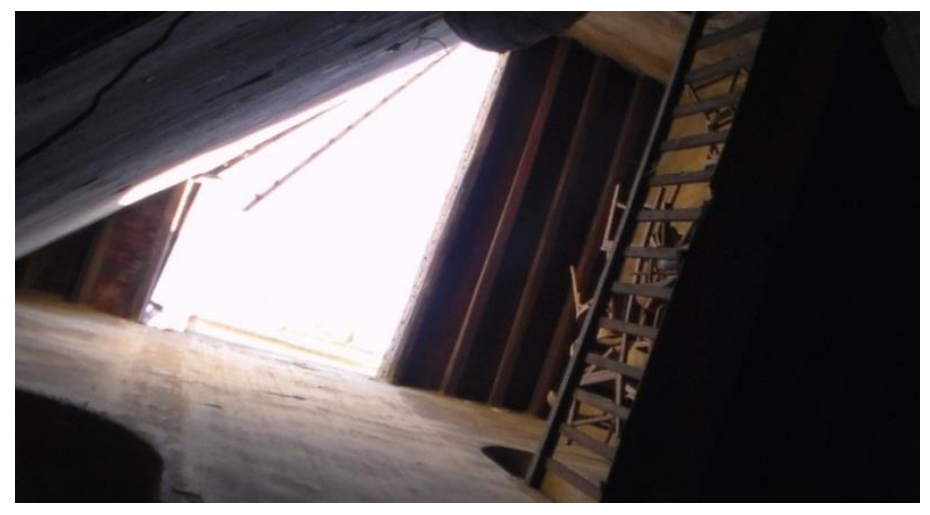

(لوحةه 7) الثرفة المؤدية لدكة المبلغ و الساحة المحصورة بين الجدار الجنوبي الغربي للجامع والمئنة 


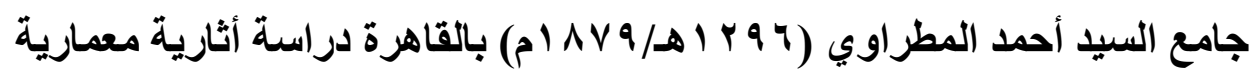

(لوحة ا V سطح الجامع والثر افات وعليه المئذنة والسياج المحدد للساحة المحصورة بين الجدار الجنوبي الغربي للجامع

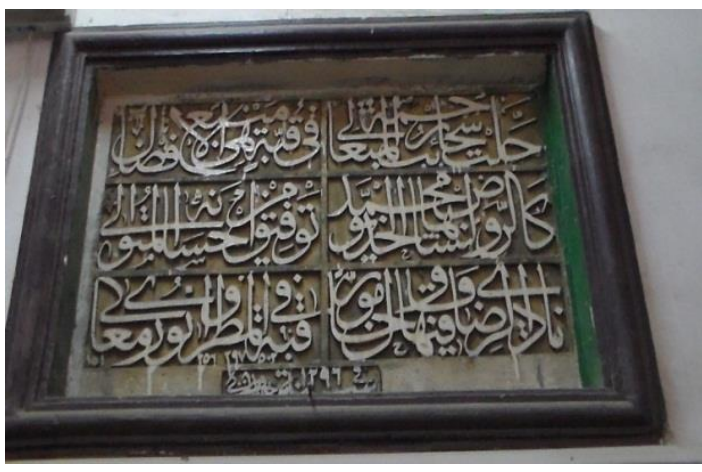

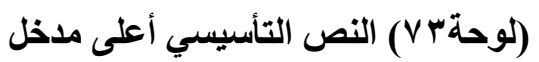

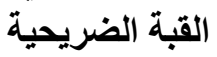

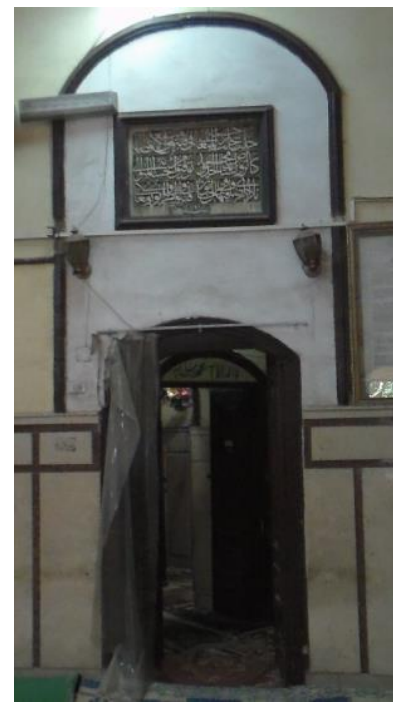

(لوحة VY) الباب المؤدي للقبة الضريحية والساحة التي تثقدمها ل 


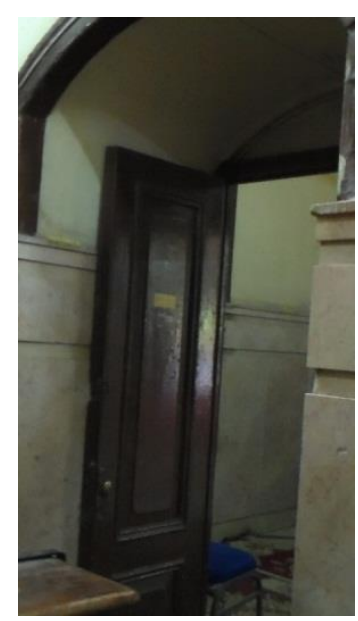

(لوحة Vداخل القبة الضريحية من داخلها بالساحة غير المنتظمة

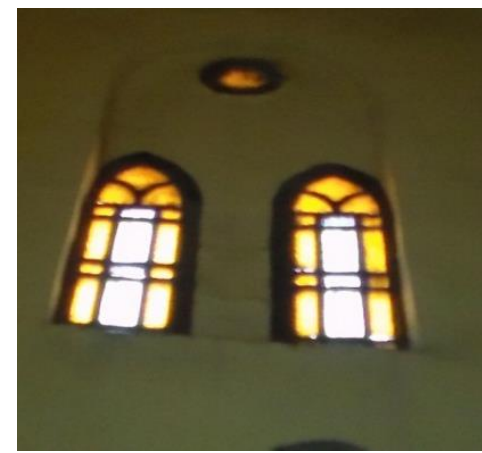

(لوحة VV) النافذة العلوية بالساحة غير المنتظمة التي تثقام القبة الضريحية

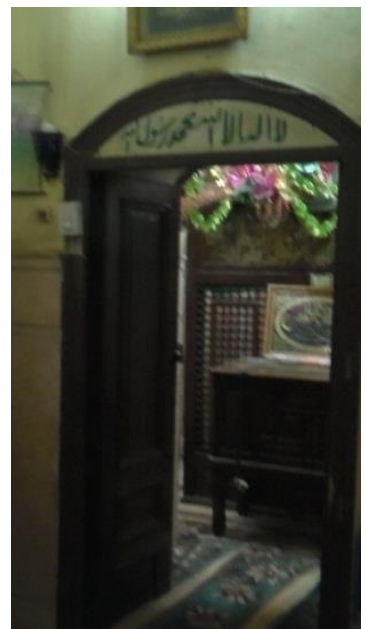

(لوحة ع المدخل المؤدي القبة الضريحية

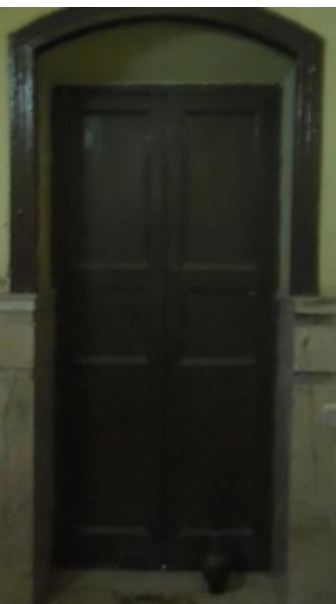

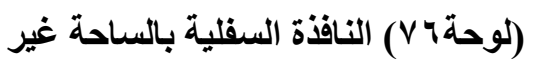
المنتظمة التي تثقام القبة الضريحية

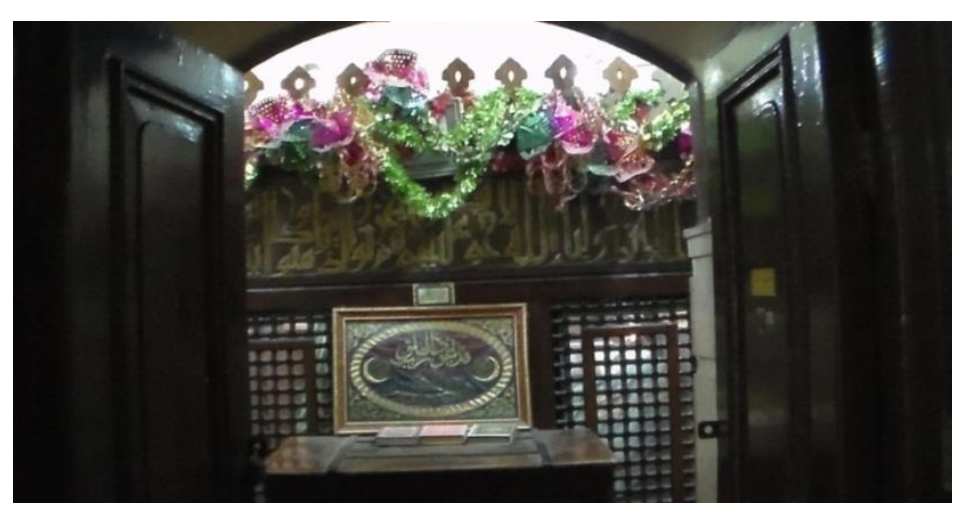

(لوحة VN) المدخل القبة الضريحية يفتح على المقصورة مباشرة 


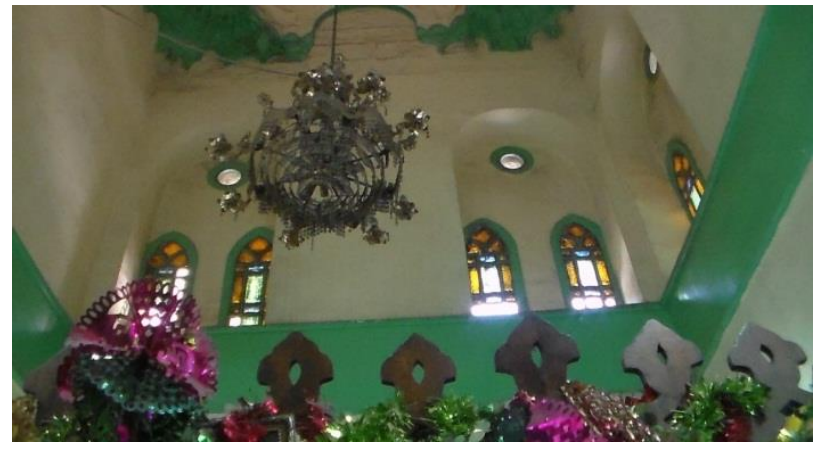

(لوحة ، (1) القتليات بالقبة الضريحية ومربع القبة

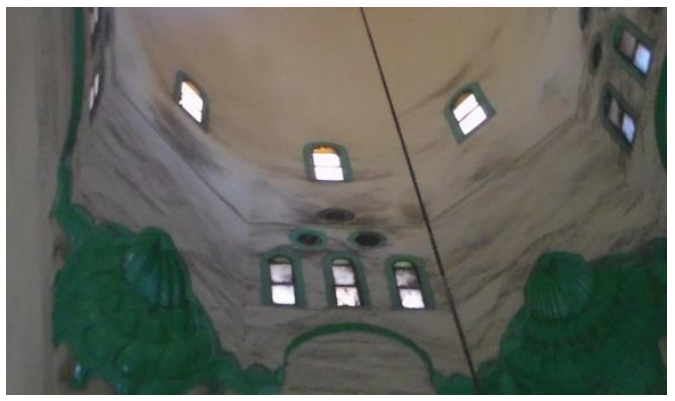

(لوحةrA ) مناطق الانتقال والرقبة

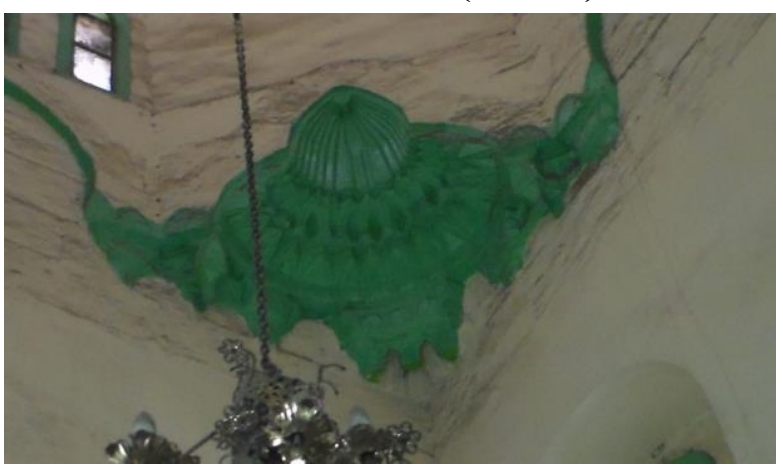

(لوحة ^ه) الحنية الركنية بالجانبين الثمالي و الجنوبي

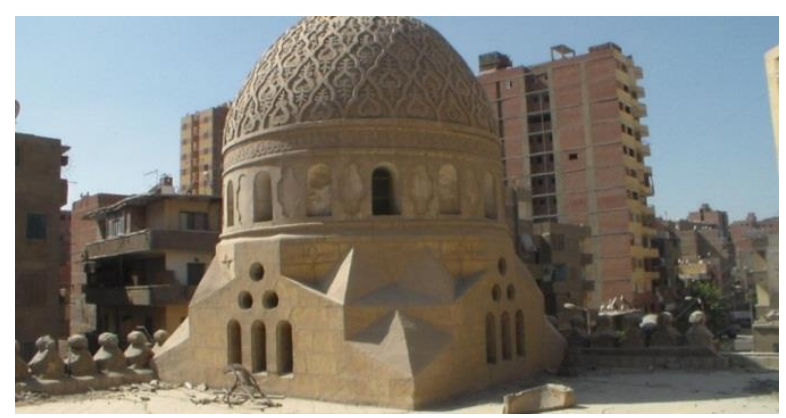

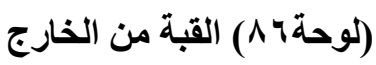

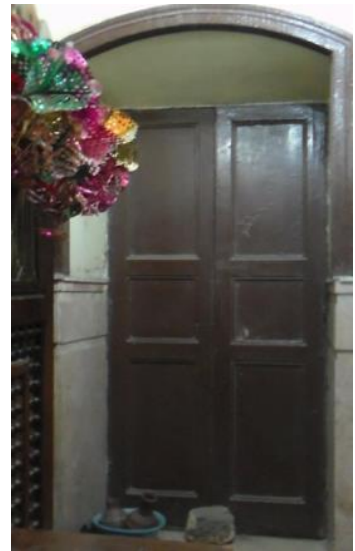

(لوحة V V) النافقة السفلية بالقبة الضريحية

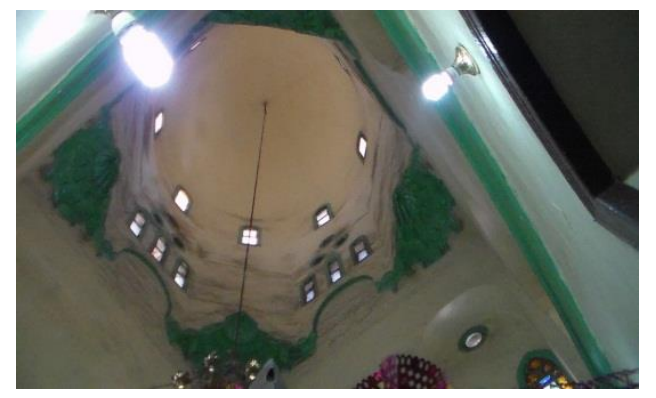

(لوحة ا م) القبة ومربعها من الاخل

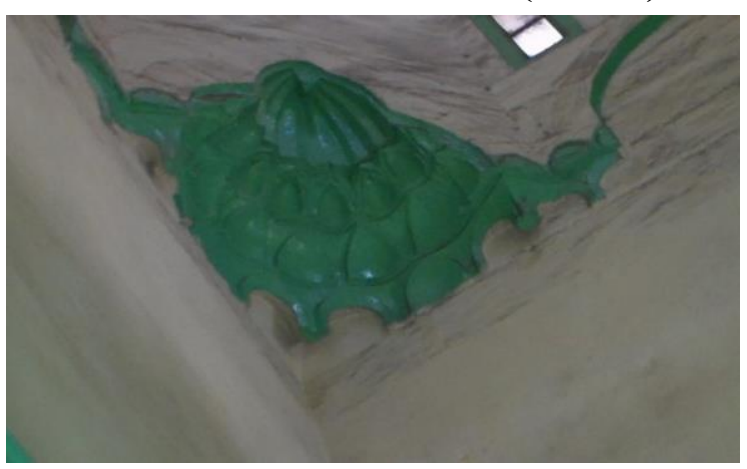

(لوحةثم) الحنية الركنية بالجانبين الثرقي والغربي

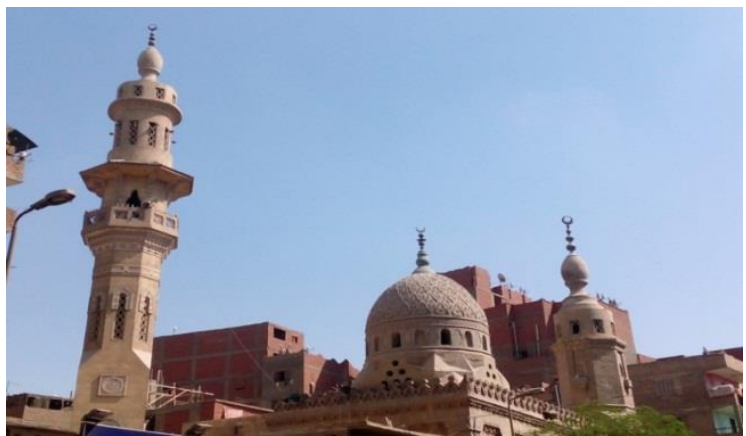

(لوحةهم) سقف الجامع وعليه القبة و المئنتين 
مجلة كلية الأثار - العدد الحادى والعثرون 1 1 ـ r
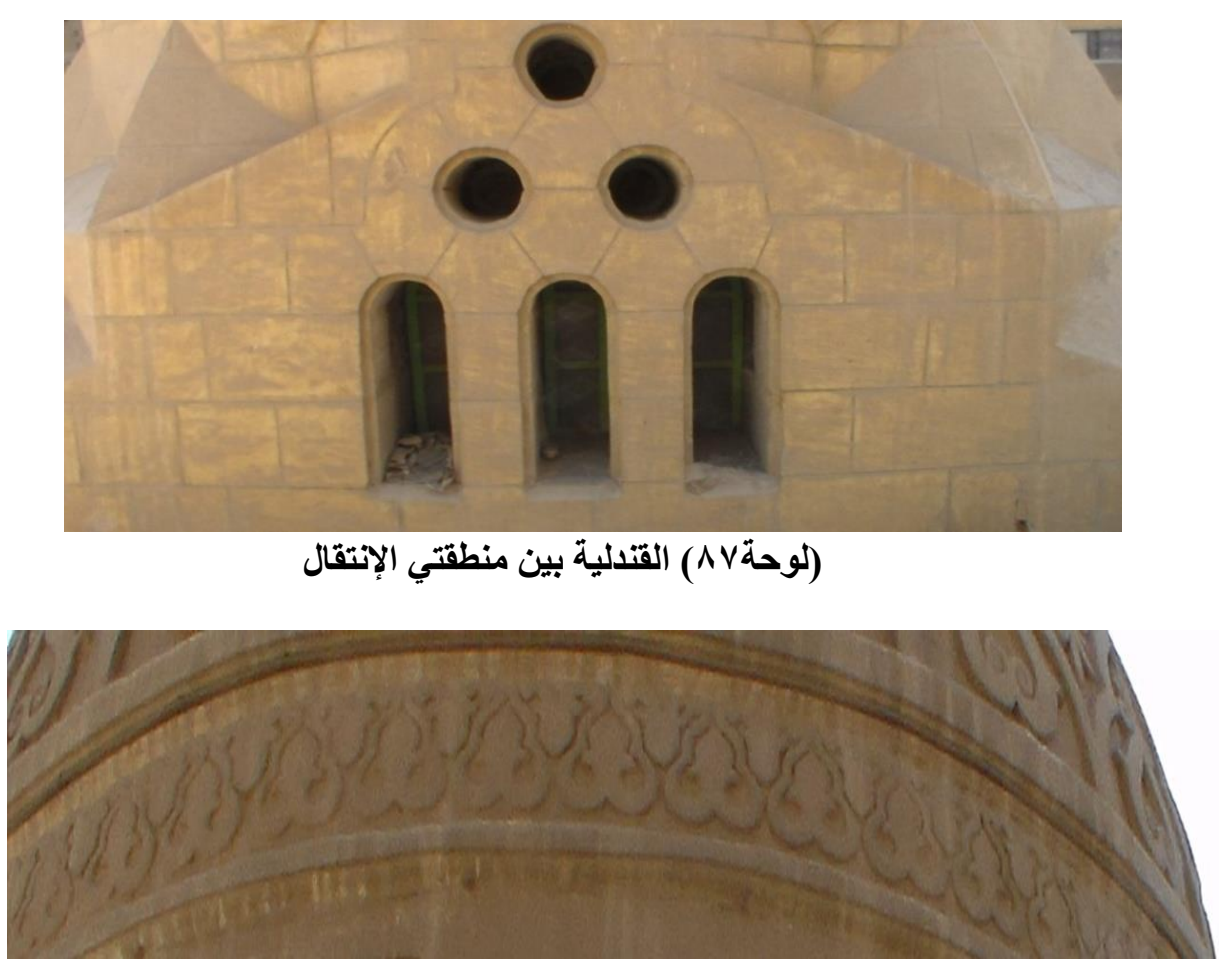

(لوحةه/م) منطقة الانتقال ورقبة القبة من الخارج
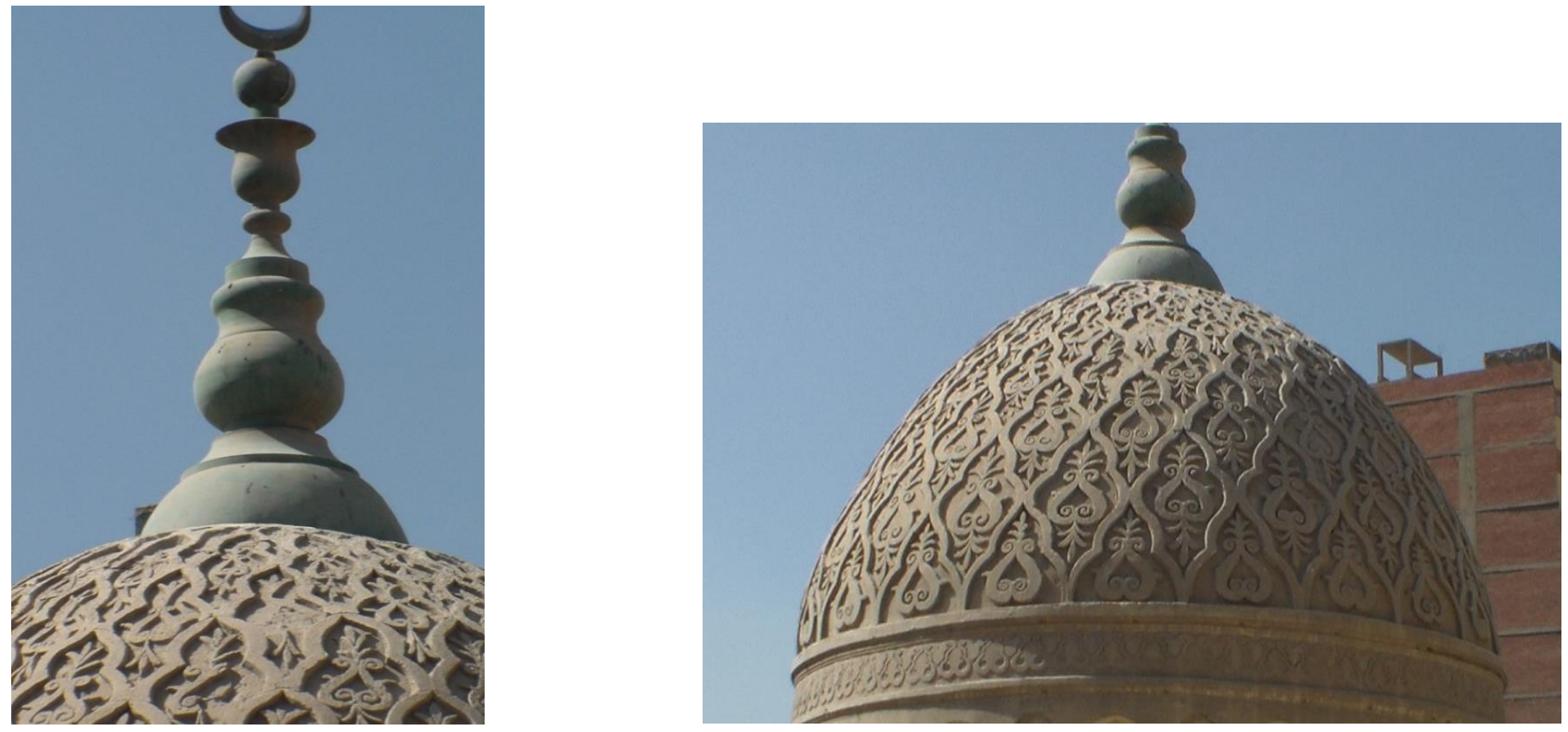

(لوحة ، 9) خوذة القبة من أعلى والقائم ذو الهلال الذي يتوجها (لوحةه م) خوذة القبة من الخارج 


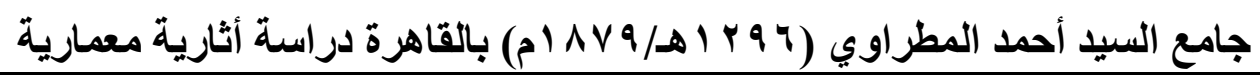
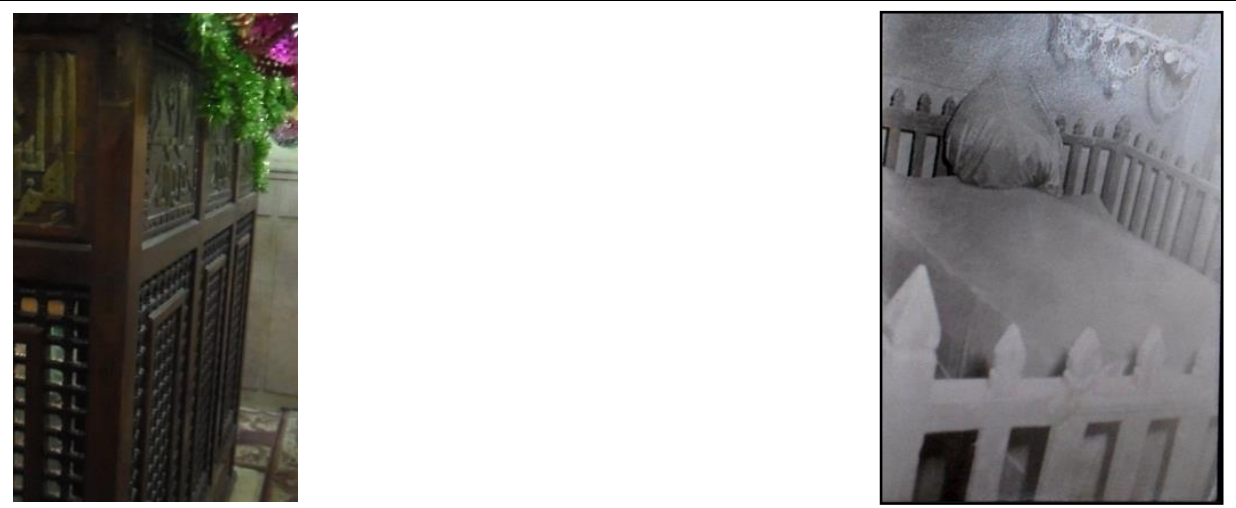

(لوحة r 9 ) جانب من المقصورة الحديثة

كاتت تحيط بالقبر الثريف
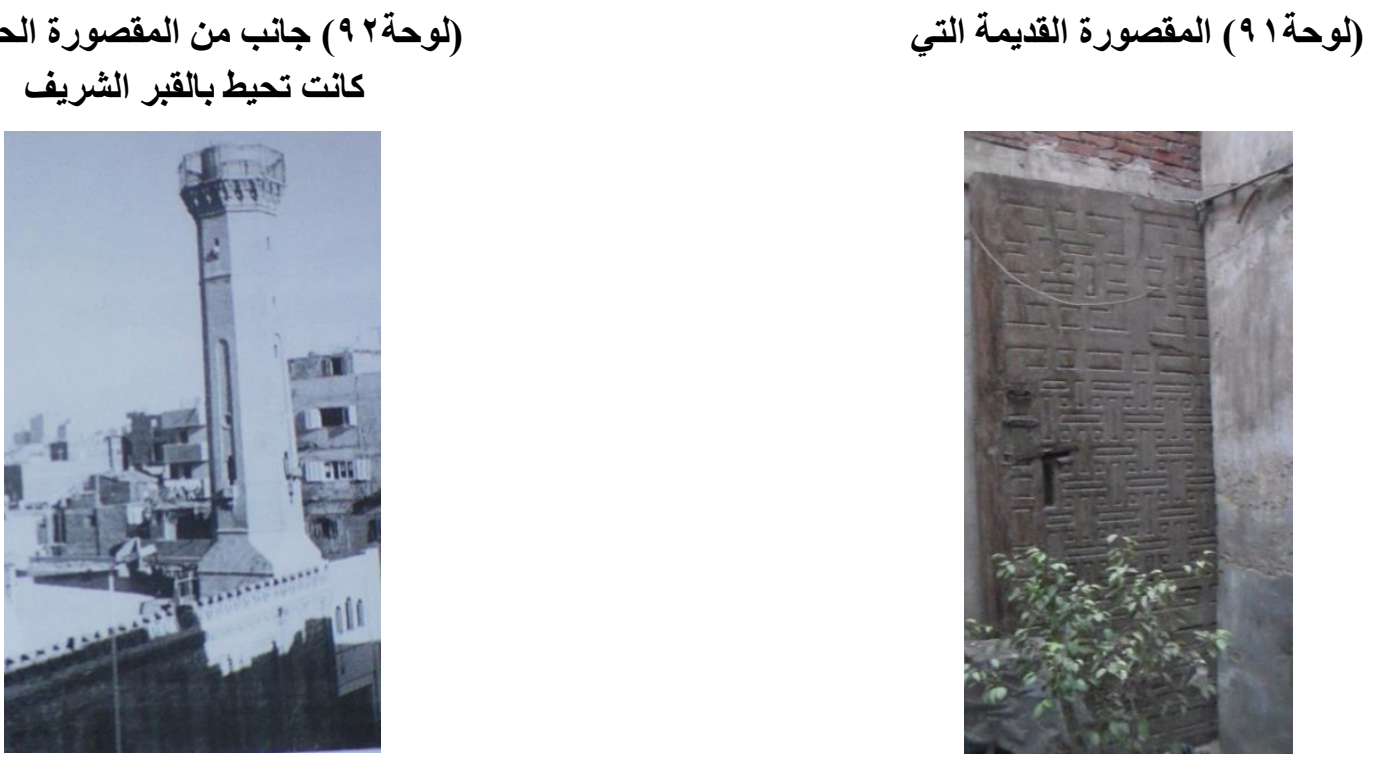

(لوحة؛ 9 ) المئذنة الأصلية للجامع

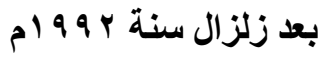

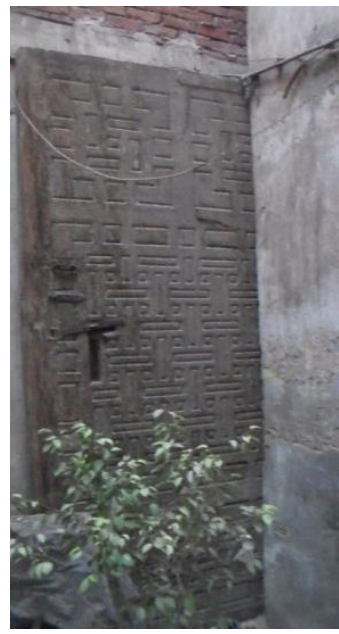

$$
\text { (لوحة 9 9) الباب الأصلي للجامع }
$$
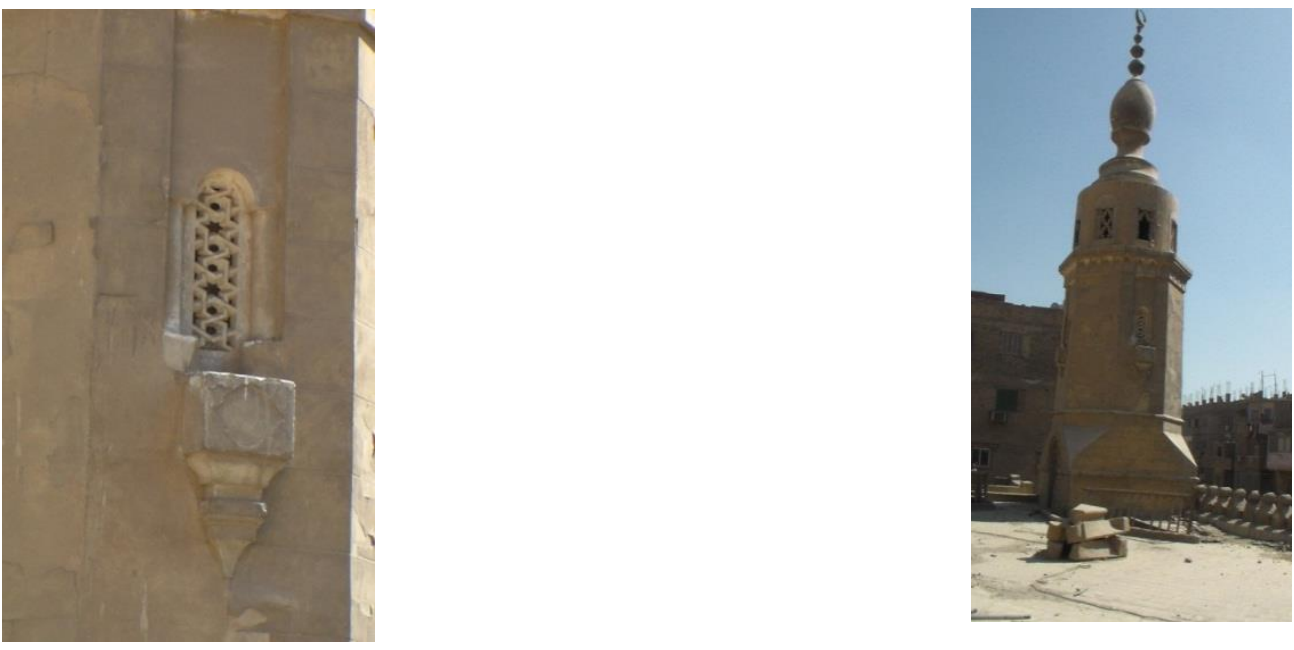

(لوحةه 9) تفصيل للناقذة والثرفة التي تثقدمها في المئننة

(لوحةه 9 ) المئذنة الأصلية بعد ترميمها 


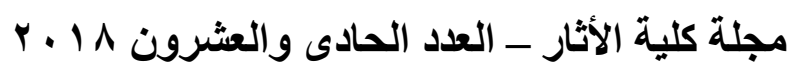

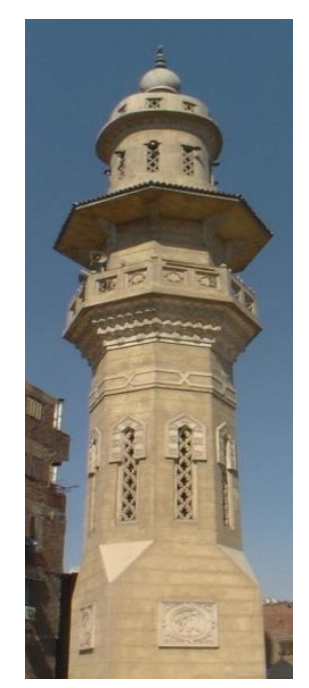

(لوحة/9) المئنة الحديثة

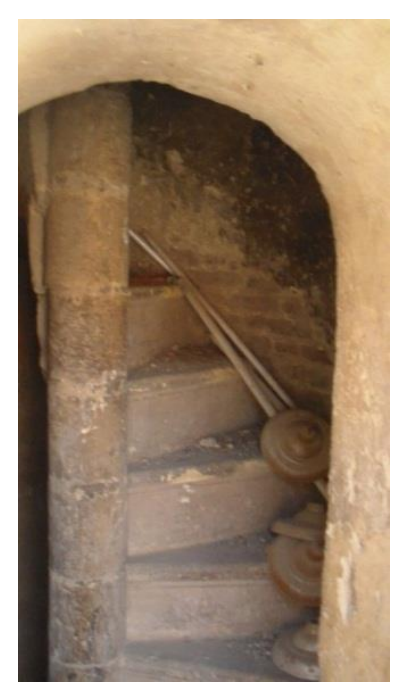

(لوحة 9 ( سلم المئنة
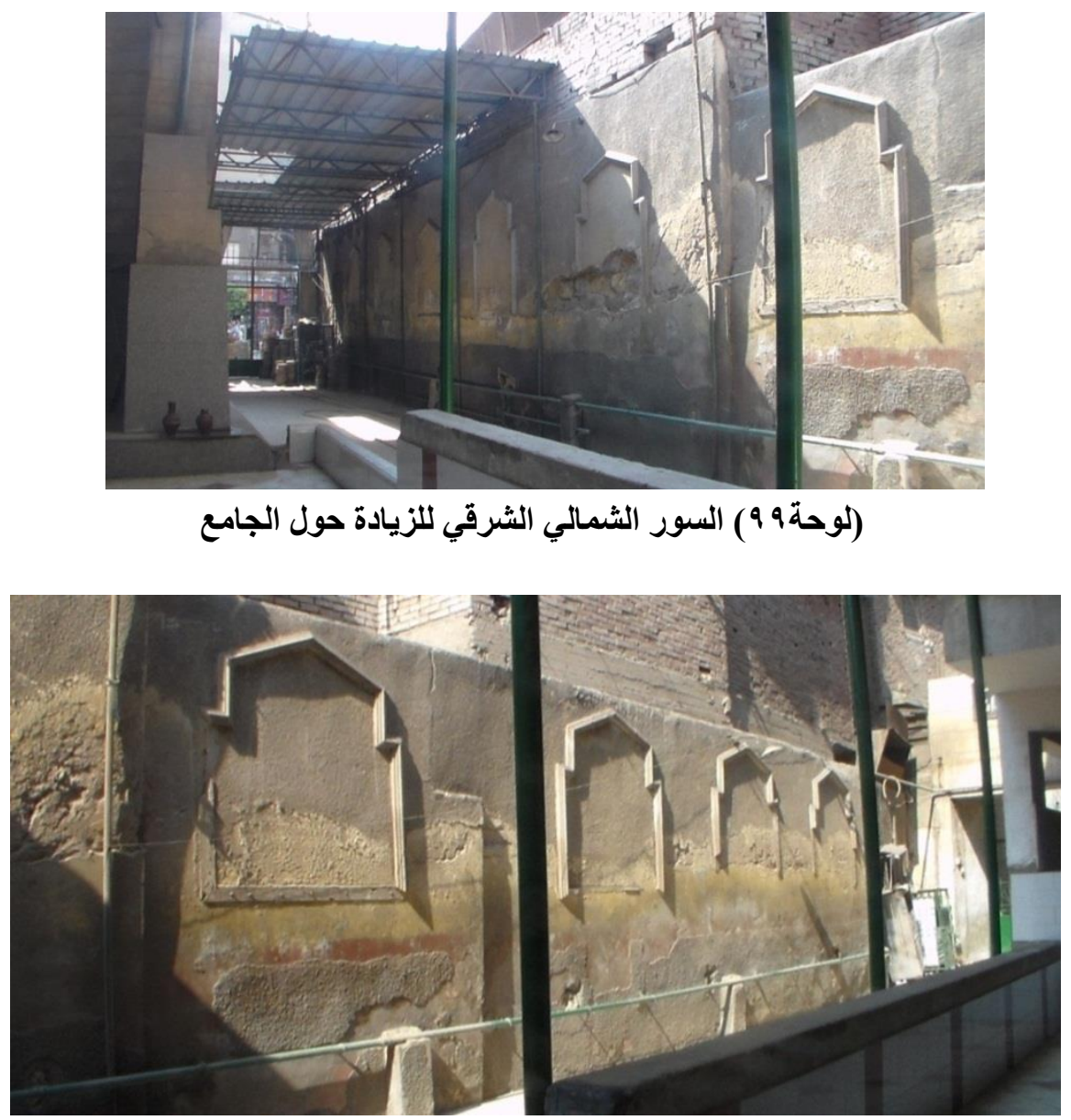

(لوحة . . 1) السور الثمالي الثرقي للزيادة حول الجامع 


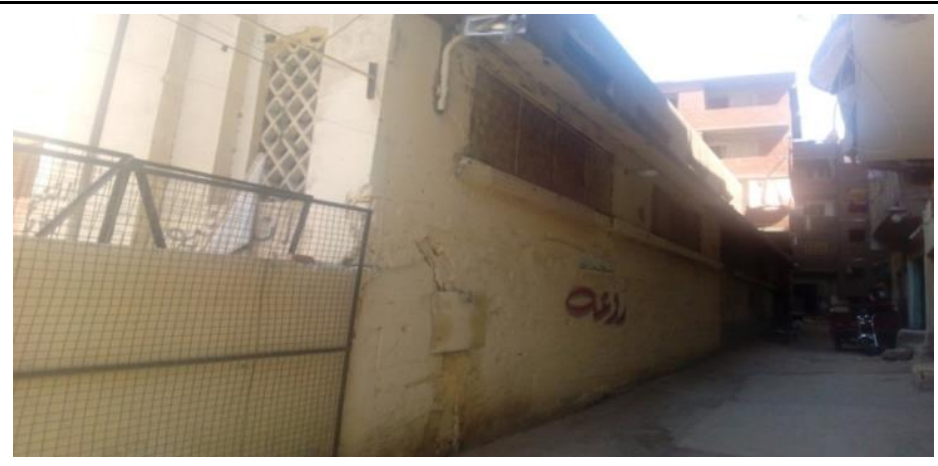

$$
\text { (لوحة ا ـ 1 ) الجانب الجنوبي الغربي من الزيادة حول الجامع }
$$
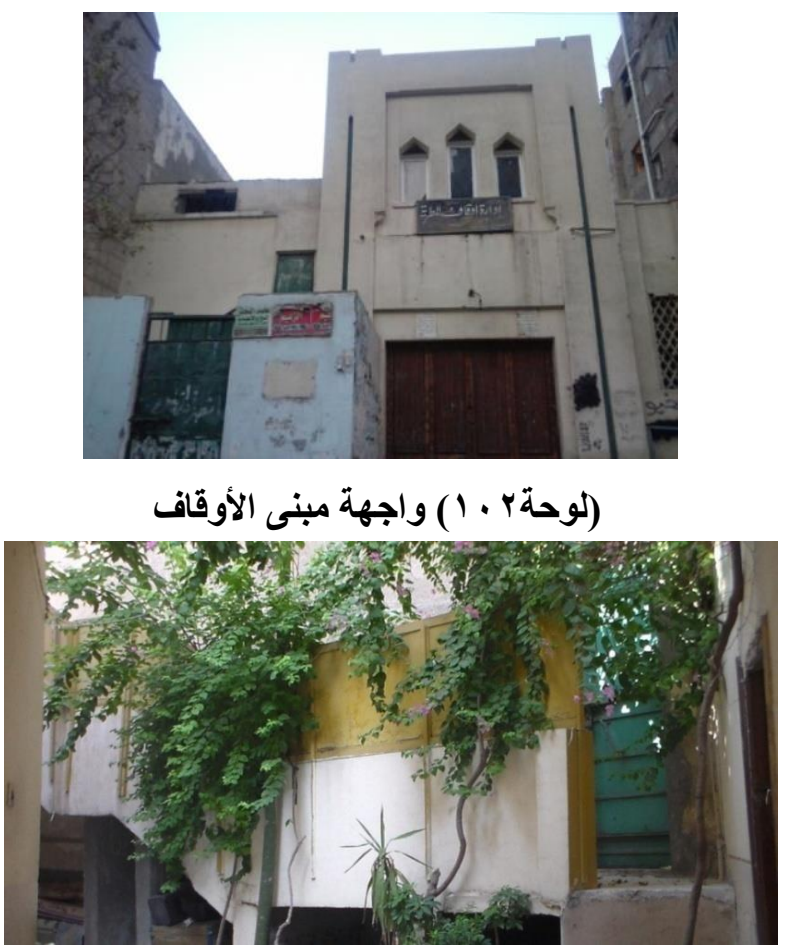

(لوحة ـ ـ 1) الباب والسلم المؤدي لمصلى السيدات بالزيادة الجنوبية الثرقية

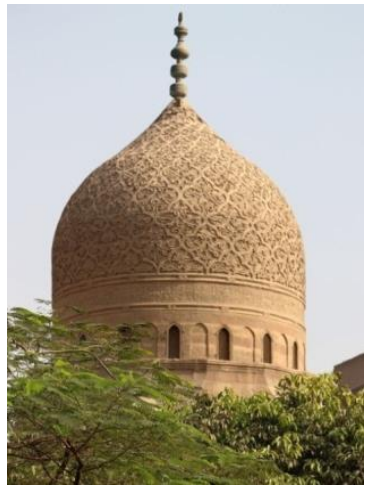

(لوحةه ـ ـ 1) جامع قاني باي الرماح

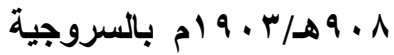

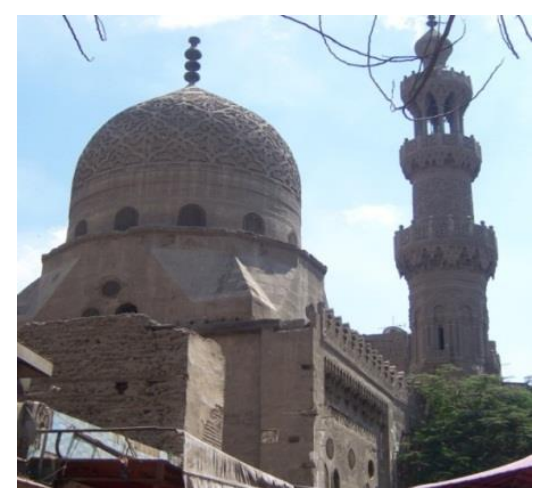

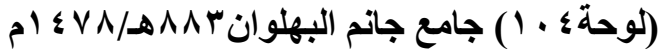




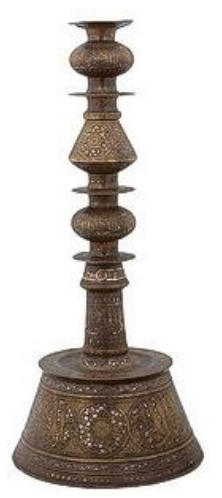

(لوحة V + 1) شمعدان من النحاس المكفت بالفضة

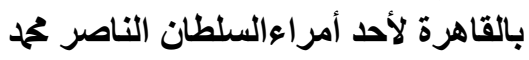

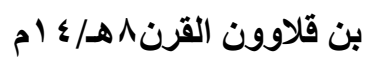

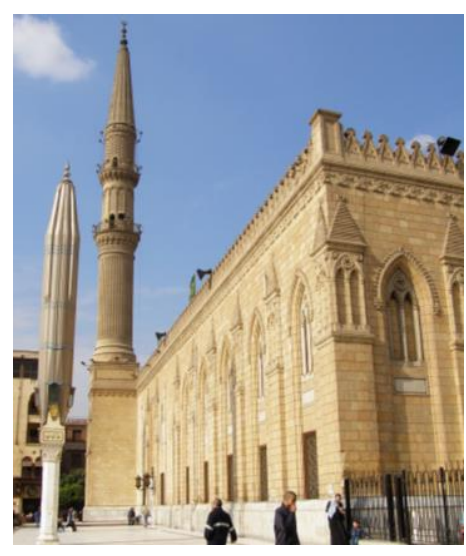

(لوحة9 ، 1 ) واجهة المسجد الحسيني الرئيسية

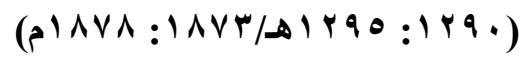

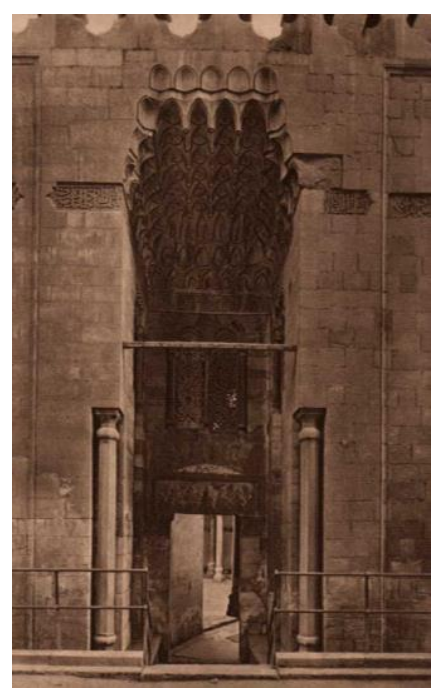

(لوحة 1 1 1) جامع الأمير ألماس الحاجب

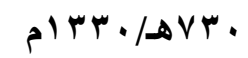

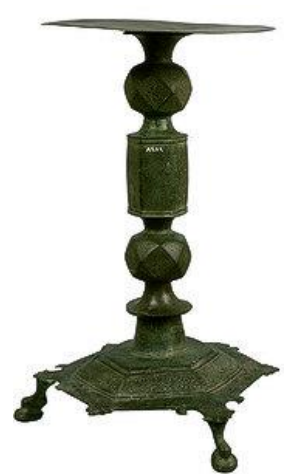

(لوحة ا ـ 1 ) شمعان ابن مكي من البرونز

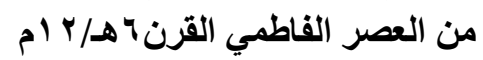
بمتحف القن الإسلامي

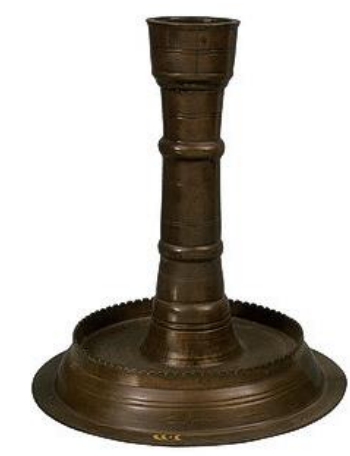

(لوحةم • 1 ) شمعان سنان باثـا من مسجد

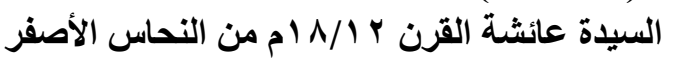

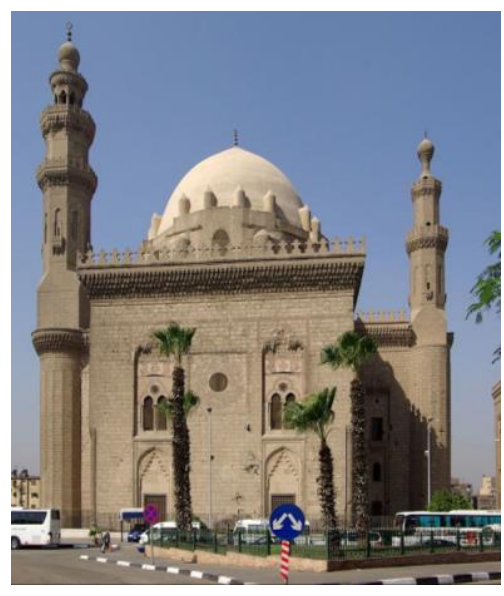

(لوحة ، 1 (1) مدرسة السلطان حسن

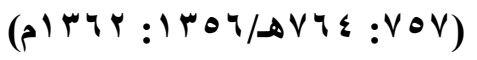




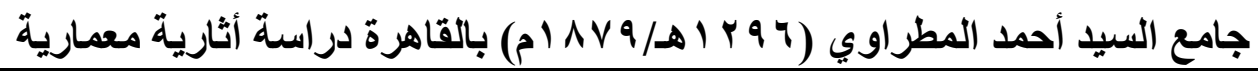
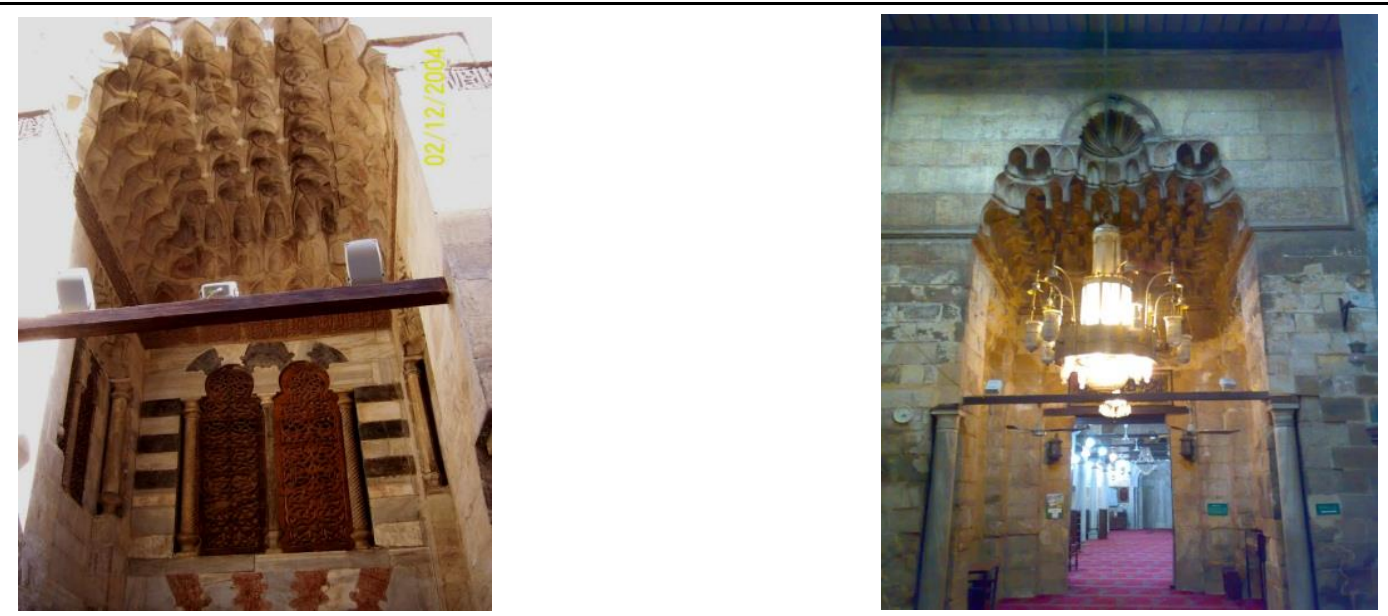

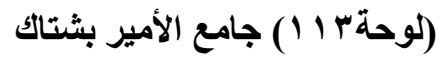

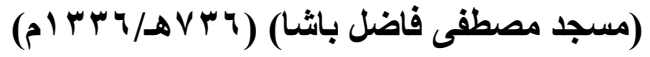
(لوحة r 1 1 ) جامع الأمير ألماس الحاجب بارب الجماميز

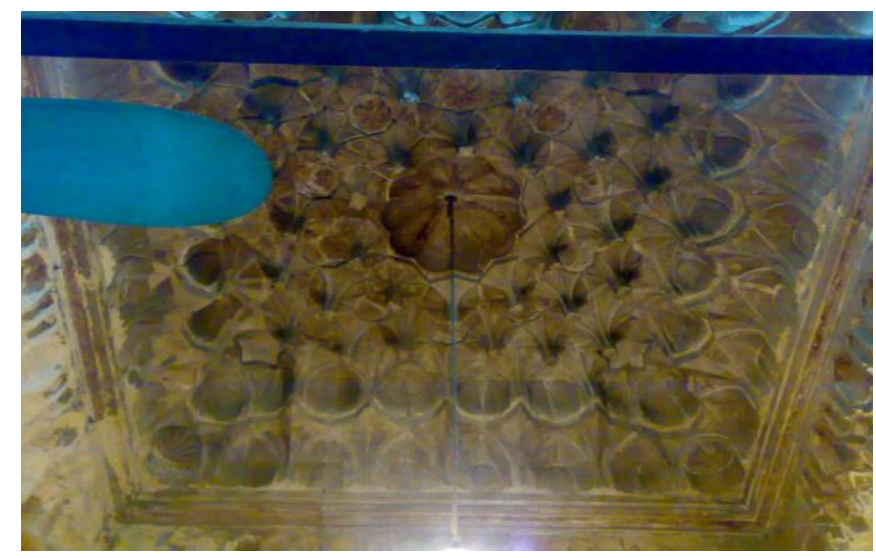

(لوحة ؛ 1 1) جامع الأمير بشتاك (مسجد مصطفى فاضل باشا)

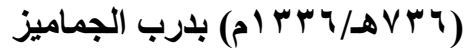

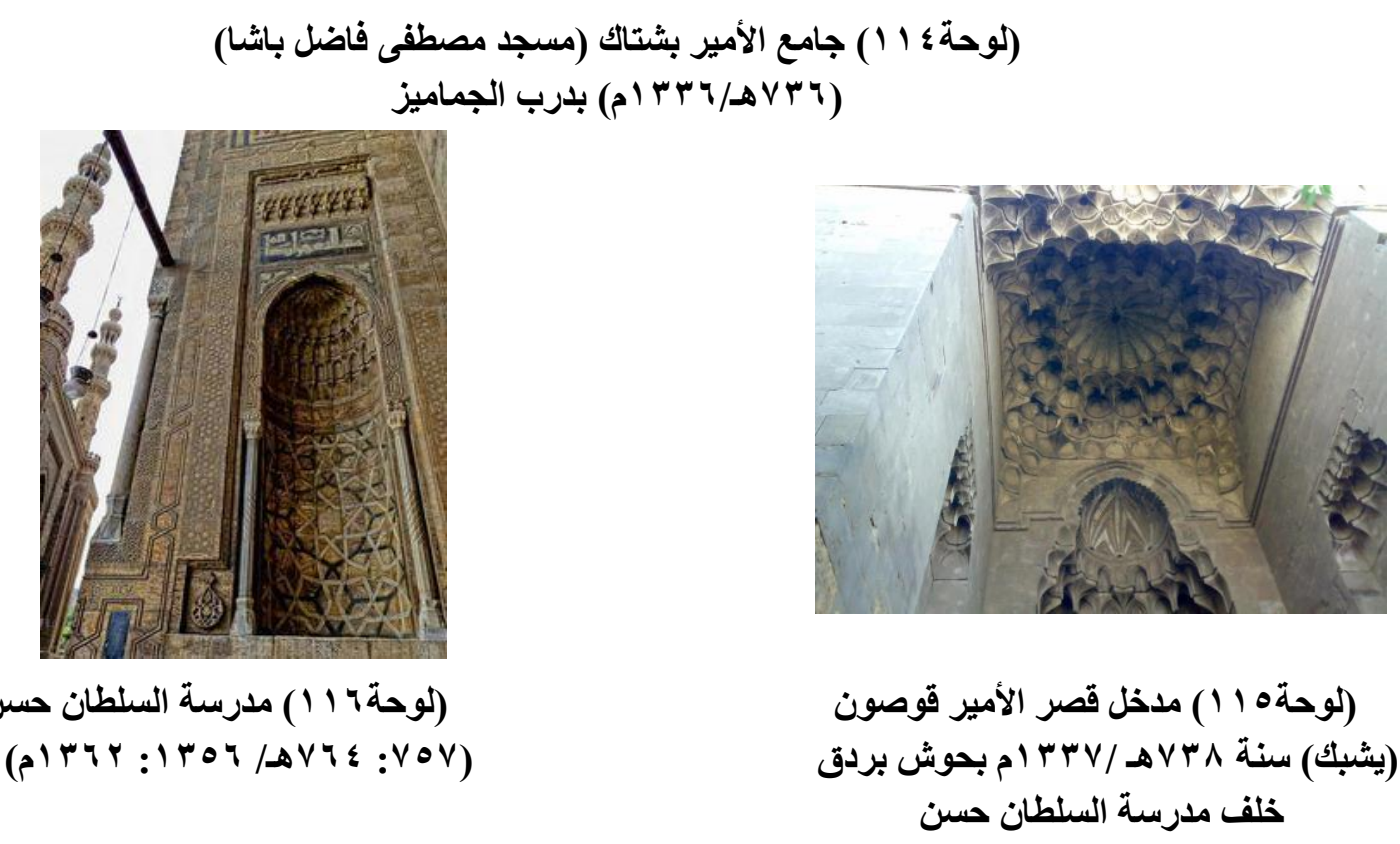

(لوحة 11 (1) ) مدرسة السلطان حسن

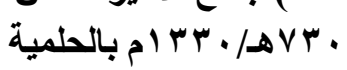




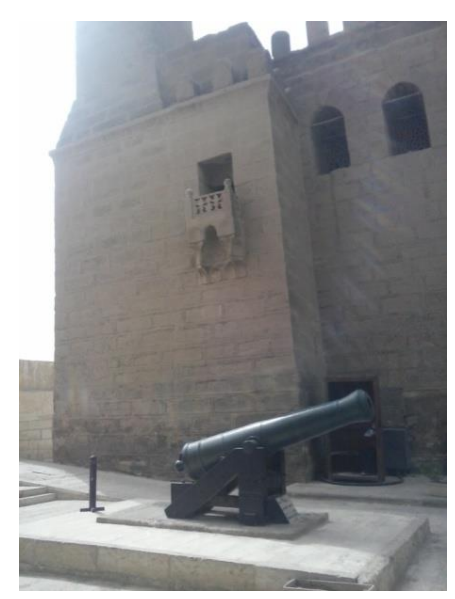

(لوحة/ 1 1 ) جامع الناصر محمد بن قلاوون

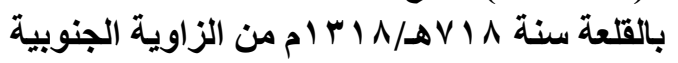

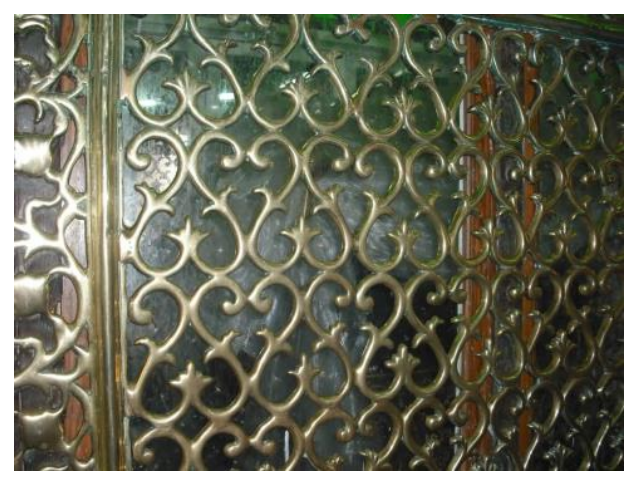

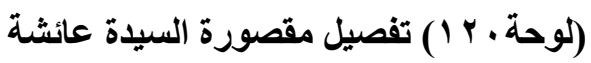

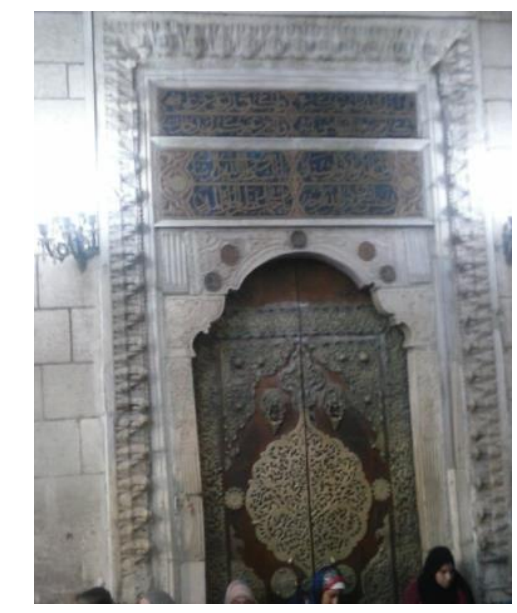

(لوحة r r 1) تفصيل للمز هرية بدخل ضريح الإمام الحسين عليه السلام السابق بلقيل

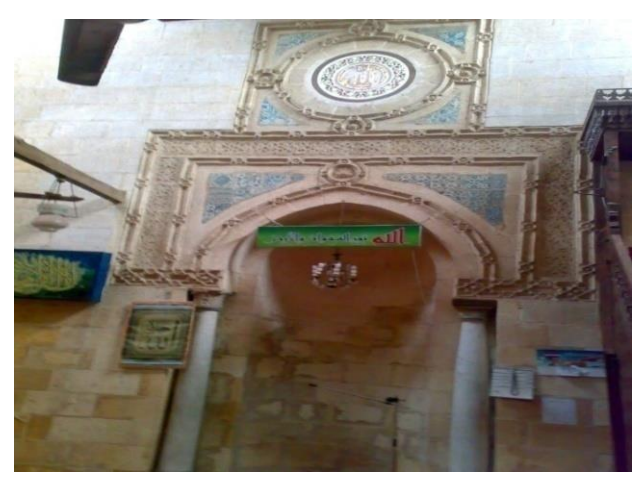

(لوحة I V I I ) وجامع أحمد العريان

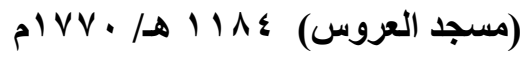

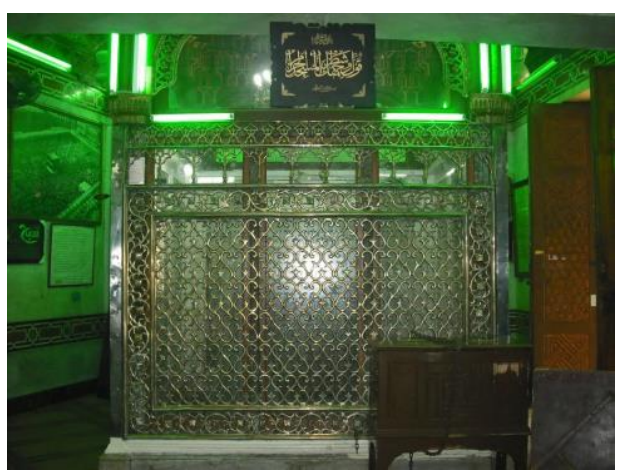

(لوحة 9 (1) ) مقصورة السيدة عائثة التي ترجع

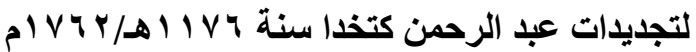

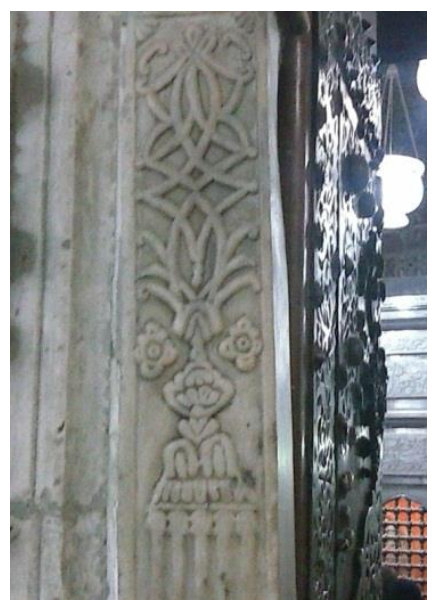

(لوحة ا ب l ) مدخل ضريح الإمام الحسين عليه السلام من داخل المسجد الإمام 